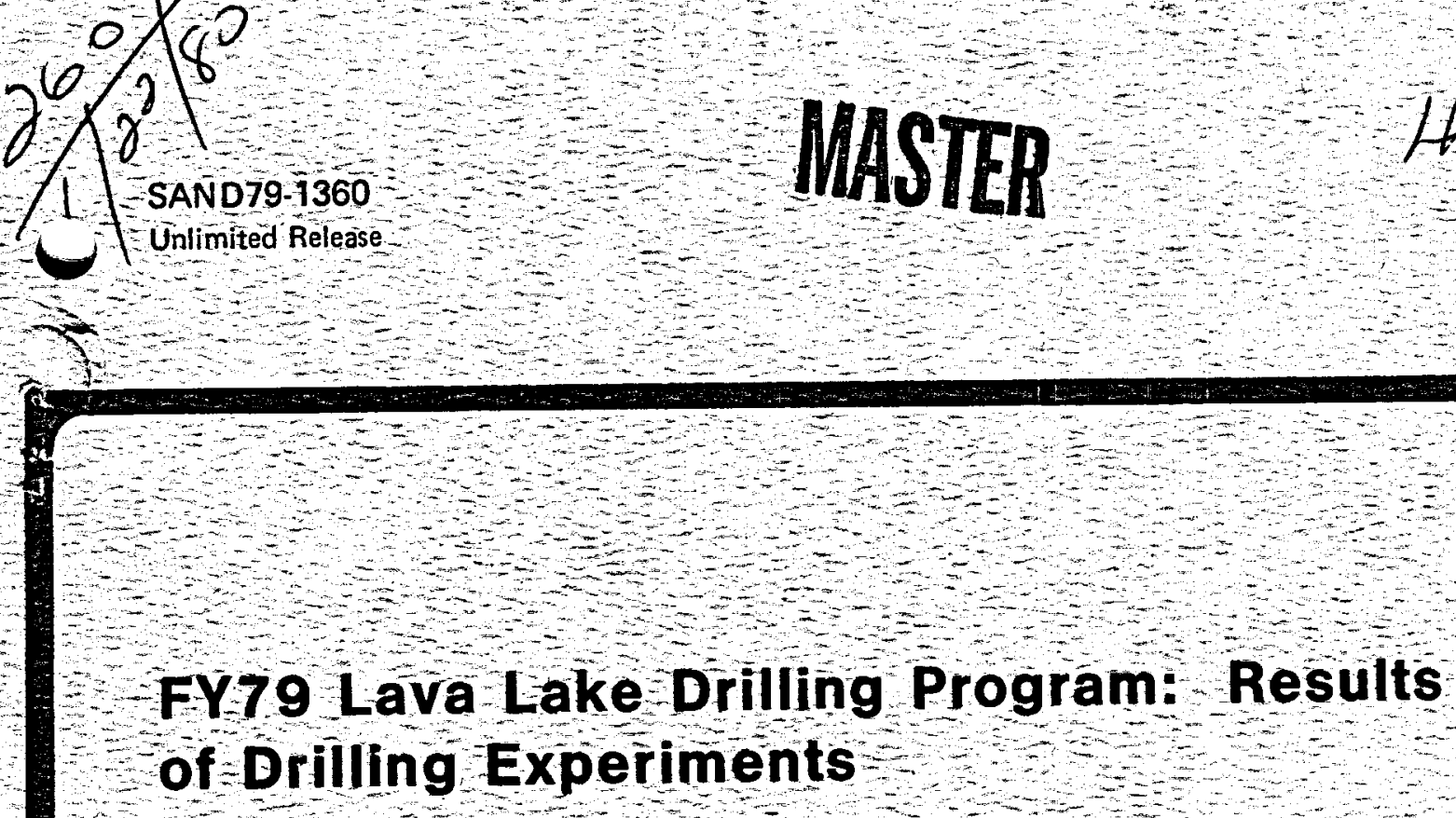

th 550

\title{
FY79 Lava Lake Drilling Program: Results of Drilling Experiments
}

Robert R. Neel, Richard P. Striker, Richard M. Curlee

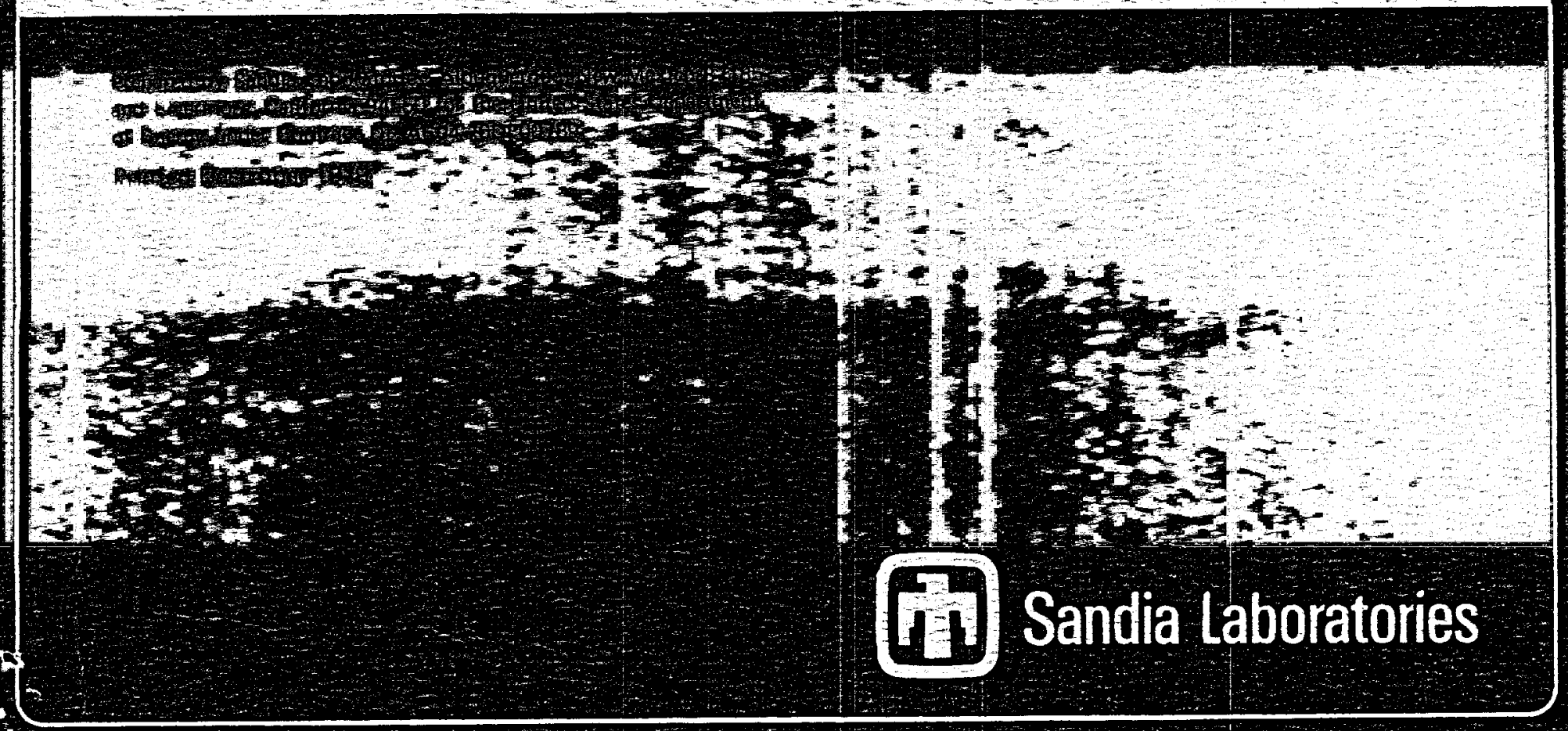

SF $2900017-731$ 


\section{DISCLAIMER}

This report was prepared as an account of work sponsored by an agency of the United States Government. Neither the United States Government nor any agency Thereof, nor any of their employees, makes any warranty, express or implied, or assumes any legal liability or responsibility for the accuracy, completeness, or usefulness of any information, apparatus, product, or process disclosed, or represents that its use would not infringe privately owned rights. Reference herein to any specific commercial product, process, or service by trade name, trademark, manufacturer, or otherwise does not necessarily constitute or imply its endorsement, recommendation, or favoring by the United States Government or any agency thereof. The views and opinions of authors expressed herein do not necessarily state or reflect those of the United States Government or any agency thereof. 


\section{DISCLAIMER}

Portions of this document may be illegible in electronic image products. Images are produced from the best available original document. 
SAND79-1360

Unlimited Release

Printed December 1979

FY79 LAVA LAKE DRILLING PROGRAM: RESULTS OF DRILLING EXPERIMENTS

\author{
Robert R. Neel \\ Richard P. Striker \\ Richard M. Curlee \\ Advanced Development Division 4731 \\ Sandia Laboratories \\ Albuquerque, NM 87185
}

ABSTRACT

A drilling program was conducted by Sandia Laboratories and the United States Geological Survey in December 1978 and January and February 1979 to continue the characterization of the solid and liquid rock components of the Kilauea Iki lava lake. Six holes were drilled from the surface and two previously drilled holes were reentered and deepened for the purposes of measuring downhole temperature profiles, recovering samples of solid, plastic, and molten rock, measuring crust permeability, and determining the performance of conventional and special drilling techniques.

Conventional HQ-size ( 3.78 inches diameter) core drilling equipment using water for cooling and cuttings removal was used to successfully drill during initial entry into $1052^{\circ} \mathrm{C}$ formations. Conventional drilling in reentering flow-back rock was less reliable. The specially designed water jet-augmented drag bit or water jet-augmented core bit was needed to drill reliably into the plastic flow-back rock and through liquid rock veins.

This document contains the drill performance data which were recorded during drilling in the crust and the plastic and molten rock zones using both conventional and special drilling procedures and equipment.

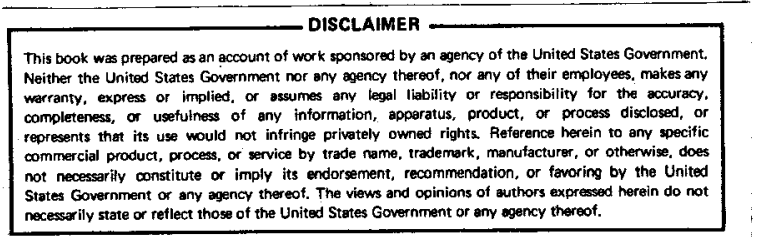


ACKNOWLEDGMENTS

Although the FY79 Lava Lake Drilling Program was defined in detail and fielded over a fairly short period of time, many of the procedures and much of the hardware used were generated over a period of several years. The work of the people who assisted in the development of the concepts and of the key people involved in carrying out the experiment is gratefully acknowledged as follows:

J. L. Colp, 4731--General Magma Energy Research Project development and direction

D. W. Larson, 5512--Insulated Drill string thermal analysis

J. C. Dunn, 5512--Water jet-augmented drilling concept formulation, analysis, and field direction

S. N. Burchett, 5521--Stress analysis as needed throughout the program

A. Ortega, 5512--Design, procurement, assembly of coolant control systems, and conduct of special hot bit tests

L. Baudoin, 9655--(retired)--Mechanical systems design

T. F. Pfeffer, 1135--Field logistics and administration

S. N. Falacy, 1124--Field instrumentation systems design, procurement, and operation

P. C. Montoya--Laboratory component and systems testing

T. L. Dobecki--Resistivity experiment design 
SUMMARY

The FY79 Lava Lake Drilling Program which was conducted between November 1978 and February 1979 was a continuation of the program of the United states Geological Survey and Sandia Laboratories. Its purpose was to characterize the Kilauea Iki lava lake and to develop methods for drilling into molten rock bodies.

Six new holes were drilled from the surface and two old holes were reentered and extended to the current depth of the molten rock. The holes were drilled to recover core samples at various locations on the lake from the surface of the lake into the molten or plastic zone, to provide holes for measuring temperature profiles in the lake's crust, and to provide holes for measuring crust permeability at several depths. The creep strength and resistance of the molten and plastic rock to penetration were studied in two locations.

Because of difficulties encountered in 1976 in drilling into liquid rock, several methods of penetrating a liquid rock lens were developed for evaluation in the FY79 Lava Lake Drilling Program. One of the methods, the water jet-augmented drilling system, was used successfully in drilling into plastic zones and zones of alternate liquid and liquid-solid materials. The high-velocity (85 fps) streams which emanated from the faces of the bit penetrated the liquid or molten rock, cooling it sufficiently to be drilled conventionally by specially modified threewing drag bits and face-discharge core bits. Core material was not recovered during this type of drilling.

The Insulated Drill String (IDS) was'designed to withstand temperatures associated with molten lava while drilling into liquid lenses. Special high-temperature structural materials and insulation techniques were used to achieve the hightemperature capability. The IDS was lab-tested using high-temperature furnaces and crucibles containing molten rock but was not field tested since significantly thick layers of liquid rock were not encountered in the lava lake.

The values of several parameters describing the operation of the drill were recorded during all phases of the drilling operation. In addition, air and cooling water pressures and flow rates were recorded during water jet drilling operations. 

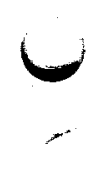

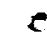

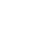

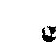


Drill Function Recording System Schematic

Drilling Out Glassy Flow-Back Chimney with Conventional HQ Core Bit (Hole 75-1)

Drilling with Jet Core Bit into Plastic zone during Reentry into Hole 79-1

\section{TABLES}

\section{$\underline{\text { Table }}$}




\section{Introduction}

Since the formation of the Kilauea Iki lava lake in 1960, field experiments have been conducted on the lake by the United States Geological Survey (USGS) to characterize the solid and molten rock of the lake and its cooling history. In the mid-1970s, Sandia Laboratories joined in the study of the lake through its Magma Energy Research Project. Since 1975, Sandia and the UsGs have jointly sponsored experiments in crustal drilling and electromagnetic and seismic measurements intended to describe the extent of the molten body contained in the crater. The FY79 Lava Lake Drilling Program, which was conducted between November 27, 1978, and February 16, 1979, was designed to further study the materials and cooling of the lava lake and to evaluate conventional and special drilling equipment used to drill into the solid and molten rock zones of the lake.

Prior to 1978, the majority of the drilling activities in the lava lake were conducted to measure the depth to the upper surface of the molten rock and to recover upper crust core samples. In July 1976, an attempt was made in a joint Sandia/USGS experiment to drill into the molten rock using conventional drilling equipment. 1 Approximately 0.54 metre below the molten rock surface, solid rock was encountered, and additional drilling was impossible. This experience led to the development of three special techniques for entering a molten lens, each of which uses different equipment. The different types of equipment used are (1) a 1 inear penetrometer, (2) a specially designed Insulated Drill string (IDs) that uses hightemperature materials, and (3) conventional core and drag bits modified to provide high-velocity, coherent cooling water jets from the faces of the bits. The three techniques were developed for the FY79 Lava Lake Drilling Program.

Several holes were drilled during the FY79 Lava Lake Drilling Program with the objective of collecting geoscience data which would be helpful in broadening the scientific understanding of the lake and its cooling history. ${ }^{2}$ Material samples in the form of cores were collected continuously from the surface for each hole drilled. Downhole temperature profiles were measured in open holes and in one specially cased hole. Formation permeability was inferred at three points in the crust in one hole by measuring pertinent water flow and pressure parameters at three discrete depths. The creep strength of the rock at plastic temperatures was investigated, and an attempt was made to measure the electrical resistivity of the plastic or liquid rock. Figure 1 shows the location of each hole entered during the FY79 Lava Lake Drilling Program. 


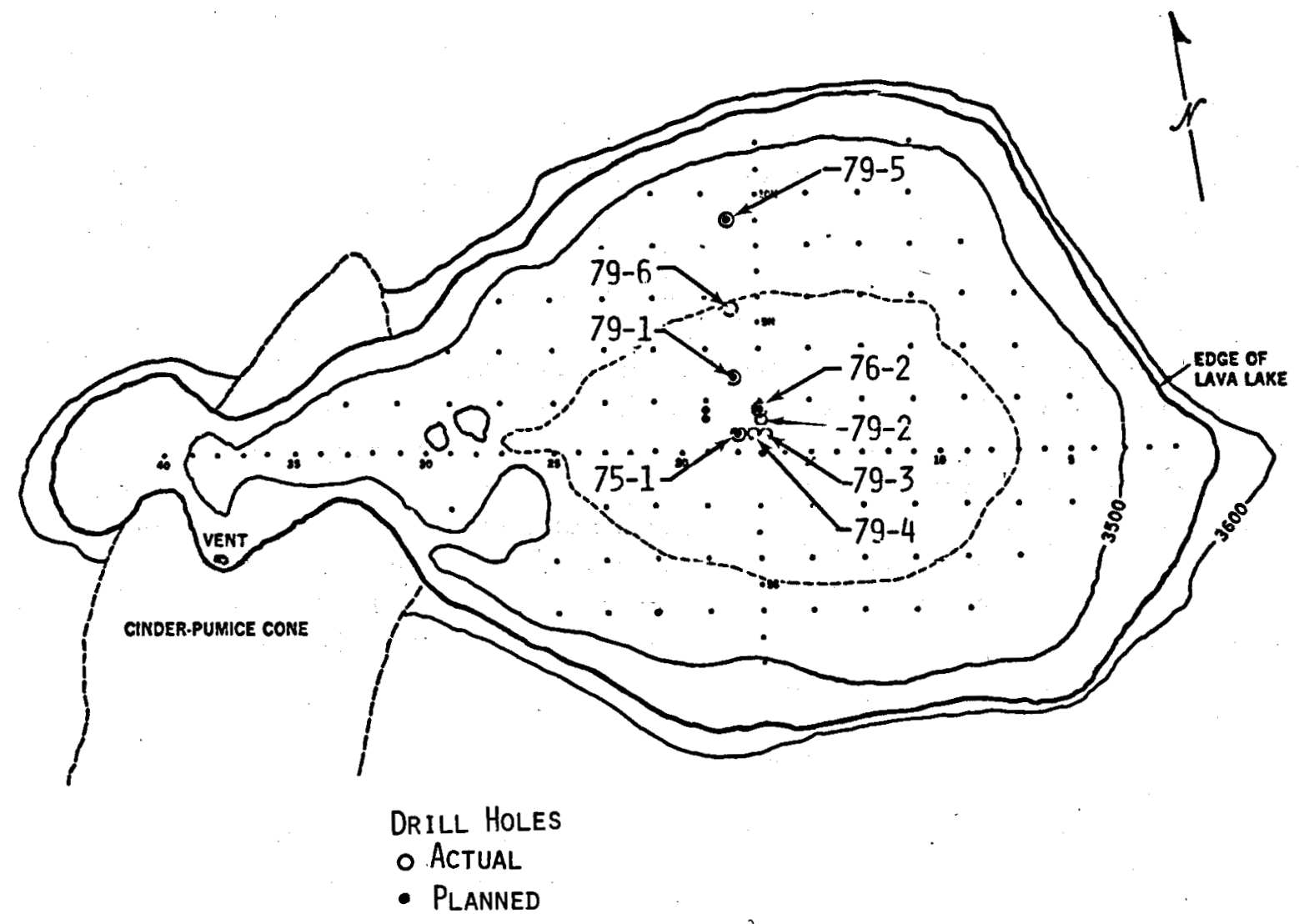

Figure 1. Map of Kilauea Iki Crater

In order to study the drilling characteristics of the lava at temperatures ranging from ambient to $\sim 1070^{\circ} \mathrm{C}$ using available bits, a significant effort was made to instrument the drill and coolant supply systems and record the response of the instrumentation during all drilling operations. The data were recorded on strip chart recorders and a datalogger/cassette tape system.

An HC-150 hydraulically driven drill manufactured by the Longyear Company was airlifted to and assembled on the floor of the crater. The drill and its crew of three (a driller and two oilers) were supplied under contract by Continental Drilling-Hawail. Drilling commenced approximately 1 week after the airlift started and continued through approximately 60 working days, ending February 16, 1979. Continental Drilling provided all standard drill support hardware. The USGS provided geologists for core logging and shop system and comunications support. Sandia provided all specialty system hardware and all instrumentation and recording systems. 
This report presents the data recorded during all drilling operations, including coolant flow during the water jet-augmented drilling activities. In addition, it provides a sufficient description of the drilling experiments and the instrumentation and recording systems to permit the reader to analyze and interpret the drill functions recorded.

Background

Development and evaluation of geophysical techniques in the Kilauea Iki lava lake are important initial steps for subsequent efforts to locate and characterize deep magma bodies as potential magma energy sources. Drilling into the lake has been performed in the past to confirm the results obtained from the geophysical measurements and to obtain thermal and chemical data at various locations within the crust for geothermal system modeling. Unfortunately, it has not been possible in the past to drill into or through the molten lens, a procedure which is necessary to confirm the geophysical measurements and to develop a realistic cooling model of the lake. Until 1976, drilling was limited to locating the depth of the uppermost liquid zone and to recovering core from various locations in the upper crust of the lake.

In spite of the many measurements made in and around the lake, a universally accepted model has not emerged, principally because drilling techniques and equipment have not been developed to confirm the dimensions of the molten lens. Confirmation of the lake model at any one time will involve drilling and coring not only the upper crust but also the lower crust and the molten and plastic zones in between.

A primary goal of the FY79 Lava Lake Drilling Program was to drill a significant distance ( 20 feet) into the molten zone by one or more specially designed drilling methods.

Experiment Description

Both geoscience and drilling experiments were performed during the FY79 Lava Lake Drilling Program. The geoscience experiments were conducted to continue the characterization of the crust and the molten lens of the lake. In addition, drilling experiments were conducted (1) to develop drilling components and procedures which will be necessary to penetrate magma bodies and (2) to support current and future geoscience experiments in the lava lake and in other near-surface bodies of molten rock.

\section{Geoscience Experiments}

The major geoscience experiments were conducted during the FY79 Lava Lake Drilling Program to

1. Measure thermal profiles through the crust of the lake, 
2. Study the strength of the rock at plastic temperatures under rapid and slow loadings,

3. Measure crust permeability at selected depths in the crust,

4. Measure the electrical resistivity and conductance of the molten rock,

5. Measure the thermal conductivity of the molten rock, and

6. Obtain material samples through continuous core drilling from the current surface to the pre-1959 lake surface.

The geoscience experiments were conducted by Colp and others during the FY79 Lava Lake Drilling Program and are described briefly in Table 1 . Details of the geoscience experiments are reported by colp. ${ }^{2}$

Table 1

Geoscience Experiments Conducted during the FY79 Lava Lake Drilling Program

Physical Parameter of Interest

Temperature vs. depth in open and closed holes

Crust permeability

Composition of solid rock layer beneath liquid layer encountered in July 1976 drilling

Long-term creep strength of lower crust

Electrical resistivity of liquid rock

Crust thermal profiles

Crust composition with depth
Experiment Description

Measure temperature vs. depth in temperature-stabilized open hole. Insert closed-ended. small-diameter pipe, stem hole with sand, and repeat temperature vs. depth temperature measurements.

Measure crust permeability at three discrete depths.

core solid crust through zone at which solid rock was encountered in 1976 beneath liquid layer.

Observe the creep of a special weighted probe into the lower crust over a period of several months.

Insert electrical contacts into the liquid rock as a part of the penetrometer probe. Measure temperature vs. depth.

Core drill hole from the current surface to the pre-59 surface

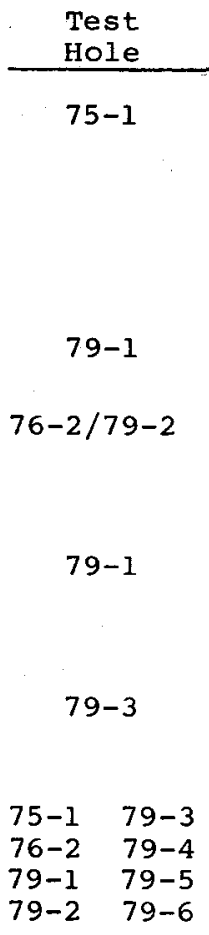

All holes

\section{Energy Extraction Experiment}

An energy extraction experiment was designed and readied on the premise that the water jet-augmented drilling operations would be successful in forming porous stalactites in the liquid lenses and the bottoms of Holes 79-3 and 79-4.

The energy extraction experiment was to be conducted in two phases. During the first phase, a stalactite of porous rock was to be formed as water jet-augmented drilling proceeded into the liquid lens in Hole 79-3. Water would be injected 
periodically into the stalactite and then allowed to return to the surface as steam. (This was referred to as the "Huff-n-Puff" experiment.) During the second phase of the water jet-augmented drilling activities, a second stalactite, at the bottom of Hole 79-4, would be created to overlap the one previously formed at the base of Hole 79-3. Water continuously injected into one of the holes (79-3) would then produce steam continuously at the surface from Hole 79-4.

The amount and quality of steam produced was to be measured to evaluate the simple heat exchange system.

\section{Drilling Experiments}

In addition to the geoscience experiments previously mentioned, three experiments classed as drilling experiments were planned and conducted for the FY79 Lava Lake Drilling Program. They were the plastic zone penetrometer experiment, the IDS drilling experiment, and water jet-augmented drilling with special drag and core bits. The three driling experiments represented attempts to enter a molten rock layer by the three methods listed below:

1. Enter the molten zone using a linear thrust only, as might be required in the insertion of an instrumentation package with a number of trailing electrical conductors (penetrometer),

2. Survive and operate in the liquid rock environment through the use of special high-temperature structural and insulating materials and design techniques (IDS), and

3. Using special cooling techniques, modify the environment of the molten zone sufficiently to enable driling to be conducted with conventional materials and hardware (water jet-augmented drilling).

Penetrometer -- The penetrometer experiment was conducted in Hole 79-3 in conjunction with the attempted electrical resistivity measurement. Figure 2 depicts the penetrometer/resistivity experiment as it was conducted. The penetrometer used contained the electrical contacts which were to be immersed in the molten rock to measure the resistivity of the molten rock. The long-term, plastic zone creep test used a similar but blunted penetrator with a steady load applied over several months.

The object of the high-loading-rate penetrometer experiment was to investigate the feasibility of thrusting a pointed, high-temperature, high-strength, corrosion-resistant rod into the plastic and liquid body which was assumed to underlie the lake crust. The penetrometer had to penetrate a layer of cooler crust; the layer was required to prevent the underlying plastic or liquid layers from flowing up the hole and hardening while the penetrometer was being lowered into the hole. An additional purpose of the penetrometer experiment was to confirm the existence of the free liquid lens and obtain a measure of its thickness:

Four electrical contacts were located in an insulating insert near the tip of the penetrometer. High-temperature conductors passed through the hollow center of 
the penetrometer to a special junction at the penetrometer's top. At this point. the transition was made to conventional, organic, insulated conductors passing through the center of the water-filled drill string to the surface. Two thermocouples in the penetrometer tip were intended to measure the temperature near the resistivity measurement. ।
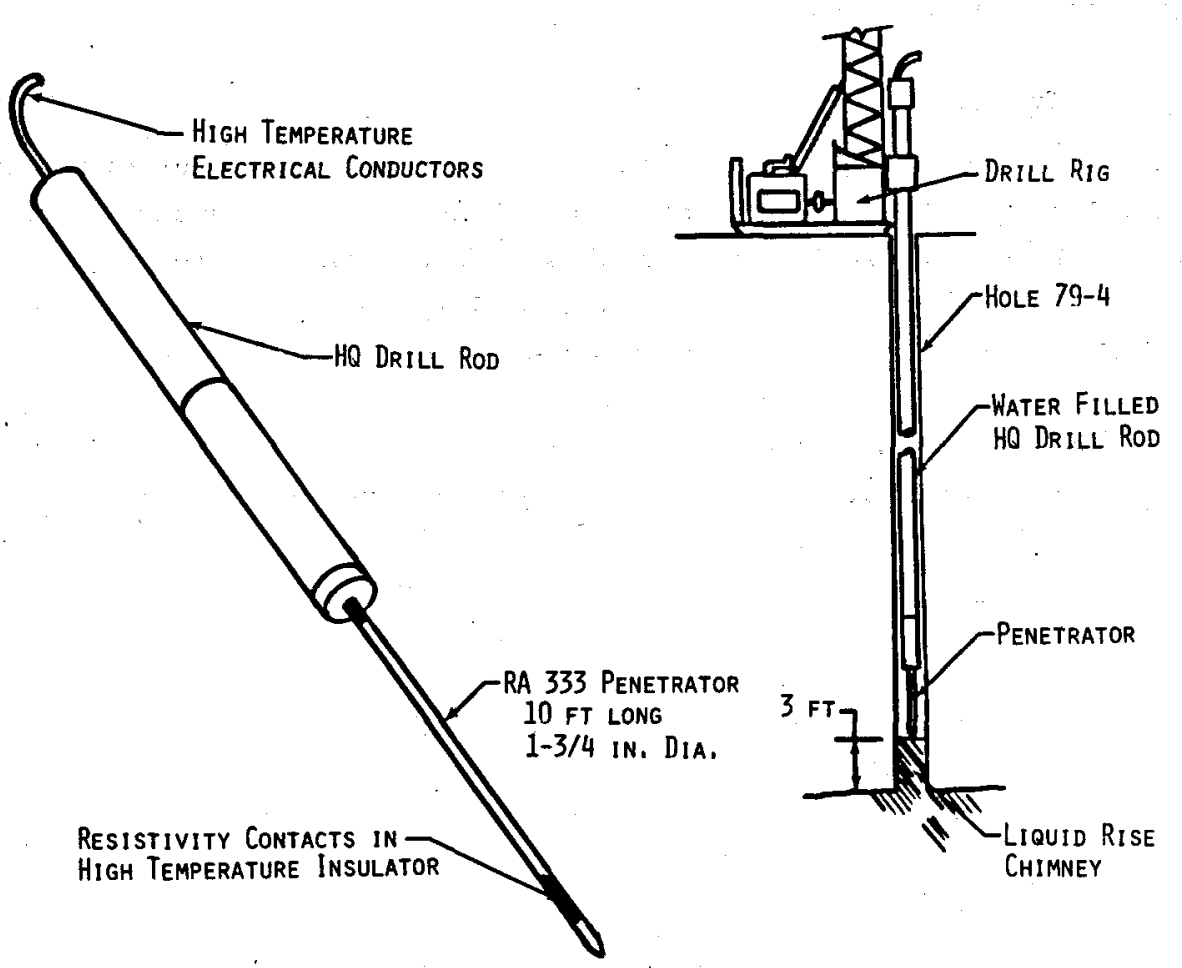

Figure 2. Liquid Penetrator with Resistivity Contacts

Insulated Drill string -- The IDS was conceived as a result of the experience gained during the drilling program conducted in 1976. During that program, a hole (76-1) was drilled to a depth of about 45.4 metres (149 feet) into what appeared to be a free liquid layer about $54 \mathrm{~cm}$ (2l inches) thick. Almost immediately, the liquid froze around the bit, preventing further rotation or vertical movement of the drill string. The next day, when the temperature of the drill string had risen to the temperature of the surrounding liquid and the rock frozen to the drill: string had melted, the drill string could be rotated and moved vertically. The basic concept of the IDS, taken from the results of this experiment, was to allow the outer surface of the drill string to operate at liquid-rock temperature, while an inner torque tube was kept at a low enough temperature, through insulation and cooling, to retain sufficient strength for drilling. In addition, a three-wing drag bit was fabricated from a high-temperature super alloy which retains high strength at liquid-lava temperatures $\left(\sim 1100^{\circ} \mathrm{C}\right)$. 
The downhole part of the IDS system consisted of the special three-wing drag bit, a special instrument section, six 10-foot lengths of insulated drill rod, a central coolant pipe, a thermal expansion joint, and a transition to standard HQ-size ( 3.5 inches) rods. Cooling air and water supply and control systems were at the surface. Figure 3 is a schematic of the IDS system, including the coolant control and casing pressurization systems. Figure 4 shows the cross section of the IDS. Figure 5 is a photograph of the special drag bit.

The insulated drill rod consisted of an outer drill rod 4-1/2 inches in diameter constructed of RA $330 \mathrm{high}$ nickel/chromium content steel. This outer drill rod was not to be cooled but allowed to operate at the full temperature of the surrounding liquid rock. An inner, 3-inch-diameter drill rod of RA 310, of similar composition, was to be cooled to a maximum temperature of about $100^{\circ} \mathrm{C}$. A highefficiency insulation system of alternate Kaowool ${ }^{*}$ and nickel foil layers secured by an outer layer of 302 stainless steel shim stock (0.002 inch) wrapped with 24gauge Nichrome wire was used between the inner and outer drill rods. A thin film of cooling water was supplied to the inside of the inner drill rod through periodic spray holes in a central, 1/2-inch-diameter water tube. The cooling water was supplied at a pressure of about 30 psi above the pressure in the drill string and at a total flow rate of about $4 \mathrm{gpm}$. The center of the inner drill rod was pressurized with air to a pressure of about 220 psi, slightly above the expected liquid rock lithostatic pressure. This pressurization of the central drill rod was required to prevent the liquid rock from flowing into and plugging the nozzles in the face of the drag bit. Upon completion of the drilling operation, a measure of the lithostatic pressure would have been obtained by noting the inner rod air pressure at which the lithostatic pressure was able to force the liquid rock into the bit discharge ports, thereby stopping the air flow.

A longitudinal slip joint at the top of the 60-foot insulated drill rod section permitted the inner and outer drill rods to be coupled mechanically in the face of the approximately 1 -foot differential thermal expansion.

A special lava seal (Figure 6) was an integral part of the IDS. The lava seal, coupled with air pressure exceeding lithostatic pressure applied to the annulus between the drill rod and casing, was needed to prevent the pressurized liquid rock from moving up the hole inside the casing and around the drill rod when the liquid level was penetrated. When this outflow occurred in the past, the liquid rock quickly cooled to the temperature of the surrounding material (rock, casing, drill rod), solidified, and prevented further drill rod and bit movement.

The lava seal, as it was planned for use during the FY79 Lava lake Drilling Program, consisted of a serles of four stainless steel rings sealing off the volume between the lower part of the casing and the outer drill rod. The lower 18 inches of the casing were made of Inconel 617 to minimize radial creep from the internal pressure load. The diameters of the lower ring and the third ring from the bottom

\footnotetext{
*Kaowool is the trade name of a fibrous insulation manufactured by the Babcock and Wilcox Company.
} 


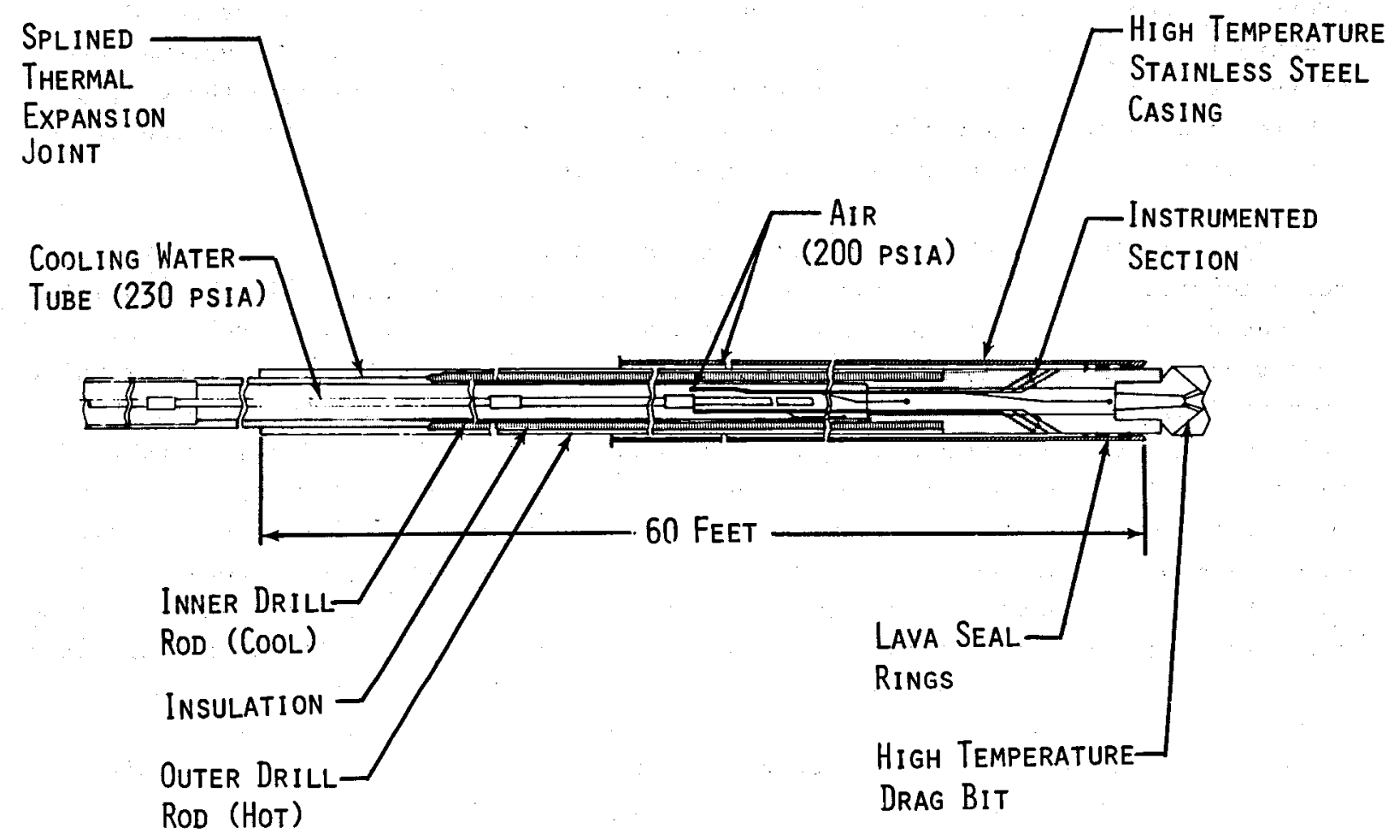

Figure 3. Insulated Drill String Schematic

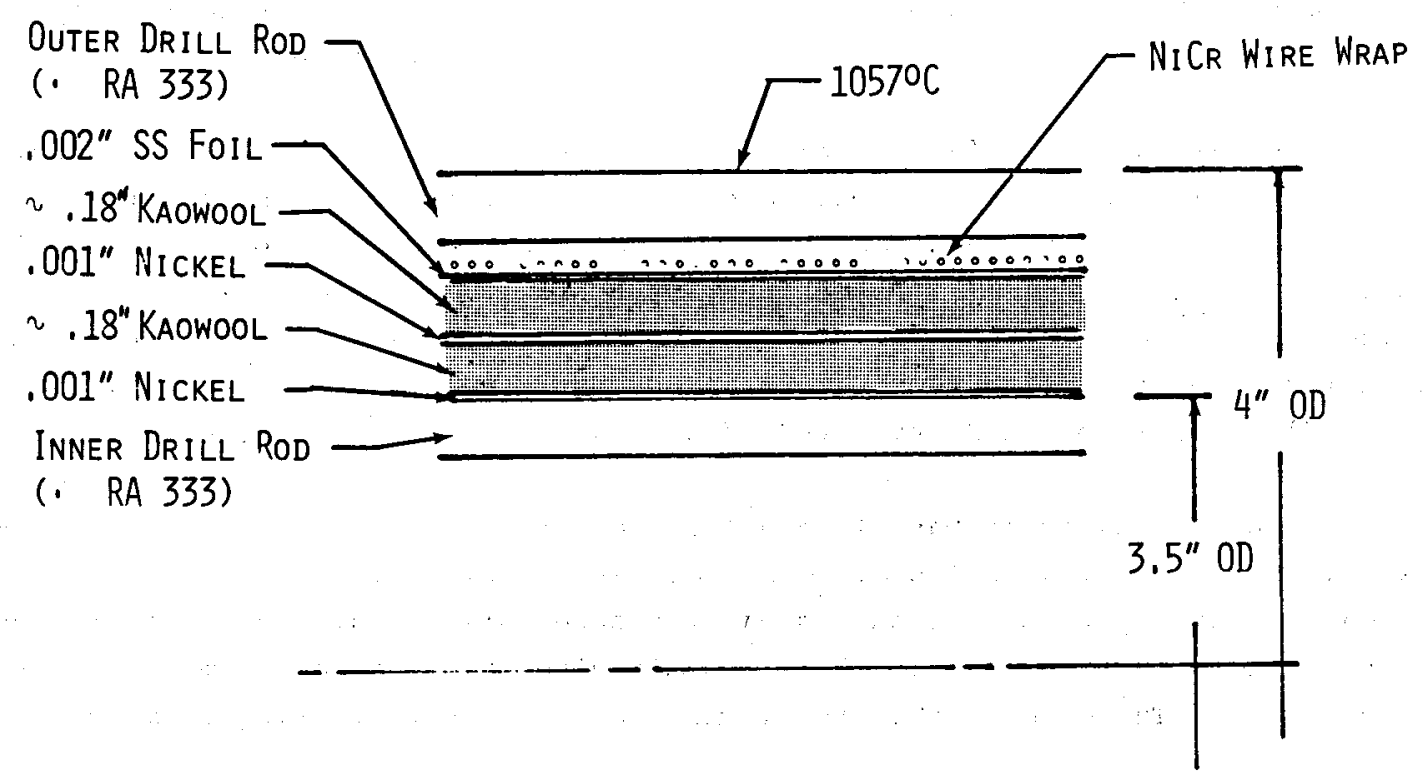

Figure 4. Insulated Drill String 


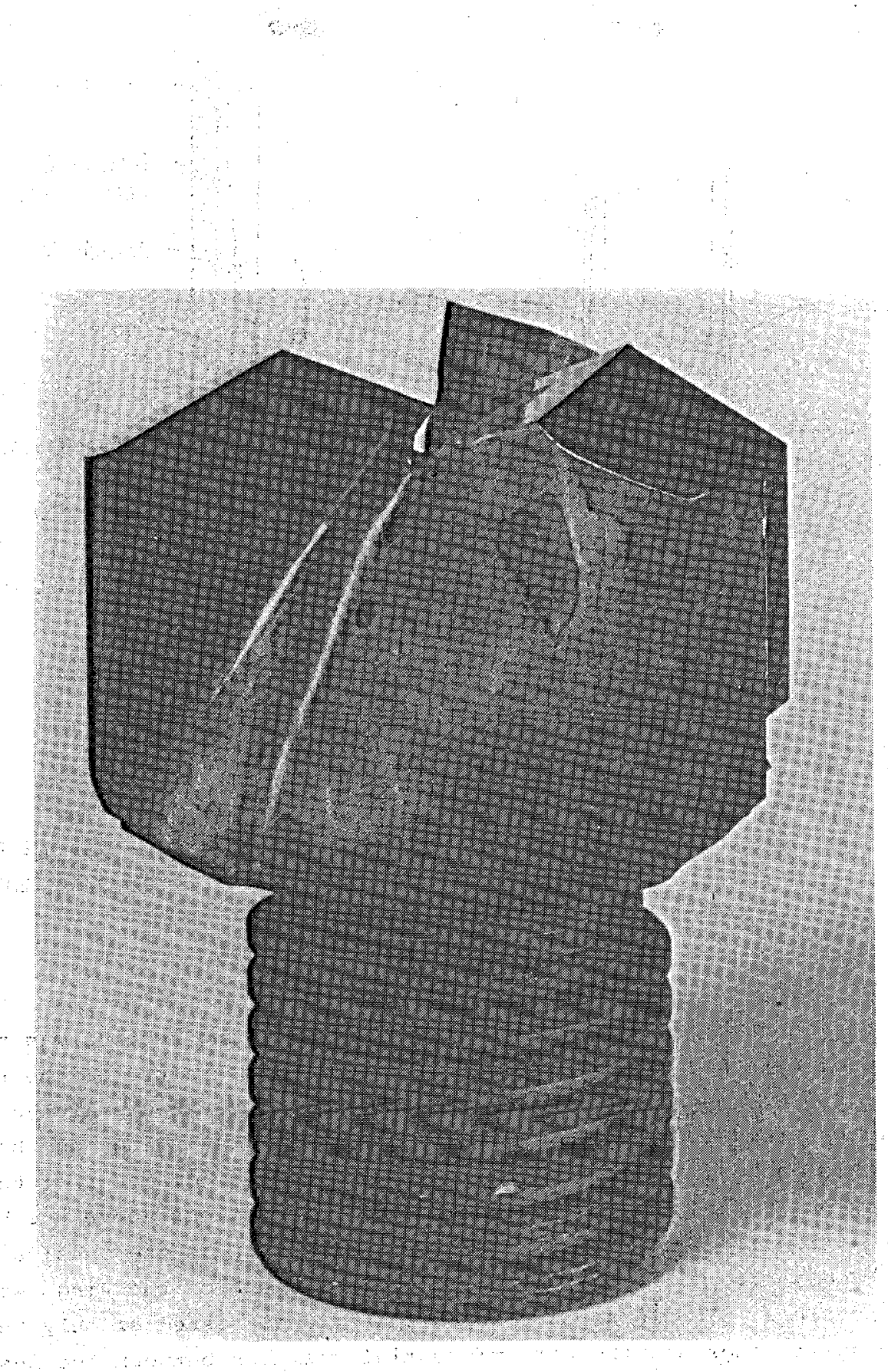

Figure 5. Special Drag Bit 


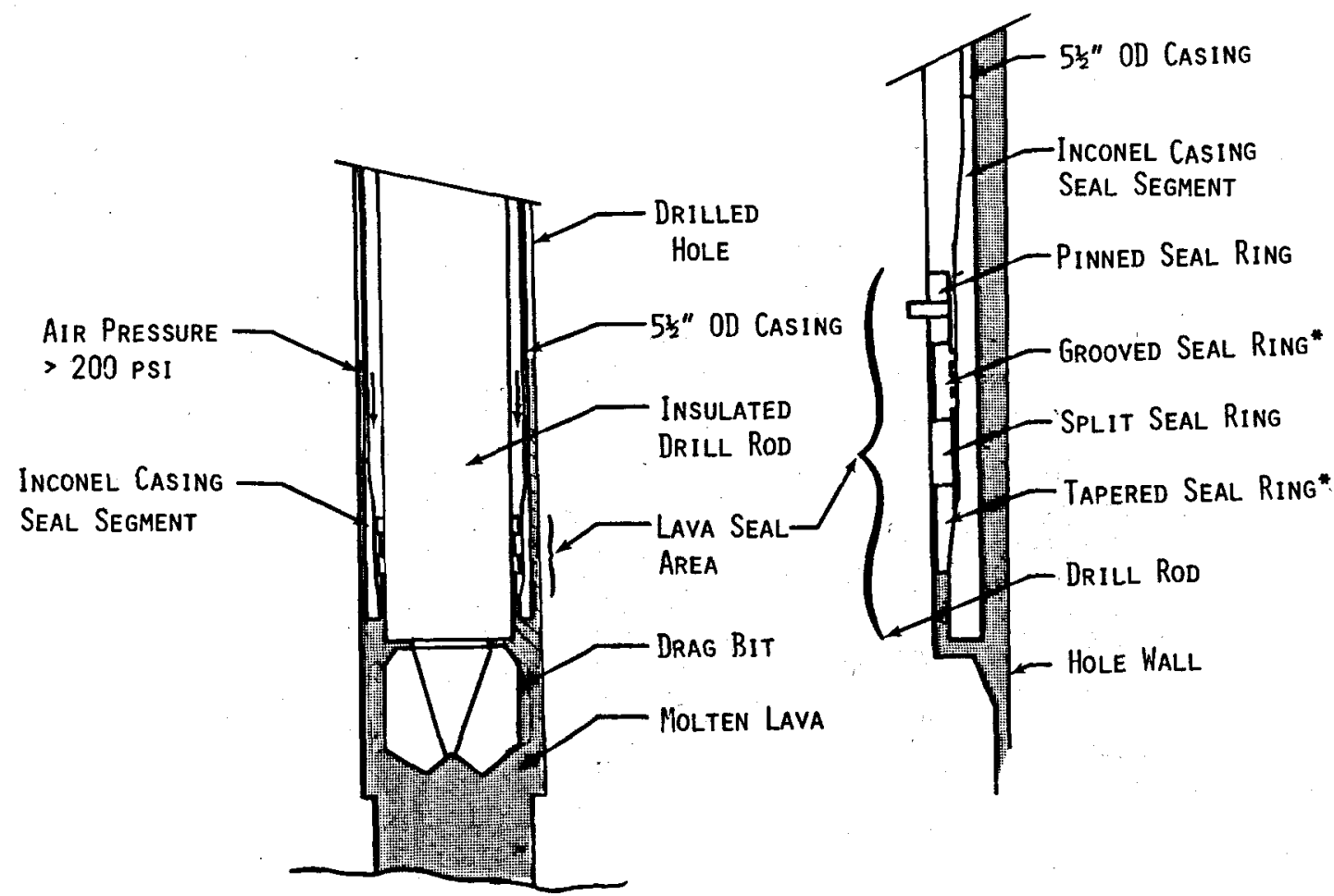

"Interference fit at Operating Temperature

Figure 6. IDS Lava Seal Schematic

were configured in such a way that, when the Inconel casing section was hot and the rings were cold, assembly clearance existed. As the temperature of the ring reached about $260^{\circ} \mathrm{C}$, the differential thermal expansion between stainless steel and Inconel would cause interference between the stainless steel ring and the Inconel casing. In this manner, an airtight seal along the inside diameter of the casing was attained. Split rings at the second and fourth positions above the bottom were sprung around the drill rod, which expanded or contracted as the outside diameter of the drill rod varied. The horizontal surfaces of each of the rings were made as parallel as possible. The leak paths which resulted consisted of only the radial split, in the split rings and the circumferential mismatch between the inside diameter of the split rings and the outside diameter of the drill rod. A leak rate less than the capacity of two of the three available compressors was expected when the casing annulus was pressurized to just above the lithostatic pressure at the bottom of the casing.

Water Jet-Augmented Drilling -- The concept of water jet-augmented drilling, as it was applied to the FY 79 Lava Lake Drilling Program, consisted of forcing coherent high-velocity streams of water forward from the face of slightly modified conventional bits into the expected plastic or liqquid rock at such a rate that the rock 
would be solidified at a reasonable drilling rate ahead of the bit. The use of the term "jet-augmented drilling". should not be confused with the more conventional "jet drilling." in which very high-velocity, high-pressure jets are formed to abrade the rock ahead of the drill and wash the resulting small rock particles away from the bottom of the hole. With conventional jet drilling, the rock is not mechanically drilled at any time in the operation as it is with the "jet-augmented drilling" described in this document."

The water jet-augmented drilling systems developed for the FY79 Lava Lake Drilling Program involved two types of bits. One was a simple, inexpensive, threewing drag bit, 2-3/8 inches in diameter, with carbide cutting surfaces. The cooling-water orifice was modified to provide a coherent high-velocity jet on the centerline of the bit, which would produce a desired flow rate of about 8 gpm at a 50-psi pressure drop across the orifice. The flow rate produced corresponded to the amount of water required to cool the molten rock ahead of the bit at a reasonable rate of drilling (1/2 to 1 inch per minute). In addition, sufficient momentum was attained to penetrate the liquid or plastic rock for a reasonable depth. Thus, the liquid rock would be solidified at a known rate ahead of the bit, and the solidified rock would then be drilled with the drag bit.

The water jet-augmented core bit is similar to the water jet-augmented drag bit except that eight orifices are distributed around the periphery of the face of a conventional, NQ-size ( 1.87 inches), face-discharge core bit. A standard NW core barrel was used in an effort to recover core from the rock solidified ahead of the bit. The total water flow of about $8 \mathrm{gpm}$ was divided between the orifices in the face of the bit ( 80 percent) and through the core barrel ( 20 percent). Figure 7 shows the water jet-augmented core bit used during the drilling in Hole 79-1 (left) and an unused bit (right). Note that the pilot lip has been worn away completely and that considerable wear has occurred along the outside of the bit and shank. Figure 8 is a closer view of the erosion suffered by the bit matrix.

Figure 9 is a photo of the two water jet-augmented arag bits used in Hole 79-4. The carbide insert tips have been badly worn. Figure 10 shows the drag bit shank deeply scoured by the cuttings generated and pushed up the side of the drill rod.

\section{Coolant supply and control system}

Both the IDS and the water jet-augmented drililing concepts required high water and air flow rates and extensive pressure control. The IDS system used a fine spray of water from the center water pipe to produce a thin film of cooling water on the inside surface of the inner drill rod. The annulus between this center pipe and the inside diameter of the inner drill rod was pressurized by air to a point above lithostatic pressure to keep the bit discharge nozzles free. The annulus between the casing and the outside of the drill string was also pressurized with air in excess of the expected lithostatic pressure during both the IDS and water jet-augmented drilling operation to prevent the molten rock from rising in the casing. An excess of water on. the inside of the insulated drill string would have overcooled the outside of the drill string, causing the molten rock to freeze 

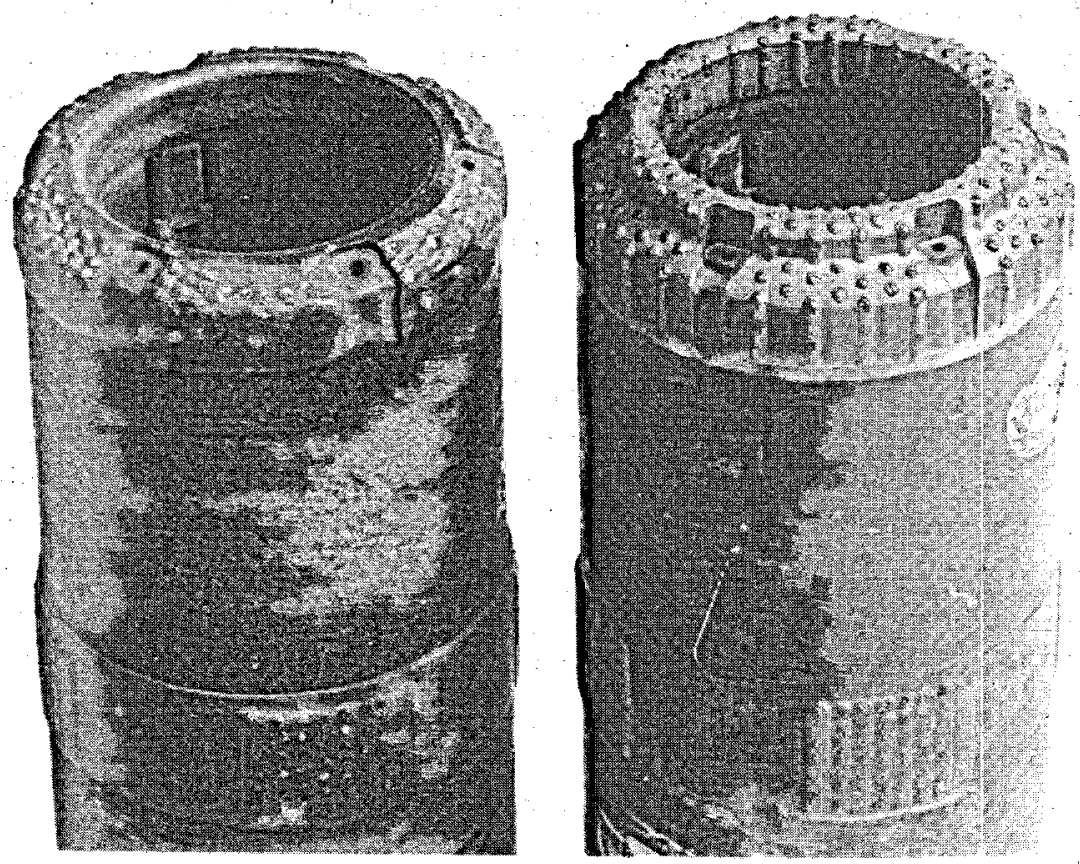

Figure 7. Water Jet-Augmented Core Bits in Hole 79-1 (L. -- used, R. -- unused)

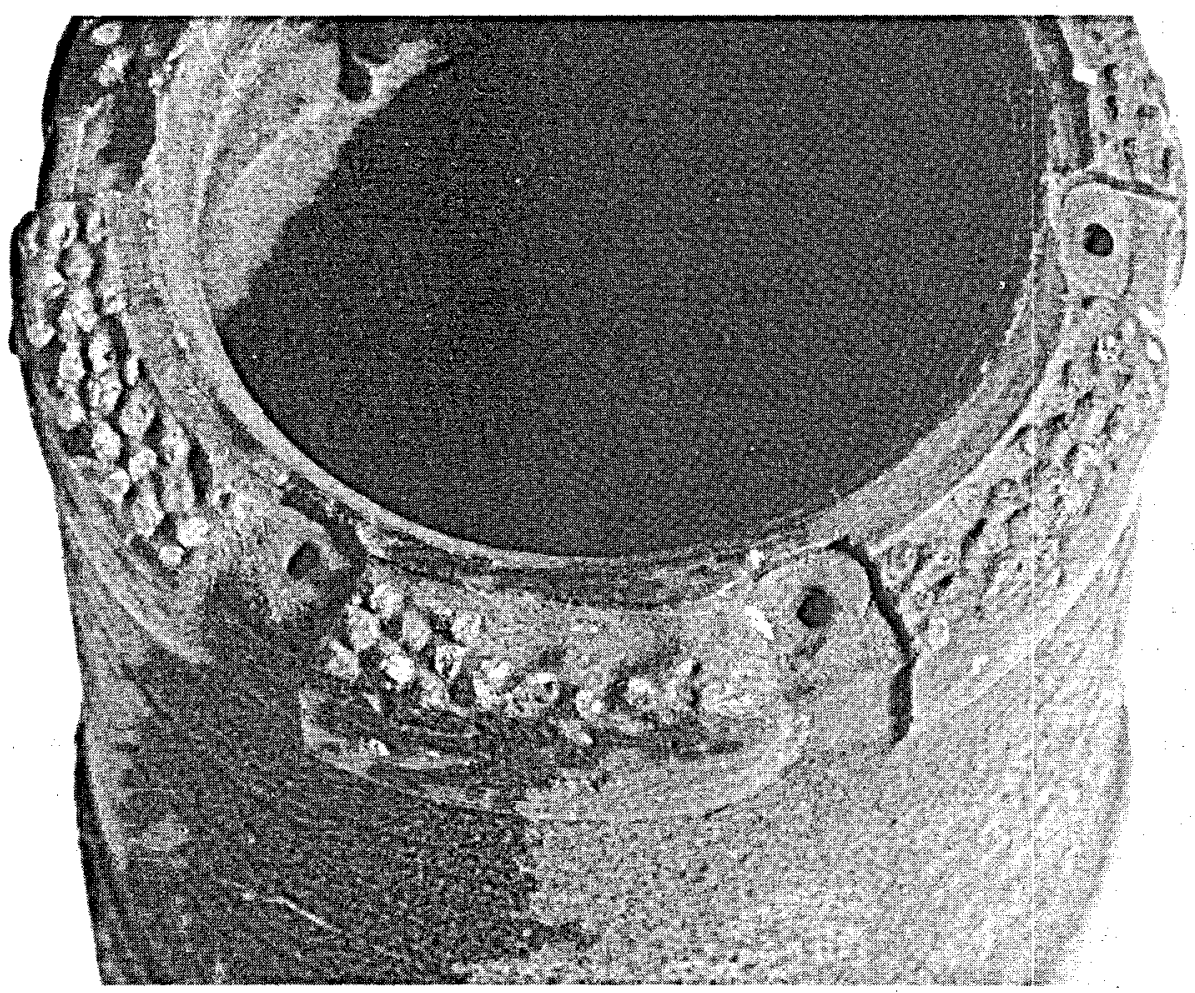

Figure 8. Closeup of Water Jet-Augmented Core Bit Used in Hole 79-1, Showing Extensive Wear 


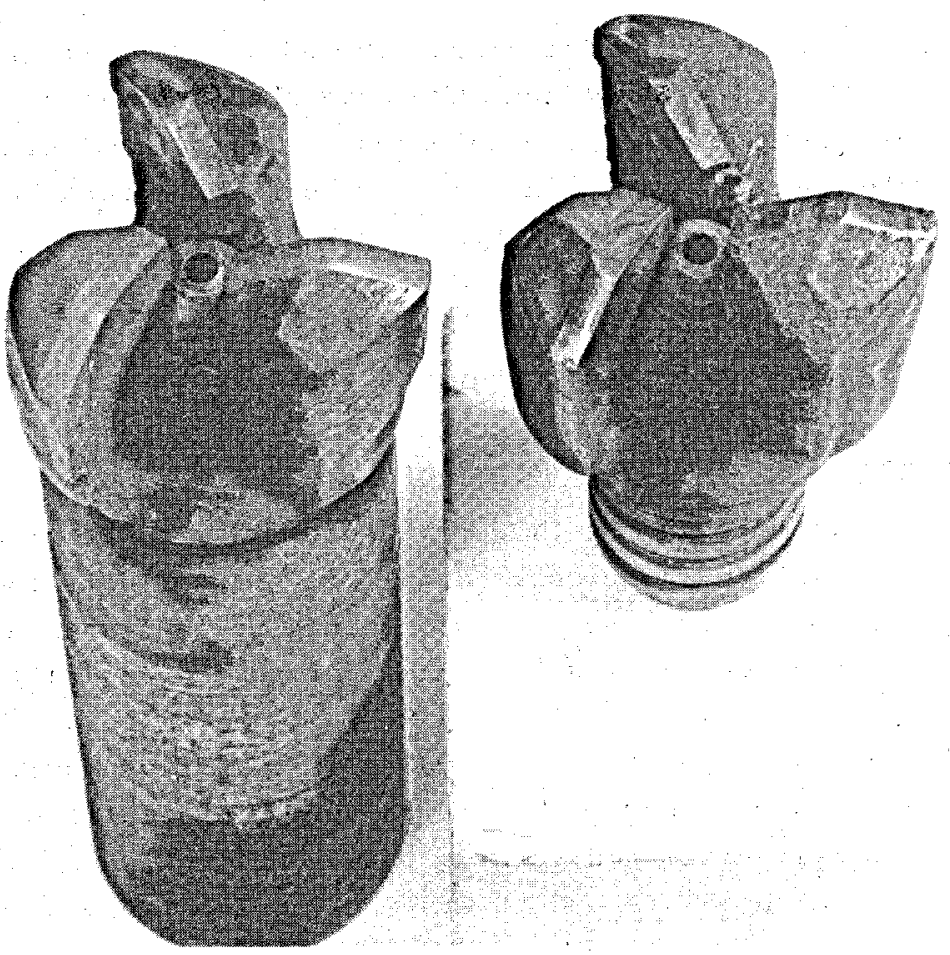

Figure 9. Water Jet-Augmented Drag Bits

Eroded during Drilling in Hole 79-4

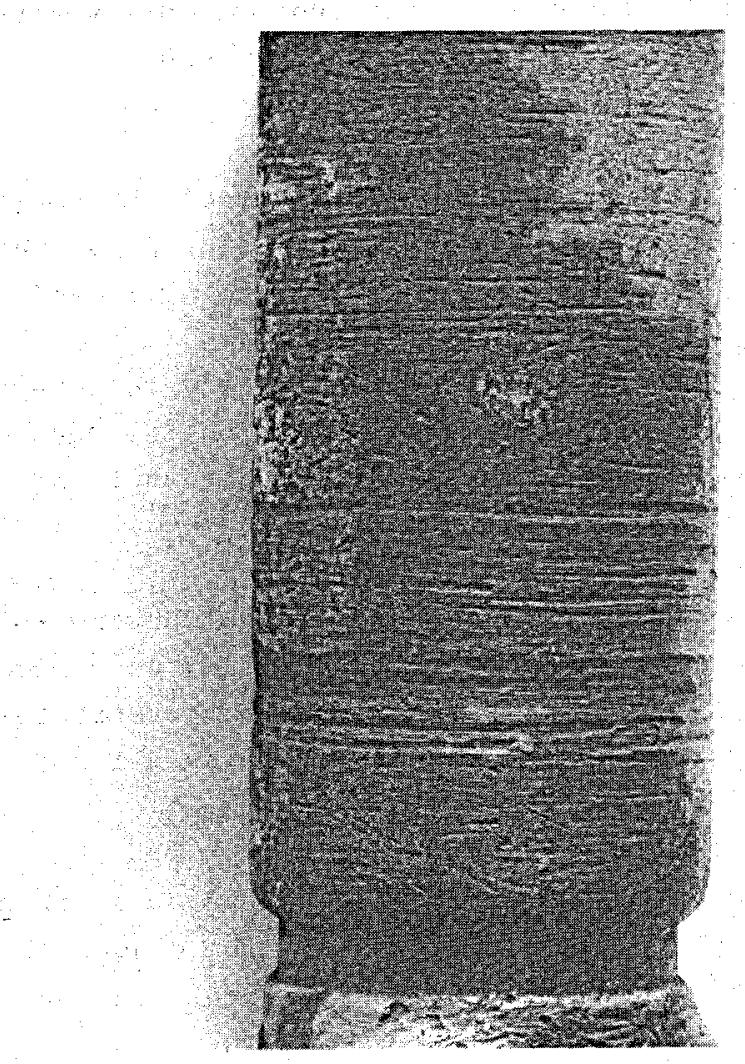

Figure 10. Scoured Water Jet-Augmented Drag Bit Shank 
on the drill string and stop its rotation. Excessive pressure in the annulus around the center water pipe would have prevented cooling water from entering the center water pipe. During water jet-augmented drilling, monitoring and adjusting of the cooling water were required in order to adjust the rock cooling rate and hence the drilling rate.

Figures 11 and 12 schematically illustrate the water and air control systems required by the IDS and water jet-augmented drilling activities.

\section{Instrumentation and Recording systems}

The HC-150 drill used in the FY79 Lava Lake Driliing Program was instrumented for the four basic drilling functions: drill rod torque, bit load, bit rotational velocity, and linear drilling rate. In addition, cooling water and air pressures and flow rates were recorded during all water jet-augmented drilling operations:

The HC-150 rig by Longyear uses a hydraulically driven drill. The main power unit drives three hydraulic pumps. The pumps supply hydraulic pressure to the wireline hoist, the main drill-rod-turning powerhead, the chuck jaws, and the pull-down cylinder, which raises and lowers and vertically loads the drill rod.

Pressure transmitters were installed in the hydraulic lines to the powerhead which applies rotational force to the drill rods. Similar transmitters also were installed in the hydraulic line to the "down" side of the pull-down cylinder. The torque-producing pressure was directly convertible to torque in foot-pounds applied to the drill rods. Figure $13^{*}$ is a plot of turning pressure versus torque for the drill used. Bit load was measured by measuring the pressure in the pull-down cylinder and converting to load.

A magnetic-pulse generator was positioned to detect the rotation of a large, castellated collar which rotated with the drill rod. The pulse rate observed was directly proportional to the rotational velocity of the drill rod.

The vertical drilling rate was measured by fixing a reel-type displacement transducer to the mast above the powerhead and attaching the reel cable to the powerhead. As the powerhead translated vertically, the resulting change in voltage with time indicated drilling rate.

Flow rates and pressures for the water and air which were supplied during water jet-augmented drilling and planned for IDs drilling were recorded during those operations. Impeller-type flowmeters calibrated appropriately for water and air flows were used. Pressure transmitters were also installed in air and water lines to record pressures.

Pressure gauges on the drill console monitored hydraulic pressures to the drill-rod-turning motor and the pull-down cylinder. The gauges provided real-time guidance to the drill operator. The pressures, the rotational velocity indicated

\footnotetext{
${ }^{*}$ From the Longyear report describing the HC-150 drill.
} 


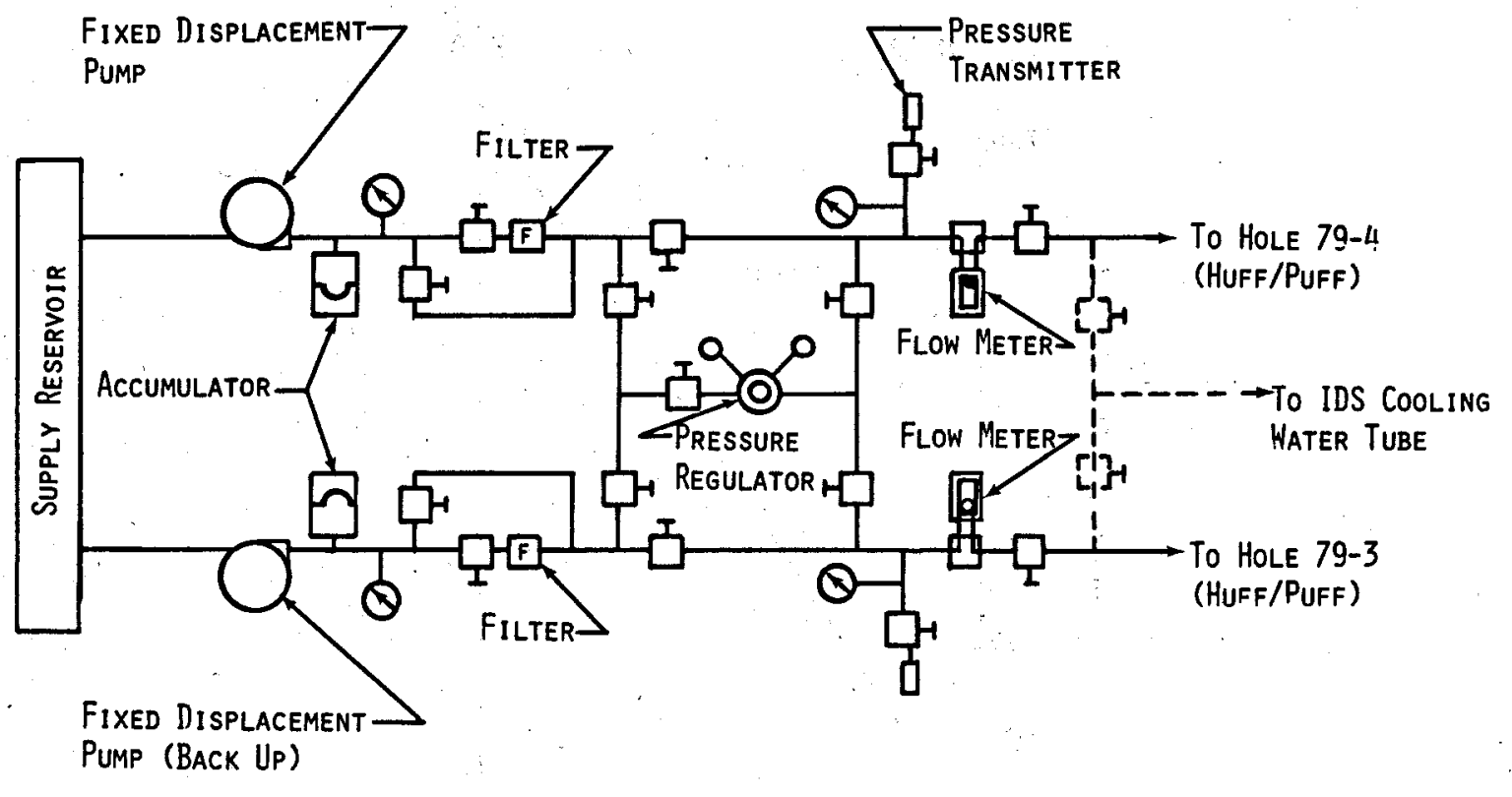

Figure 11. Water Control system

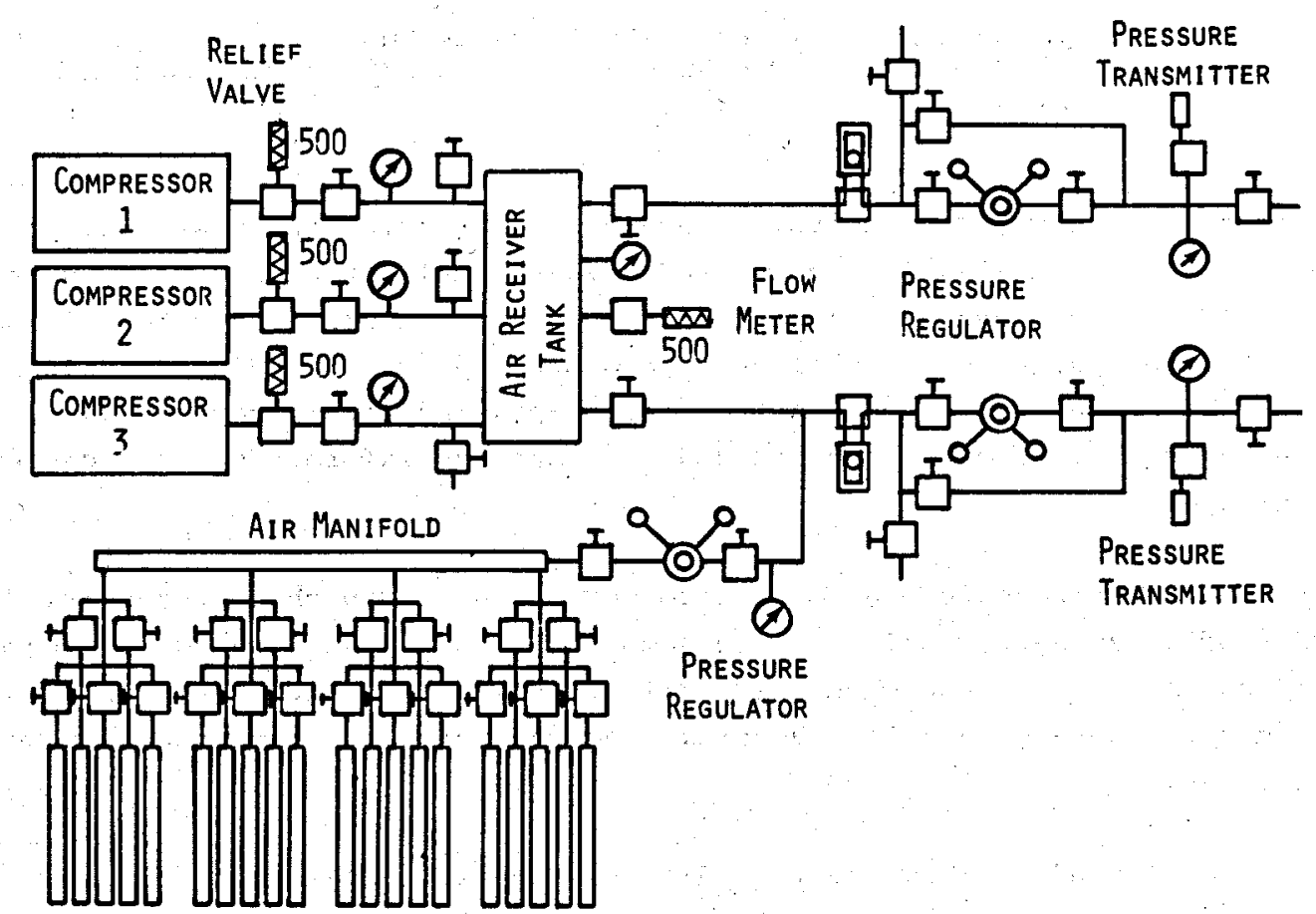

High Pressure Air Bottle

BACK UP SUPPLY

Figure 12. Casing Air Pressure Control System 


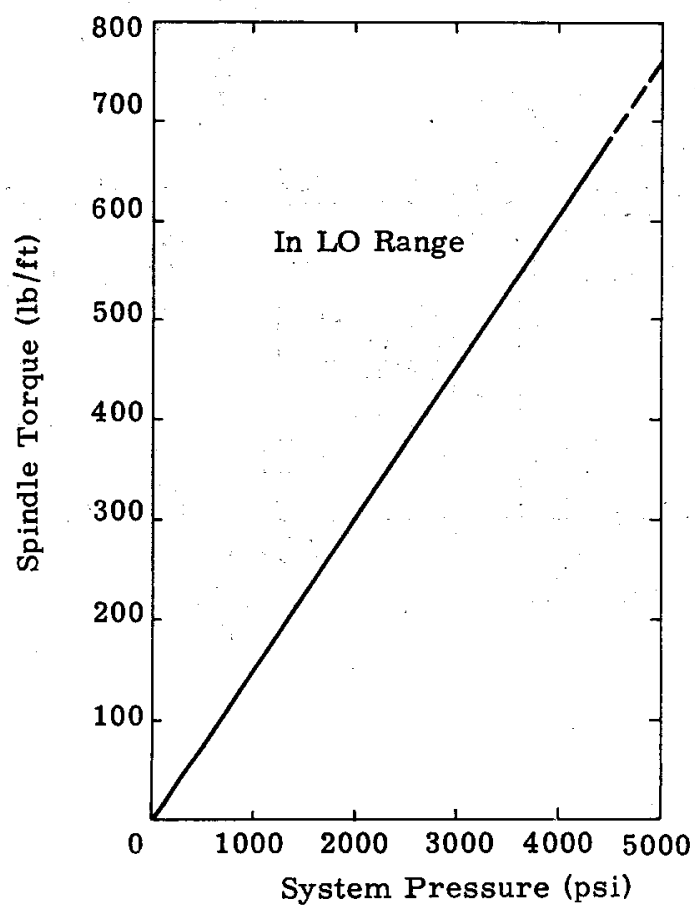

Figure 13. Spindle Torque System Pressure Curves for HC-150

Drill with Standard Speed-Change Gears in Powerhead

by the magnetic pickup, and the voltage-versus-time-indicating powerhead position were also recorded on 12-volt, dc-powered, two-channel strip chart recorders. The strip charts provided real-time rotational velocity and drilling rate information to the drilling operation, as well as a permanent record for reference after the drilling program was completed. A 12-volt, dc-powered datalogger was used to sample each channel of data recorded and to store the information on a cassette magnetic tape.

Frequency response of the data recorded on the strip chart recorders was on the order of a few hertz maximum. The sampling rate of the datalogger ranged from about 10 samples per minute when only drill functions were being recorded to about 3 samples per minute when drill functions and coolant flows and pressures were being recorded.

Figures 14 and 15 show the recording system electrical schematics for the drill functions and coolant-monitoring instrumentation. Figure 16 is the schematic of the instrumentation and recording system assembled to measure the quantity and quality of steam produced during the energy extraction experiments. 


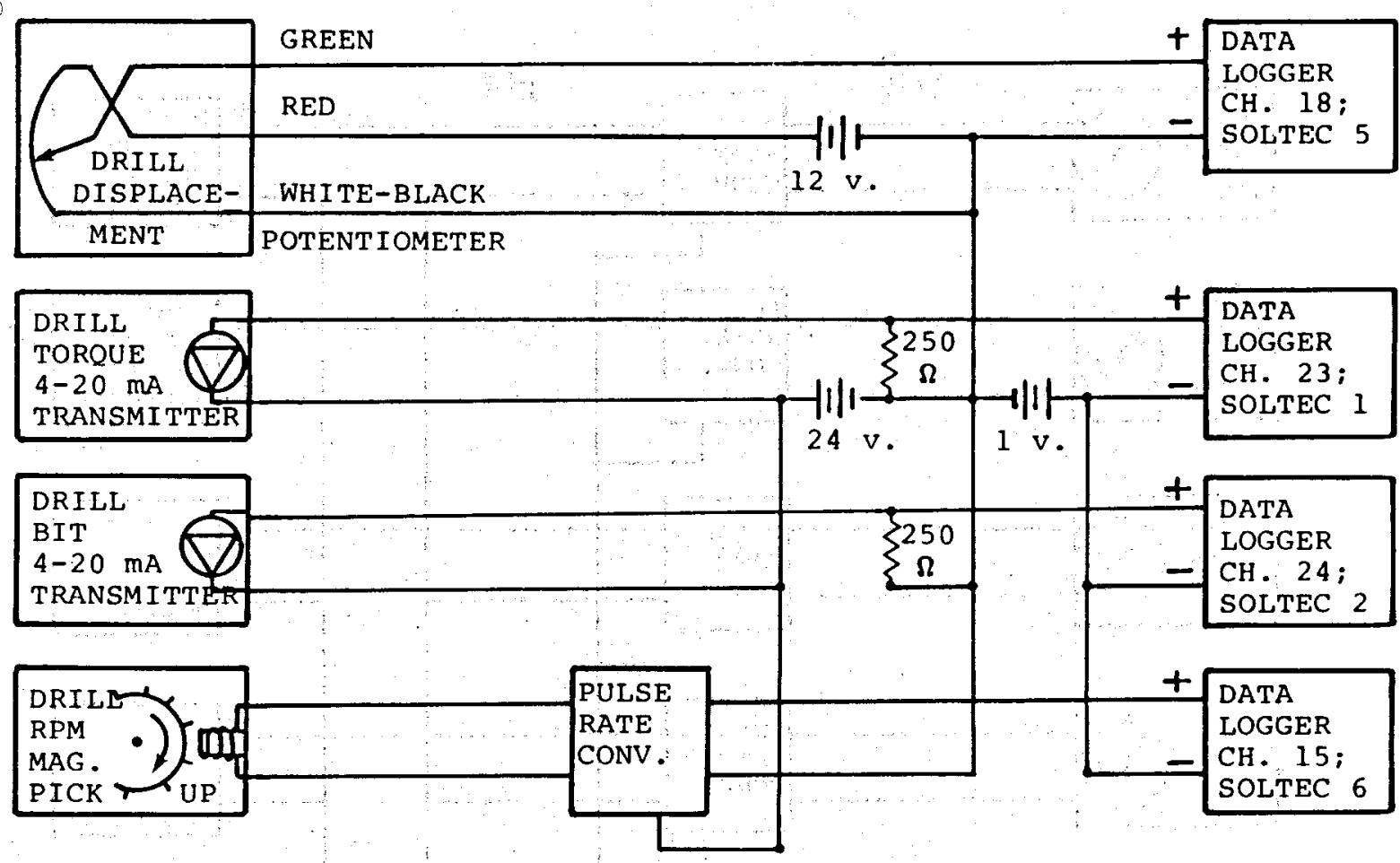

Figure 14. Drill Function Recording System Schematic.

Preliminary Results and Data Interpretation

Approximately 1,250 feet of relatively cool, crustal drilling was performed during the FY79 Lava Lake Drilling Program in preparing holes for the geoscience and drilling technology experiments. HQ-size wireline coring equipment was used for all crustal drilling. Diamond core bits were used predominantly, with occasional shifts to carbide core bits when high-temperature, soft rock was encountered.

Drilling rates of up to 6 inches per minute were achieved in the upper crust, using clear water as a drilling fluid. Circulation of the drilling fluid was lost to the formation within 6 . inches of the surface after each hole was started. Gels, soap solutions, and other lubricants were used only in holes 75-5 and 75-6; when special permission was obtained to use a lightweight oil to lubricate the drill string.

The water jet-augmented drag bit system was used to drill approximately 15 feet through thin, low-viscosity velns of rock in Hole 79-4. Drilling through the liquid layers proceeded steadily when the air pressure surrounding the drill rod could be held above local lithostatic pressure. Drilling with the drag bit in the hardened, glassy, flow-back material was not successful. Considerable bit wear resulted under these conditions. Drilling with the water jet-augmented core bit in the plastic flow-back rock in Hole 79-1 proceeded steadily for about 20 feet after drilling with the standard wireline equipment was halted by the plastic rock. Core material was not recovered during the water jet-augmented core drilling. Although the water jet-augmented core drilling proceeded smoothly and steadily, considerable 


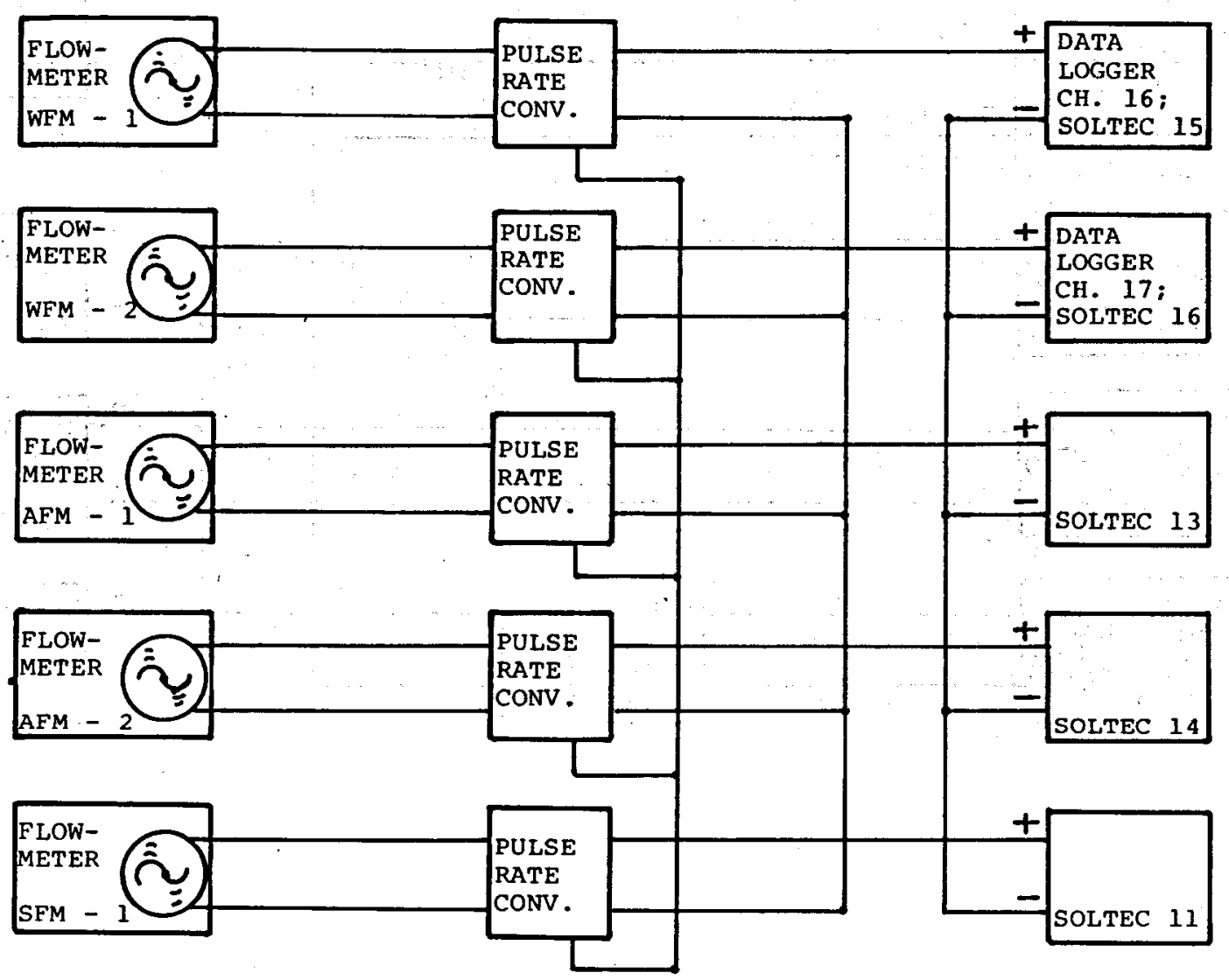

\begin{tabular}{|l|l|l|l|l|}
\hline $\begin{array}{l}\text { WATER } \\
\text { PRESSURE } \\
4-20 \mathrm{~mA}\end{array}$ \\
TRANSMITTER
\end{tabular}

Figure 15. Coolant Recording System Schematic 
bit wear resulted from the high temperatures encountered. Table 2 summarizes the results of the drilling experiments conducted.

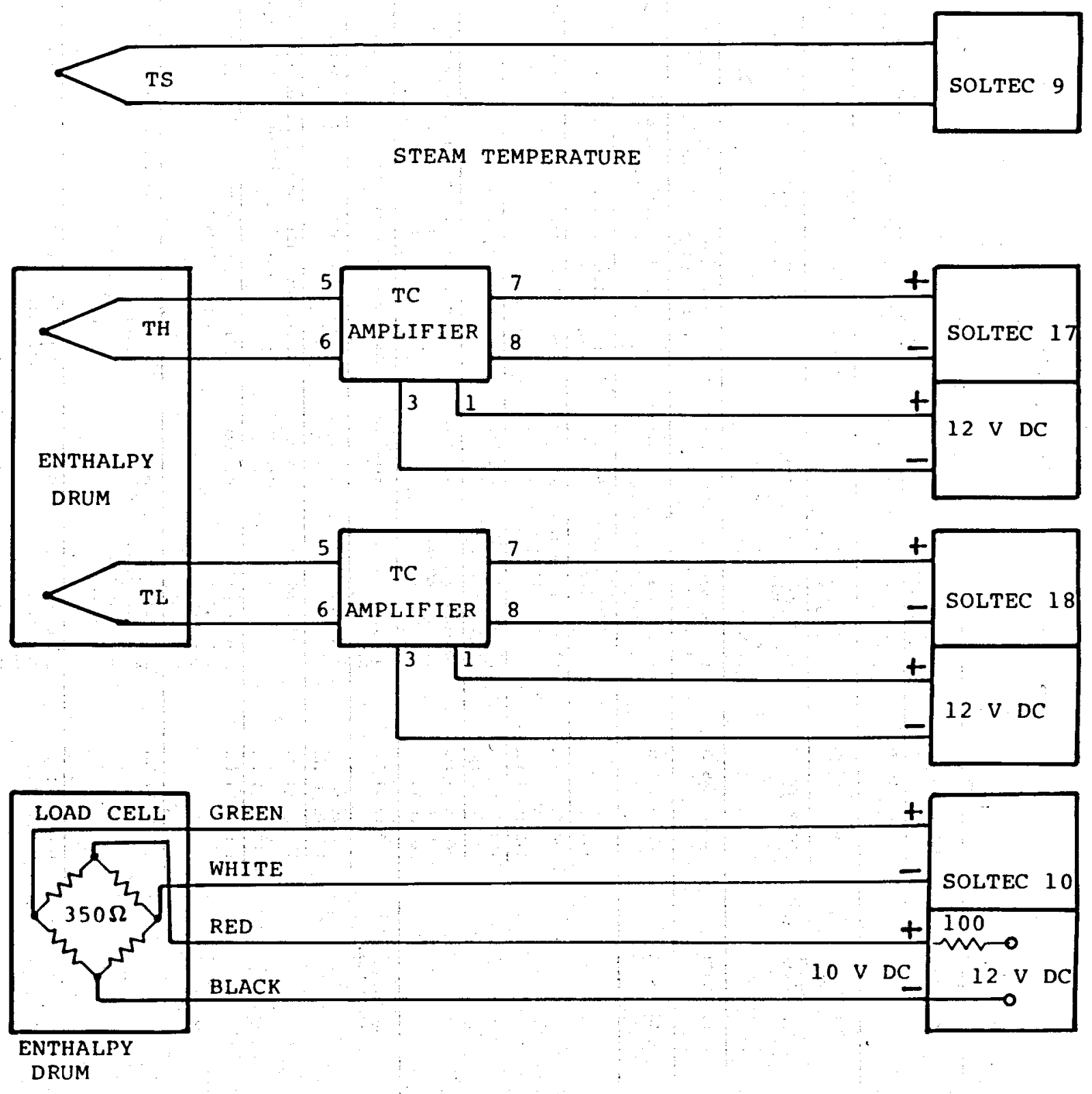

Figure 16. Steam Output Recording System Schematic 
Table 2

Drilling Technology Experiments

\begin{tabular}{|c|c|c|c|c|c|}
\hline $\begin{array}{c}\text { Hole } \\
\text { Designation }\end{array}$ & $\begin{array}{l}\text { Purpose } \\
\text { of Hole }\end{array}$ & $\begin{array}{c}\text { Depth } \\
\text { Interval } \\
\end{array}$ & $\begin{array}{l}\text { Bit } \\
\text { Type }\end{array}$ & $\begin{array}{l}\text { Coring } \\
\text { System }\end{array}$ & Comments \\
\hline \multirow[t]{2}{*}{$75-1$} & \multirow[t]{2}{*}{ Thermal well } & 135 to $143 \mathrm{ft}$ & $\begin{array}{l}\text { HQ diamond core, } \\
\sim 10 \text { stones/carat }\end{array}$ & Wireline & $\begin{array}{l}\text { Extremely rough drilling in glassy flow-back chimney. } \\
\text { Cores -- badly fragmented black nodules. }\end{array}$ \\
\hline & & 143 to $173 \mathrm{ft}$ & $\begin{array}{l}\text { HQ diamond core, } \\
\sim 10 \text { stones/carat }\end{array}$ & Wireline & Good drilling with good core-recovery rate. \\
\hline \multirow[t]{2}{*}{$79-1$} & \multirow{2}{*}{$\begin{array}{l}\text { Crust } \\
\text { permeability } \\
\text { measurements; } \\
\text { creep strength }\end{array}$} & 0 to $165 \mathrm{ft}$ & $\begin{array}{l}\text { HQ diamond core, } \\
\sim 10 \text { stones/carat }\end{array}$ & wireline & Good drilling with good core-recovery rate. \\
\hline & & 165 to $202 \mathrm{ft}$ & $\begin{array}{l}\text { HQ diamond core, } \\
\text { 10 stones/carat; } \\
\text { alternated with } \\
\text { carbide core bit }\end{array}$ & wireline & $\begin{array}{l}\text { Good drilling in very soft basalt. Good core-recovery } \\
\text { rate. Drilling suspended by higher priority activity. }\end{array}$ \\
\hline $76-2$ & IDS drilling & $\sim 40$ to $165 \mathrm{ft}$ & $\begin{array}{l}\text { HQ diamond core, } \\
\sim 10 \text { stones/carat }\end{array}$ & Wireline & $\begin{array}{l}\text { Good initial drilling. Drill string stuck at } \sim 165 \mathrm{ft} \\
\text { by metal particle in hole. Abandoned. }\end{array}$ \\
\hline $79-2$ & IDS drilling & 0 to $165 \mathrm{ft}$ & $\begin{array}{l}\text { HQ diamond core, } \\
\text { 10 stones/carat }\end{array}$ & wireline & $\begin{array}{l}\text { Good initial drilling. Hole collapsed overnight. } \\
\text { Abandoned. }\end{array}$ \\
\hline \multirow[t]{4}{*}{$79-3$} & \multirow[t]{4}{*}{$\begin{array}{l}\text { Energy } \\
\text { extraction }\end{array}$} & $\begin{array}{r}\text { 0. to } \\
172 \mathrm{ft} 6 \mathrm{in} . \\
\end{array}$ & $\begin{array}{l}\text { HQ diamond core, } \\
\sim 10 \text { stones/carat }\end{array}$ & Wireline & $\begin{array}{l}\text { Good drilling to initial melt penetration. Good core } \\
\text { recovery. }\end{array}$ \\
\hline & & $\begin{array}{l}154 \mathrm{ft} 9 \mathrm{in} . \\
\text { to } \\
171 \mathrm{ft} 7 \mathrm{in.}\end{array}$ & $\begin{array}{l}\text { HQ diamond core, } \\
\sim 10 \text { stones/carat }\end{array}$ & Wireline & Good drilling first flow-back chimney. Core recovered. \\
\hline & & $\begin{array}{l}160 \mathrm{ft} \text { to } \\
170 \mathrm{ft} 5 \mathrm{in} . \\
\end{array}$ & $\begin{array}{l}\text { HQ diamond core, } \\
\sim 10 \text { stones/carat }\end{array}$ & Wireline & Good drilling second flow-back chimney. Core recovered. \\
\hline & & $\begin{array}{l}166 \mathrm{ft} 8 \mathrm{in} . \\
\text { to } \\
169 \mathrm{ft} 10 \mathrm{in.}\end{array}$ & $\begin{array}{l}\text { HQ diamond core, } \\
\sim 10 \text { stones/carat }\end{array}$ & Wireline & Good drilling third flow-back chimney. Core recovered. \\
\hline \multirow[t]{6}{*}{$79-4$} & \multirow[t]{6}{*}{$\begin{array}{l}\text { Energy } \\
\text { extraction }\end{array}$} & 0 to $40 \mathrm{ft}$ & $\begin{array}{l}\text { HQ carbide core } \\
\text { bit }\end{array}$ & Wireline & Good drilling with good core recovery. \\
\hline & & $\begin{array}{r}40 \mathrm{ft} \text { to } \\
172 \mathrm{ft} \quad 6 \mathrm{in} . \\
\end{array}$ & $\begin{array}{l}\text { HQ diamond core } \\
\text { bit }\end{array}$ & Wireline & Good drilling with good core recovery. \\
\hline & & $\begin{array}{c}172 \mathrm{ft} 6 \text { in. } \\
\text { to } \\
173 \mathrm{ft} 3 \mathrm{in.}\end{array}$ & NQ diamond bit & $\begin{array}{l}\text { Standard } \\
\text { NW core } \\
\text { barrel }\end{array}$ & $\begin{array}{l}\text { Experienced difficulty in getting bit through bottom } 12 \\
\text { ft of casing. Tapped liquid layer for casing seal. }\end{array}$ \\
\hline & & $171 \mathrm{ft} 10 \mathrm{in}$. & $\begin{array}{l}\text { NQ-piloted, } \\
\text { water jet- } \\
\text { augmented } \\
\text { core bit } \\
\end{array}$ & $\begin{array}{l}\text { Standard } \\
\text { NW core } \\
\text { barrel }\end{array}$ & $\begin{array}{l}\text { Failed to get core bit and core barrel to pass through } \\
\text { lower part of casing. }\end{array}$ \\
\hline & & $171 \mathrm{ft} 10 \mathrm{in}$. & $\begin{array}{l}2-3 / 4-\text { in. } \\
\text { diameter, water } \\
\text { jet-augmented, } \\
\text { three-wing drag } \\
\text { bit } \\
\end{array}$ & None & $\begin{array}{l}\text { Drilled to } 179 \text { ft } 9 \text { in. when liquid layer was } \\
\text { encountered. }\end{array}$ \\
\hline & & $\begin{array}{l}167 \mathrm{ft} 3-1 / 2 \text { in. } \\
\text { to } 168 \mathrm{ft}\end{array}$ & $\begin{array}{l}2-3 / 4-i n .- \\
\text { diameter, water } \\
\text { jet-augmented, } \\
\text { three-wing drag } \\
\text { bit } \\
\end{array}$ & None & $\begin{array}{l}\text { Drilling flow-back chimney. Drilling difficult with } \\
\text { drag bit. }\end{array}$ \\
\hline
\end{tabular}


Table 2 (Continued)

\begin{tabular}{|c|c|c|c|c|c|}
\hline $\begin{array}{c}\text { Hole } \\
\text { Designation }\end{array}$ & $\begin{array}{l}\text { Puxpose } \\
\text { of Hole. }\end{array}$ & $\begin{array}{l}\text { Depth } \\
\text { Interval }\end{array}$ & $\begin{array}{l}\text { Bit } \\
\text { Type }\end{array}$ & $\begin{array}{l}\text { Coring } \\
\text { system }\end{array}$ & Comments \\
\hline & & $\begin{array}{l}168 \mathrm{ft} \text { to } \\
174 \mathrm{ft} 3 \mathrm{in}\end{array}$ & $\begin{array}{l}\text { BQ diamond } \\
\text { core bit }\end{array}$ & $\begin{array}{l}\text { 5-ft } B Q \\
\text { wireline }\end{array}$ & Drilling out flow-back chimney. \\
\hline ' & : & $\begin{array}{l}174 \mathrm{ft} 3 \mathrm{in} . \\
\text { to } \\
185 \mathrm{ft} 11 \mathrm{in} .\end{array}$ & $\begin{array}{l}2-3 / 4 \text { in,- } \\
\text { diameter, water } \\
\text { jet-augmented, } \\
\text { three-wing drag } \\
\text { bit }\end{array}$ & None & $\begin{array}{l}\text { Drilling haited occasionally by liquid layers. } \\
\text { Drilling rate very slow }-0.2 \text { to } 0.5 \text { in./min. Drilling } \\
\text { more sure when casing pressure was held. }\end{array}$ \\
\hline & & $\begin{array}{l}185 \mathrm{ft} 11 \text { in. } \\
\text { to } \\
186 \mathrm{ft} 5-1 / 2 \text { in. }\end{array}$ & $\begin{array}{l}\text { BQ diamond } \\
\text { core bit }\end{array}$ & $\begin{array}{l}\text { 5-ft BQ } \\
\text { wireline }\end{array}$ & Drilling for core samples in apparently cool rock. \\
\hline $\begin{array}{c}79-1 \\
\text { Reentry }\end{array}$ & $\begin{array}{l}\text { Core through } \\
\text { lake }\end{array}$ & $\begin{array}{l}165 \mathrm{ft} \text { to } \\
178 \mathrm{ft}\end{array}$ & $\begin{array}{l}\text { HQ diamond } \\
\text { core bit }\end{array}$ & Wireline & Thin glass layers evident intermittently. \\
\hline & & $\begin{array}{l}172 \mathrm{ft} 10 \mathrm{in} . \\
180 \mathrm{ft} 6 \mathrm{in} .\end{array}$ & $\begin{array}{l}\text { HQ diamond } \\
\text { core bit }\end{array}$ & Wireline & Drilling in flow-back rock. \\
\hline & & $\begin{array}{l}180 \mathrm{ft} 6 \mathrm{in} \\
\text { to } \\
181 \mathrm{ft} 10 \mathrm{in} .\end{array}$ & $\begin{array}{l}\text { HQ carbide core } \\
\text { bit }\end{array}$ & wireline & Core recovered --26 in. long. \\
\hline & " & $\begin{array}{l}181 \mathrm{ft} 10 \mathrm{in} . \\
\text { to } \\
183 \mathrm{ft} 4 \mathrm{in} .\end{array}$ & $\begin{array}{l}\text { HQ carbide core } \\
\text { bit }\end{array}$ & Wireline & Lost face of bit. Very soft rock. \\
\hline & & $\begin{array}{l}179 \mathrm{ft} 10 \mathrm{in} \text {. } \\
\text { to } \\
183 \mathrm{ft} 7 \mathrm{in} .\end{array}$ & $\begin{array}{l}\text { HQ diamond } \\
\text { core bit }\end{array}$ & Wireline & Drizling to recover bit face. Very soft rock. \\
\hline & & $\begin{array}{l}180 \mathrm{ft} 8 \mathrm{in} \\
\text { to } \\
188 \mathrm{ft} 1 \mathrm{in} .\end{array}$ & $\begin{array}{l}\text { NQ-piloted, } \\
\text { water jet- } \\
\text { augmented } \\
\text { core bit }\end{array}$ & $\begin{array}{l}\text { Standard } \\
\text { NW core } \\
\text { barrel }\end{array}$ & $\begin{array}{l}\text { Water pressure at pump }-150 \text { to } 200 \text { psi. Drilled to } \\
188 \mathrm{ft} 1 \mathrm{in} \text {. No core recovered. Small plug } \sim \mathrm{in} \text {. } \\
\text { thick in end of bit/core barrel. }\end{array}$ \\
\hline & & $\begin{array}{l}188 \mathrm{ft} l \mathrm{in} . \\
\text { to } \\
192 \mathrm{ft} 5 \mathrm{in} .\end{array}$ & $\begin{array}{l}\text { NQ-piloted, } \\
\text { water jet- } \\
\text { augmented } \\
\text { core bit }\end{array}$ & $\begin{array}{l}\text { Standard } \\
\text { NW core } \\
\text { barrel }\end{array}$ & Attempted to recover core. Unsuccessful. \\
\hline $79-5$ & $\begin{array}{l}\text { Core through } \\
\text { lake }\end{array}$ & 0 to $342 \mathrm{ft}$ & $\begin{array}{l}\text { HQ diamond } \\
\text { core bit }\end{array}$ & wireline & $\begin{array}{l}\text { Continuous drilling. Erratic wall drag dictated } \\
\text { lubricating hole. Continuous core recovered to depth } \\
\text { of } 342 \mathrm{ft} \text {, at which time the lower crust had been } \\
\text { intercepted. }\end{array}$ \\
\hline \multirow[t]{2}{*}{$79-6$} & $\begin{array}{l}\text { Locate melt } \\
\text { zones }\end{array}$ & 0 to $192 \mathrm{ft}$ & $\begin{array}{l}\text { HQ diamond } \\
\text { core bit }\end{array}$ & wireline & $\begin{array}{l}\text { Continuous drilling to depth where high-pressure } \\
\text { liquid was encountered. }\end{array}$ \\
\hline & & $\begin{array}{l}142 \mathrm{ft} \text { to } \\
188 \mathrm{ft}\end{array}$ & $\begin{array}{l}\text { HQ diamond } \\
\text { core bit }\end{array}$ & Wireline & $\begin{array}{l}\text { Redrill flow-back chimney. Iiquid encountered rising } \\
\text { to about } 150 \mathrm{ft} \text {. Hole abandoned. }\end{array}$ \\
\hline
\end{tabular}


Analyses and interpretation of the results of the FY79' Lava Lake Drilling Program are expected to continue for some time at several locations within the DOE and the USGS. Appendices A through $D$ contain plots of the drill functions recorded for each of the experimental holes drilled. Plots of the data for Hole 79-1 reentry were obtained directly from the strip chart recordings, while those for the remaining holes came from the data sampled by the datalogger. The datalogger sampling rate was much lower $(0.05$ to 2.0 hertz) than that of the strip charts (several hundred hertz). Therefore, where the characteristic of a high-frequency component is important to the interpretation of results, care must be taken to use data from the original paper record.

\section{Conventional Drilling}

Although the bit load, displacement, and drill speed were helpful in controlling the drilling operation and in interpreting other data, the drilling torque was the most useful parameter in evaluating drilling performance.

Regarding the drill functions, no significant difference was recorded between drilling with conventional $\mathrm{HQ}$ wireline equipment in the $\mathrm{co0}\left(100^{\circ} \mathrm{C}\right)$ upper crust and in the high-temperature rock just above the liquid or melt zones. However, there was a sharp difference between the torque signatures observed during drilling of the hard, fractured, glassy rock of the old flow-back chimney in Hole 75-1 (Figure 17) and those observed during drilling of the softer, hot rock (not yet liquid) encountered during drill back into Hole 79-1 (Figure 18a). It was also noted that there were similarities among torque signatures obtained under differing circumstances. The signature obtained from the flow-back chimney (Figure 17) during drilling with the conventional HQ bit was similar to that obtained during drilling in liquid or plastic veins in Hole 79-4 with the water jet-augmented drag bit (Figure 18c). These resembled the signature obtained during drilling in the plastic region of Hole 79-1, using the water jet-augmented core bit (Figure 18b).

The rough drilling in Hole 75-1, indicated by the high-frequency component superimposed on the basic torque value, was caused by the highly fractured, glassy rock in the flow back. The hard fragments tended to roll around beneath the bit, causing the rough drilling. In this case, a number of the fragments were retained in the core barrel, obstructed by a short plug of complete core encountered as the drilling proceeded beyond the glassy flow-back material. This observation leads to the assumption that, during the water jet-augmented drilling, the high-velocity cooling water was forced into the rock, cooling it so rapidly that it was shattered just ahead of the bit. In the case of the water jet-augmented core arilling, a "solid" plug of material below the glassy rock was not available to retain the particles of fractured, glassy rock in the core barrel, and the core was ground into cuttings.

The penetration of the liquid layer at the bottom of Hole 75-1 afforded the first opportunity to observe changes in the drill functions which indicated drilling into liquid rock. Subsequent planned experiments, such as the IDS drilling and the experiment to determine minimum plastic layer thickness for a stable hole, would depend upon the ability of the experimenters to sense if drilling was taking 

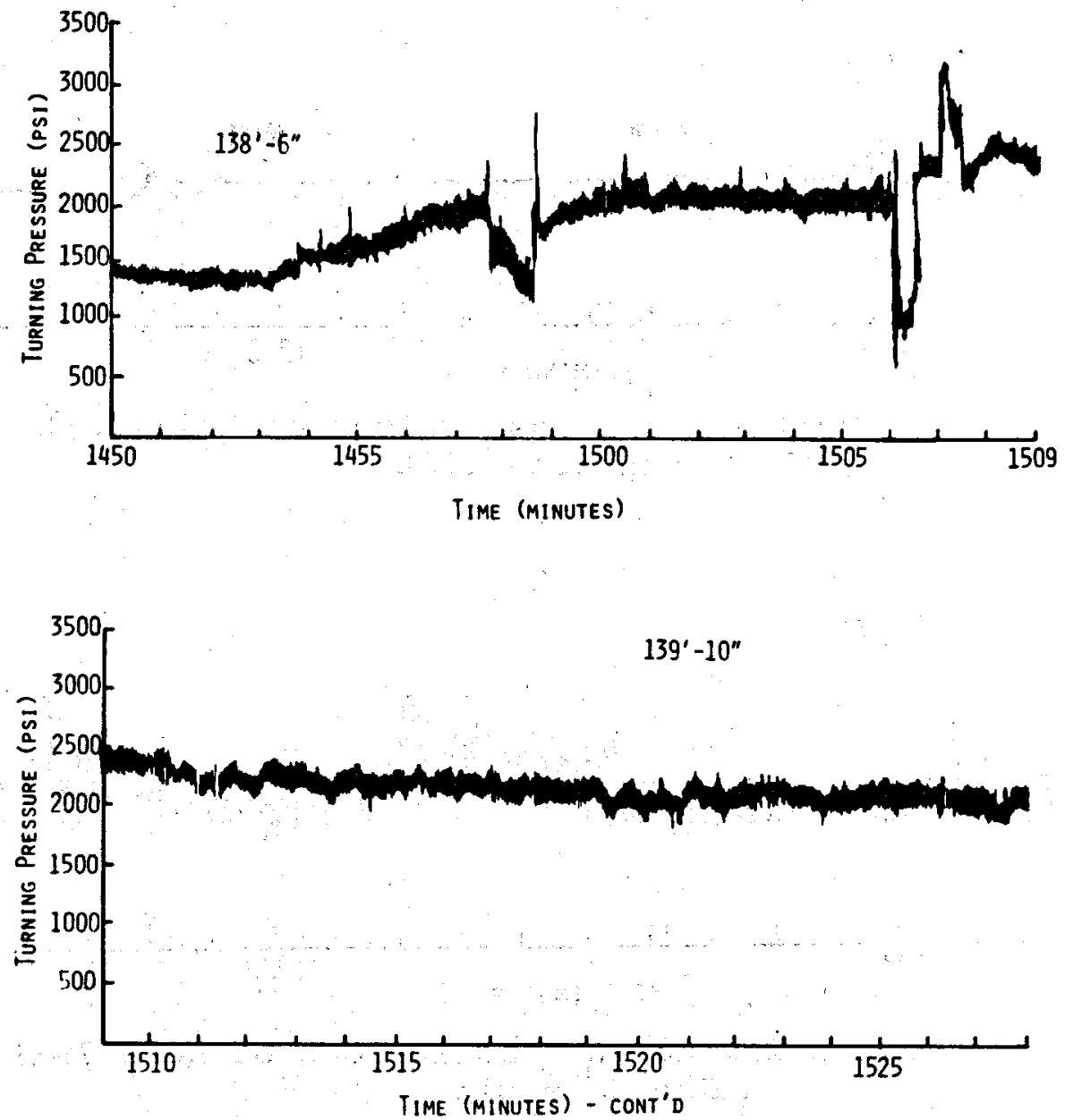

Figure 17. Drilling Out Glassy Flow-Back Chimney with Conventional HQ Core Bit (Hole 75-1)

place in a component rock or in liquid or plastic rock. Figure 19 shows the change in turning torque which was recorded during the first penetration of the liquid layer in Hole 75-1. This type of change was typical of those noted during succeeding penetrations of liquid rock.

The following sub-sections contain a detalled description of the results of the drilling activities and the penetrometer experiment.

Penetrometer Experiment

During the penetrometer experiment, a peak load of about 1.1,100 pounds was applied to the penetrometer. The load components consisted of a 9,300-pound downward drill load, about 1,300 pounds of rods, and about 500 pounds of water. Cycled and steady loads were applied as shown in Figure 20 .

The available load was not sufficient to force the penetrometer through the chilled cap at the top of the flow-back chimney, and therefore, the liquid layer was not penetrated. 


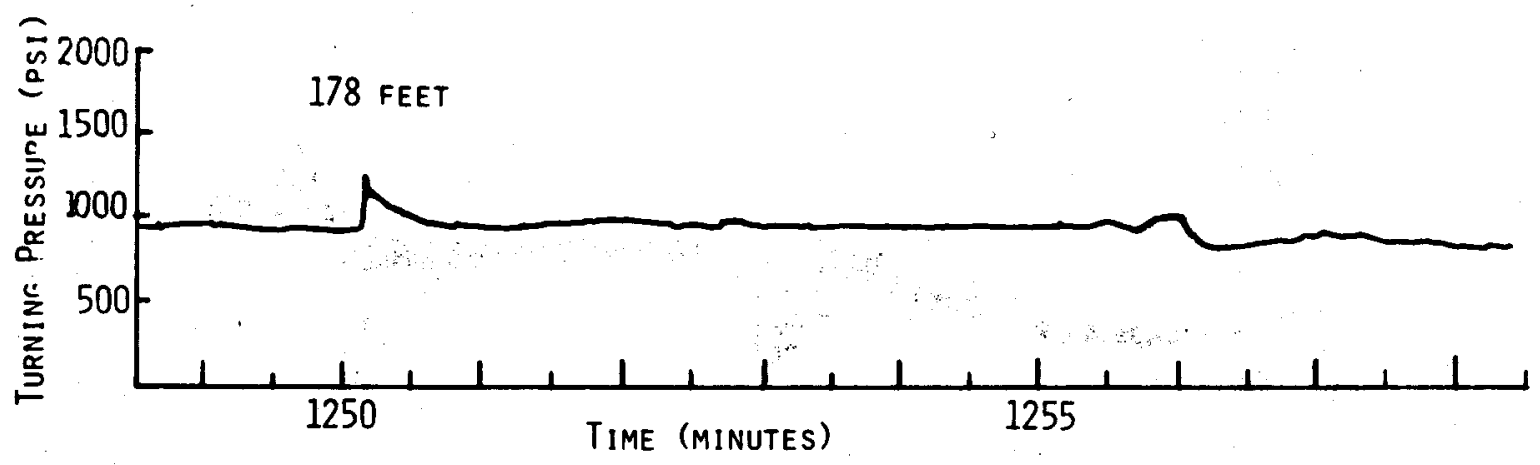

A. Drilling in Plastic Zone of Hole 79-1 with Conventional Bit

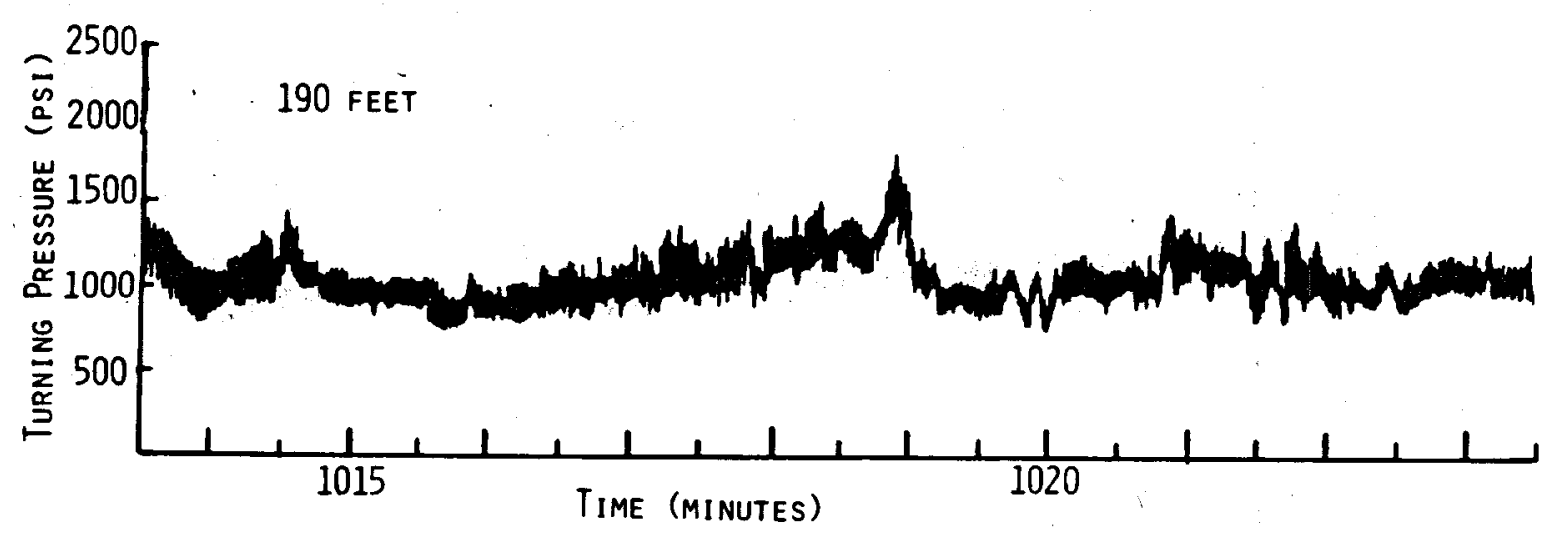

B. Drilling in Plastic zone of Hole 79-1 with Jet Core Bit

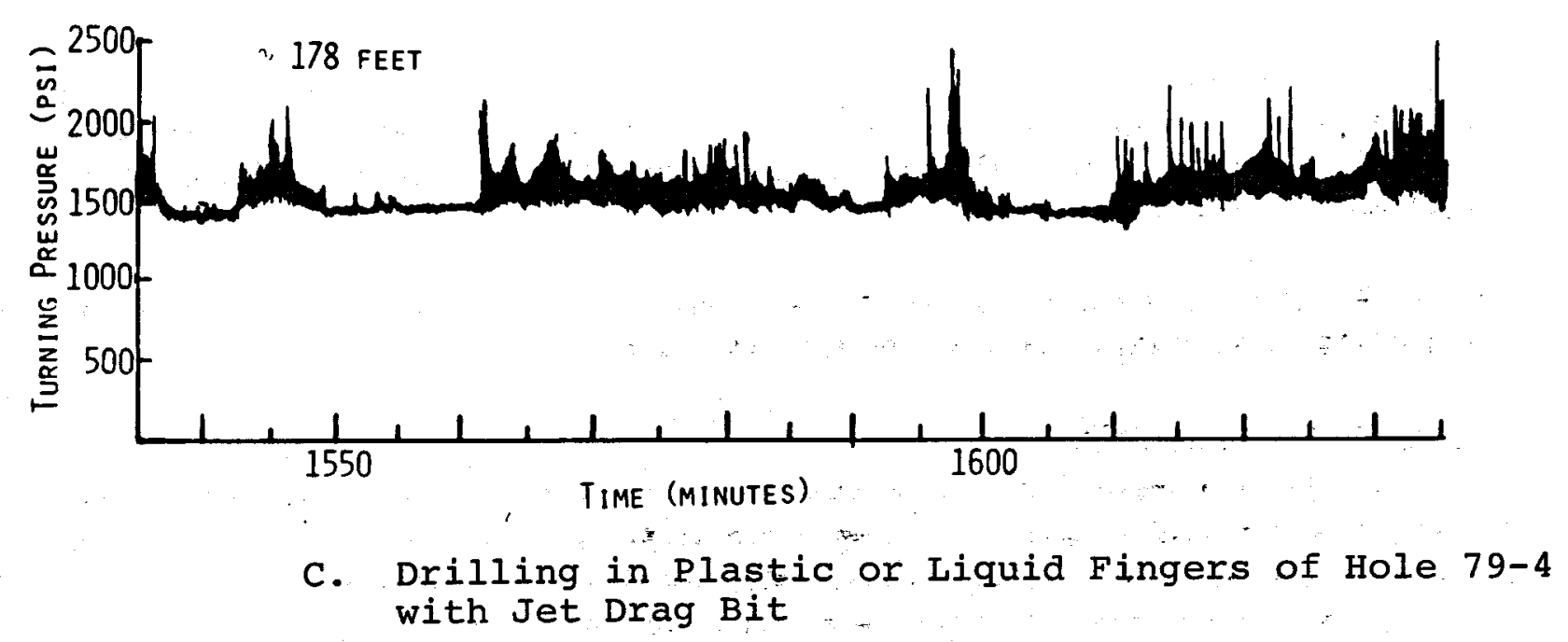

Figure 18. Drilling with Conventional, Jet Drag, and Jet Core Bits 


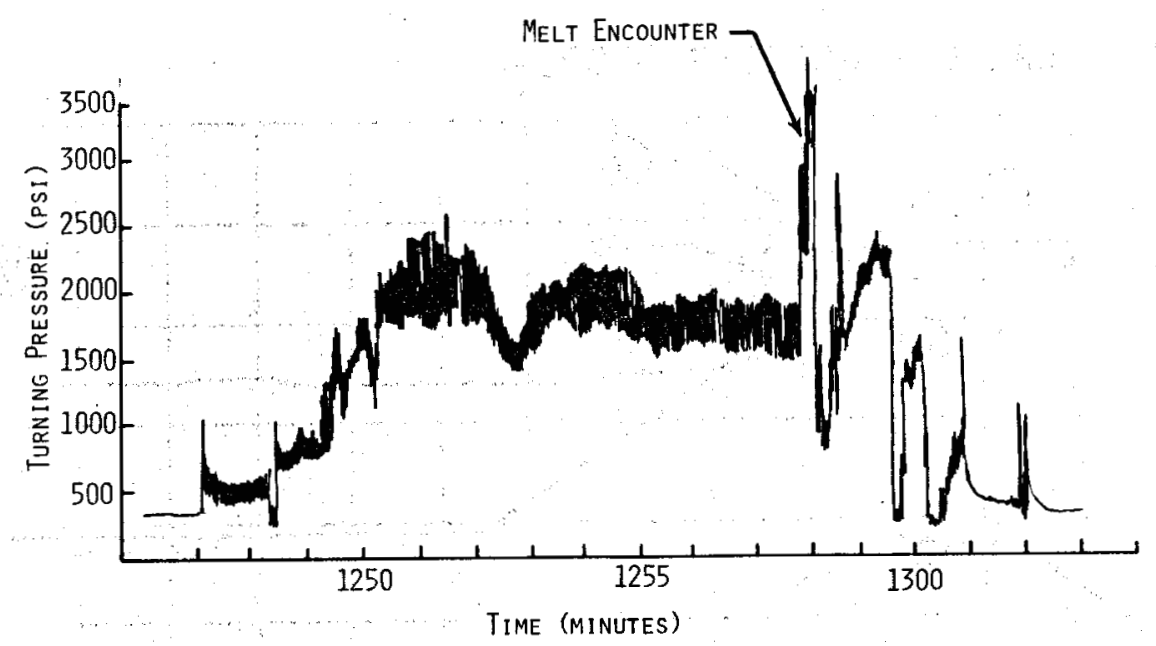

Figure 19: Initial Melt Encounter at $173 \mathrm{ft} l$ inch (Hole 75-1)

Examination of the penetrometer tip after it was removed from the hole revealed no change in the appearance or shape of the tip as a result of the test. Its sharp point was intact and still possessed its as-machined lustre. There were no signs of frozen rock adhering to the tip. The insulating insert between the electrical contacts of transite was blackened and, except for one crack, was intact. After the test, contact electrical isolation was 200 kilohms open circuits to both thermocouples precluded taking bottom-hole temperatures during the test.

The following is a sequential interpretation of the displacement/pressure records made during the penetrometer experiment; bit loads and displacements are shown in Figure 20.

Point 1. Initial point -- bit load equals zero displacement at starting point of about +3 inches.

Point 2. Bit load is increased in steps to a maximum. The displacement indicates about 3 inches downward travel. This represents the slack being taken up in the drill and some lifting of the front of the drill. The cause of the displacement was confirmed by visual observation of the drill rod position relative to the lake surface during loading.

Point 3. Bit load is removed.

point 4. The powerhead and chuck are lifted relative to the arill rod for better grip.

Point 5. Bit pressure is applied again and held at a steady load for almost 3-1/2 minutes. Initial downward indication of about $1-1 / 2$ inches signifies slack being taken up in the drill..

Point 6. At point 6 , the bit load is cycled as rapidly as is practical (once every few seconds) between zero and maximum possible.

Point 7. Bit load cycling and attendant raising and lowering of drill against its hold-down chains and slack removal take place.

Point $7 \mathrm{a}$. The chuck jaws start to slip on the drill rod until added pressure is applied to increase their grip on the rod.

Point 8. Steady maximum pressure is applied for approximately 10 minutes.

Point 9. Bit load is removed, and penetrometer is lifted a few inches off bottom: 
COMBIN ONE :-

Y79 L L DRILL FUNCTIONS DISPL- 6

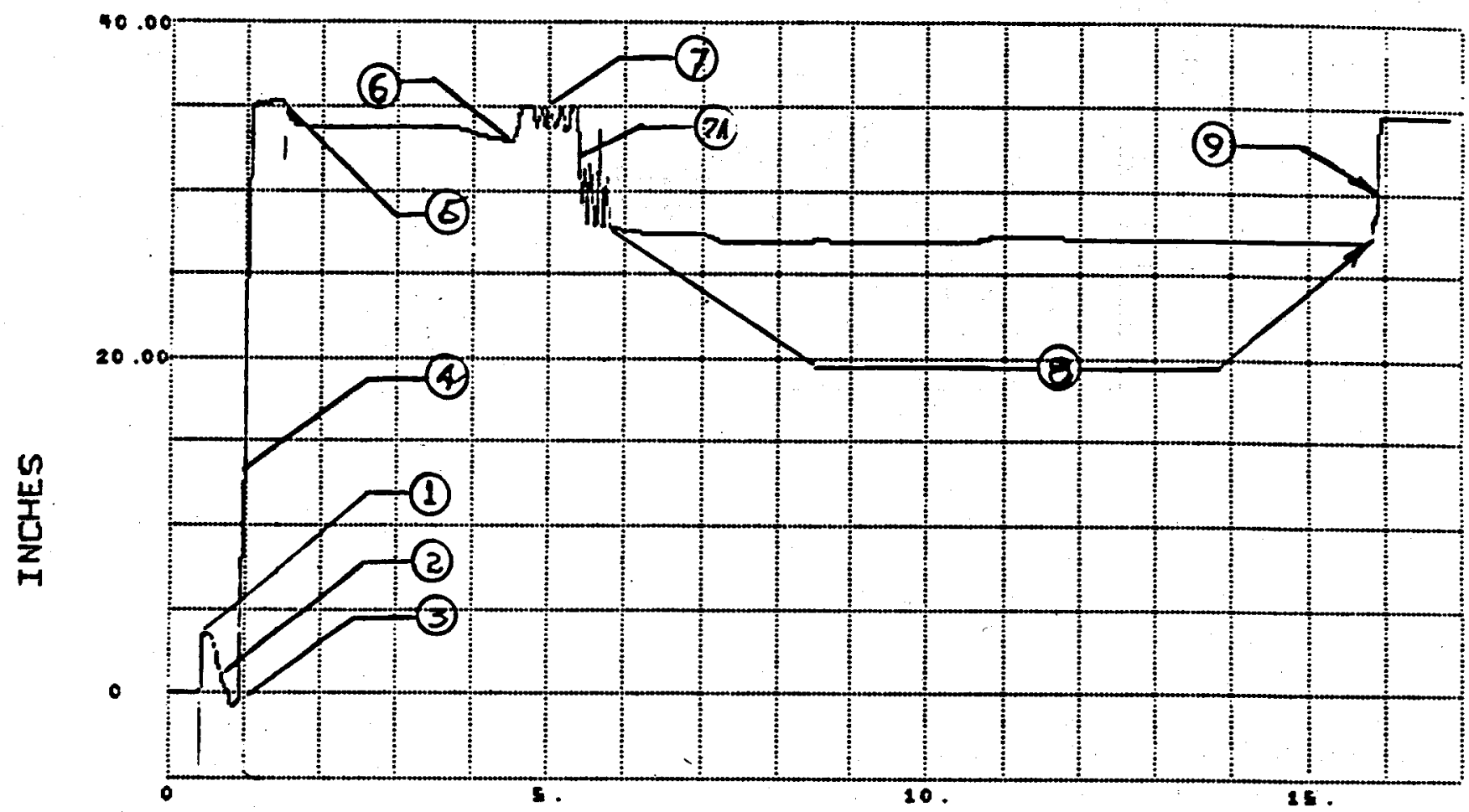

Y79 L L DRILL FUNCTIONS BP-E

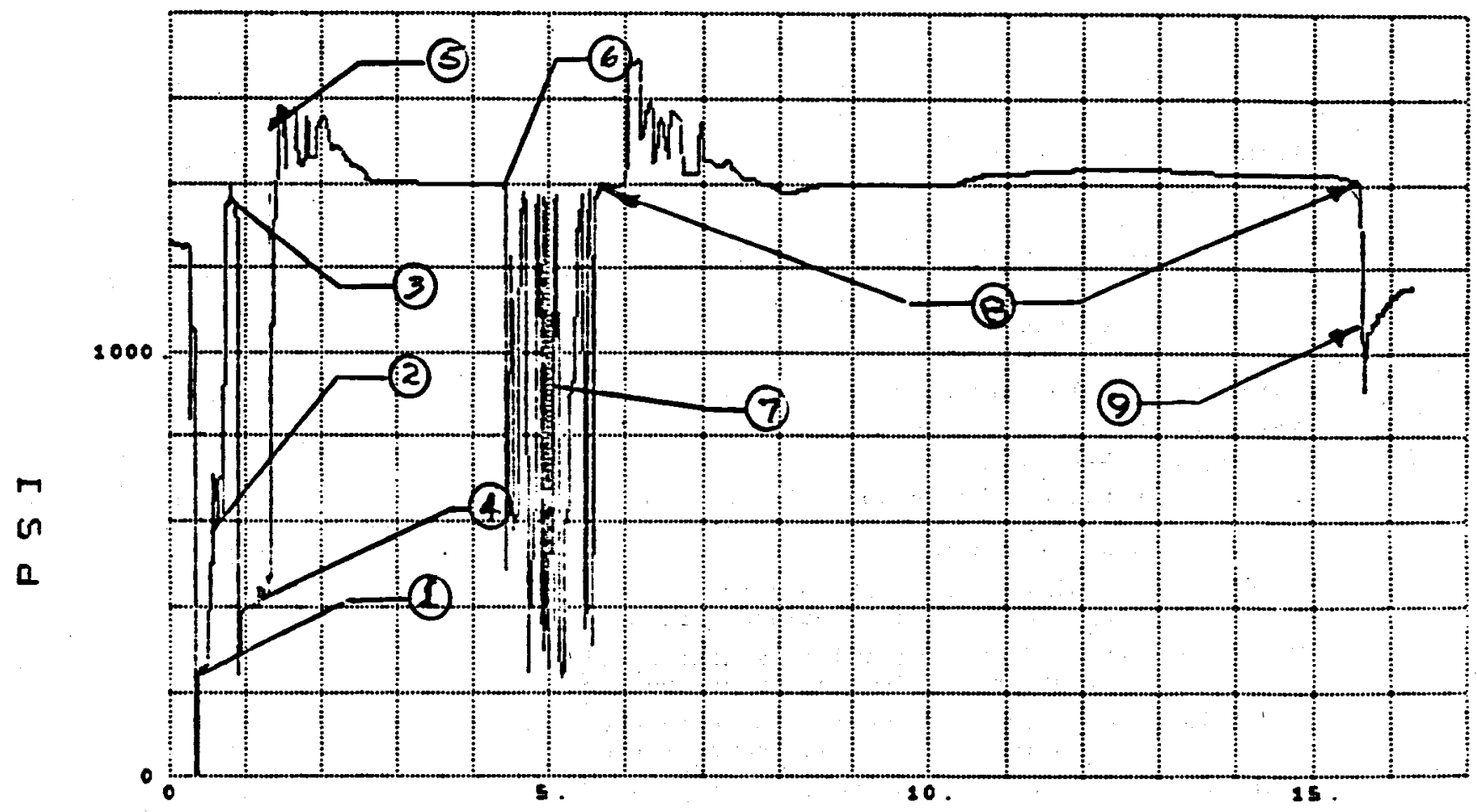

Figure 20. Penetrometer Experiment Readings 
The IDS was conceived to provide a means of entering and ariling through a rather thick, highly liquid layer of lava. The drilling experience in Holes 79-4 and 79-1 and thermal profiles indicated that low viscosity lens was not present. This lack of a low viscosity liquid, changes in logistics due to initial results. and limitation of funds resulted in cancellation of the IDS experiment.

Water Jet-Augmented Drilling Experiment:

The water jet-augmented drilling operations were conducted in Hole 79-4 and during the reentry into Hole 79-1. Hole 79-4 (and its companion 79-3) was 10cated about 7 feet east of Hole 75-1 and 3 feet west of Hole 79-3. Hole 79-4 was drilled to a depth estimated to be 6 inches above the liquid rock layer encountered during drilling in foles 75-1 and 79-3. The hole was cased to within 6 inches of its bottom, the liquid layer was penetrated, and the liquid rock flowed around the bottom of the casing, creating a seal between the casing and the liquid lens. The casing was pressured with air. Subsequently, the hole was entered with the water jet-augmented core bit and the NW core barrel to drill the glass plug out of the bottom of the casing and enter the liquid layer. Interference between the casing and the core barrel (possibly caused by a crooked lower section of the hole) prevented drilling in the cased hole with the water jet-augmented core drill and barrel. The forces required to pull the water jet-augmented core bit and core barrel from the casing were excessive, and the glass-to-metal seal at the bottom of the casing was broken. The seal loss prevented pressuring the casing, and allowed liquid rock to fise around and freeze the drill string in place.

At that time, the smaller diameter water jet-augmented drag bit was inserted, and drilling to the liquid layer began. The purpose of this operation was to repuncture the liquid zone and reestablish the seal at the bottom of the casing. After drilling about 2 feet to a depth of about 174 feet (about 1 foot below previously encountered liquid), the casing seal was reestablished. It was also apparent by this time that the several-foot-thlck liquid layer which had been expected did not extst at these depths. Figure 21 shows the drill functions as drilling proceeded through the expected liquid horizon at 173 feet 3 inches.

Water jet-augmented drag bit driling continued in Hole $79-4$ to a depth of 186 feet $2-1 / 2$ inches. Maintenance of casing pressure was impossible, or sporadic at best, between 173 feet and 174 feet 6 inches (See Appendix C, Figures C-12a, $c-13 a,(-14,(-15)$. During this period, liquid rock under pressure forced the arag bit to be withdrawn at least three times. Between 174 feet and 186 feet, fairly uniform casing pressure was maintained, and jet drag bit drilling proceeded smoothly to a 186-foot depth (see Appendix C. Figures C-28a through C-45a).

Figure 22 is a record of the four drilling functions during a short interval in the jet drag bit drilling when a layer of plastic or liquid lava was encountered at a depth of 184 feet 6 inches. The figure indicates the drill advance rate was about 1.3 inches per minute until the layer was encountered, at which time cooling without bit advance was conducted. Shortly after drilling was resumed, the layer was once again encountered, and additional cooling was required. Drill rotational 
DRILL SPEED

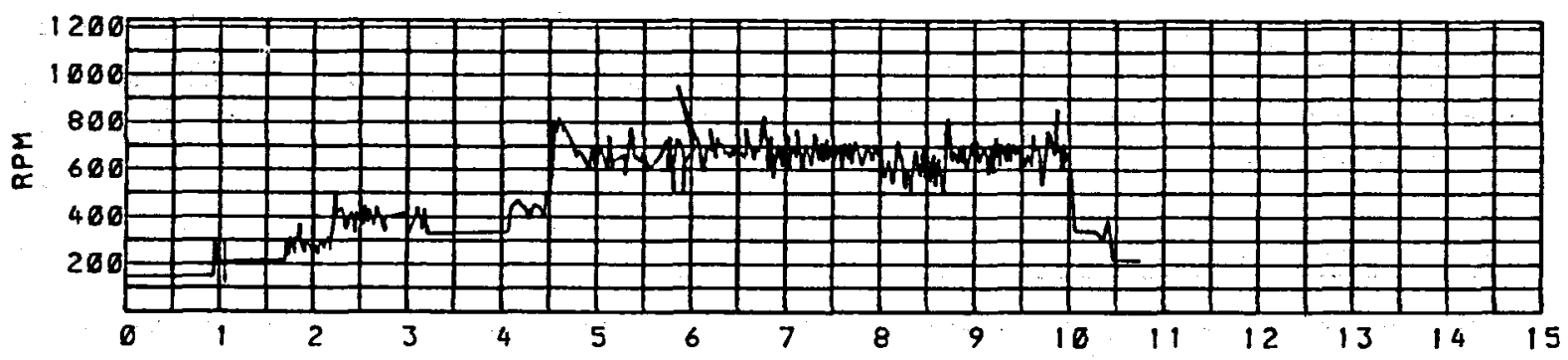

DI SPLACEMENT

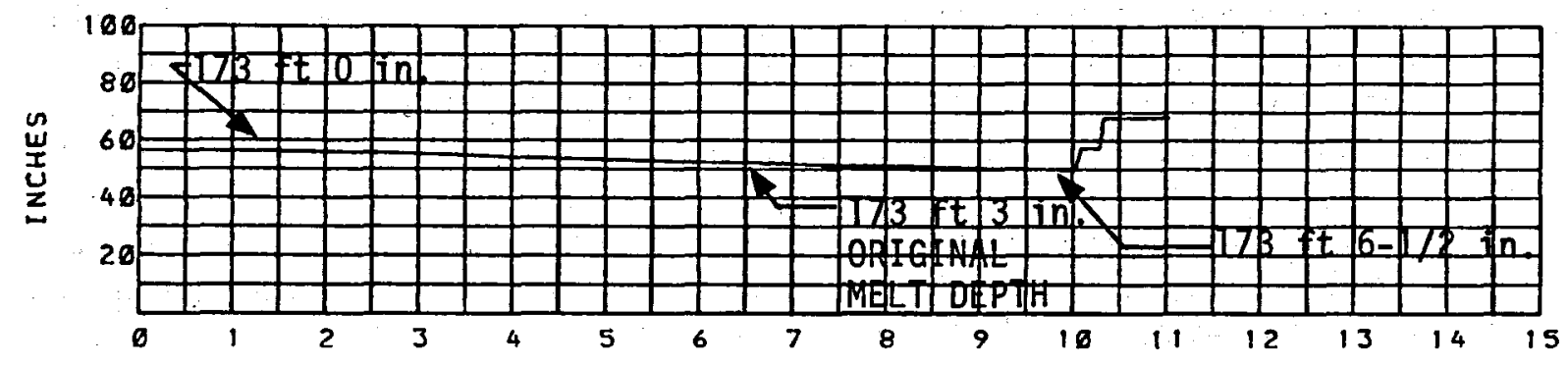

TORQUE
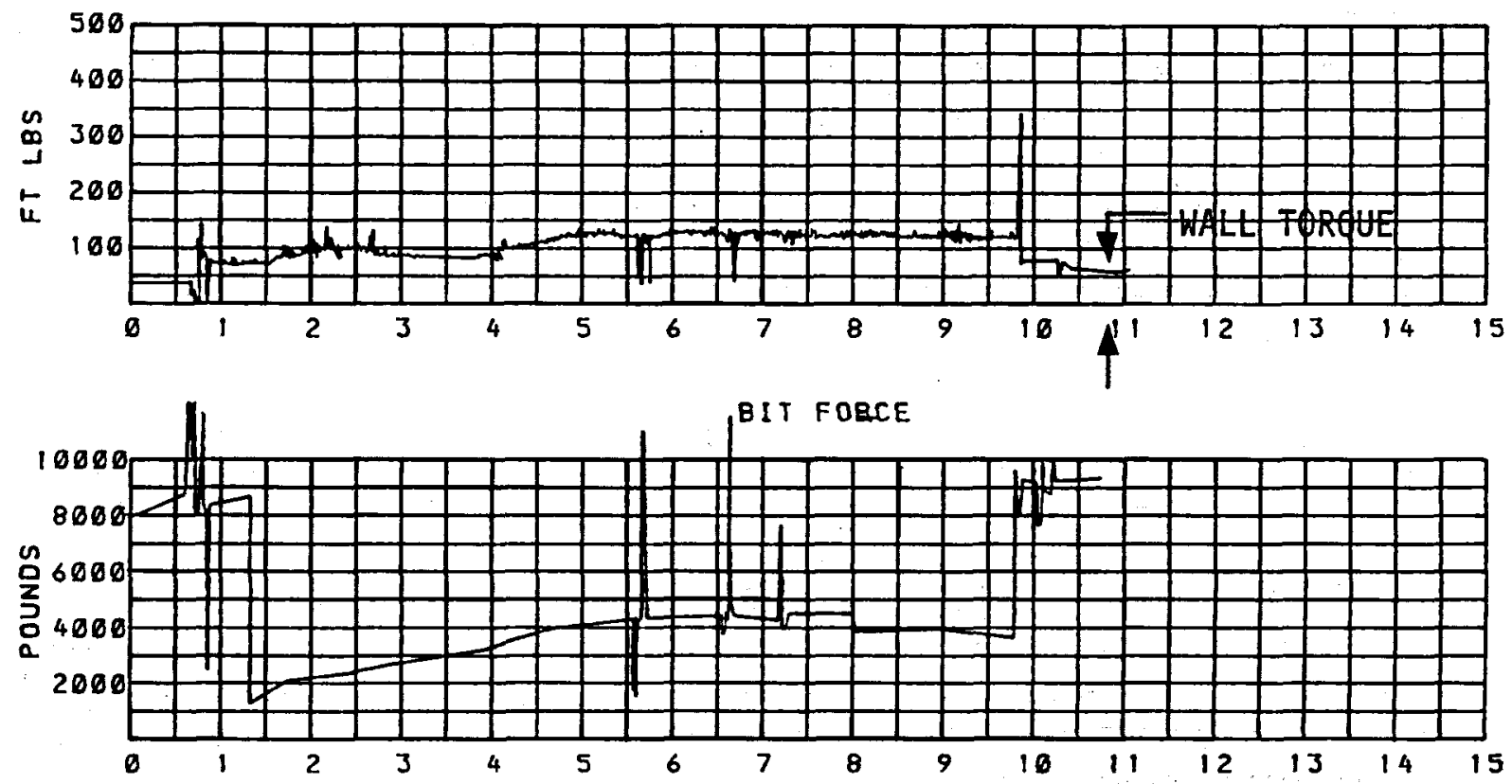

TIME IN MINUTES FROM $18 \quad 16 \quad 1200 \quad 1979$

Figure 21. Drilling with Jet Drag Bit through the Initial Melt Depth (Hole 79-4) 
COMBIN ONE 5 A

Y79 L L DRILL FUNCTIONS DISPL-5

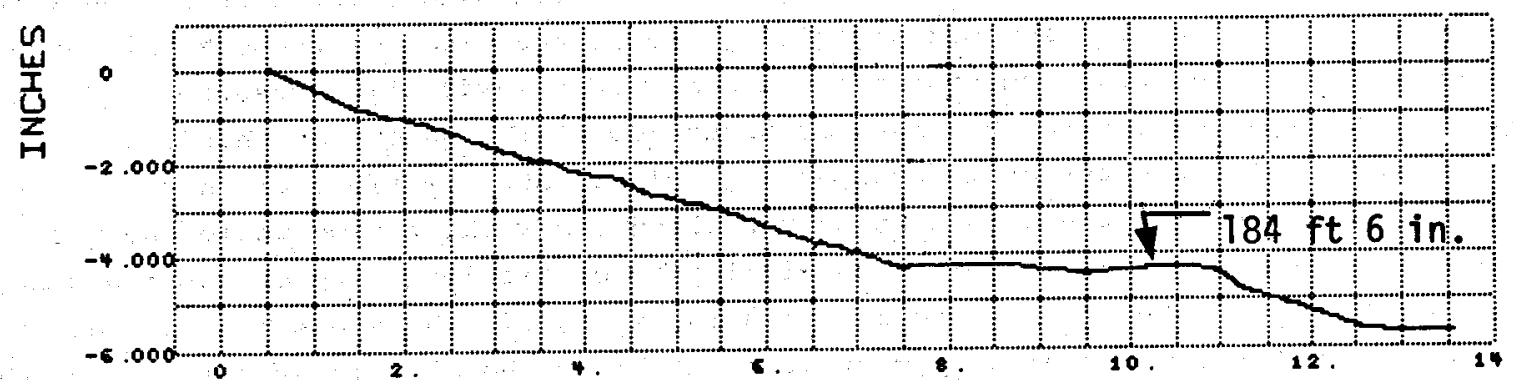

Y79 L L DRILL FUNCTIONS RPM-5

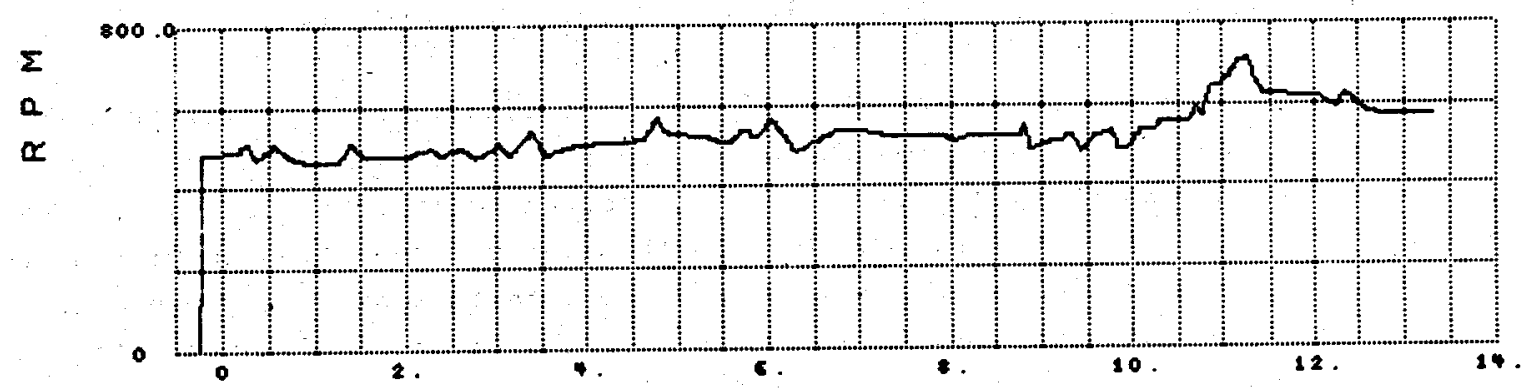

Y79 L L DRILL FUNCTIONS TOROUE-5

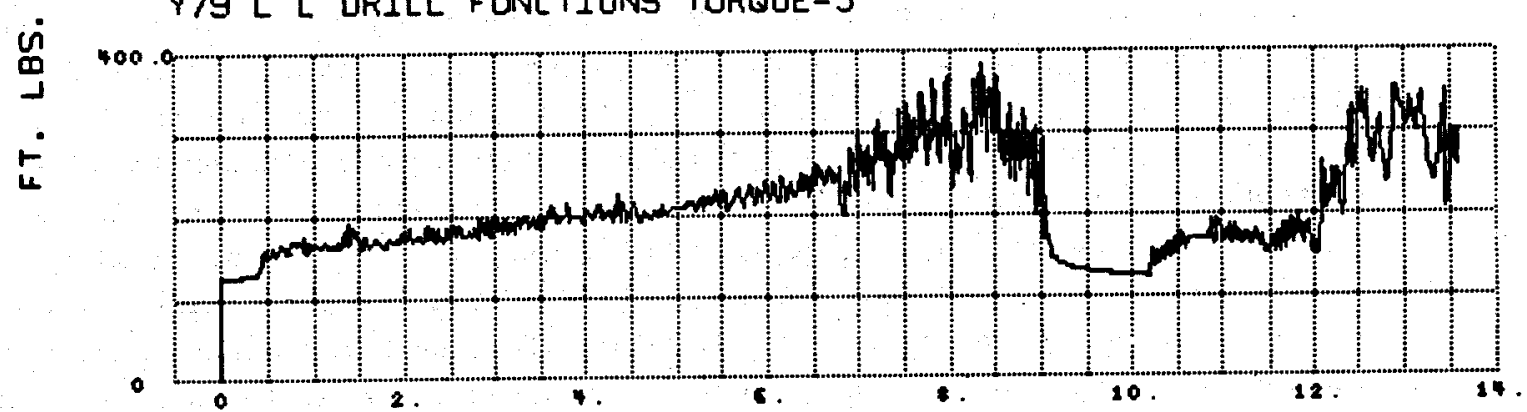

Y79 L L DRILL FUNCTIONS BP-5

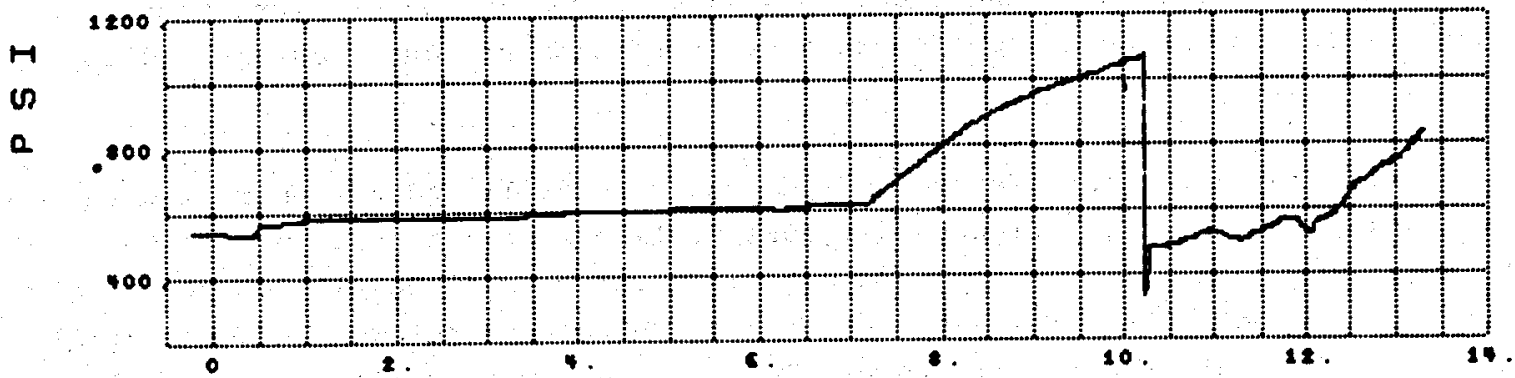

\section{TIME IN MINUTES}

Figure 22. Jet Drag Bit Drilling through Plastic or Liquid Lava 
velocity was maintained at about $500 \mathrm{rpm}$. As the soft area was entered initially, the torque increased sharply 30 to $40 \mathrm{ft}-1 \mathrm{~b}$. The torque then slowly increased during the next few inches of drilling, at which time wild excursions in the torque indicated that the plastic rock was rising around the wings of the drag bit and impeding its rotation. The system's maximum working-hydraulic-pressure of about 2,000 psi produces a turning torque of about $300 \mathrm{ft}-1 \mathrm{~b}$, which, on this record, is exceeded about 7 minutes from the starting point. At this time, bit advance was halted, but the resistance to turning persisted for a short time while the rising plastic rock was cut away. Note the similarity of the torque record during drag bit drilling and the torque record, shown in Figure 17, which was recorded during drilling with conventional equipment at 145 feet in the old glassy chimney in Hole 75-1. Since core (or information about the formation) was not being obtained and the drilling advance rate was slow, this experiment was terminated.

Bit load records and, in particular; bit load transients are difficult to interpret because of the nature of the bit-pull-down hydraulic system and because hydraulic pressure is the parameter which is measured to indicate bit load. Compensating hydraulic pressure is applied to both sides of the pull-down piston under zero bit-advance conditions. The desired advance rate is achieved by bleeding pressure from the lifting side of the piston. As the bit then advances into the hole, the pressure on the "down" side of the piston is maintained by the hydraulic pump. In most instances, rapid or temporary drill rate changes were made by merely changing the hydraulic selector valve from DOWN to OFF or UP without changing the needle valve; the needle valve changes the rate of bleeding pressure from the lifting side of the piston. With this system, bit loads recorded under steadystate conditions can be assumed to be accurate representations of the bit load, and transient activities are meaningful for very short times. Indications of flow build-up in bit load (between 7 and 10 minutes in Figure 20) are sometimes erroneously inferred from the bit pressure record. Combining the bit pressure data with the displacement data permits correct interpretation, as for example in Figure 20, which shows bit displacement to be zero during the time when the bit load appears to increase. Bit load during steady drilling is meaningful, as for example in Figure 22, when, at about 10-1/4 minutes, increasing pressure was applied to restart drilling.

Because of the interference of the jet core drill and core barrel with the casing in Hole 79-4, the planned jet core drilling was not performed in that hole. However, when difficulty was experienced in reentry drilling with conventional equipment in Hole 79-1, the jet core bit and NW core barrel were used to drill about 15 feet into the plastic zone. Two intervals were drilled; however, core was not recovered from either interval.

The first jet core drilling interval in Hole 79-1 began at a depth of 180 feet 8 inches and proceeded to a depth of 188 feet 1 inch for a total of 7 feet 5 inches. Figures 23 and 24 show the four drill functions at two depths when drilIing in plastic rock was evident. Since the hole was not cased, air pressure could not be applied to the bottom of the hole to suppress the upward surge of plastic rock when it was encountered. Characteristically, as a liquid zone was entered, the bit pressure increased slightly and continued to rise after the bit advance was 
DRILL SPEED

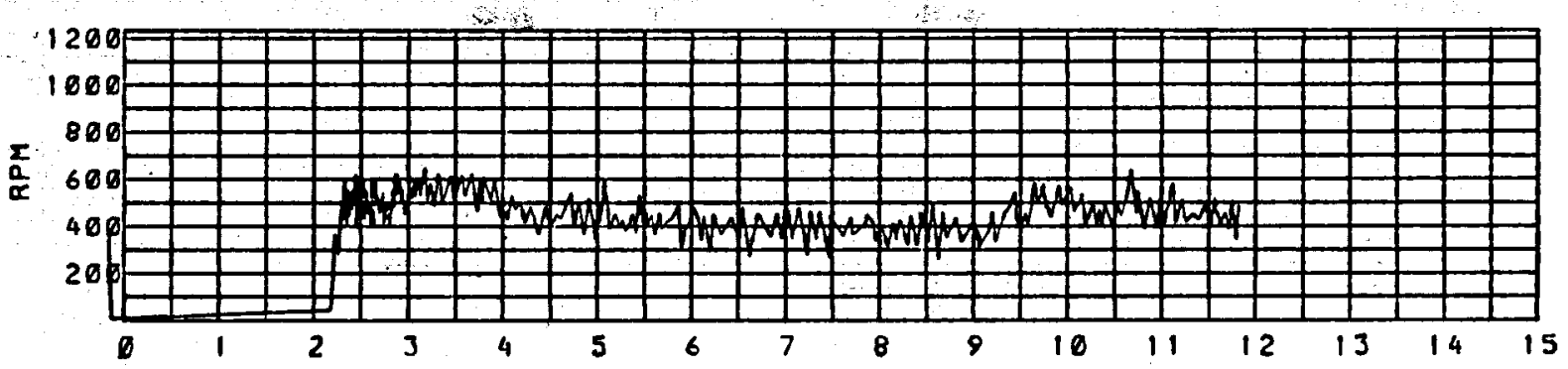

DISPLACEMENT

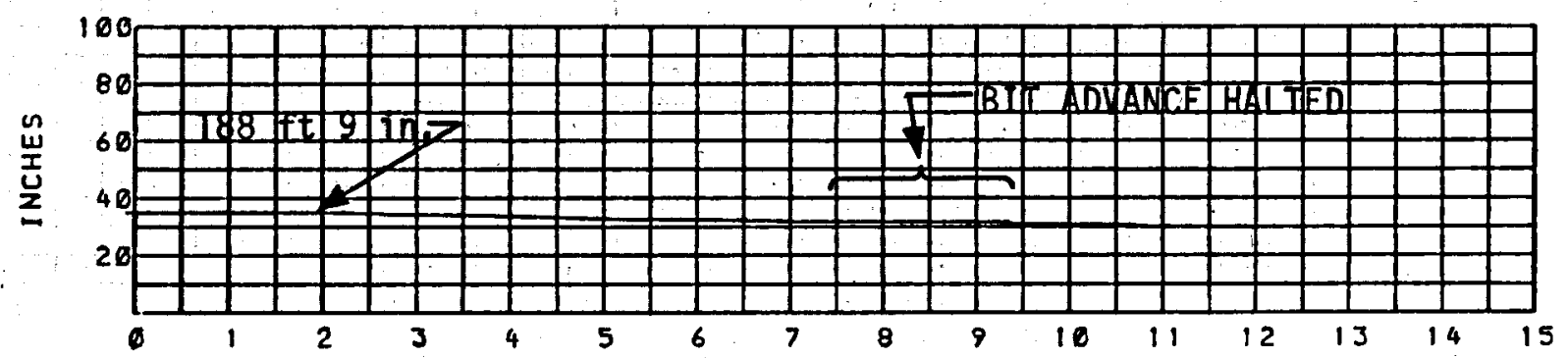

TORQUE

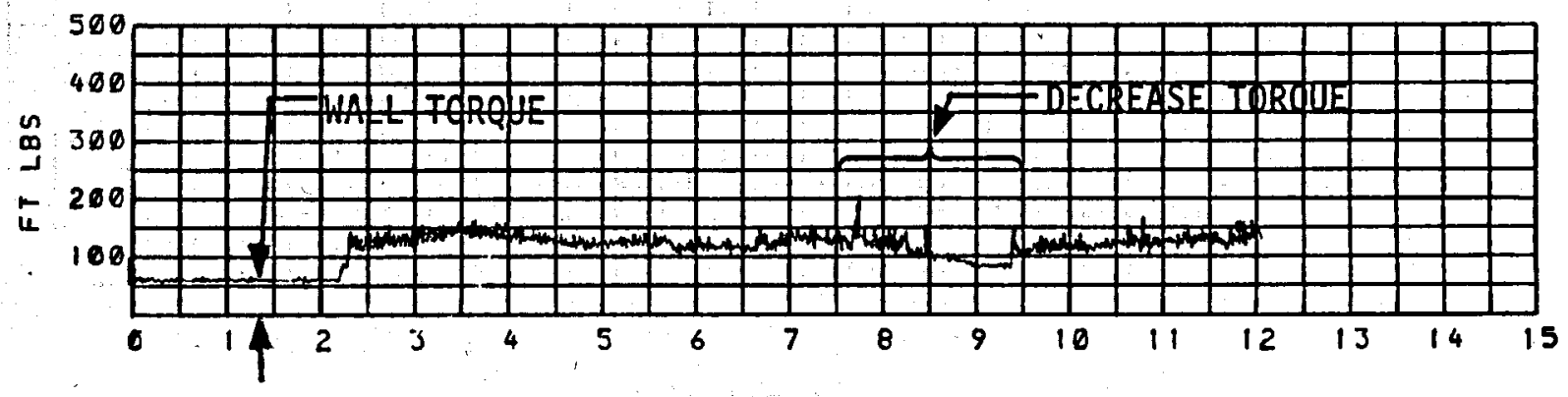

BIT FORCE

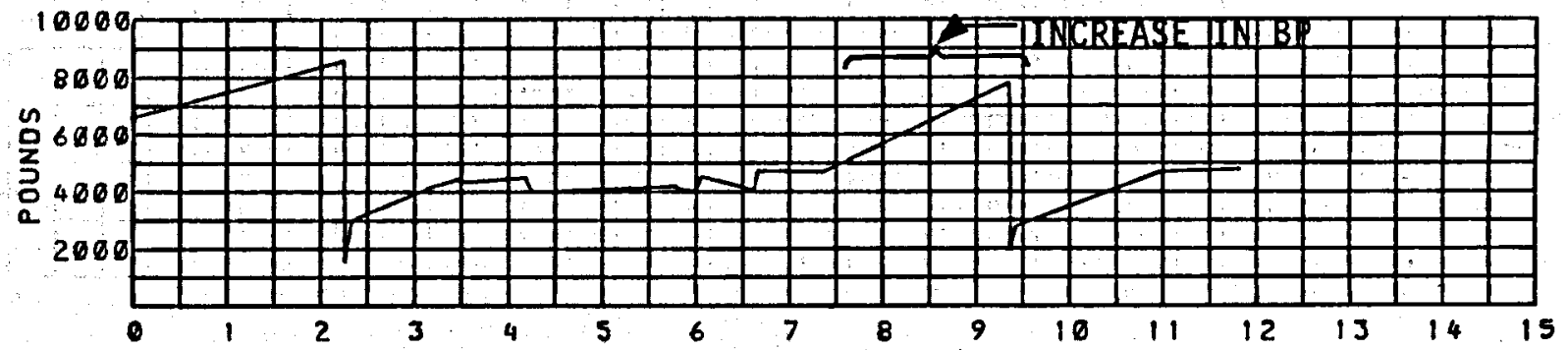

TIME IN MINUTES FROM $2909 \quad 44 \quad 001979$

Figure 23. Drilling with Jet Core Bit into

Plastic Region during Reentry into Hole 79-1 
DRILL SPEED

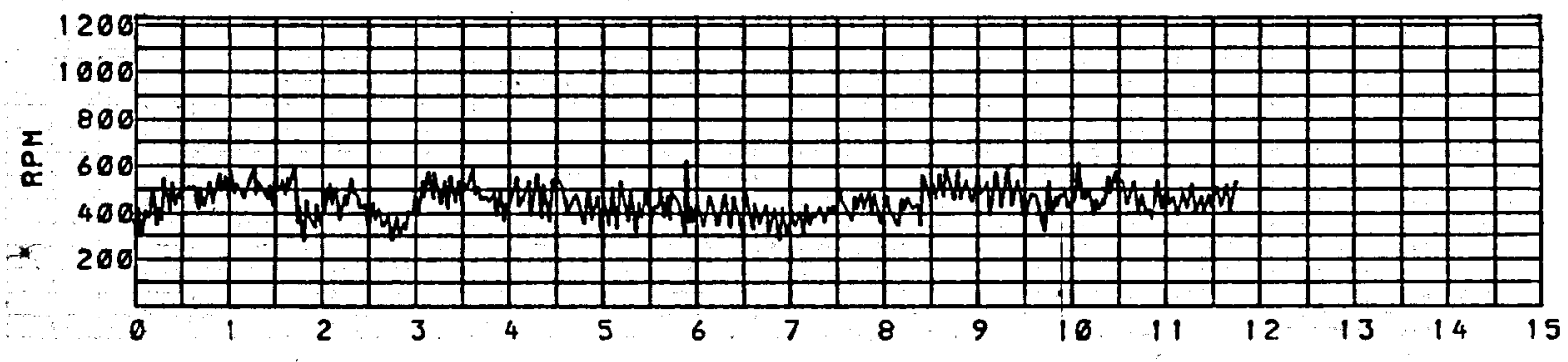

DISPLACEMENT

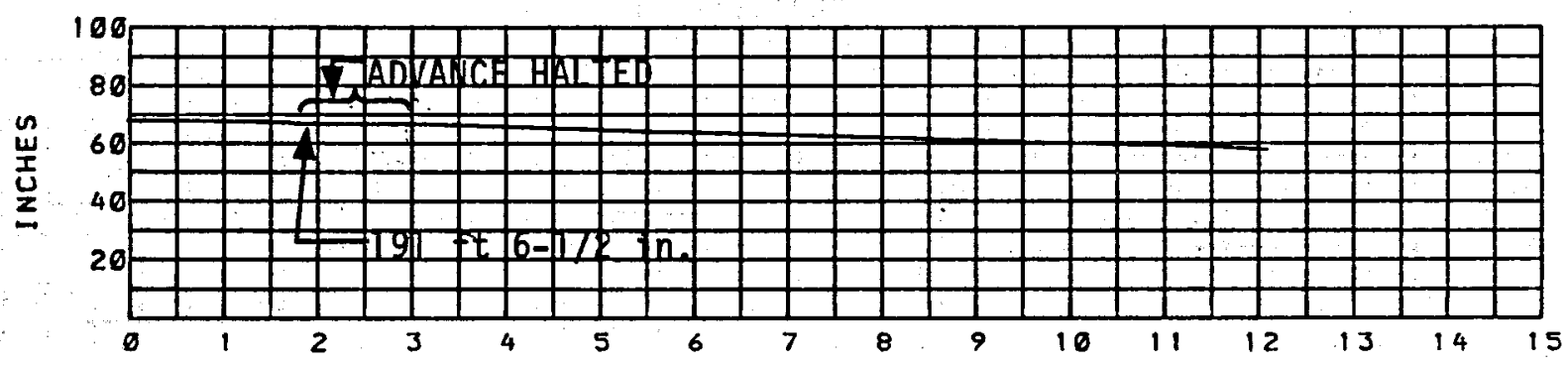

TORQUE

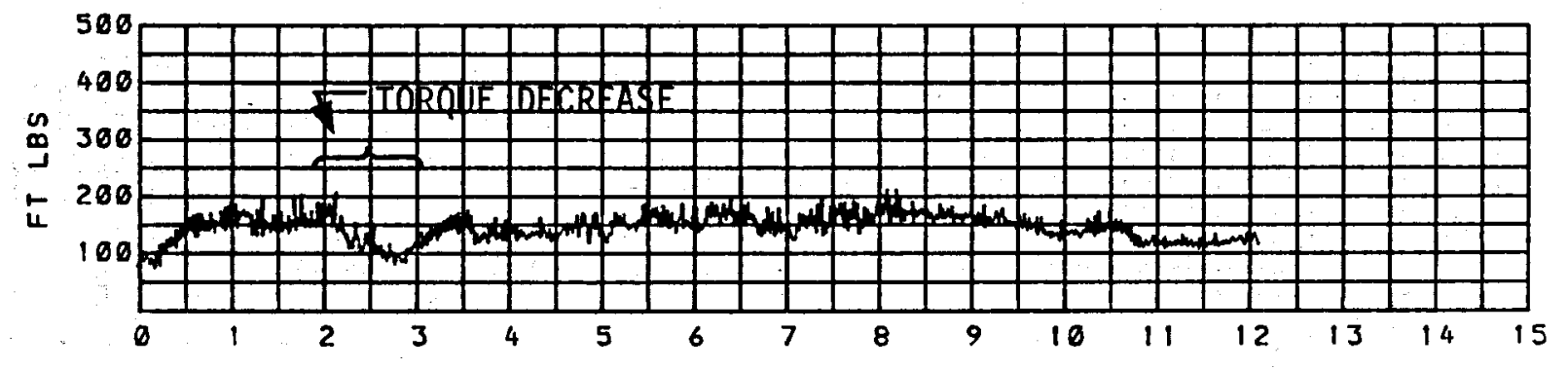

BIT FORCE

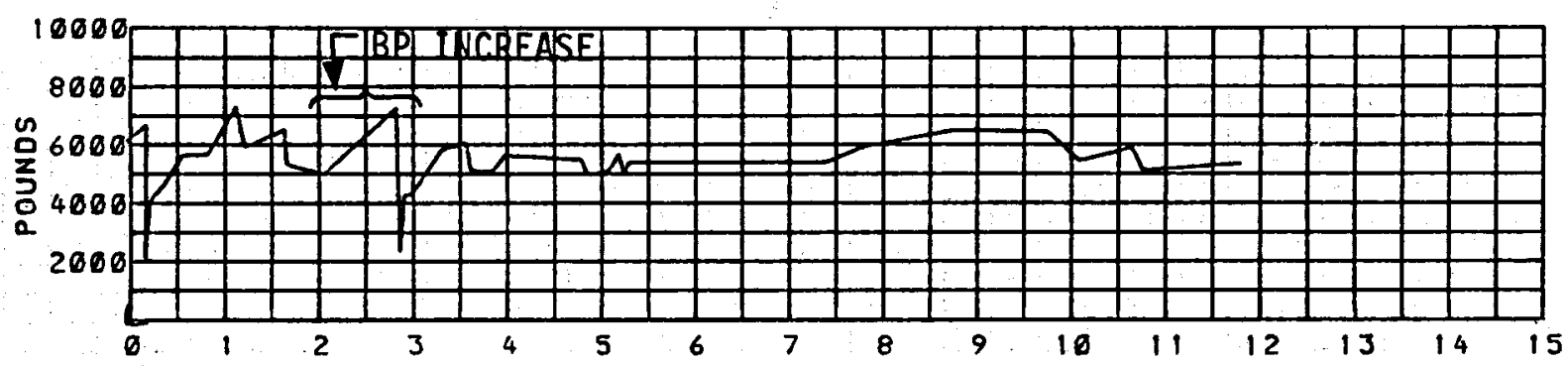

TIME IN MINUTES FROM $29 \quad 10 \quad 32 \quad 00 \quad 1979$

Figure 24. Drilling with Jet Core Bit into

Plastic Zone during Reentry into Hole 79-1 
halted. While the turning torque decreased, the water pressure at the output side of the positive displacement pump rose, indicating that the water outlets were plugging in the face of the bit and in the annulus around the inner core barrel. As the water pressure increased to several hundred psi ( 400 to 600$)$, the material blew out of the orifices and the pressure dropped to normal. When the jet core drilling commenced, water pressure at the pump was adjusted to about 150 psi, resulting in a pressure of about $230 \mathrm{psi}$ at the bit. This pressure was allowed to increase to a maximum of about $250 \mathrm{psi}$ at the surface ( 330 psi at the bit). Normal operating pressure was between 150 and 200 psi at the surface.

Upon removal of the core barrel at 188 feet 1 inch, 1 to 2 inches of frozen rock were found in the bottom of the core barrel. The remainder of the core barrel was empty.

A second interval was drilled to a depth of 192 feet 5 inches. Once again the core barrel was empty.

After the second interval was drilled, the drill was rested in the bottom of the hole and water flow was begun. Suddenly, a downhole pressure excursion lifted the drill string about 15 feet to the top of the drill mast. It was believed that the pressure excursion was caused by the pressure of several feet of drill cuttings in the bottom of the hole.

Since Hole 79-1 was started in HQ size ( 3-1/2 inches diameter) and the jet core bit was NW size ( 2-7/8 inches diameter), the probability of the drill becoming hopelessly plugged with settled cuttings as the flow of cooling water was stopped to add another length of rod to the drill string was thought to be high. Also, no core was being obtained, so jet drilling in Hole 79-1 was abandoned.

Conclusions and Recommendations

Water jet-augmented drilling into the liquid and plastic zones was successful to a depth of at least 30 feet below the first depth at which molten rock was encountered. Pressurizing the annulus around the drill rod to a pressure greater than the local lithostatic pressure was helpful in drilling in a zone of thin liquid veins with the water jet-augmented drag bit. Casing pressure appeared not to be necessary during drilling with the water jet-augmented core bit into the higher viscosity plastic zone encountered during the reentry of Hole 79-1.

The torque records indicate that drilling with the conventional HQ core bit into the known, fractured, old glassy plug in Hole 75-1 and with the jet drag and jet core bits in Holes 79-4 and 79-1 were similar. The conclusion was reached that, during jet drilling with either the drag or core bit, a highly fractured glassy material was formed ahead of the bit by the sudden chilling of the liquid or plastic rock. 
Special care must be taken in the design of core catchers to assure the recovery of core while jet drilling in the quickly frozen liquid or plastic material. Experimentation should continue to determine the best coolant flow rates for optimization of drilling rates and core configuration.

Attention should be given to the design of jet bits for both drilling and coring in order to improve bit cooling, cuttings flow, and wear characteristics. Upper crust drilling rates should be improved to reduce the time required to reach the hot-rock zones of interest.

Study should continue on alternate drilling systems such as the IDS, the operation of which is not dependent upon freezing the rock ahead of the bit. Special drilling systems which are devised for future use in drilling into molten lenses should be designed to be less sensitive to the accuracy of the postulated physical models of the molten lens and to the interface between the molten lens and the solid crust.

Future attempts to drill, into molten or plastic regions should employ an instrumented drill which has a higher torque capacity (at low rotational velocity) than was available with the Longyear HC-150 drill.

Linear penetration of a liquid zone can probably be accomplished by combining the penetrometer with a wireline core barrel latching mechanism, thereby reducing the time between drilling into the soft rock and applying the load to the penetrometer. Instrumentation of drilling functions should be continued during all developmental drilling.

References

${ }^{1} \mathrm{~J}$. L. Colp and R. Okamura, "Drilling into Molten Rock at Kilauea Iki," Transactions, Volume 2 (Geothermal Resources Council, July 1978).

${ }^{2}$ J. L. Colp. "FY79 Lava Lake Drilling Program -- Geoscience Studies; Plans and Results," SAND79-1361 (Albuquerque: Sandia Laboratories, to be published). 


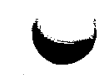

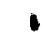

₹

APPENDIX A

Drilling Records for Reentry into Hole 75-1 


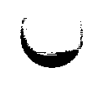

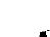


Hole 75-1 was drilled initially to a depth of 130 to 140 feet in 1975 to provide the means of making electrical contact with the molten rock for a surface geophysics experiment. Since the hole existed to this depth and was located near the geometrical center of the lake's surface, the existing hole was extended to the melt and used for the enclosed thermal well experiment.

Driling in Hole 75-1 began on December 8, 1978, at which time the hole was reamed to existing depth. Between December 8, 1978, and December 11, 1978, the hole was drilled to a depth of 173 feet 1 inch, where a low-viscosity layer of liquid was encountered. In preparing the hole for a penetrometer test to determine the minimum thickness of solid rock that could be penetrated in the bottom of the hole, one of the drill's chuck jaws was inadvertently dropped into the hole. Drilling was then suspended in Hole 75-1, and the enclosed thermal well was installed.

Hole 75-1 was the first drilled or reentered during the FY79 program. One or more of the drill functions were not monitored because of gauge or recording system malfunctions. During the first day's drilling, the datalogger was not in operation. Consequently, digitized plots of the drilling functions are not available.

When the hole had been reamed to a depth of about 138 feet, a metal object was encountered. Drilling characteristic of drilling through metal was experienced for about 12 inches, after which the metal object appeared to have been drawn into the core barrel. However, the torque indications and rough drilling did not become smooth for about 8 more feet. Drilling continued about 6 inches more after smooth drilling was encountered.

Examination of the contents of the core barrel revealed a large ( 2 inches diameter by 24 inches long) brass weight, followed principally by a zone of highly rubberized, glassy, black rock. Finally, a plug ( 6 inches long) of typical, slowly cooled crust material closed the end of the core barrel.

Normal, rather smooth drilling was conducted from below the old glassy chimney to a low-viscosity liquid layer at a depth of 173 feet 1 inch. A rapid increase in turning torque indiçated penetration of the liquid. A sudden increase of the water pressure to the drill string, caused by the molten rock flowing into and plugging the water flow from the bit, confirmed the encounter with the liquid. 
MAGMA TAPE 1

DRILL SPEED
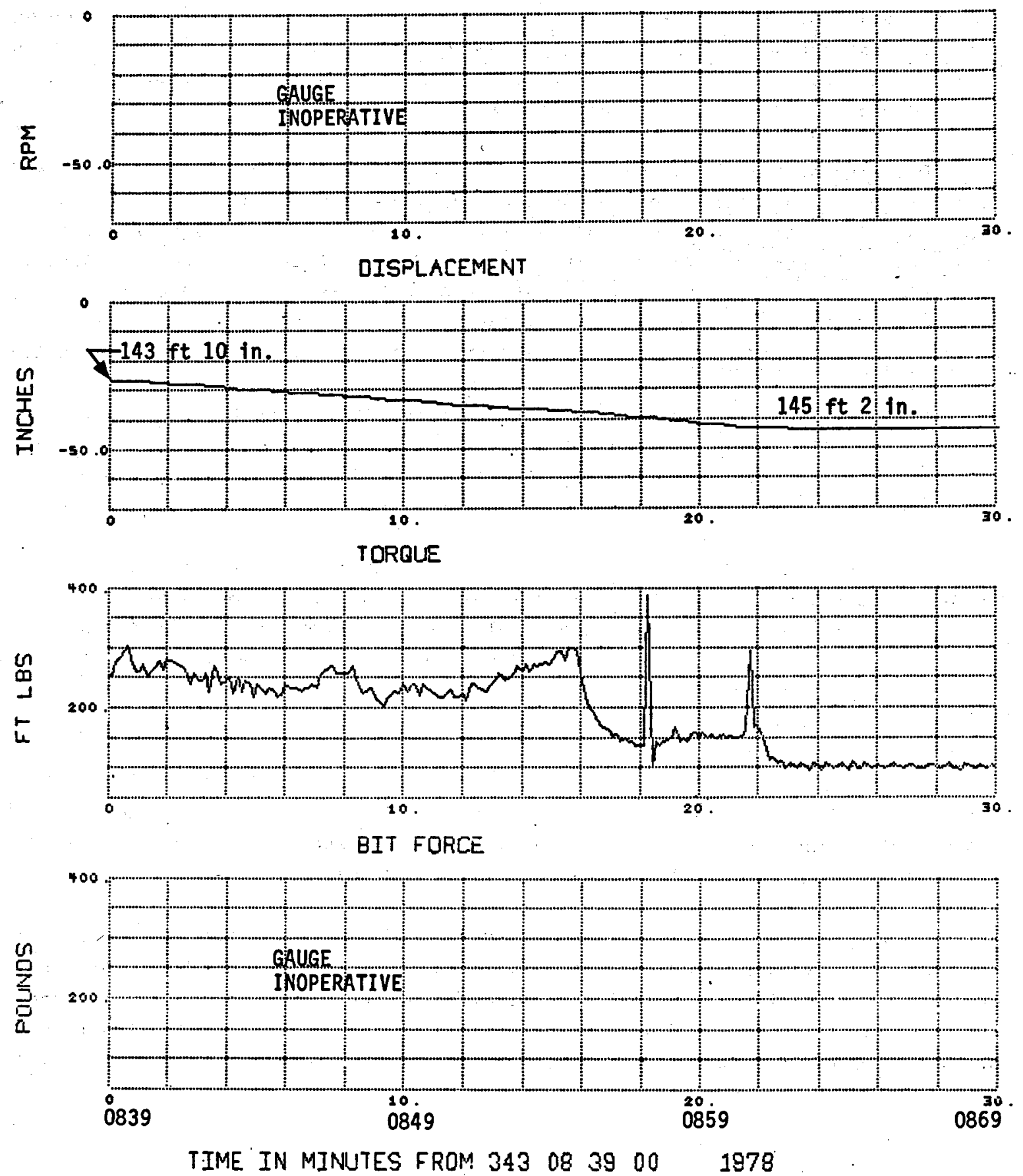

Figure A-1. Drilling in old Flow-Back Chimney in Hole 75-1 with Conventional $\mathrm{HQ}$ Core Bit (HQ -- 3.78 inches diameter -- wireline coring equipment) 
MAGMA TAPE 1

DRILL SPEED
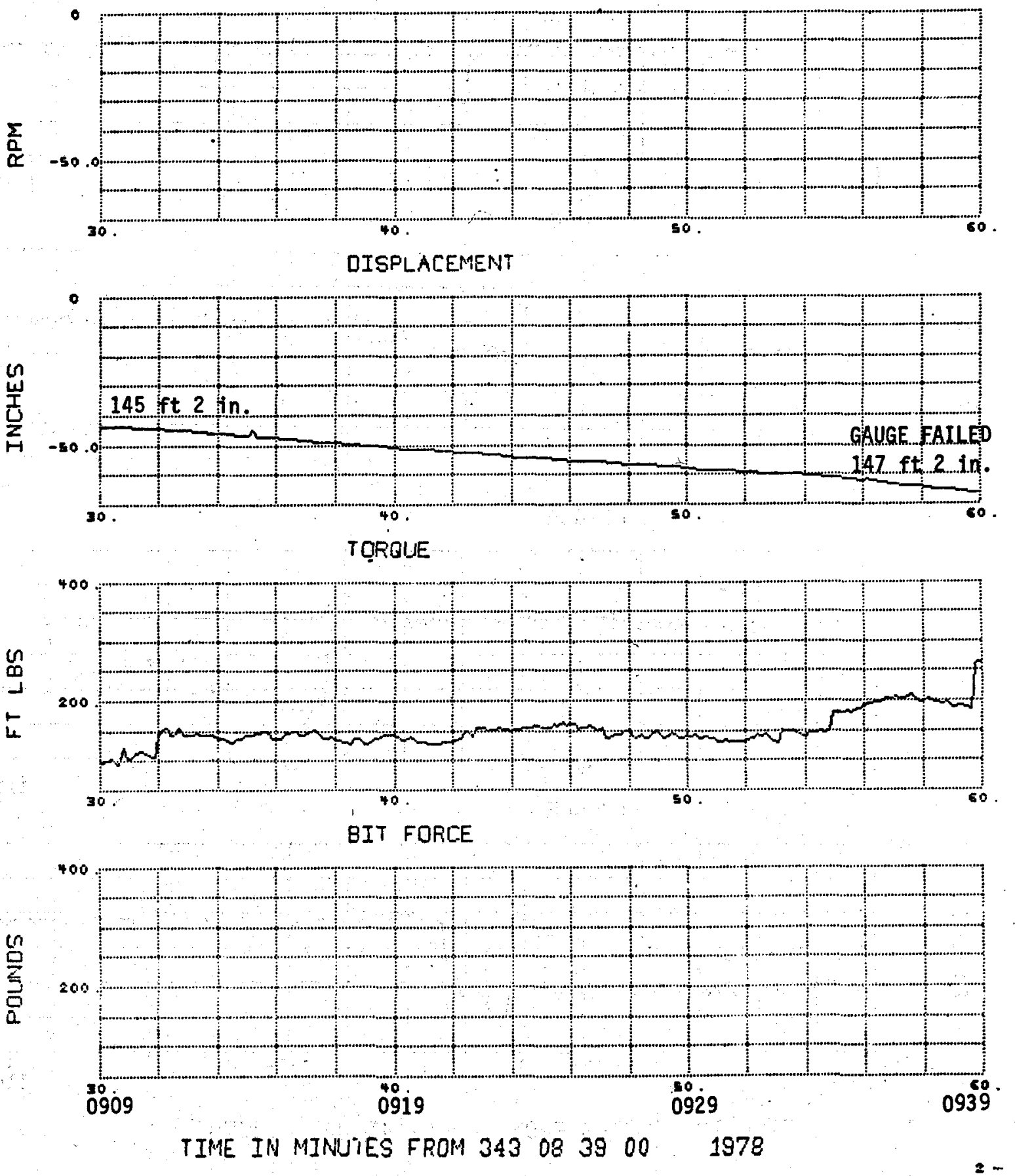

Figure A-2. Drilling in old Flow-Back Chimney in Hole 75-1 with Conventional HQ Core Bit 
TORQUE

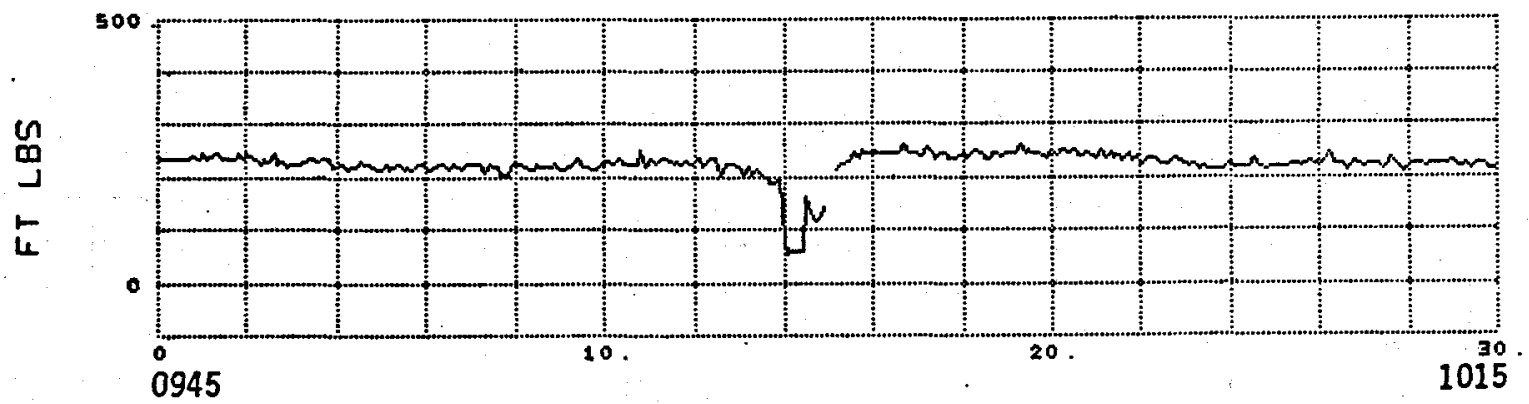

TORQUE

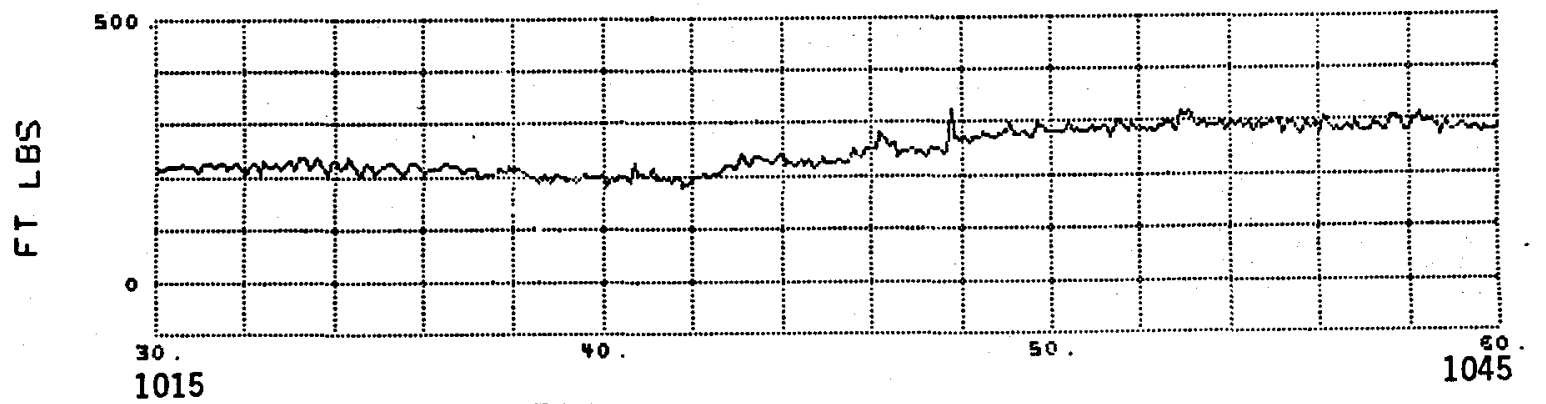

TORQUE

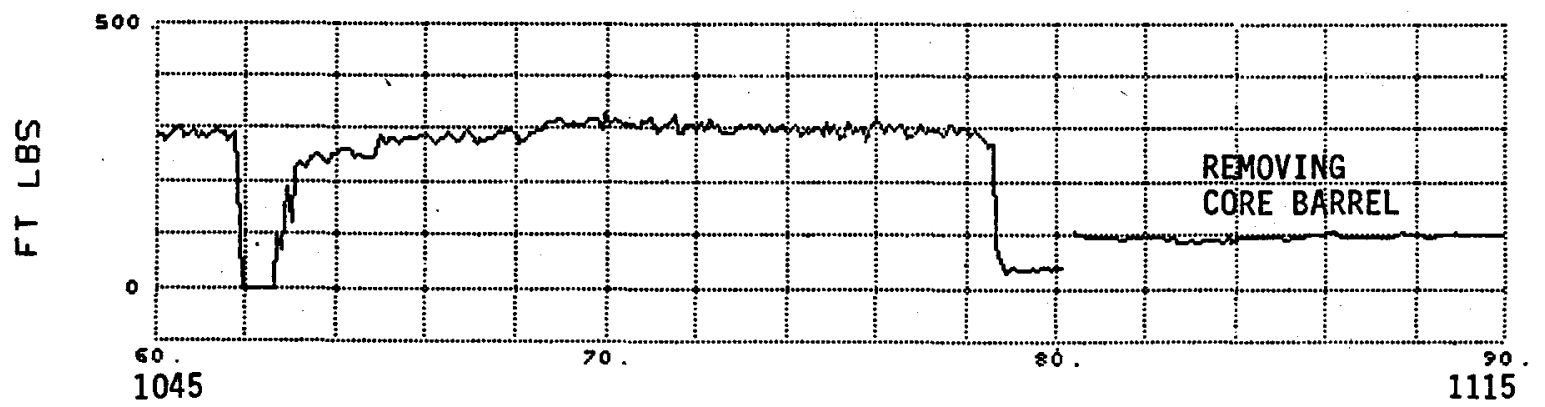

TORQUE

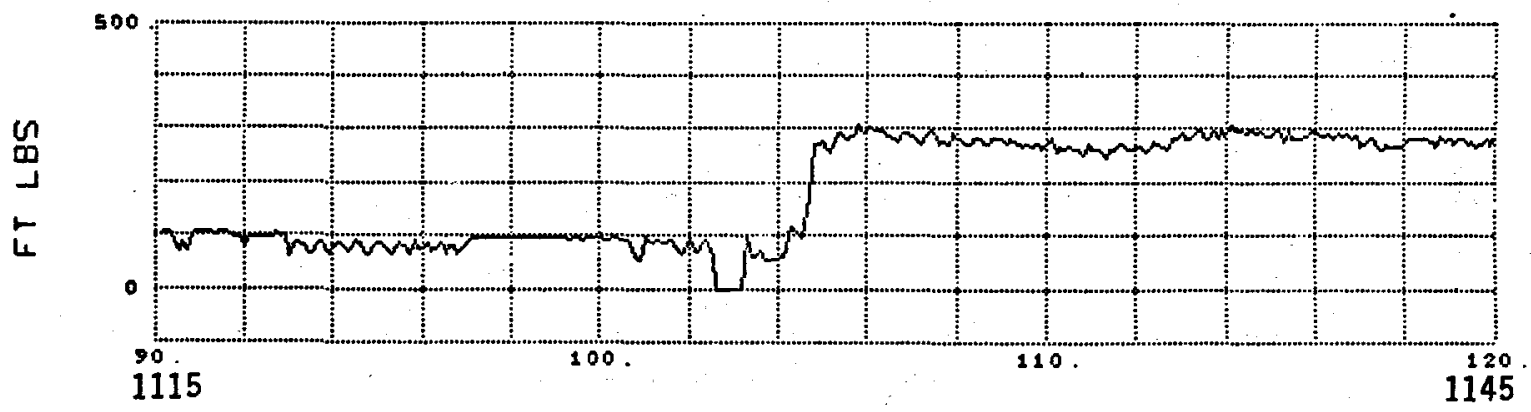

TIME IN MINUTES FROM $343 \quad 0945^{\circ} 00 \quad 1978$

Figure A-3. Drilling in Lower Part of Upper Crust in Hole 75-1 with Conventional HQ Core Bit 

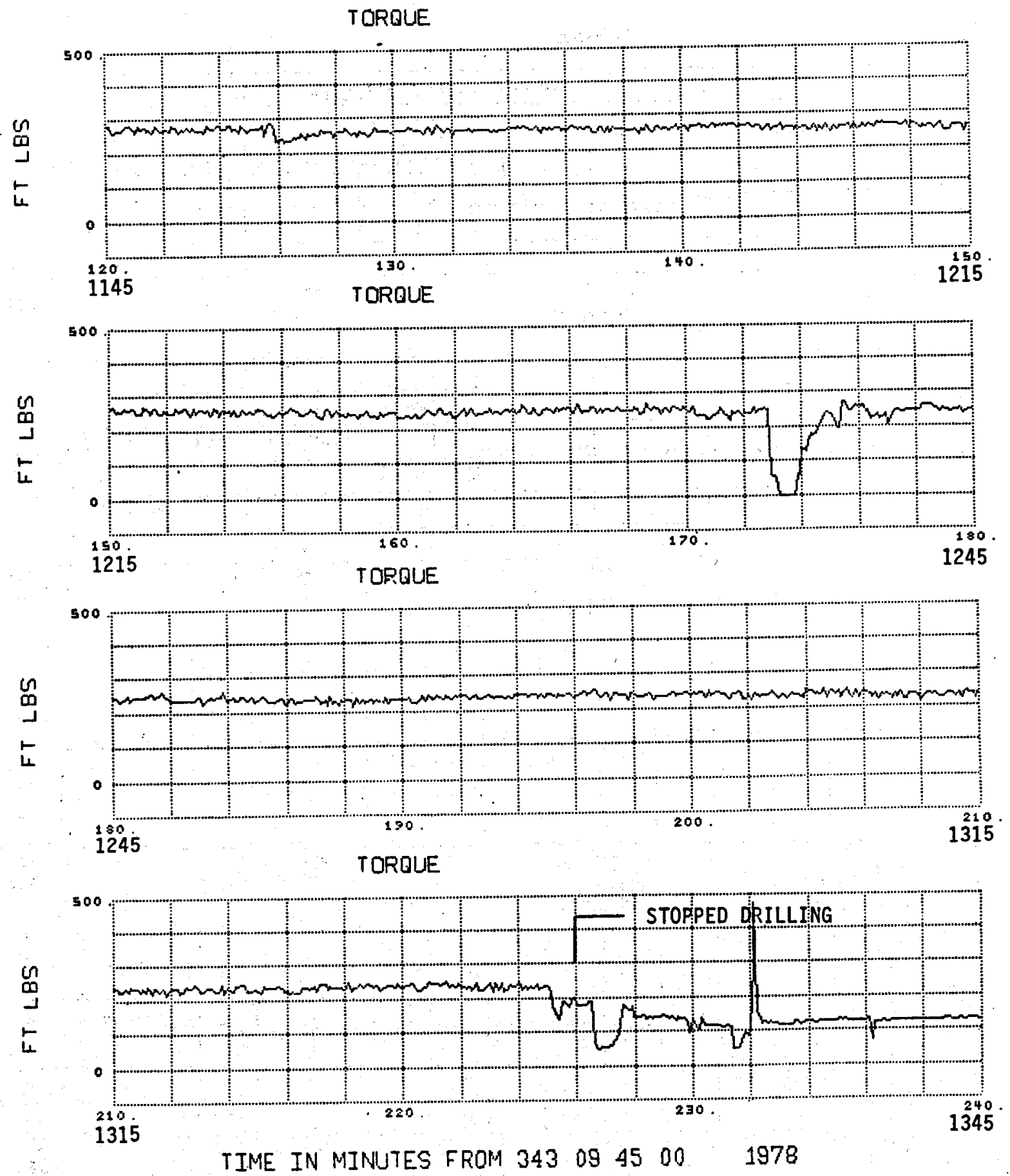

Figure A-4. Drilling in Lower Part of Upper Crust in Hole 75-1 with Conventional HQ Core Bit 
TORQUE
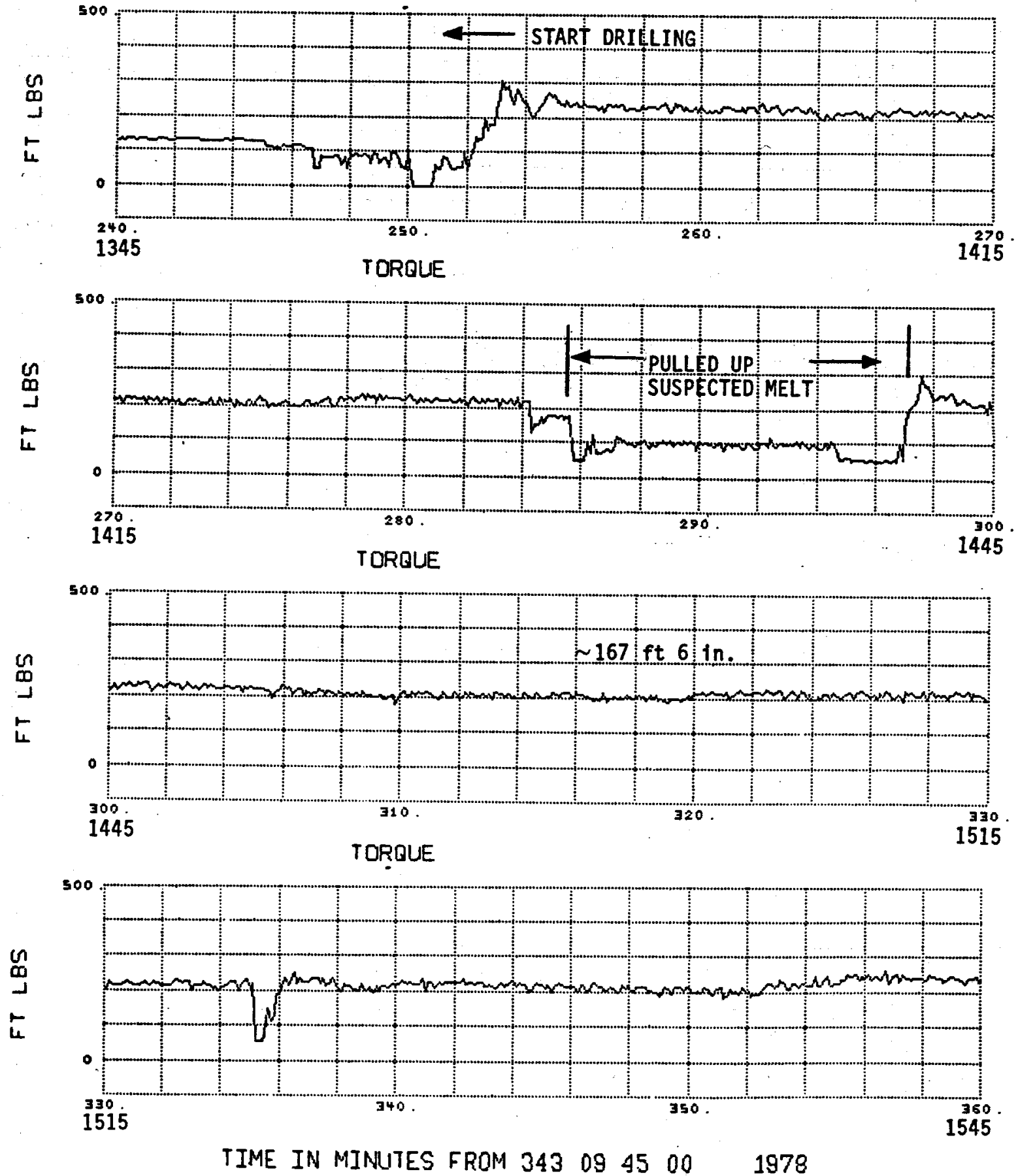

Figure A-5. Drilling in Lower Part of Upper Crust in Hole 75-1 with Conventional HQ Core Bit 
TOFIULE

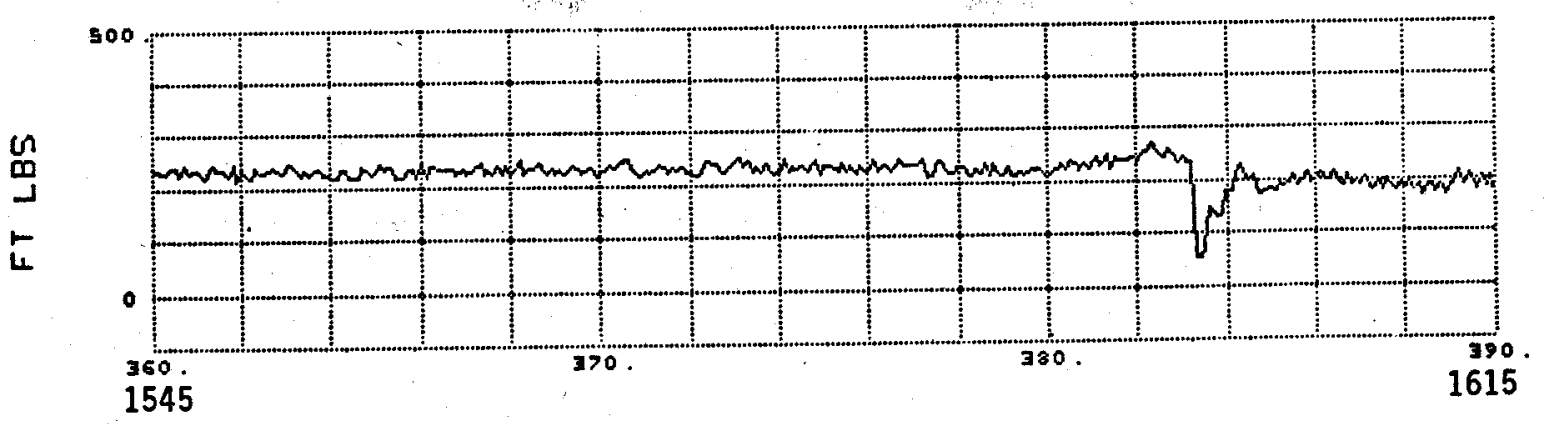

TIME IN MINUTES FROM $343 \quad 0945 \quad 00 \quad 1978$

TORQUE

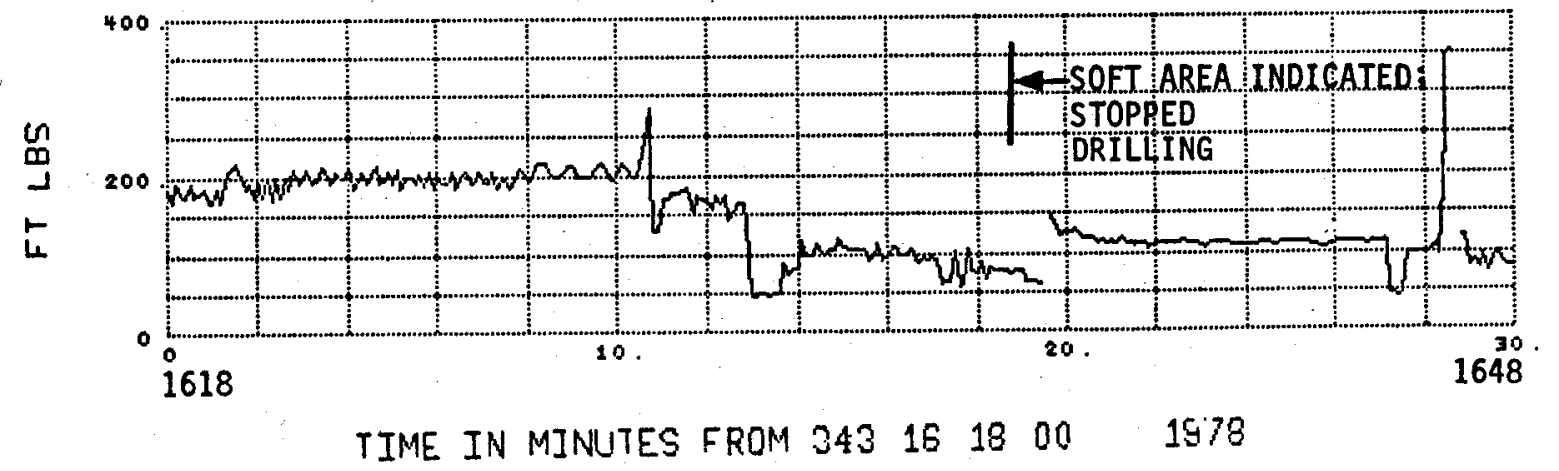

TORQUE

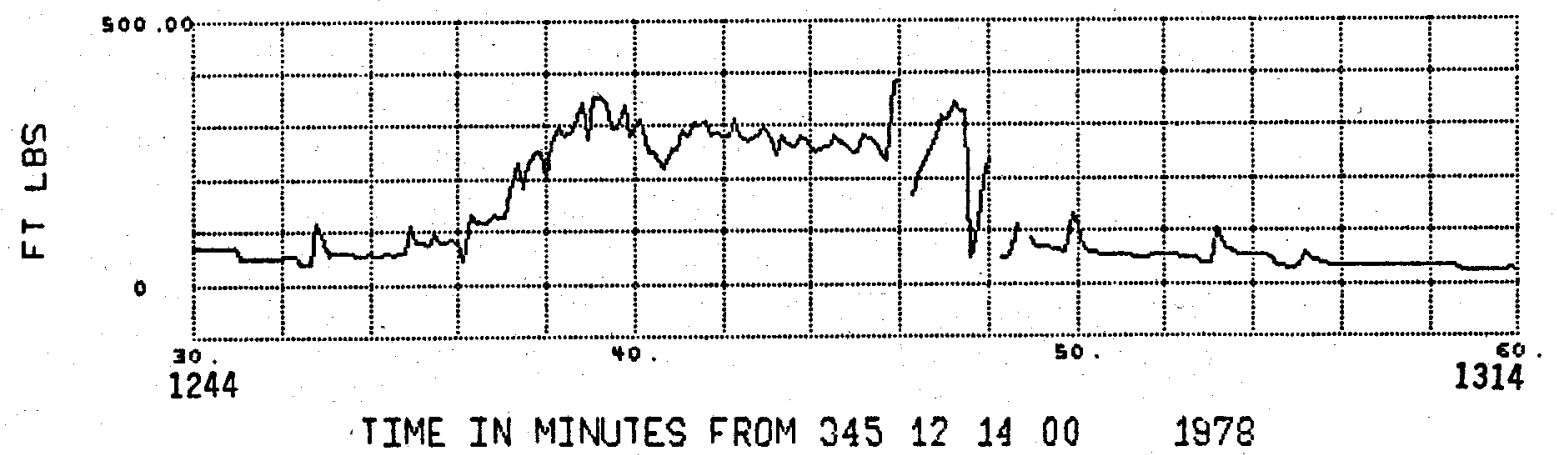

Figure A-6. Drilling in Lower Part of Upper Crust including First Melt Encounter in Hole 75-1 with Conventional HQ Core Bit 
U 
APPENDIX B

Drilling Records for Hole 79-3 


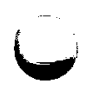

1

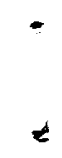

$\omega$ 
Hole 79-3 was drilled between January 8, 1979, and January 11, 1979. The first liquid layer was encountered on January 10,1979. After liquid was encountered, at a depth of 172 feet 6 inches, liquid rock rose to a depth of 154 feet 10 inches ( 17 feet 8 inches flow back). This plug was then drilled out. Liquid was encountered at 171 feet 17 inches, and the 1 iquid rock rose 11 feet 7 inches to a new depth of 160 feet. As drilling continued to a depth of 170 feet 5 inches, molten rock, which rose 3 feet 3 inches to a depth of 166 feet 8 inches, was encountered again. The final drilling left a plug 3 feet thick above the original liquid depth of 172 feet 10 inches.

Figures $B-1$ through $B-8$ are the records of the drill functions (arilling rate, RPM, torque, bit load) during the drilling from 155 feet in Hole 79-3 through the final melt encounter and subsequent flow-back chimney drilling. These records were obtained by sampling the output of the transducers with a datalogger and recording the sampled data. The sampling rate was about one set of data points - every 6 seconds. (Note: A set of data points includes one point for each of the four drill functions.) Occasionally, this rather slow sampling rate resulted in some transient data being missed. Figure B-6 is a duplicate of the section of the strip chart made during the initial melt penetration at about 1150 on January 10 , 1979. Drill functions were not recorded during the drilling in the second and third flow-back chimneys. 

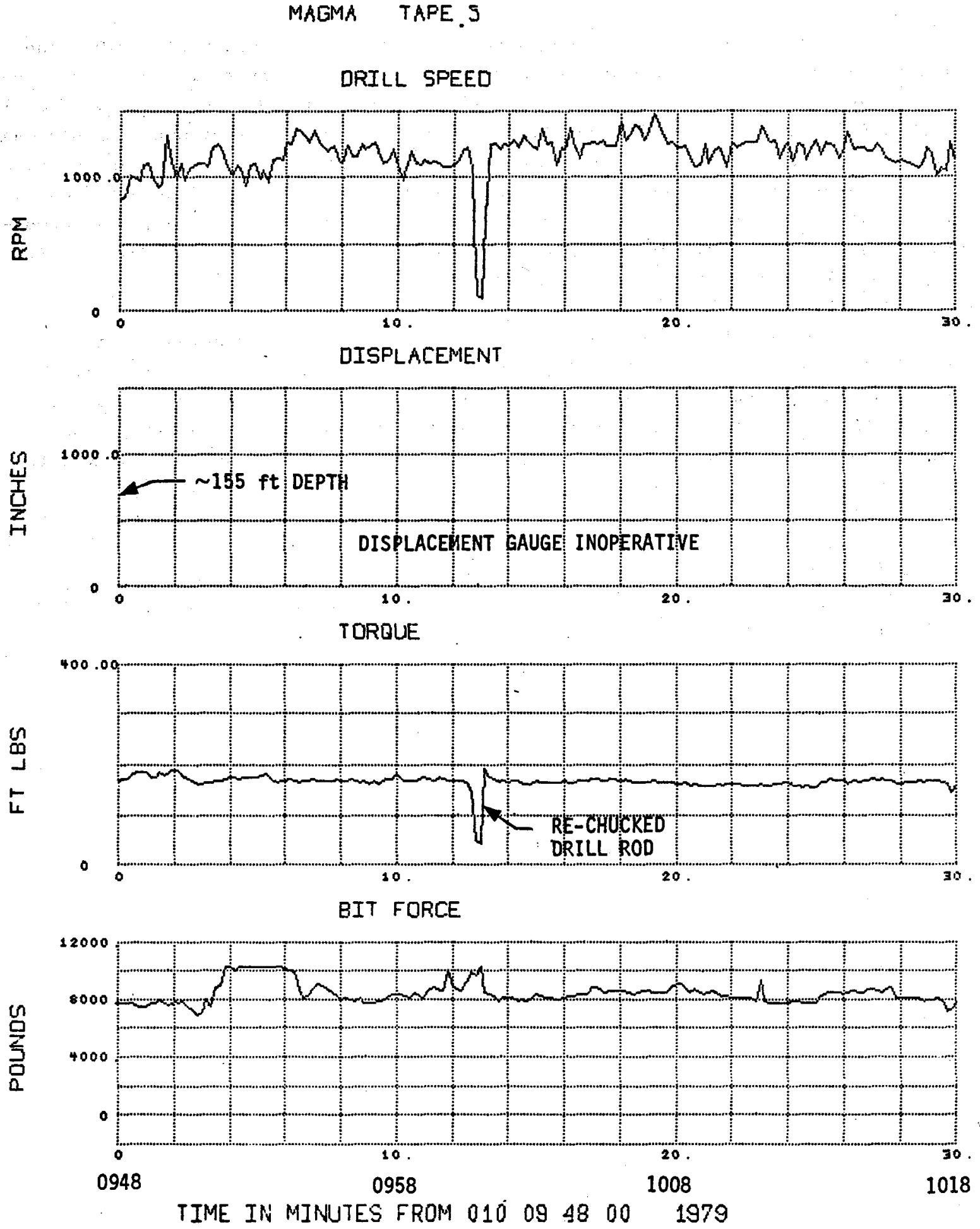

Figure B-1. Drilling in Hole $79-3$ prior to the First Liquid Encounter (HQ -- 3.78 inches diameter -- wireline coring equipment) 
MAEMA TAPE 5

DRILL SPEED
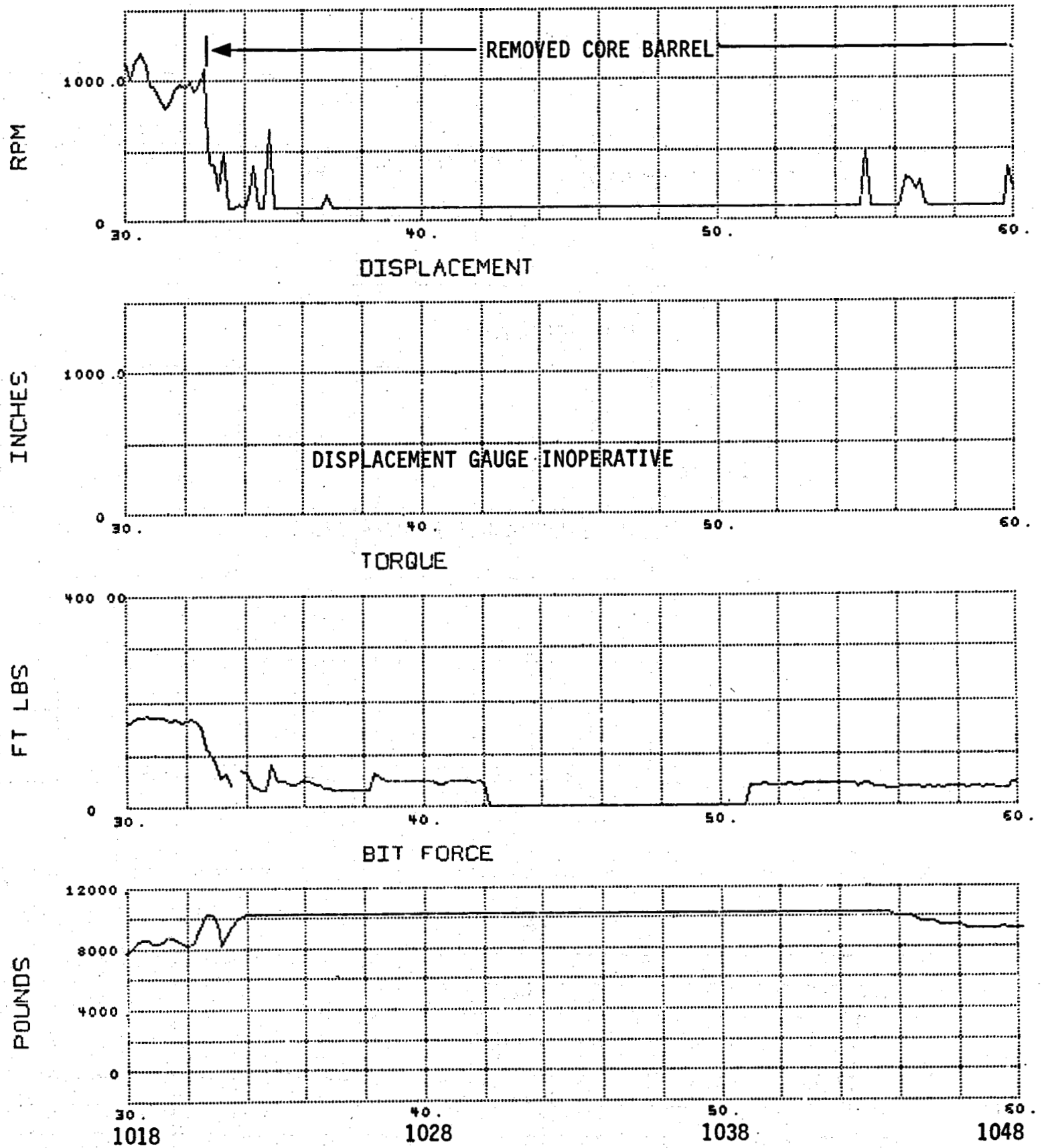

TIME IN MINUTES FROM 0100948 O0 1979

2

Figure B-2. Drilling in Hole 79-3 prior to the First Melt Encounter (HQ -- 3.78 inches diameter -- wireline coring equipment) 
MAGMA TAPE 5

DRILL SFEED
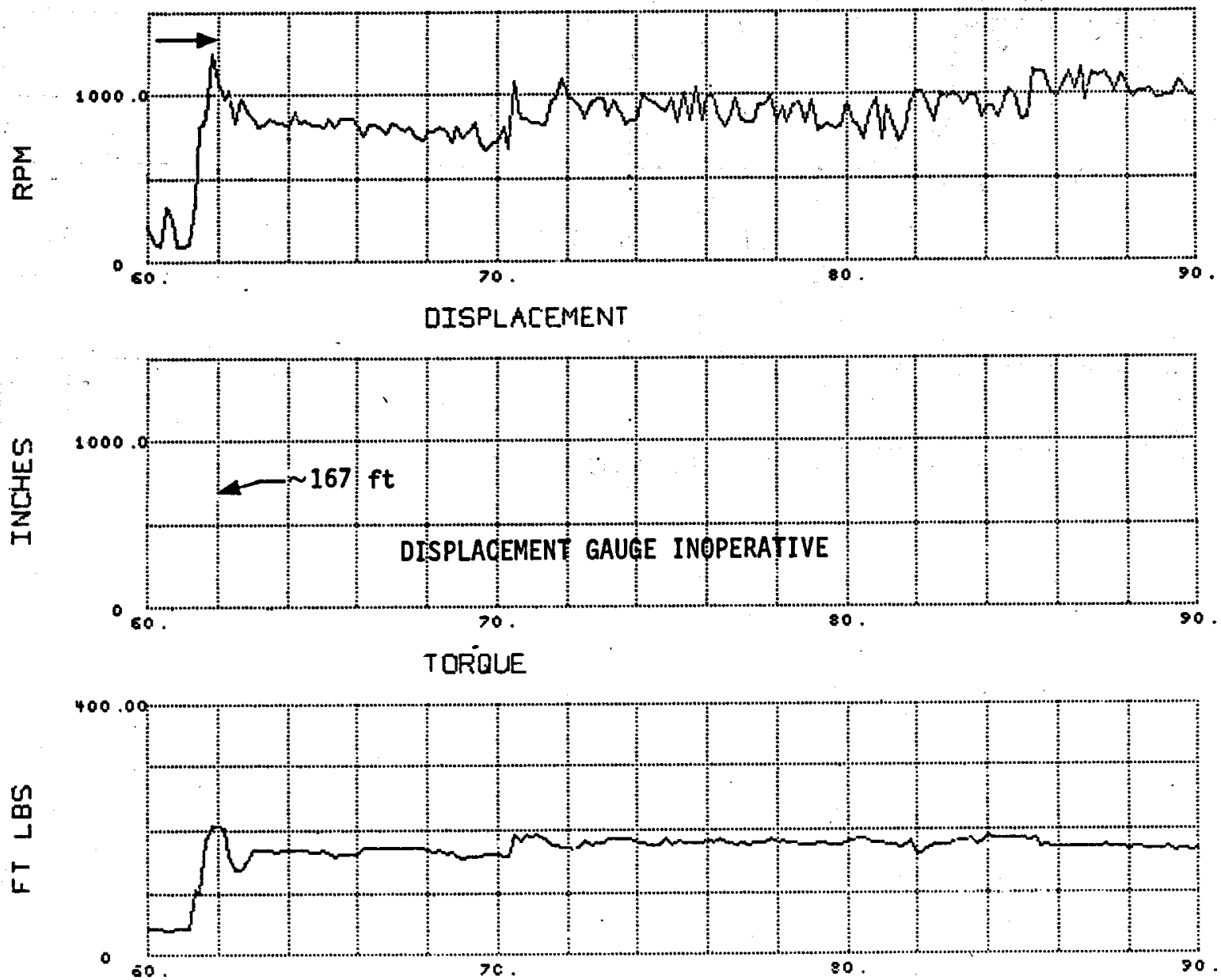

BIT FDRCE

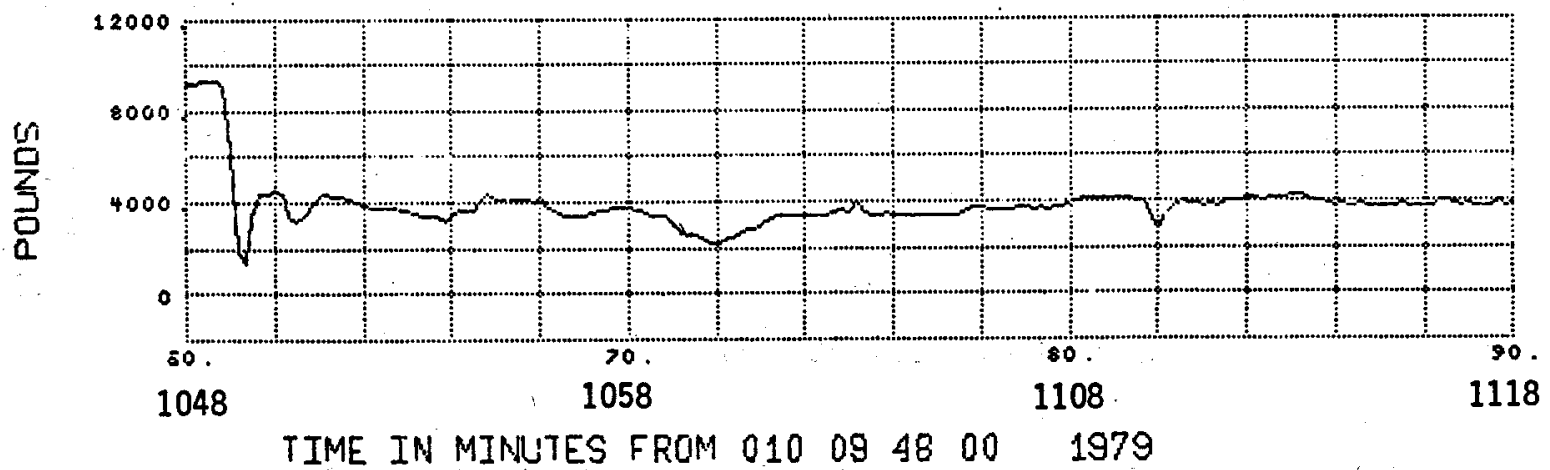

Figure B-3. Drilling in Hole $79-3$ prior to the First Melt
Encounter (HQ -- 3.78 inches diameter -- wireline
coring equipment) 
MAGMA TAPE 5

ORILL SPEED
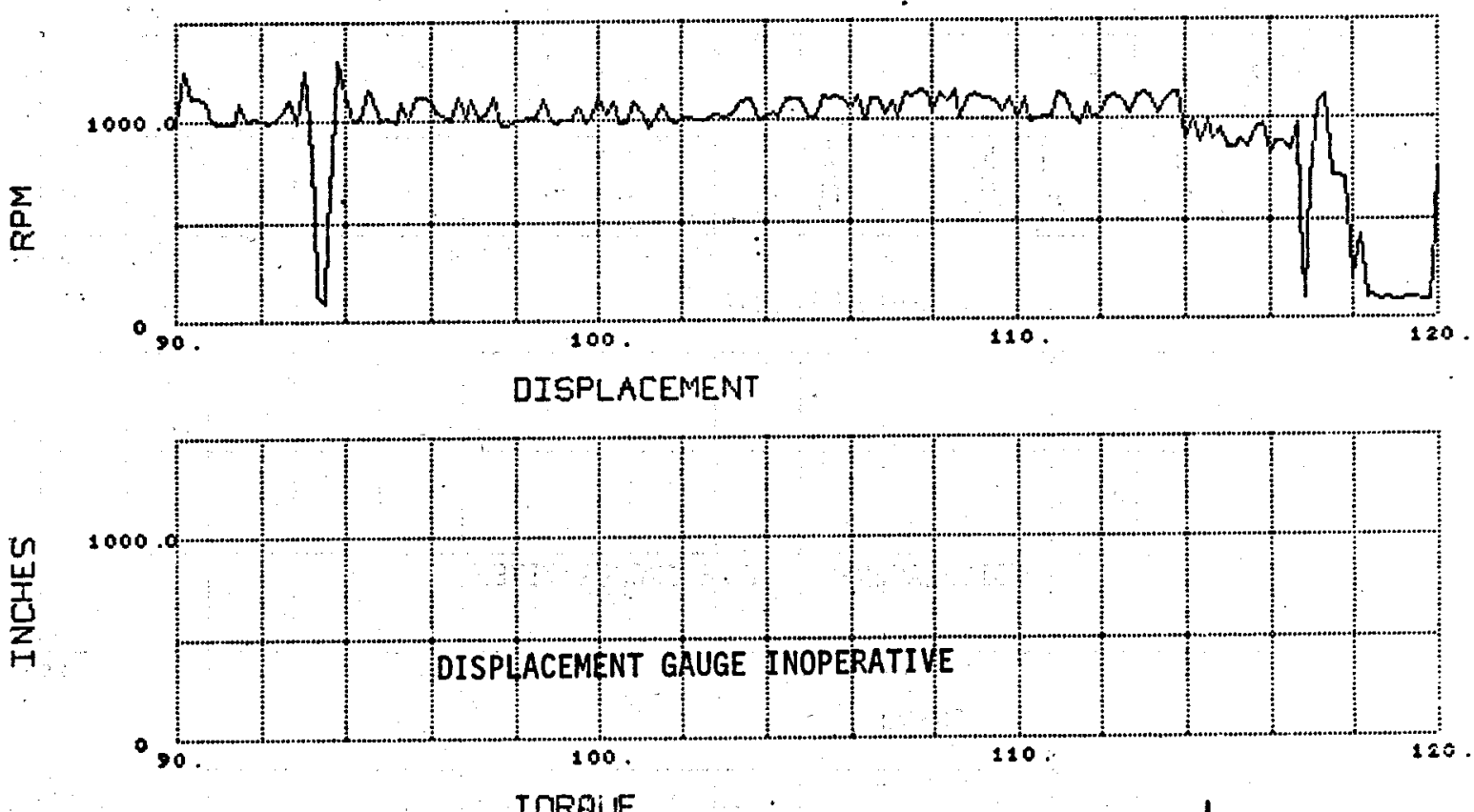

TORQULE

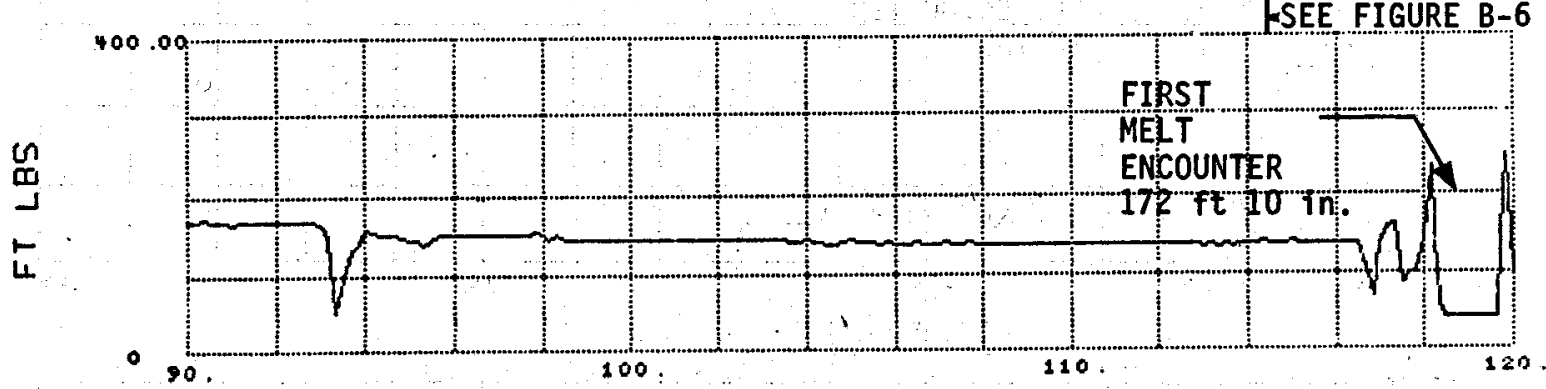

BIT FORCE

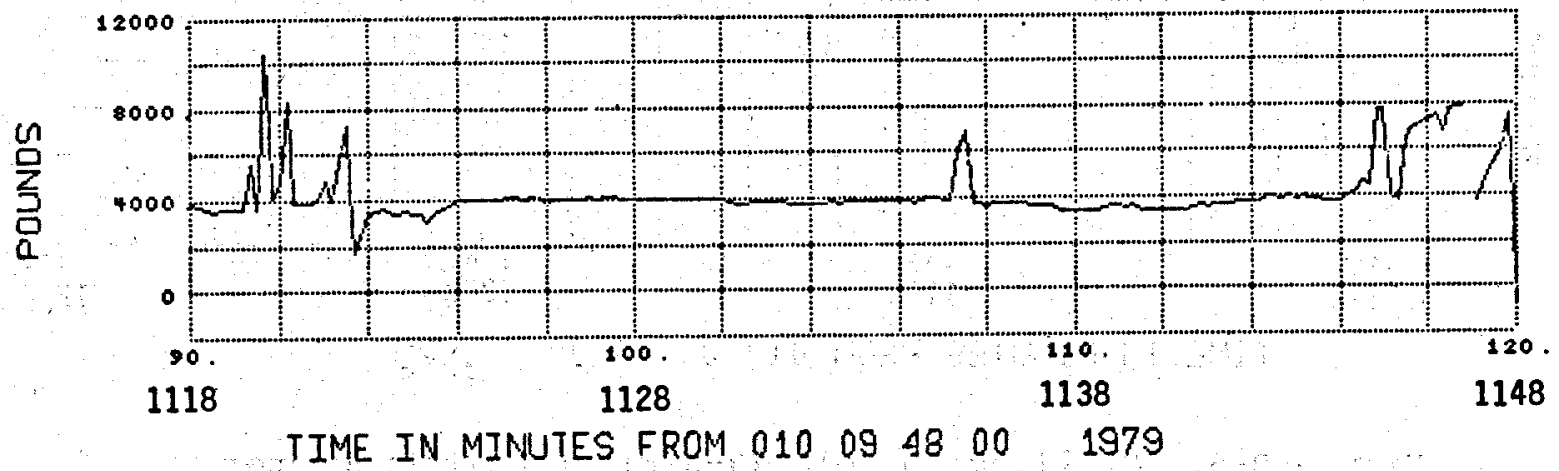

Figure B-4. Drilling in Hole 79-3 including First Melt Encounter (HQ -- 3.78 inches diameter -- wireline coring equipment) 
MAGMA TAPE 5

DRILL SPEED
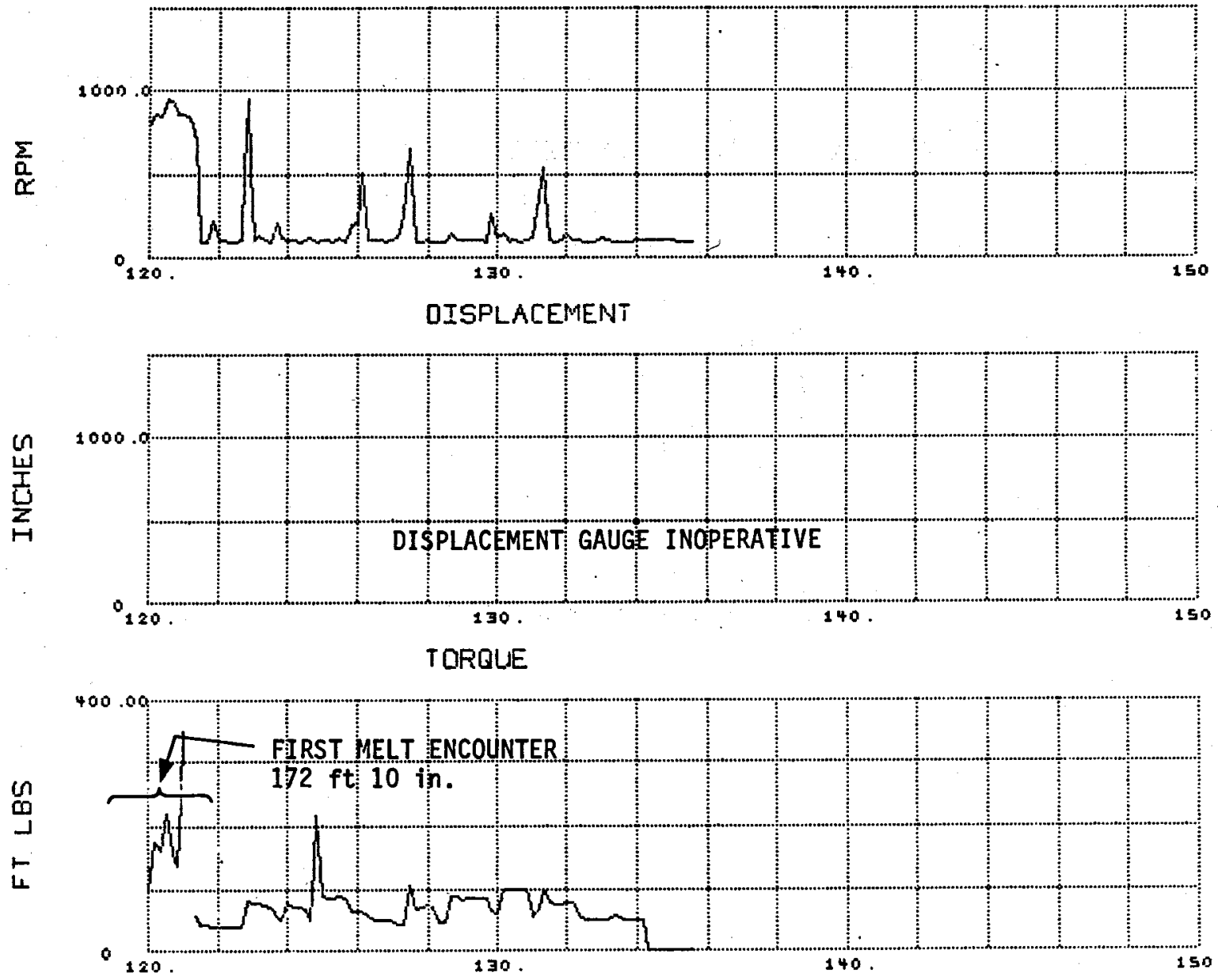

BIT FORCE

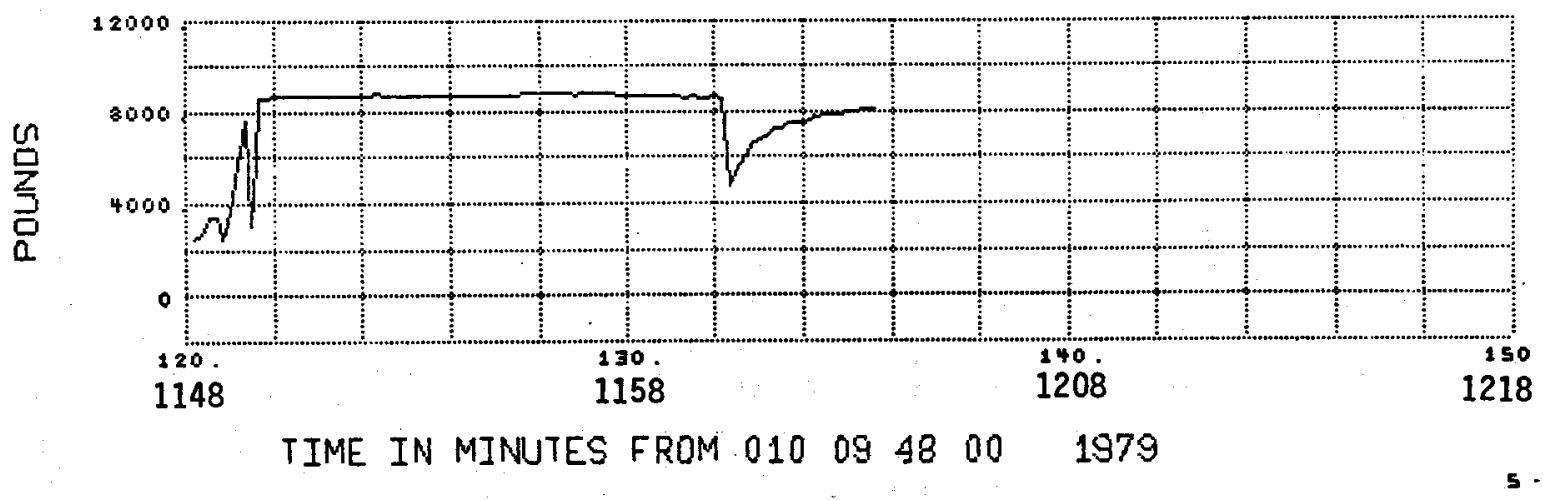

Figure B-5. Drilling in Hole 79-3 First Melt Encounter (HQ -- 3.78 inches diameter -- wireline coring equipment) 
DRILL SPEED

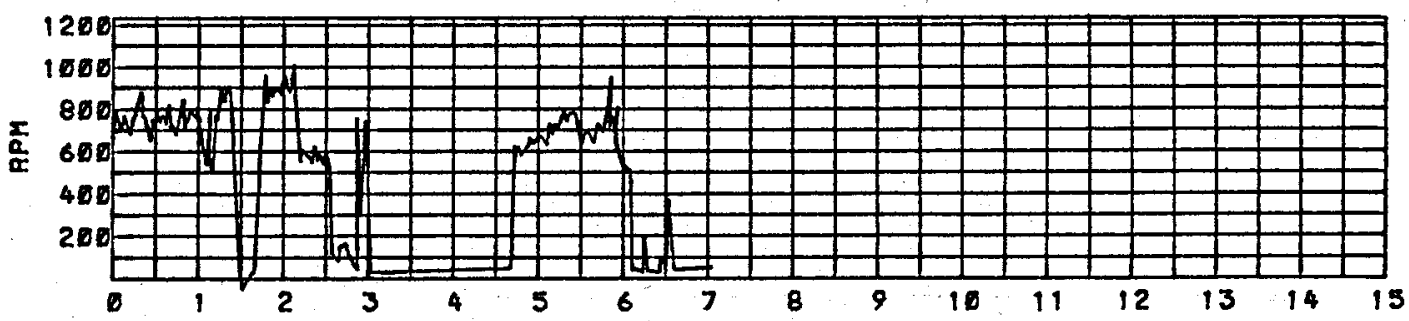

DISPLACEMENT

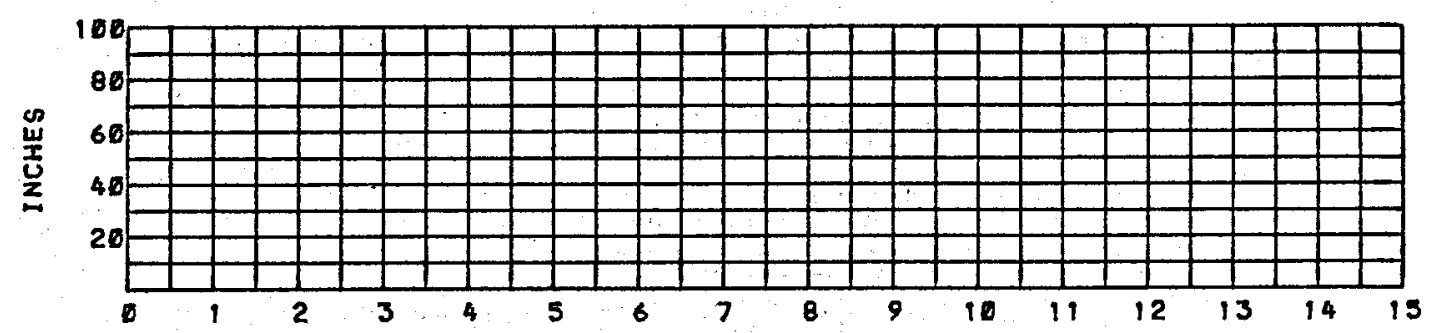

TORQUE

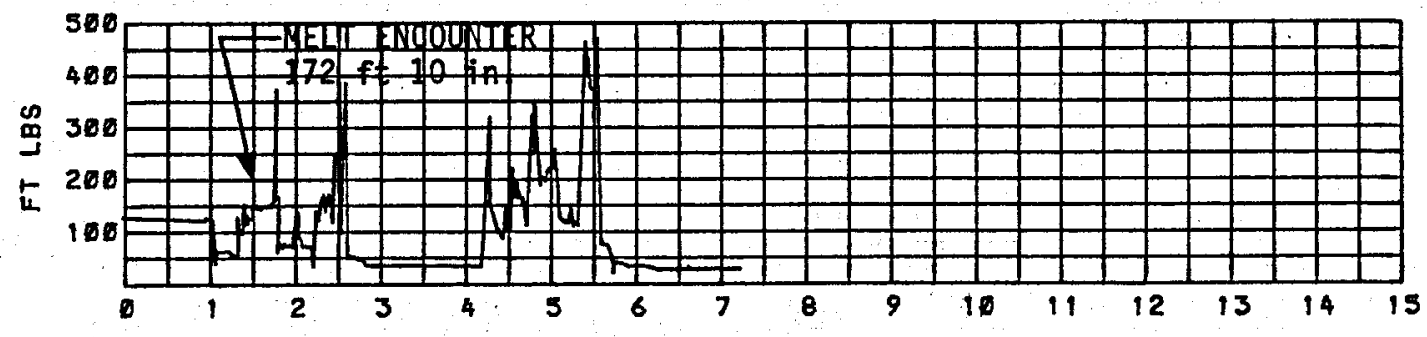

BIT FORCE

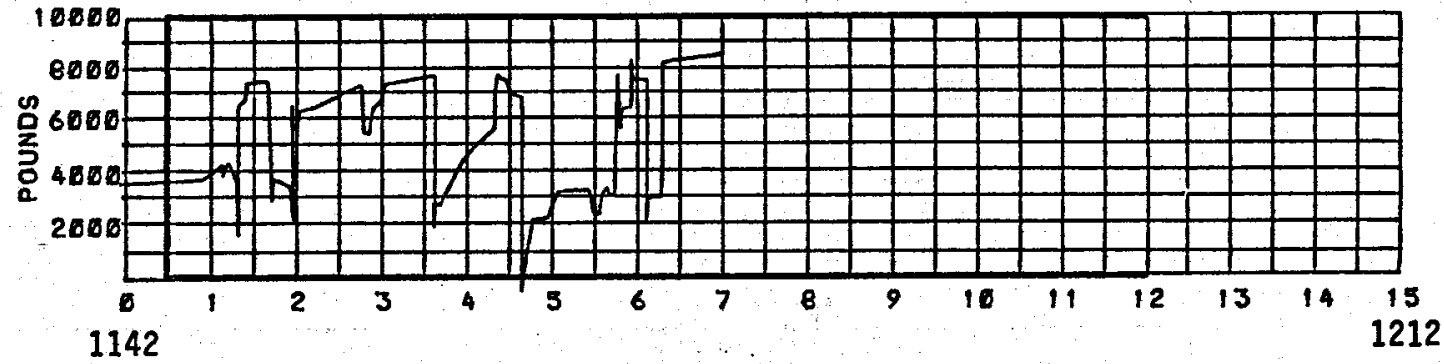

TIME IN MINUTES FROM $10 \quad 11 \quad 42 \quad 00 \quad 1979$

Figure B-6. First Melt Encounter while Drilling in Hole 79-3 with Conventional Core Bit 
MAGMA TAPE 5

DRILL SPEED
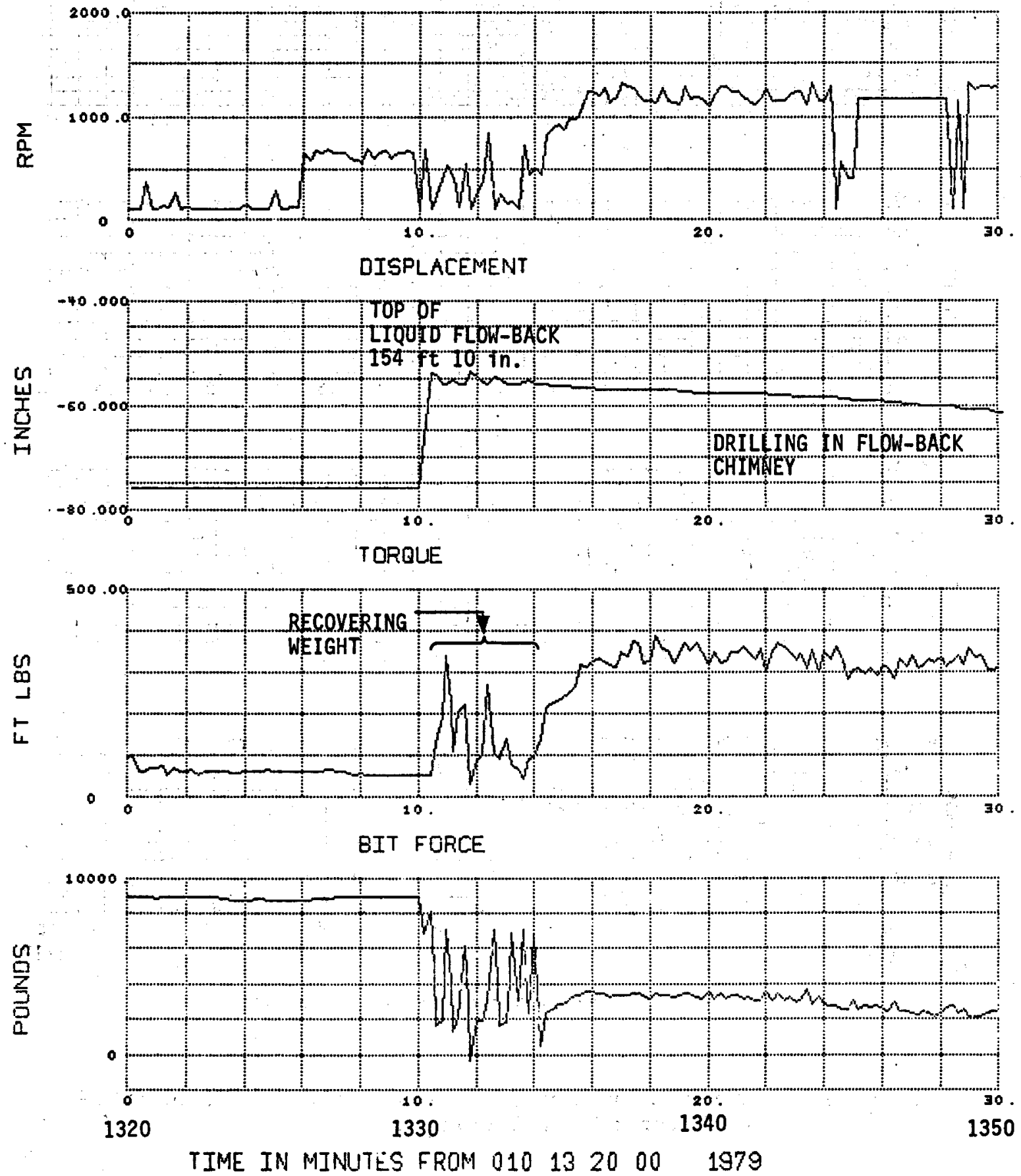

Figure B-7. Drilling in Hole 79-3 Liquid Flow-Back Chimney to Recover Sounding Weight (HQ -- 3.78 inches diameter -- wireline coring equipment) 
MAGNAA TAPE 5

DRILL SPEED
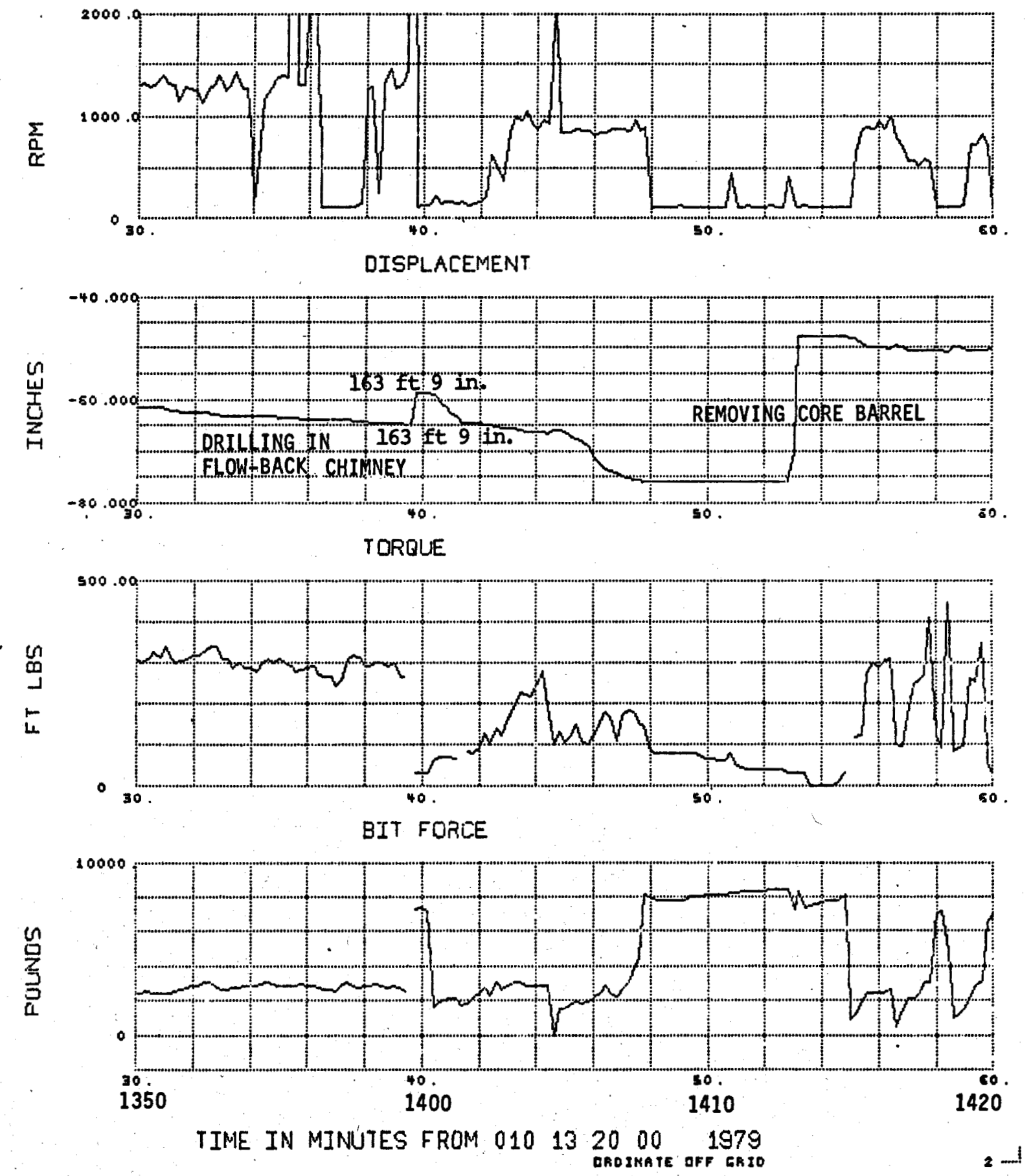

Figure B-8. Drilling in Hole 79-3 Liquid Flow-Back Chimney after First Liquid Penetration (HQ -- 3.78 inches diameter -- wireline coring equipment) 


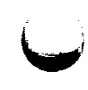


APPENDIX C

Drilling Records for Hole 79-4 
U 
The drilling of Hole 79-4 started on January 12, 1979, and ended on January 24, 1979, when the jet drilling in the liquid stringer zone was stopped. Drilling from the surface through the upper crust to within 6 inches of the expected liquid interface was completed on January 16. The hole then was cased with NW casing. The lower 40 feet of casing was 3-1/2-inch oD 316 stainless steel. Standard 3-1/2-inch OD carbon steel casing was used for the remainder of the casing, which reached the surface. After casing was completed, an excellent glass-to-metal seal was obtained by arilling into the liquid rock which flowed up around the bottom of the casing.

Attempts to drill with the jet core bit and standard 10-foot-long NW core barrel were unsuccessful because the core barrel tended to bind inside the casing. A slight bend in the lower 10 to 20 feet of the hole was the probable cause of the binding. The jet drag bit was then used to drill approximately 13 feet through several thin layers of liquid-rock and plastic zones. It was concluded that the ability of the jet drag bit system had been demonstrated by the drilling completed to date. It was further concluded that the probability of encountering a thick liquid layer required for the formation of a solid stalactite of porous rock in a liquid zone was poor, and therefore, the hole should be abandoned in favor of recovering the continuous core from Hole 79-5.

Figures C-1 through C-7 show the drill functions which were recorded as the hole was being drilled with conventional equipment to the initial casing depth. Figures C-14 through C-50 show the drill functions recorded during jet drag bit drilling through the solid, plastic, and liquid layers below the 173-foot depth. Figures $c-13 b, c-15 b, c-17, c-18, C-21 a, c-22 a, c-31 b, \& c-43 b$ are detailed plots showing the high-frequency components of the torque and the RPM function.

Figures c-12a, C-14a, c-15a, c-28a, c-29a, c-30a,c-31a,c-32a, c-33a, c-34a, $c-35 a, c-36 a, c-37 a, c-38 a, c-39 a, c-40 a, c-41 a, c-42 a, c-43 a, c-44 a, c-45 a, c-48 a$, $c-49 \mathrm{a}$, and $\mathrm{c}-50 \mathrm{a}$ show the casing air pressure and cooling water flow rates during the jet drilling operations. 
MAGMA TAPE 6

DRILL SPEED
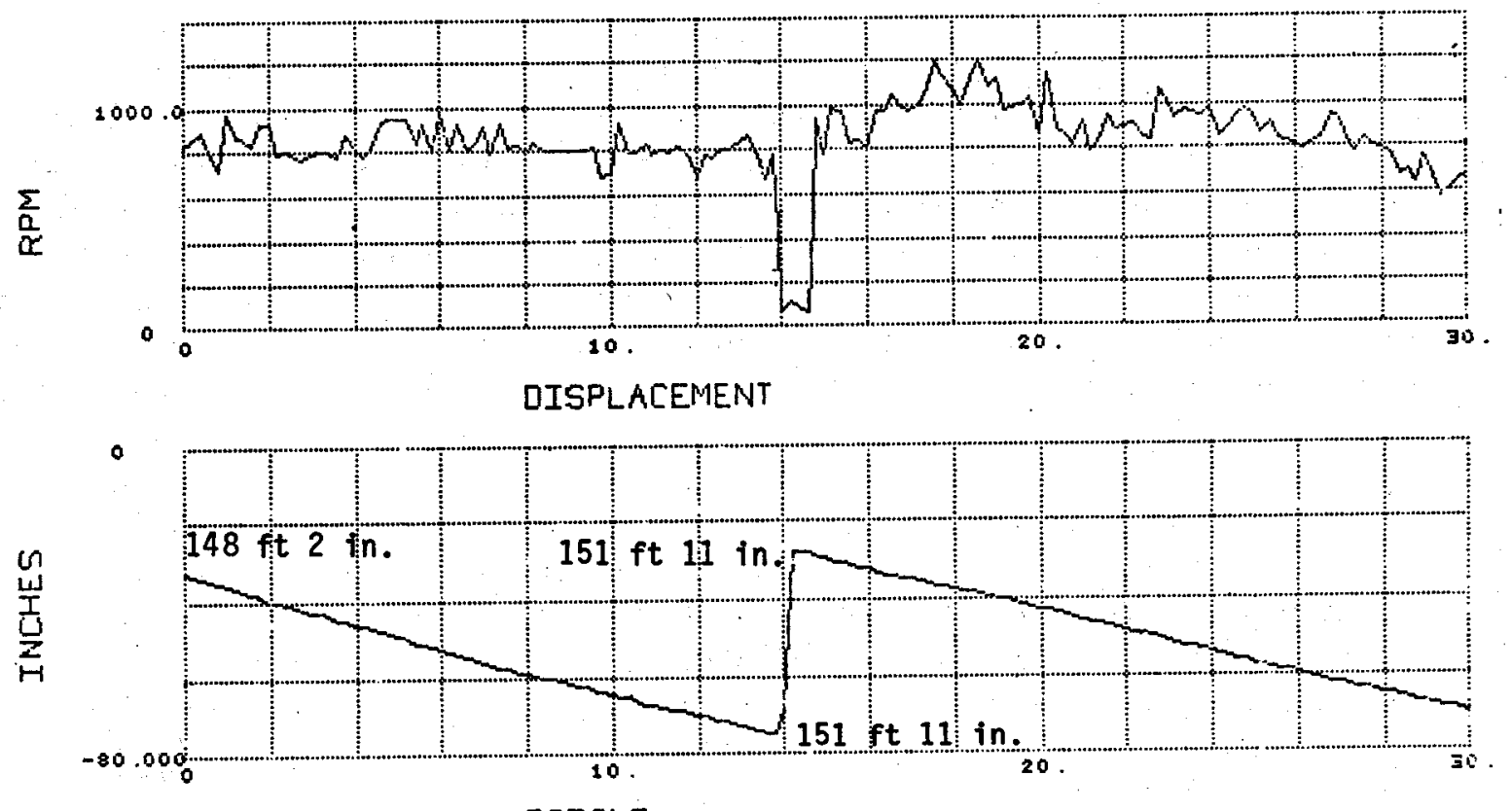

TORQLE

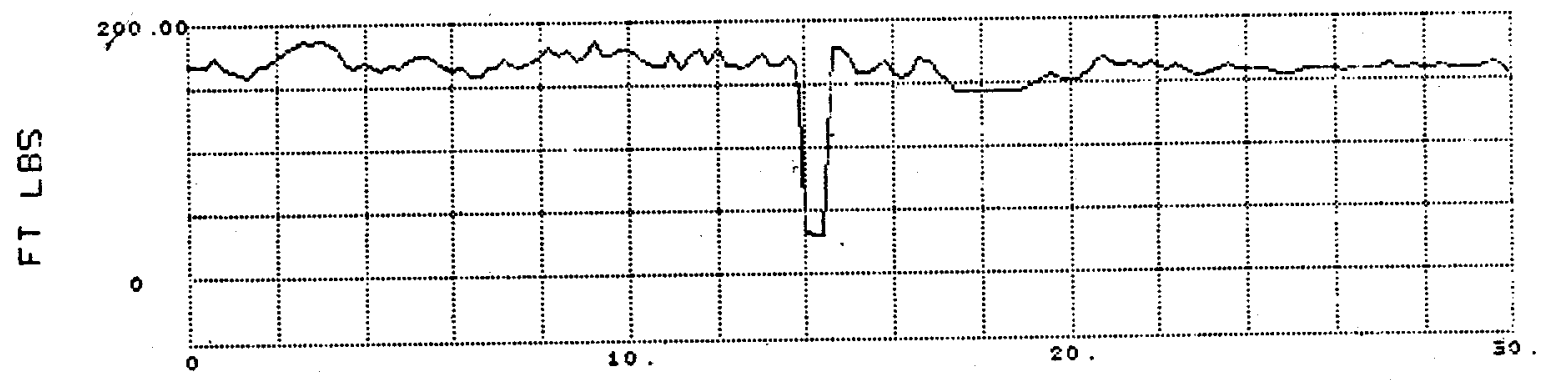

BIT FORCE

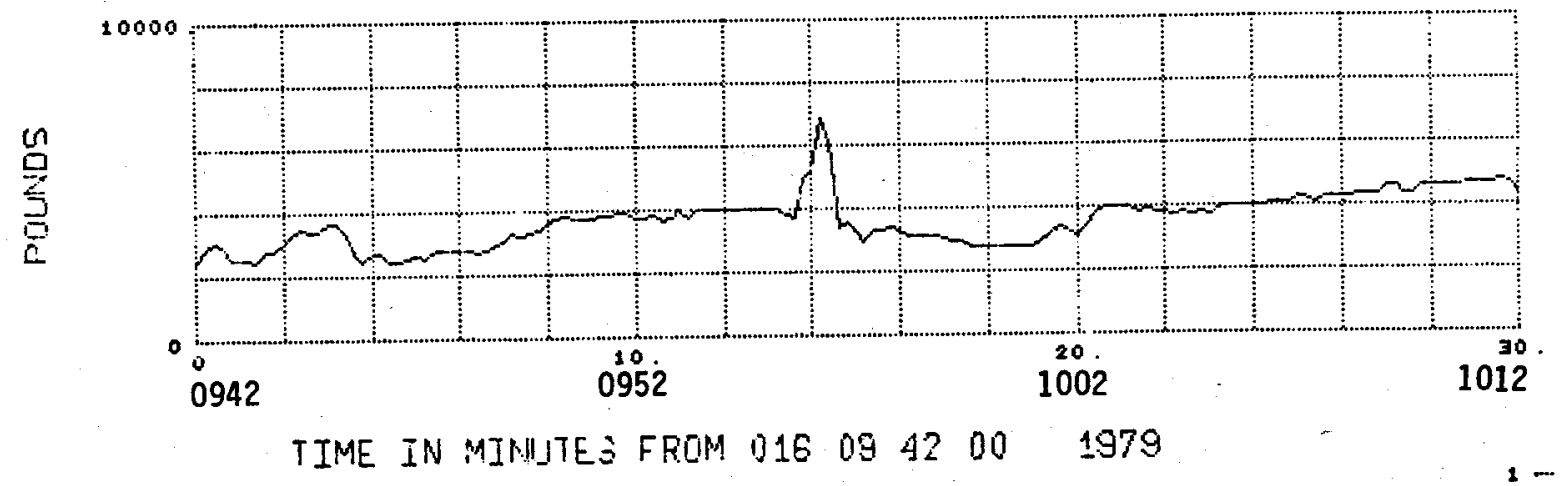

Figure C-1. Drilling in Crust in Hole 79-4 (HQ -- 3.78 inches diameter -- wireline coring equipment) 
MAGMA TAFE 6

DRILL SPEED
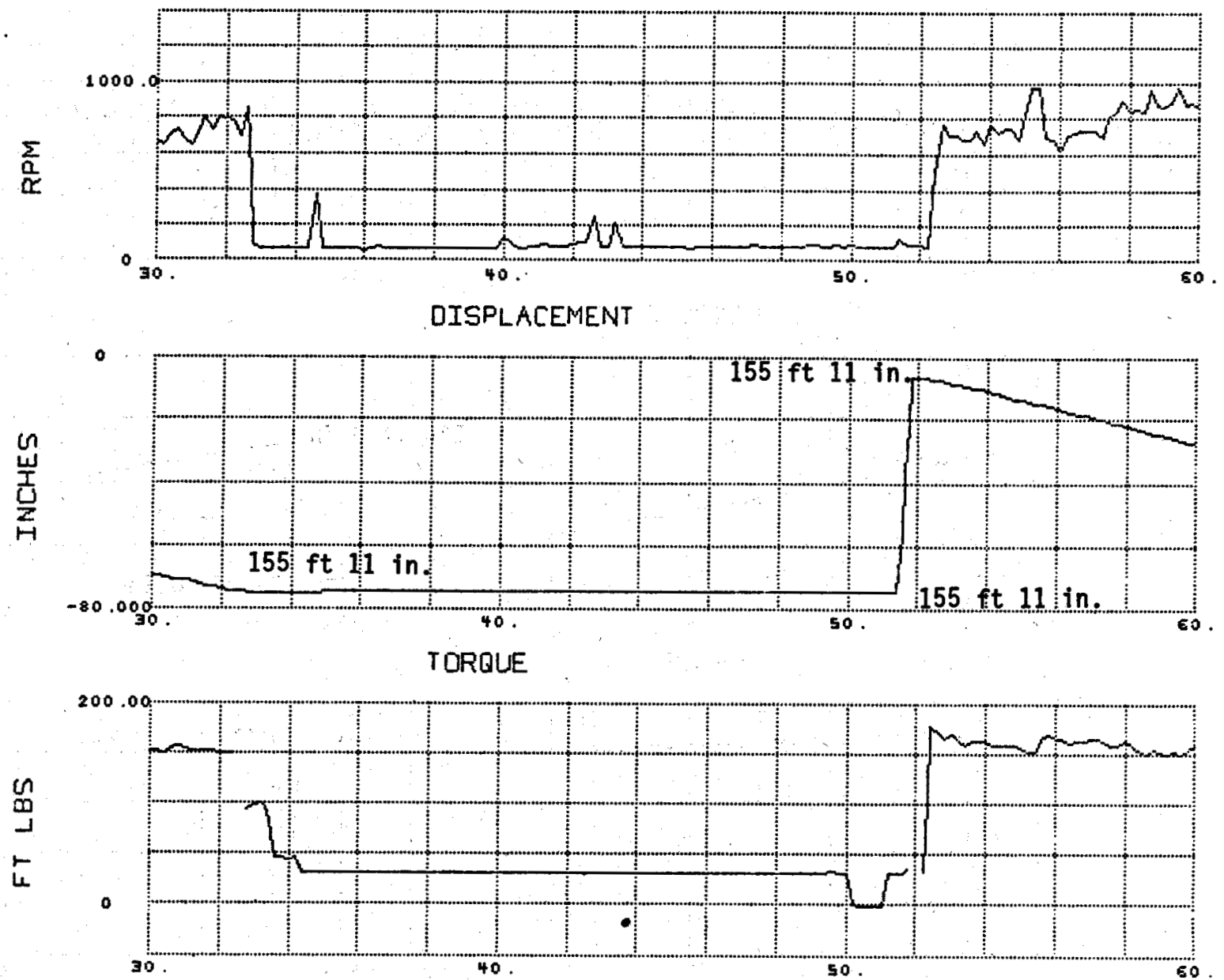

BIT FORCE

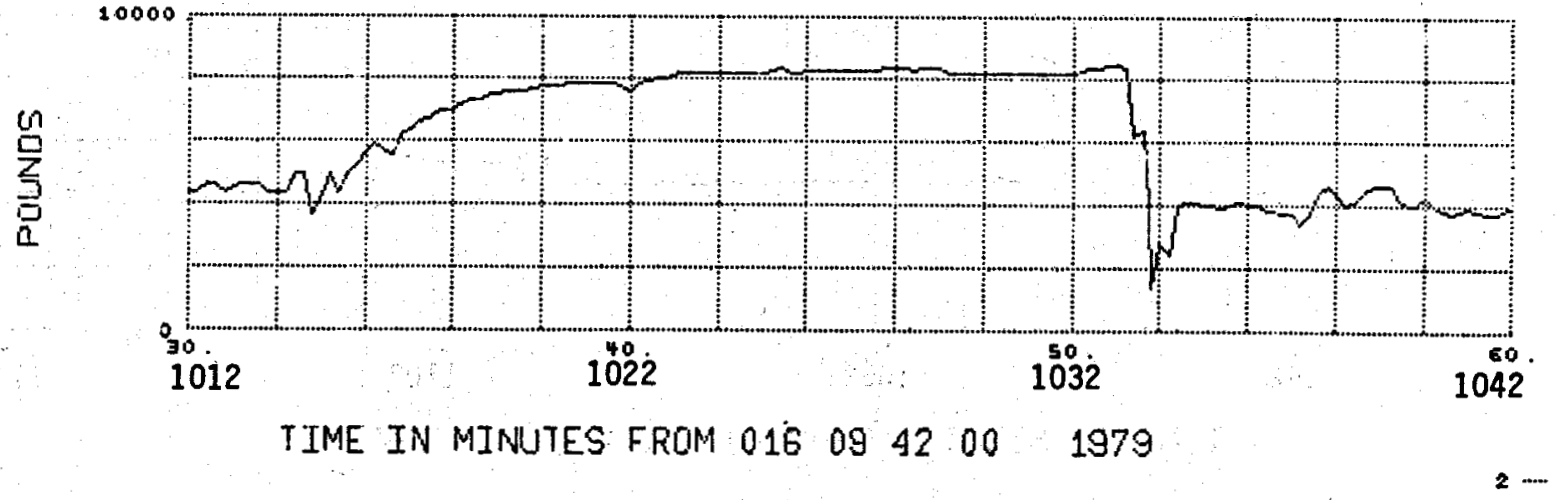

Figure C-2. Drilling in crust in Hole $79-4$ (HQ - 3.78 inches diameter -- wireline coring equipment) 
MAGMA TAPE G

DRILL SPEED
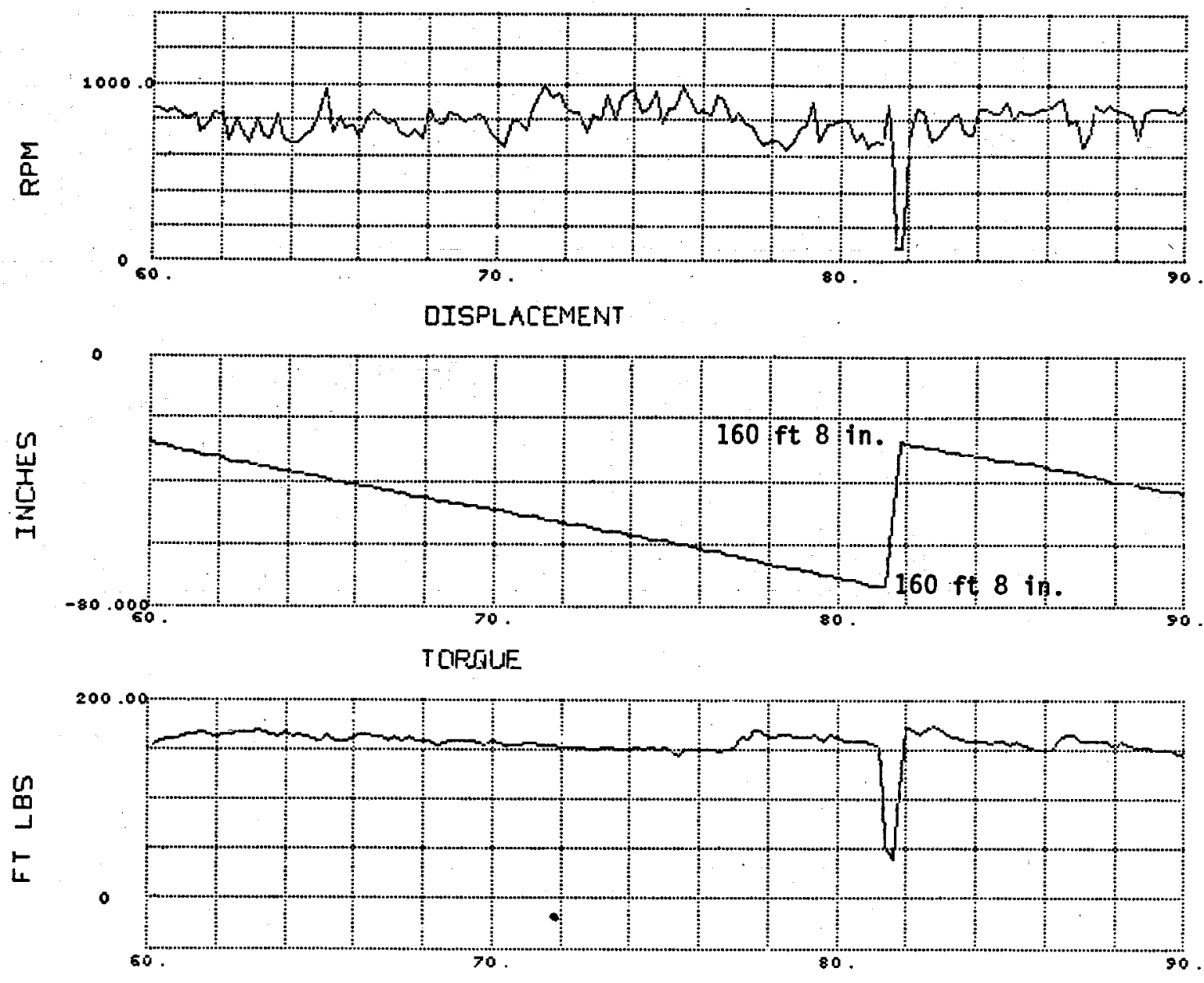

BIT FORCE

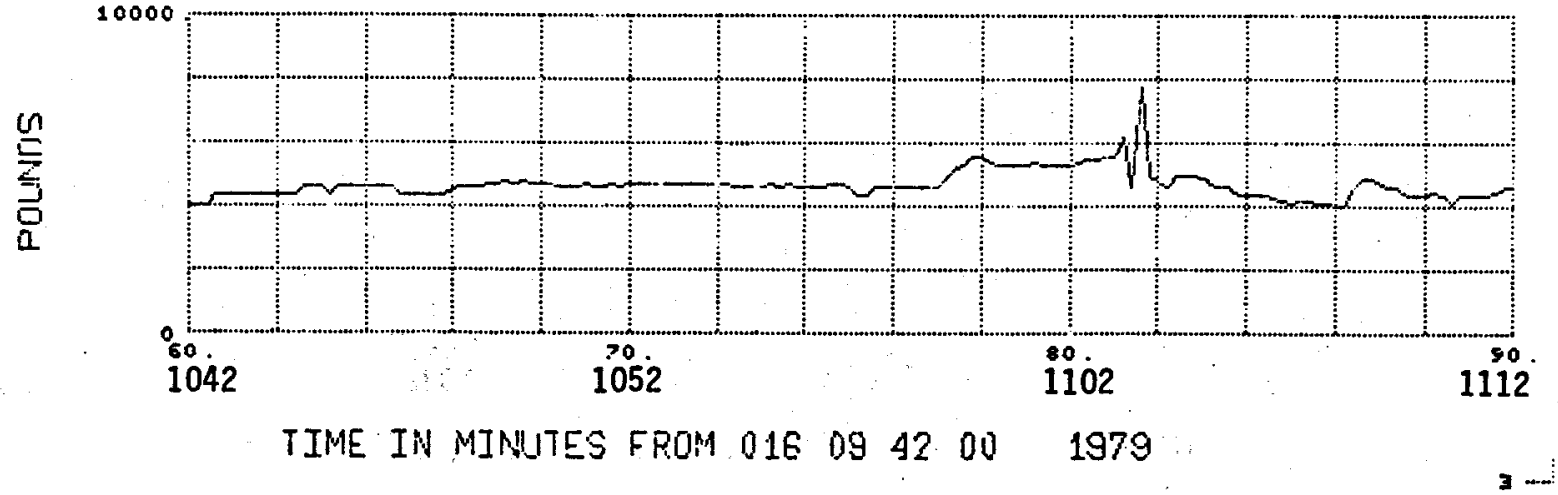

Figure C-3. Drilling in Crust in Hole 79-4 (HQ -- 3.78 inches diameter -- wireline coring equipment) 

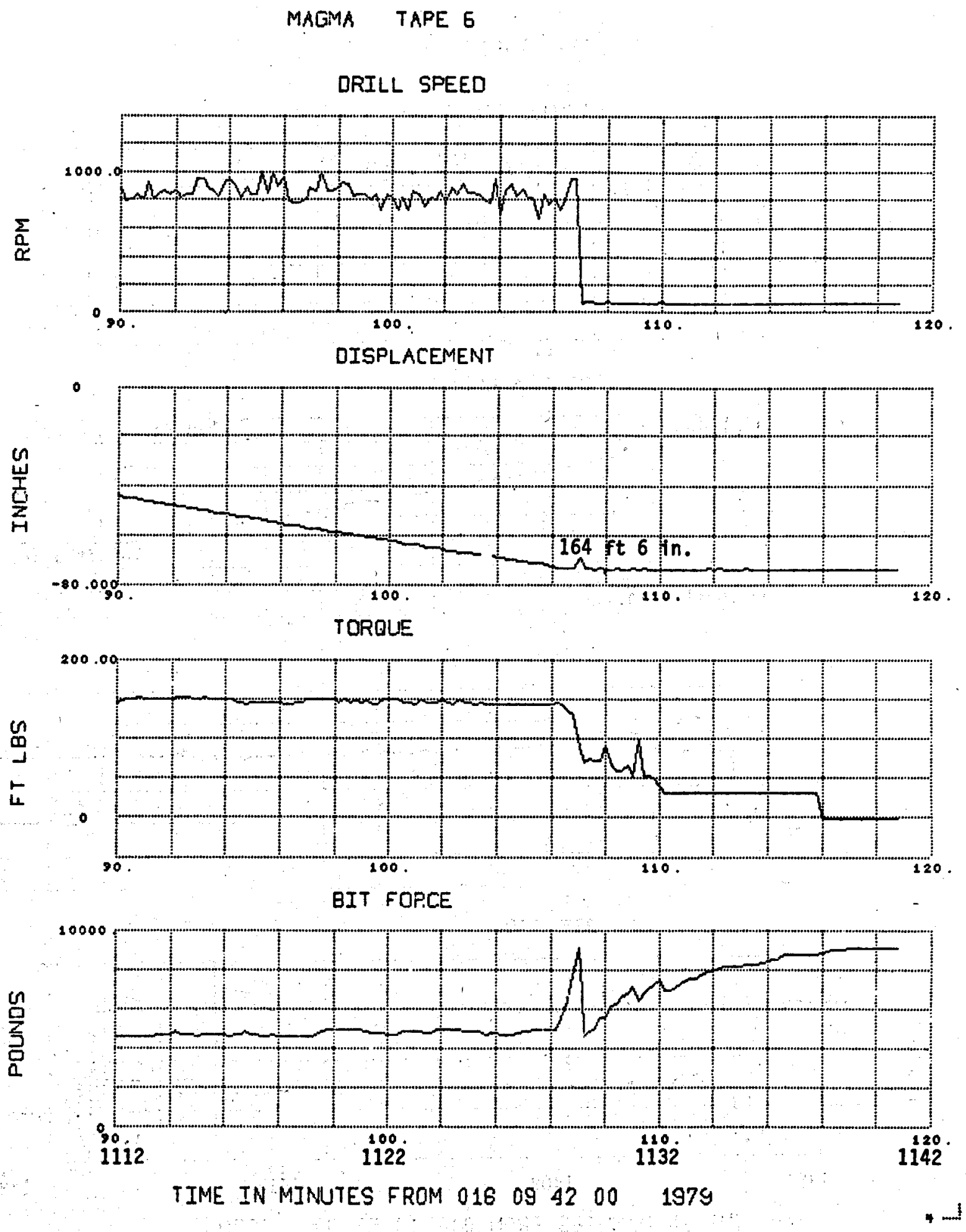

Figure C-4. Drilling in Crust in Hole 79-4 (HQ -3.78 inches diameter -- wireline coring equipment). 
MAGM TAPE 6

DRILL SPEED
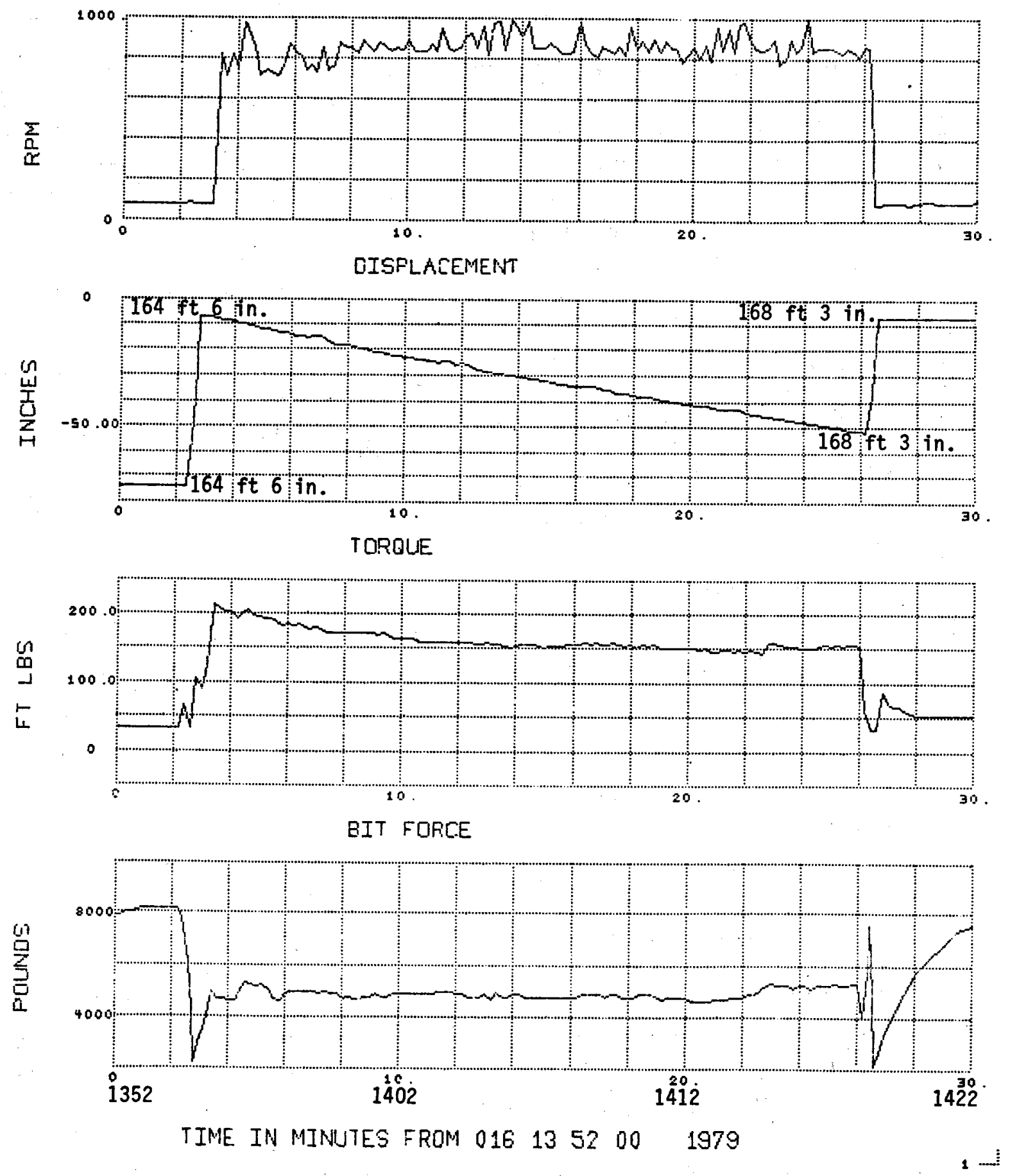

Figure C-5. Drilling in Crust in Hole 79-4 (HQ -- 3.78 inches diameter -- wireline coring equipment) 
MAGMA TAFE 6

DRILL SPEED
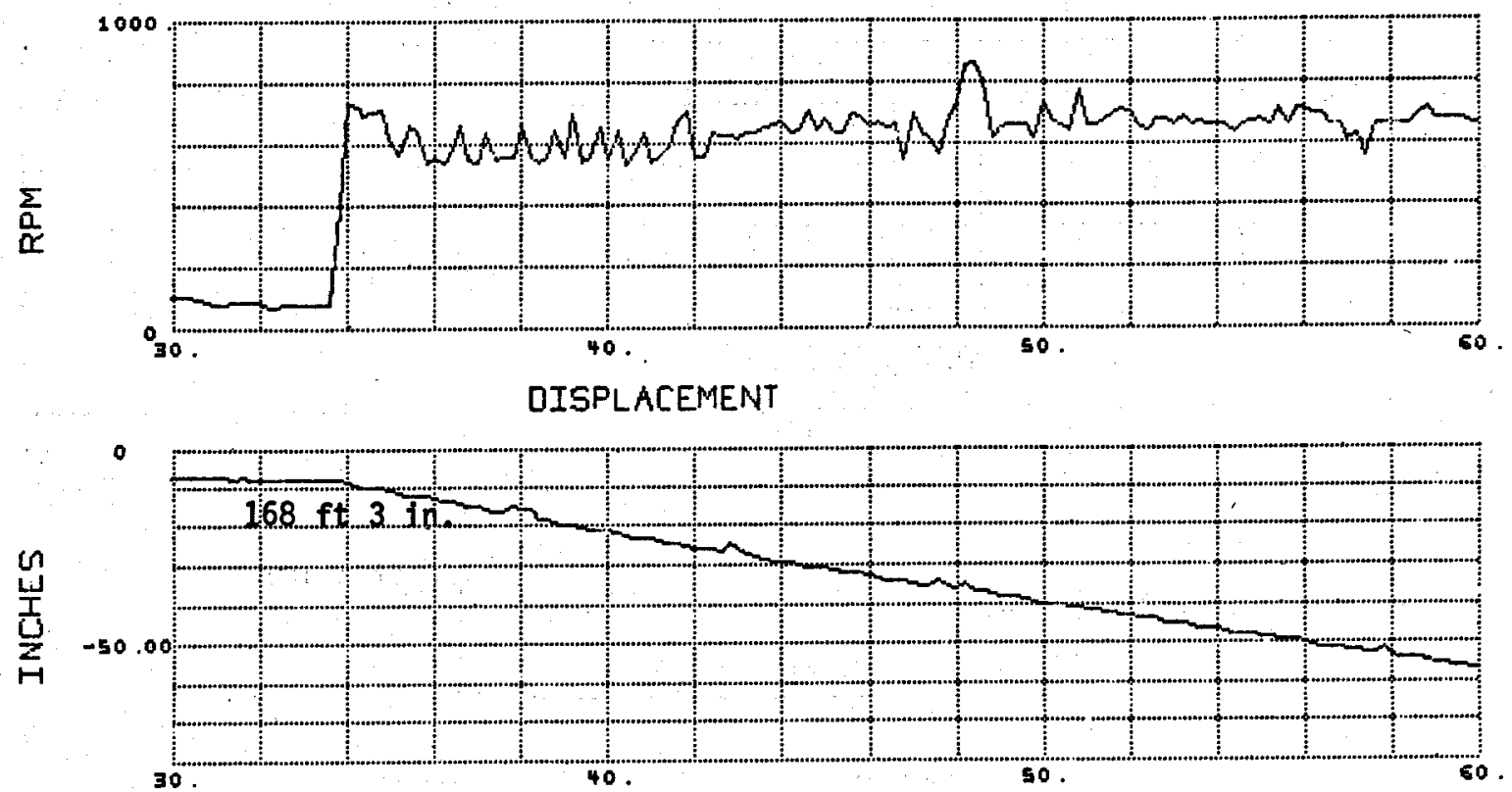

TORQLE

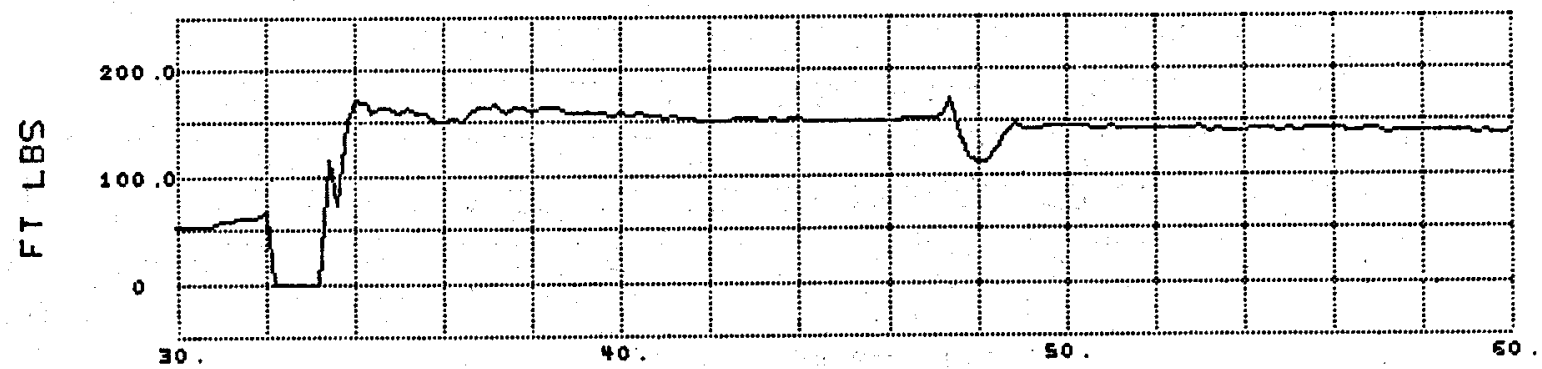

BIT FORCE

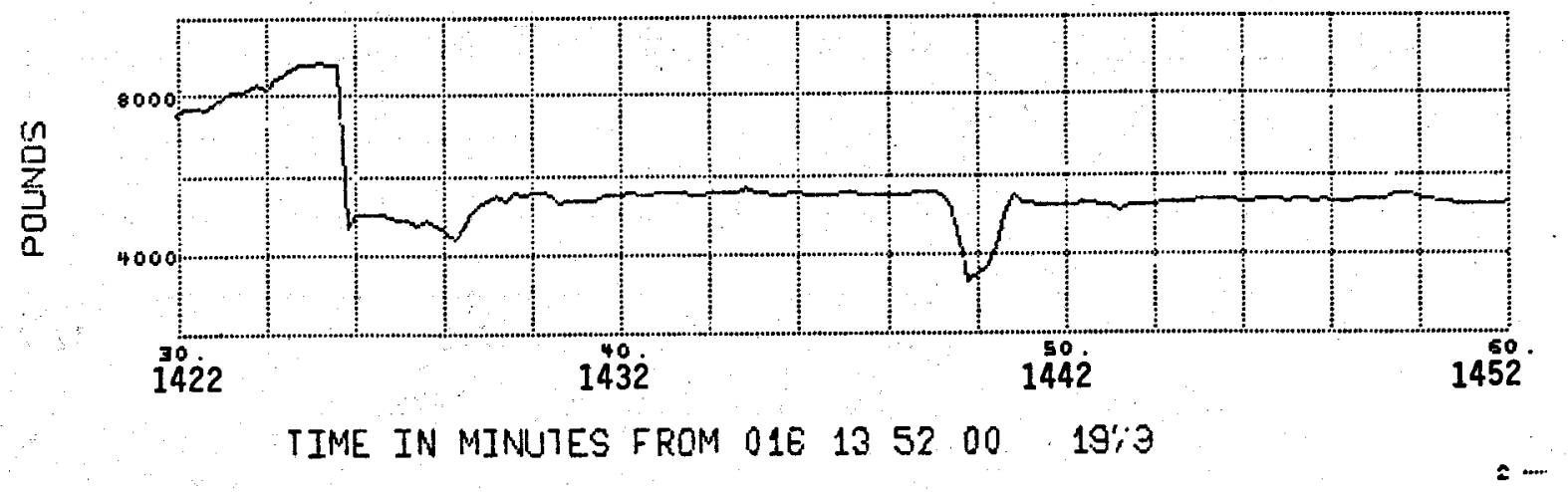

Figure C-6. Drilling in Crust in Hole 79-4 (HQ -- 3.78 inches diameter -- wireline coring equipment) 
MAGMA TAPE 6

DRILL SFEED
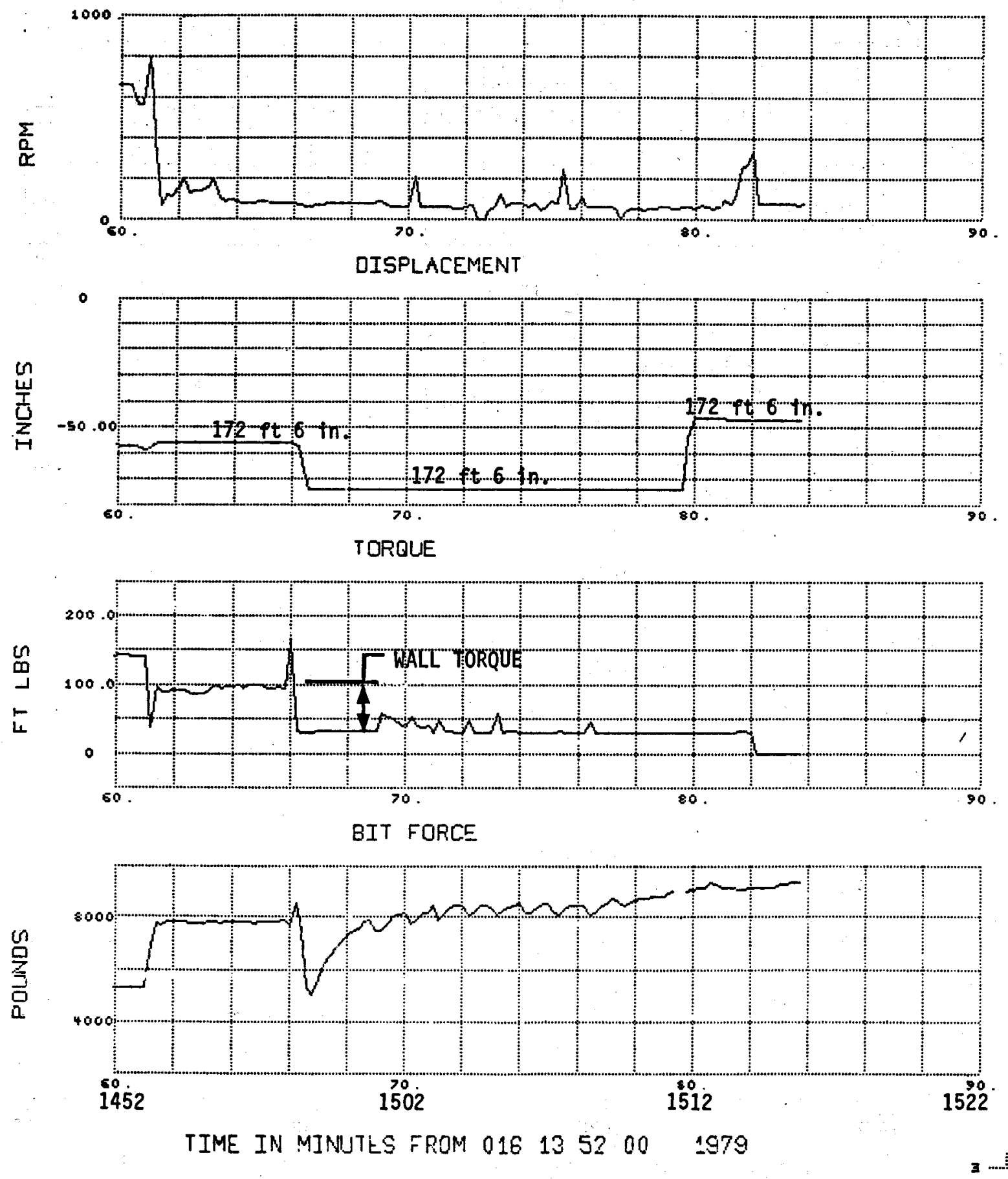

Figure C-7. Drilling in Crust in Hole 79-4 (HQ -- 3.78 inches diameter -- wireline coring equipment 
MAGMA TAPE 7

DRILL SPEED
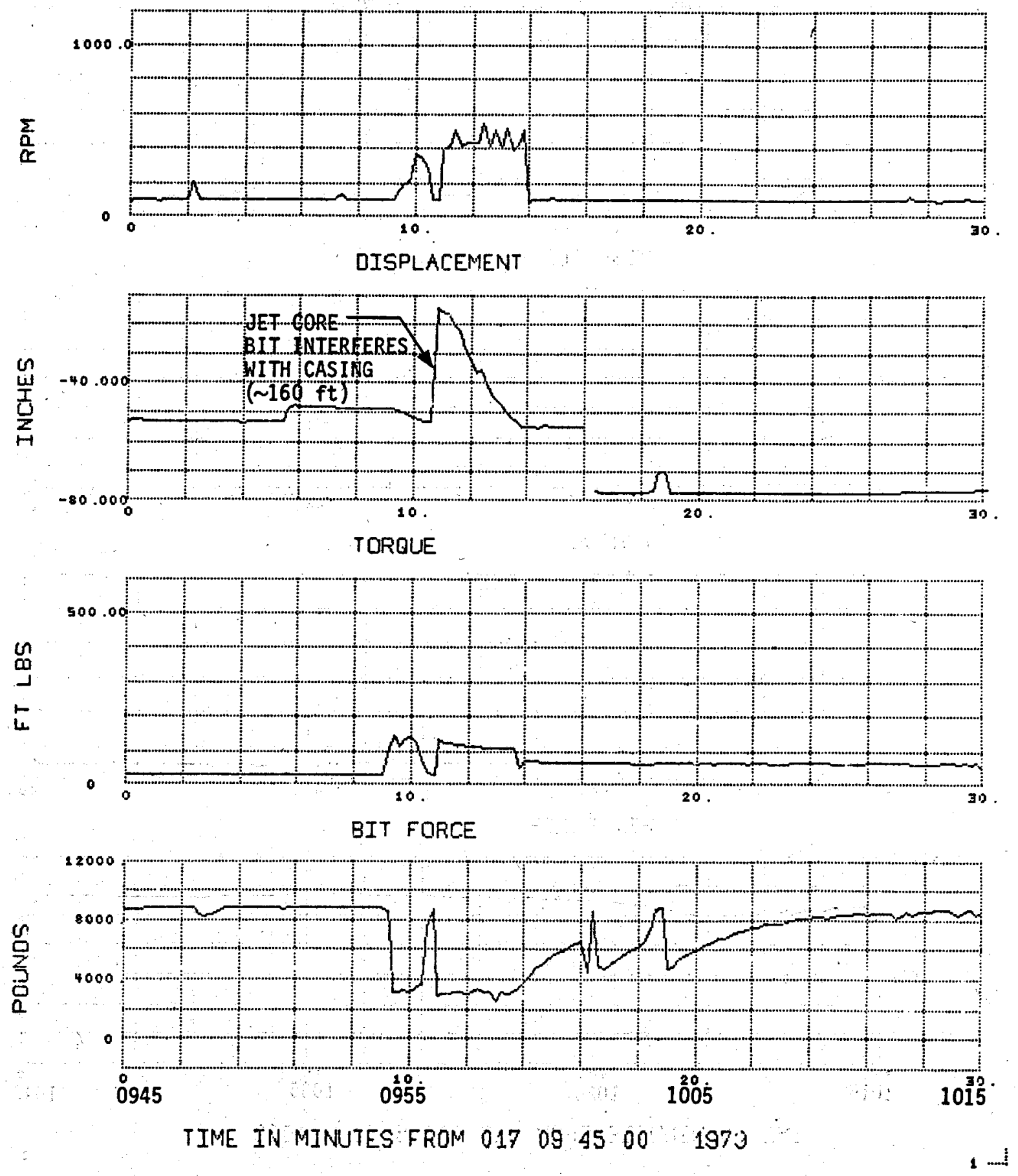

Figure C-8. Inserting Jet Core Bit in Cased Hole 79-4 (NQ - 2.98 inches diameter - - jet core bit and core barrel) 
MAGMA TAPE 7

ORILL SPEED
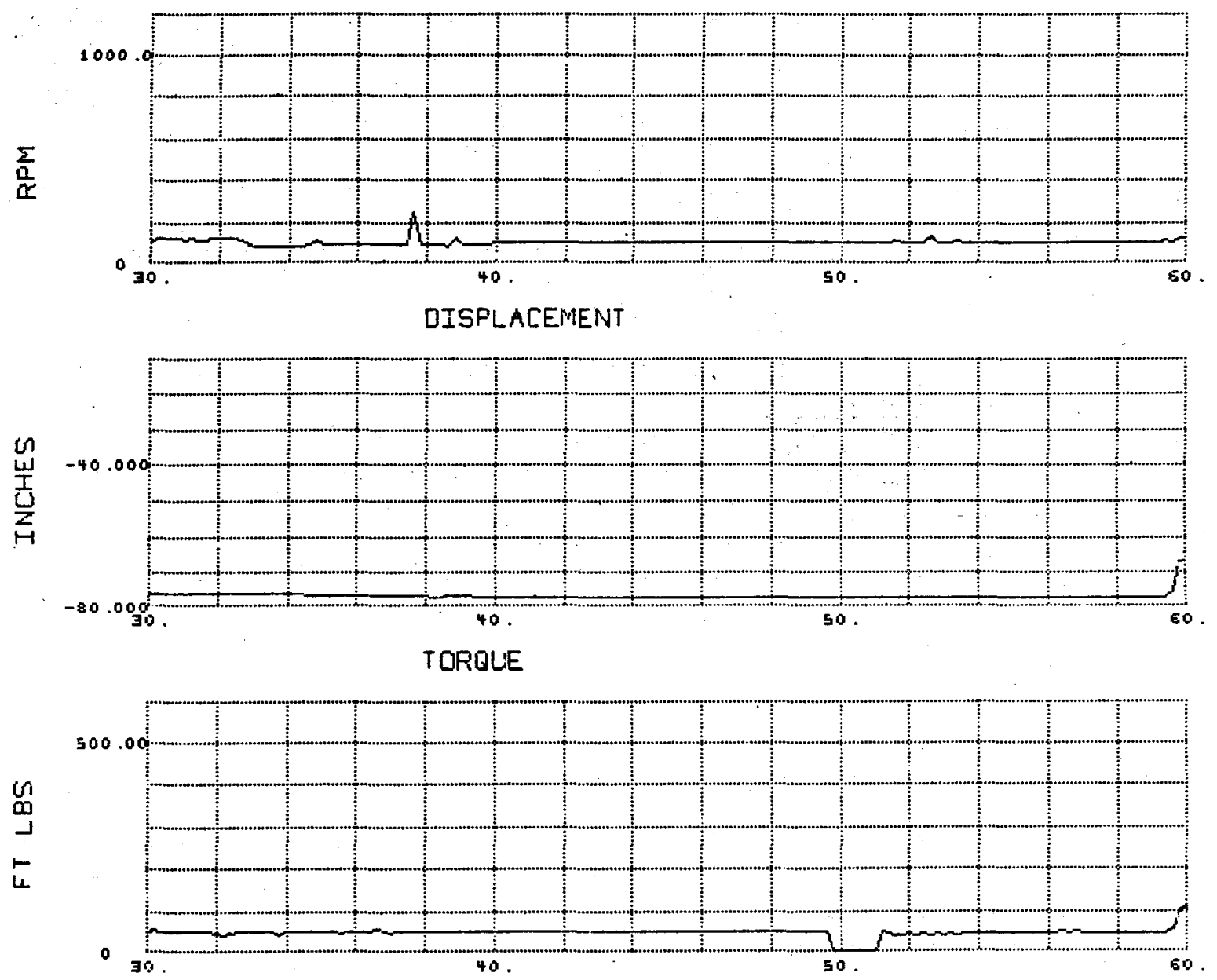

BIT FORCE

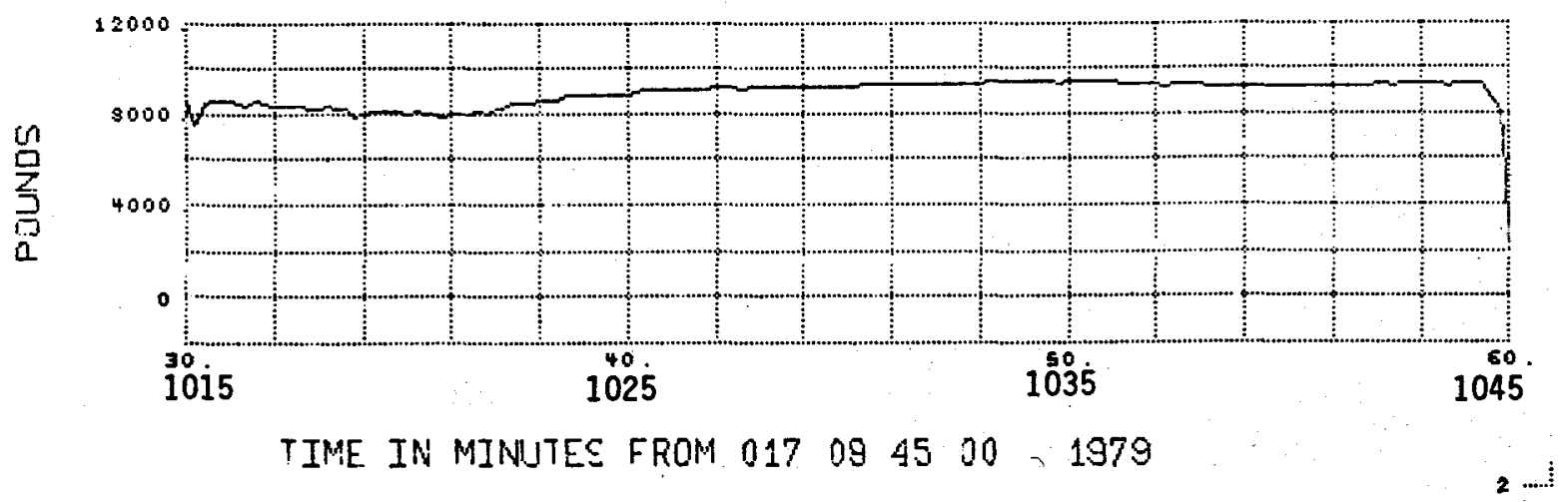

Figure C-9. Inserting Jet core Bit in Cased Hole 79-4 (NQ -- 2.98 inches diameter -- jet core bit and core barrel) 
MAGMA TAPE 7

DRILL SPEED
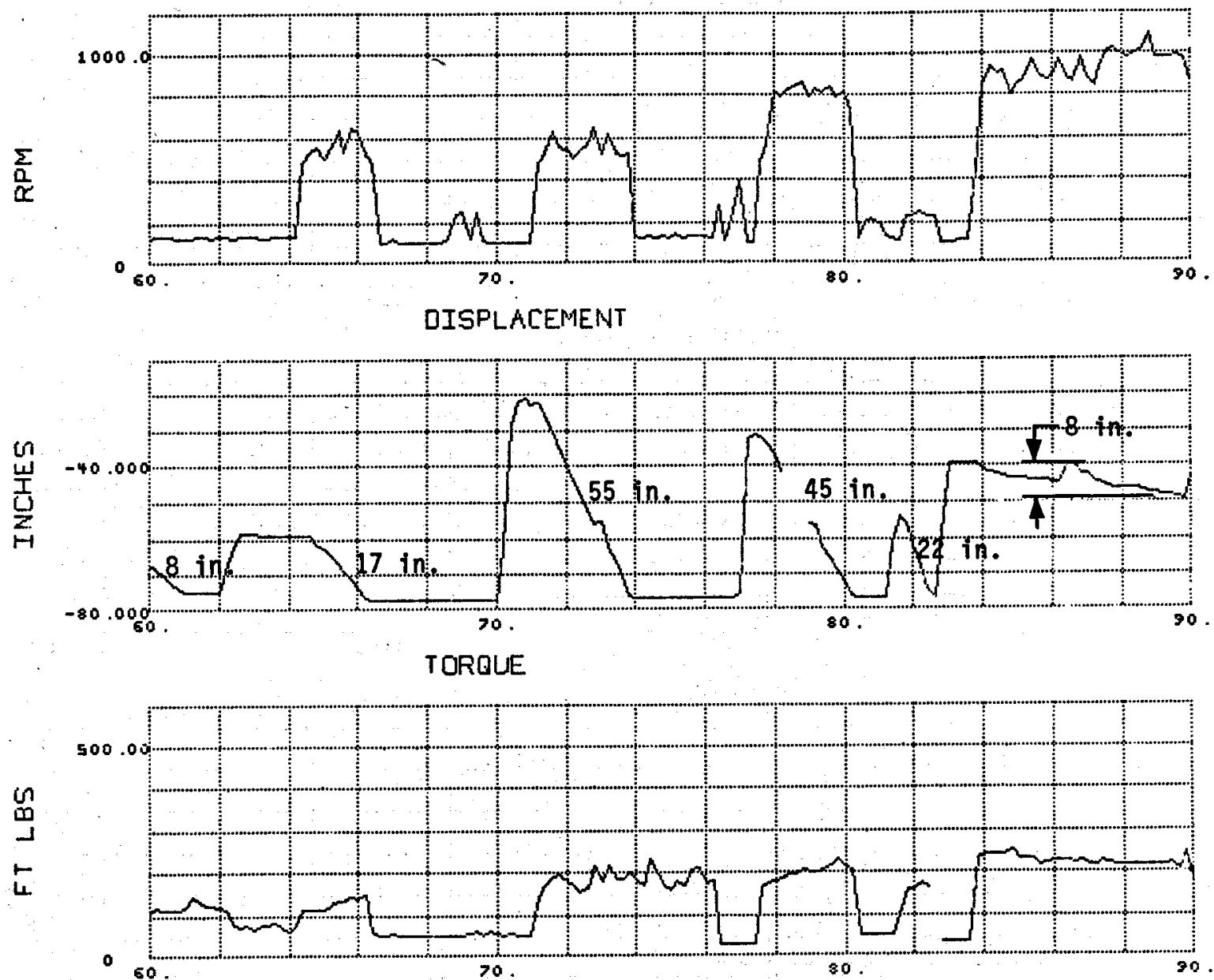

BIT FORCE

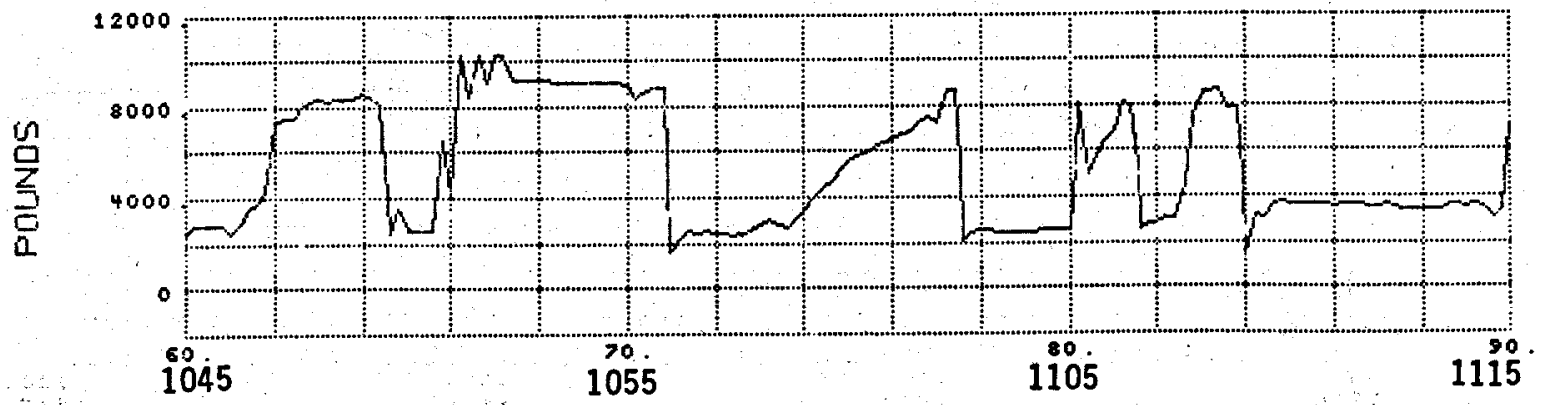

TIME IN MINUTES FROM $01709 \quad 4500$ 197s

$3 \ldots$

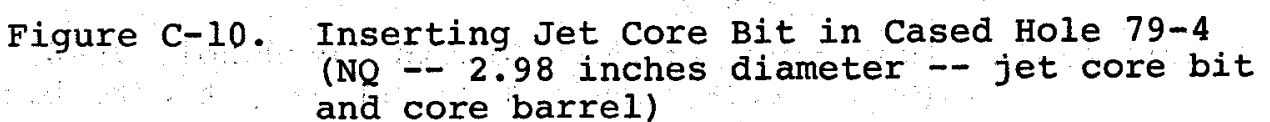


MAGMA TAPE 7

DRILL SPEED
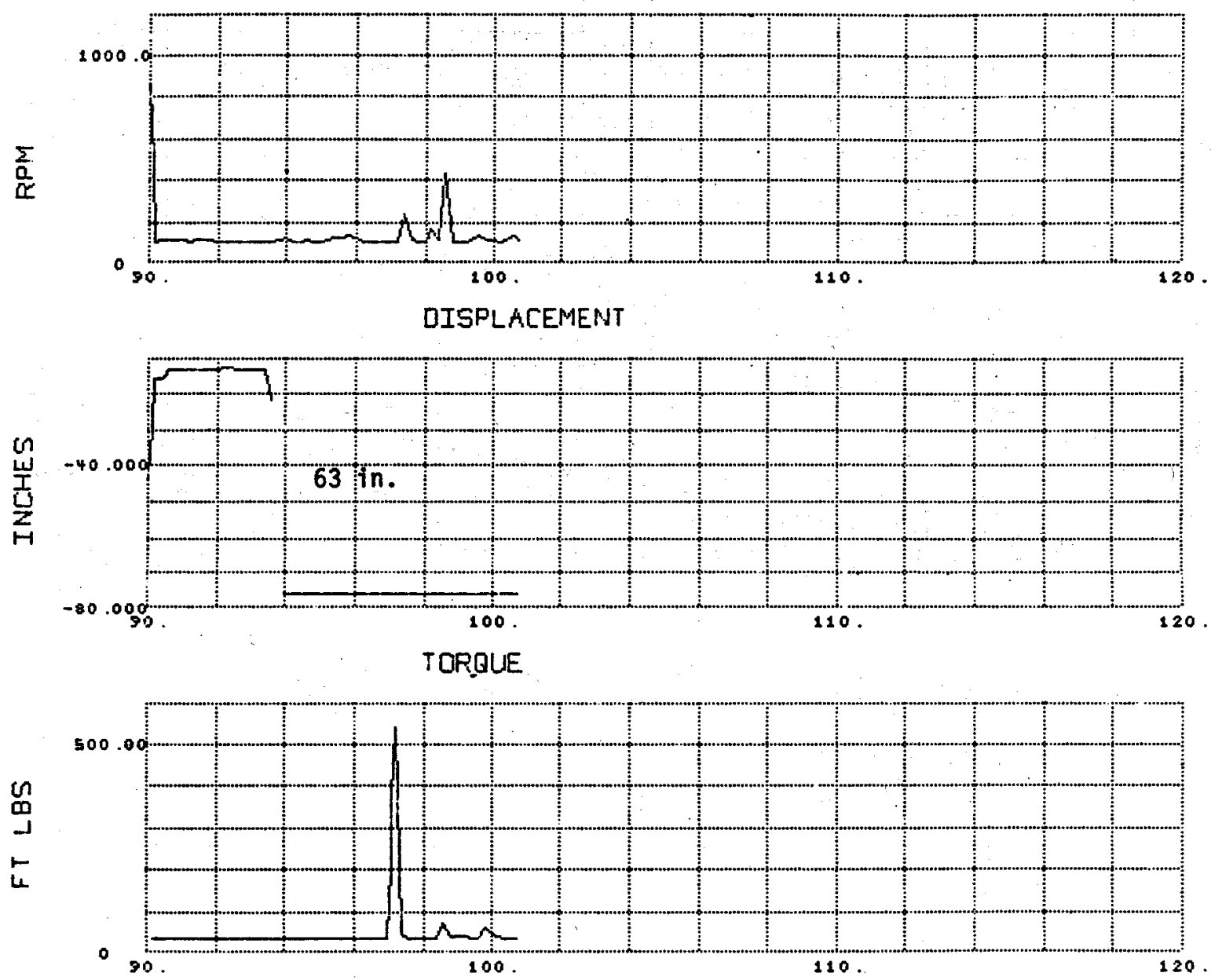

BIT FORCE

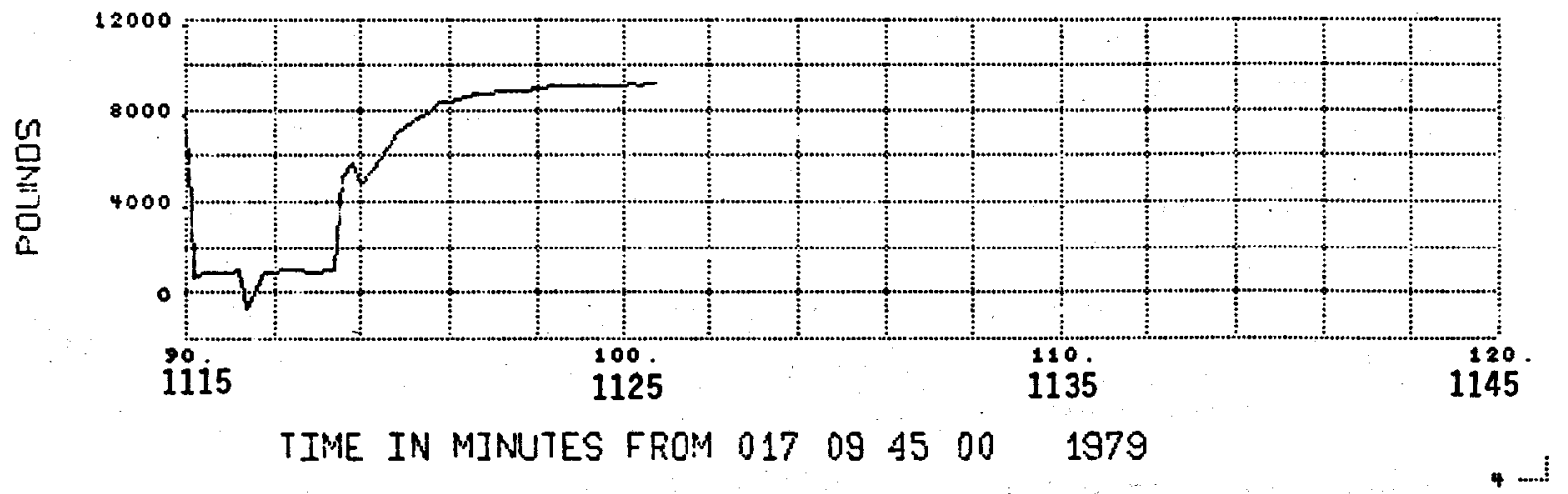

Figure C-11. Inserting Jet Core Bit in Cased Hole 79-4 (NQ -- 2.98 inches diameter -- jet core bit and core barrel) 
MAGMA TAPE 7

DRILL SPEED
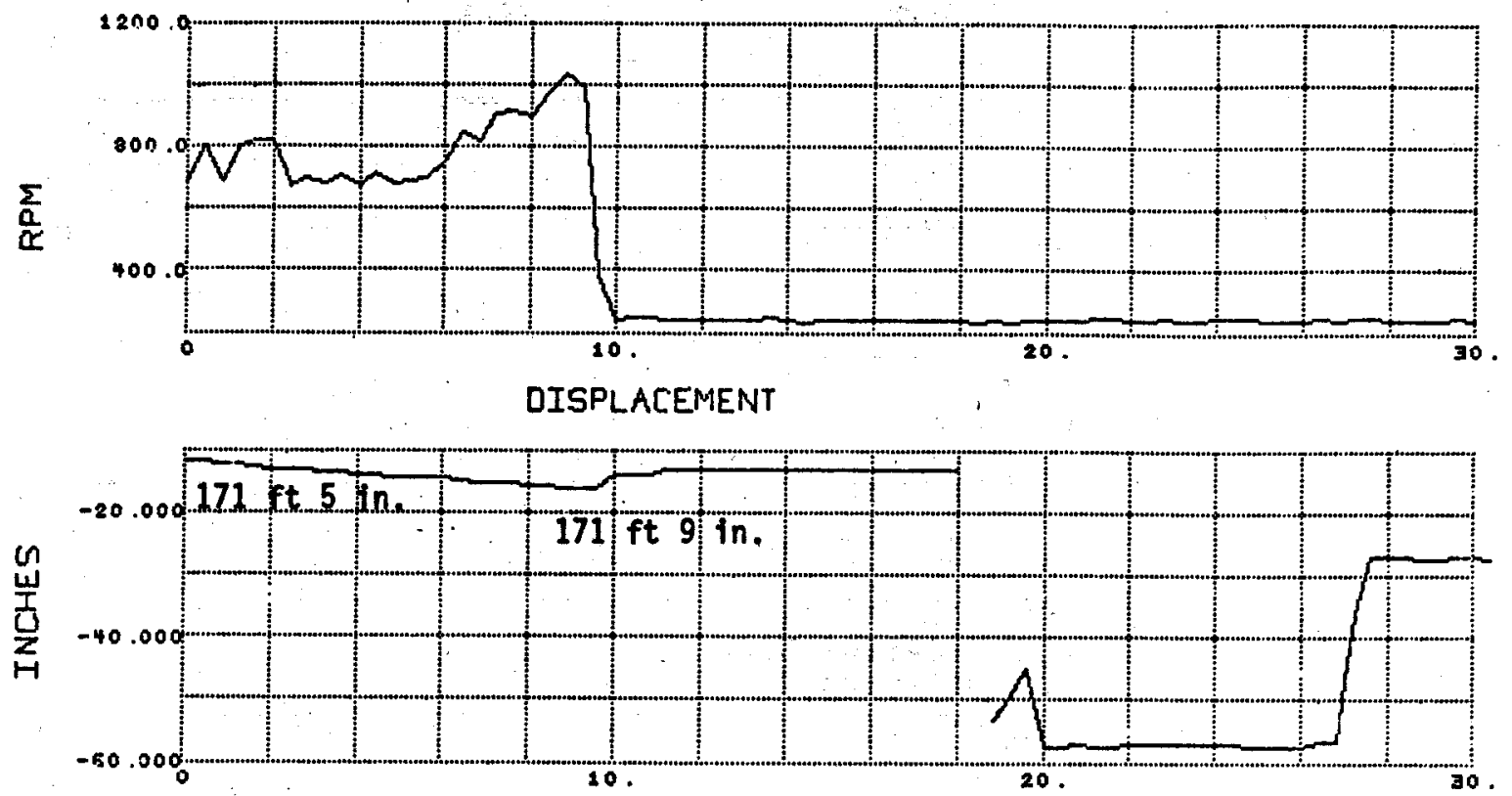

TORQUE

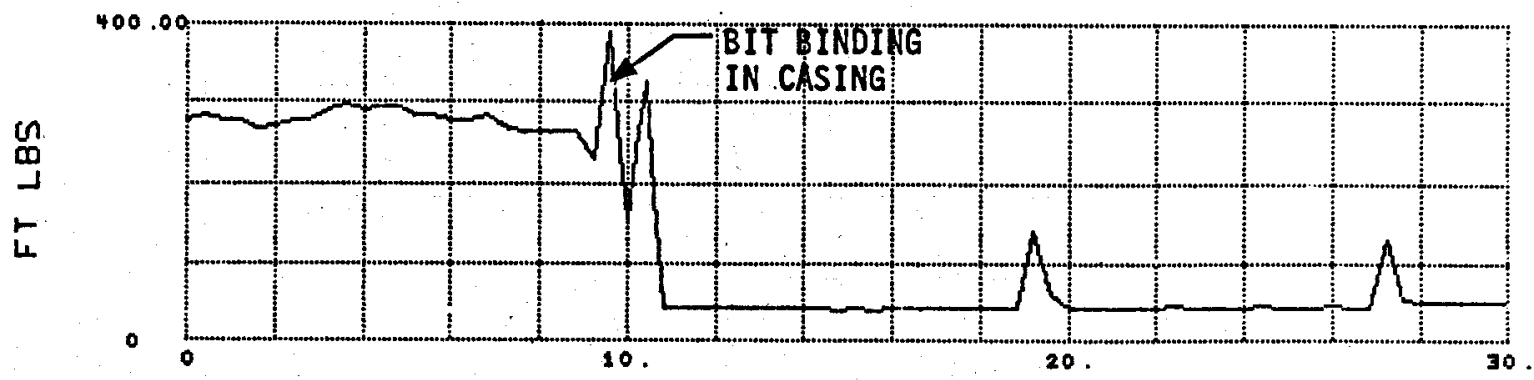

BIT FORCE

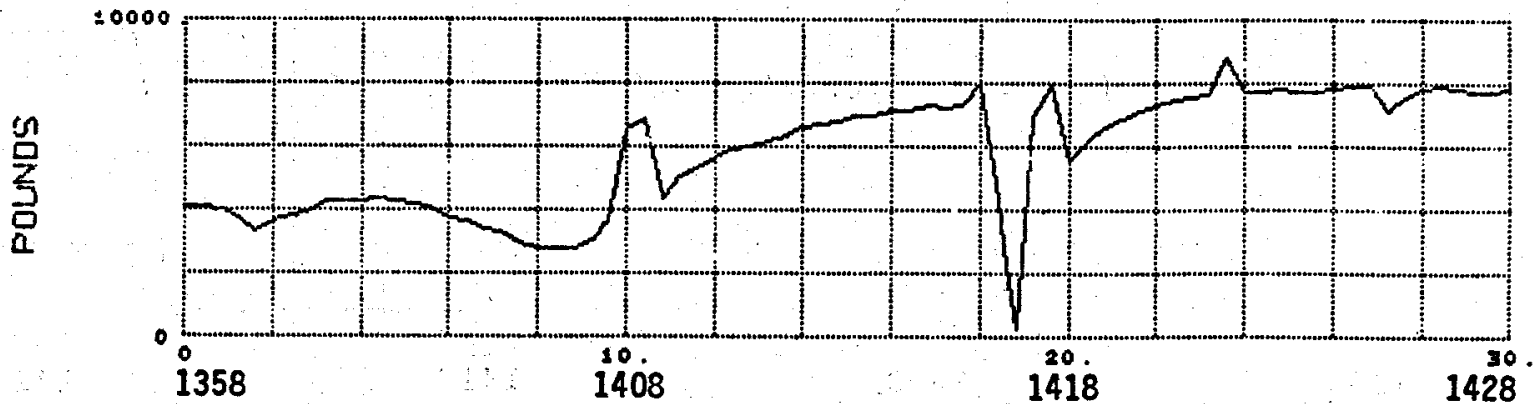

TIME IN MINUTES FROM $018 \quad 1358 \quad 00 \quad 1976$

Figure C-12. Drilling Flow-Back Chimney with Jet Core System (NQ - 2.98 inches diameter -- jet core bit and core barrel) 
MAGMA TAPE 7

WATER FLOW METER 1

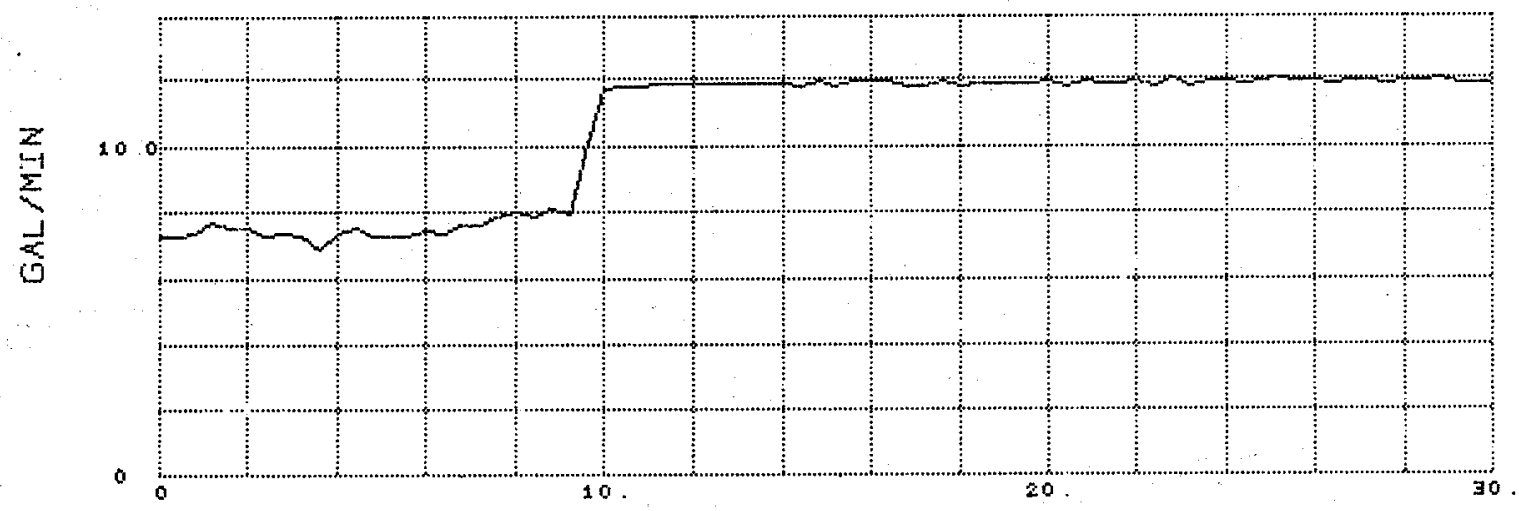

CASING MIR PRESSURE NO, 1
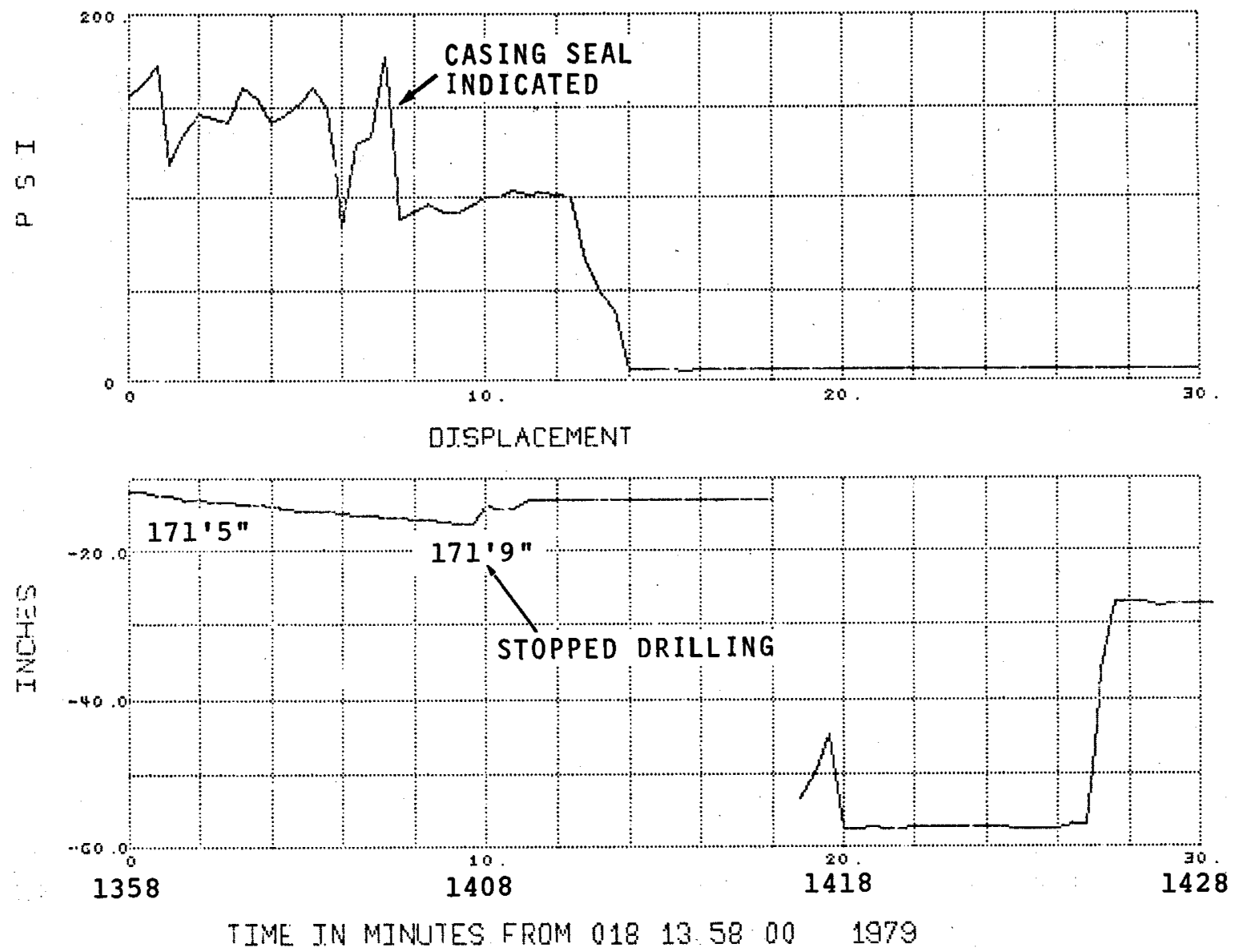

Figure C-12a. Casing Air Pressure and Water Flow Rate -Jet Core Drilling in 79-4 
MAGMA TAPE 7

DRILL SPEED
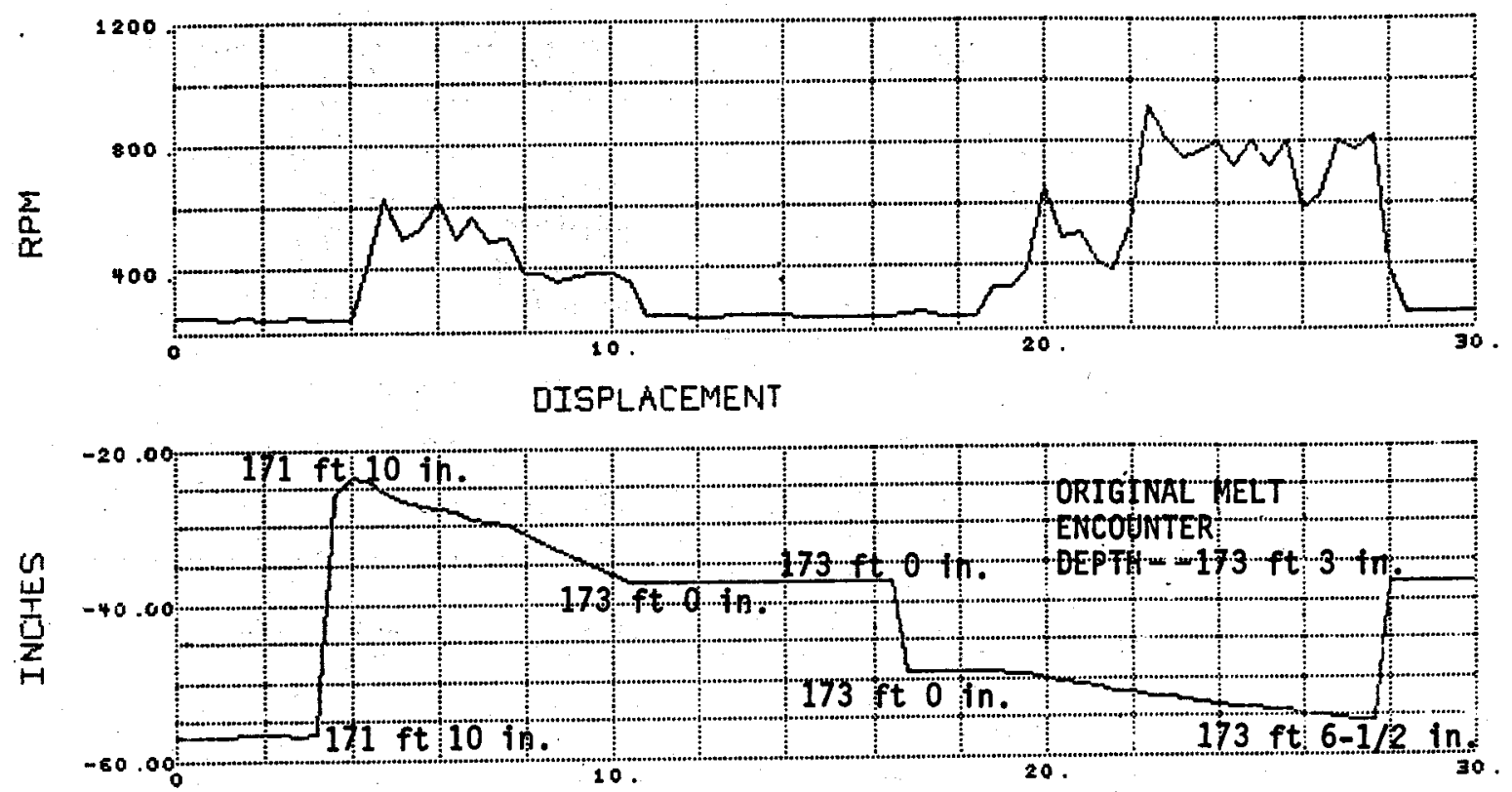

TORQUE
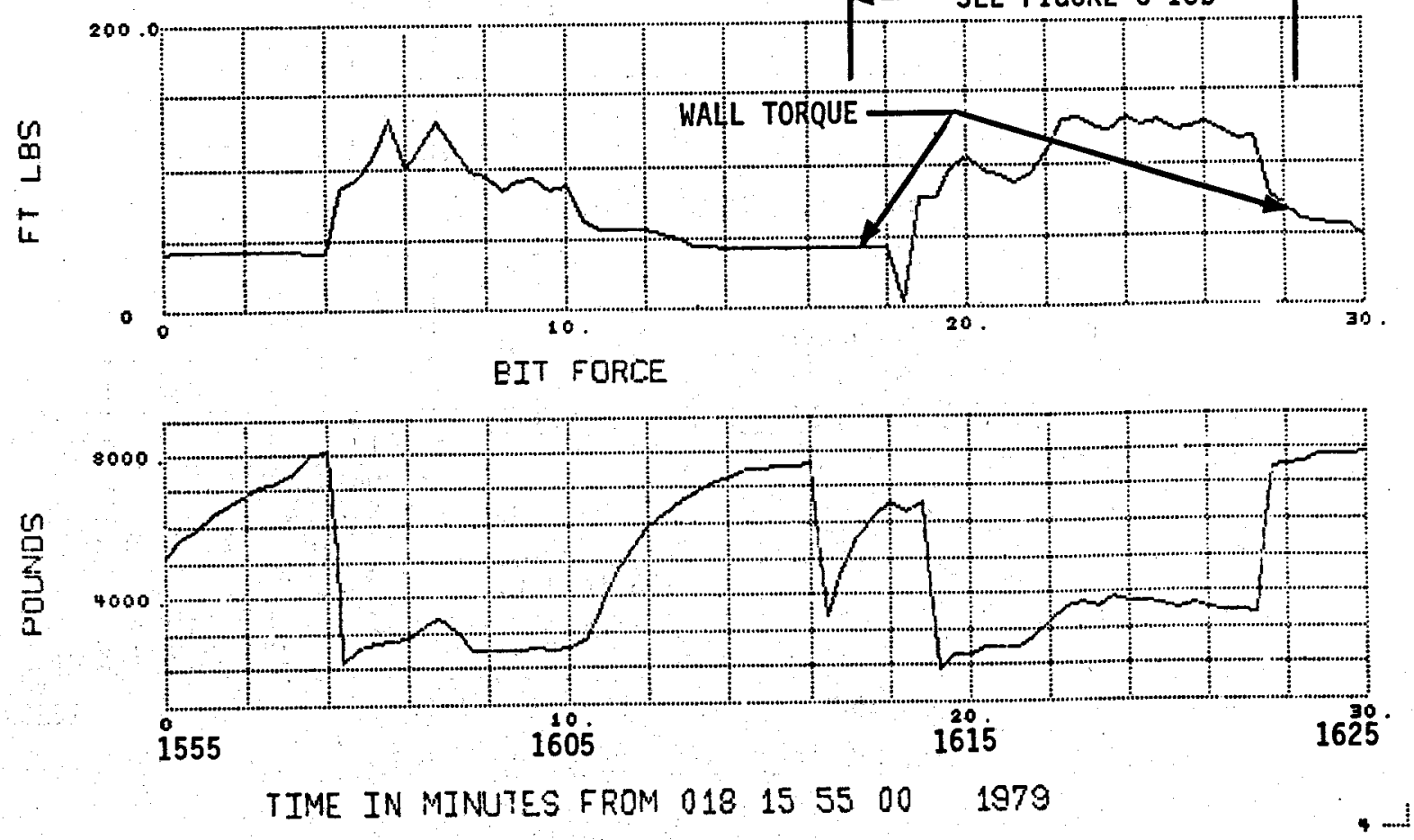

Figure C-13. Drilling with Jet Drag Bit in Hole 79-4 through Casing Seal (three-wing jet drag bit) 
MAGMA TAPE 7

WATER FLOW METER 1
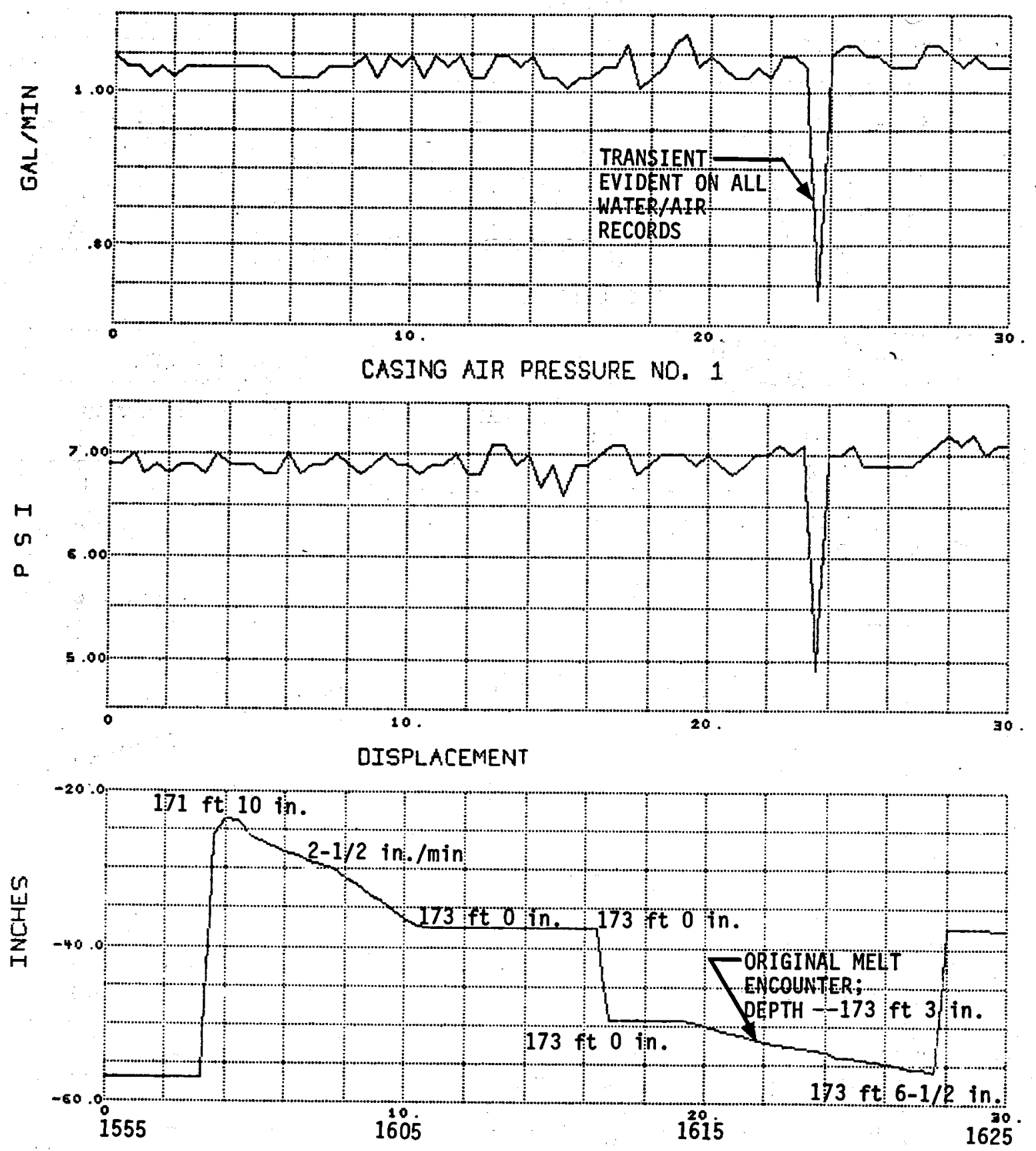

TIME IN MINUTES FROM $018 \quad 1555$ '00 $19 \% 9$

Figure C-13a. Casing Air Pressure and Water Flow Rate -Jet Drag Bit Drilling in Hole 79-4 
DRILL SPEED
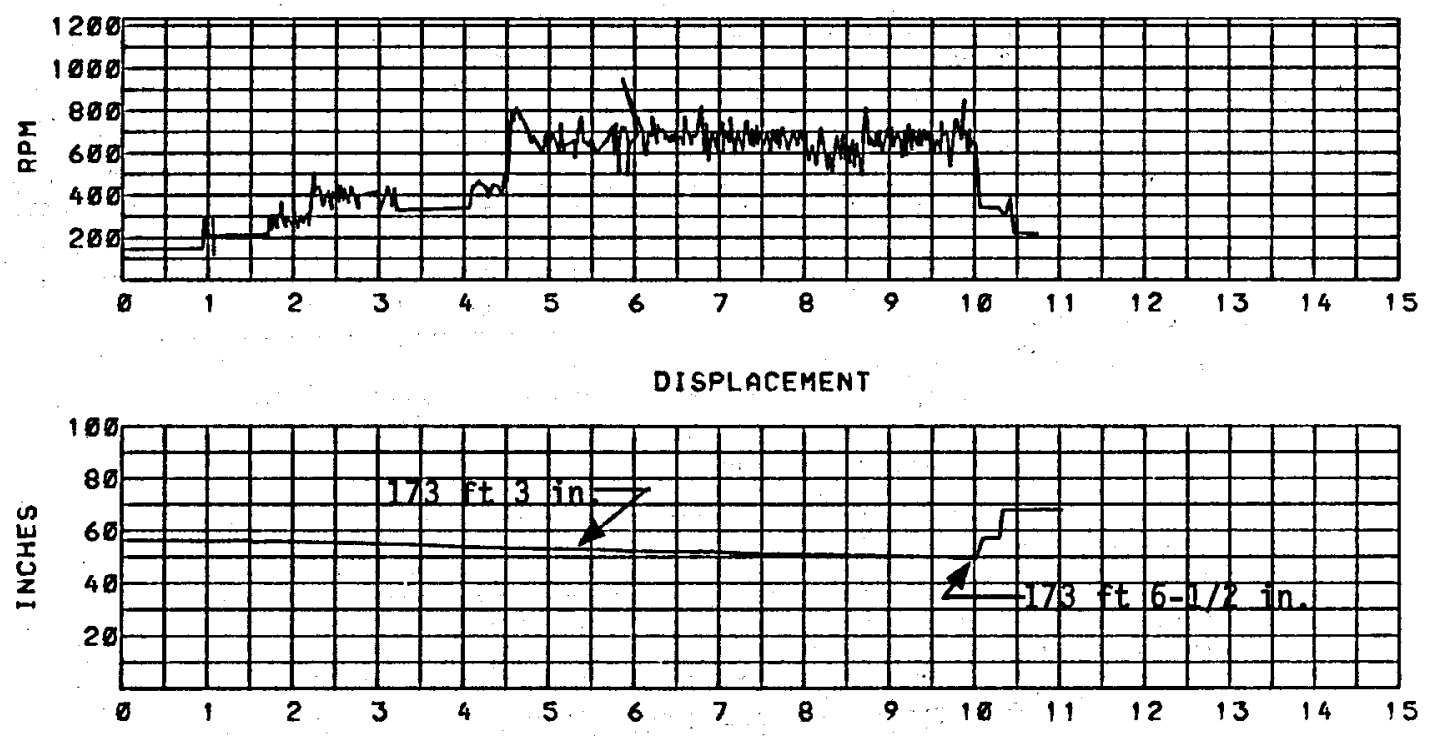

TORQUE
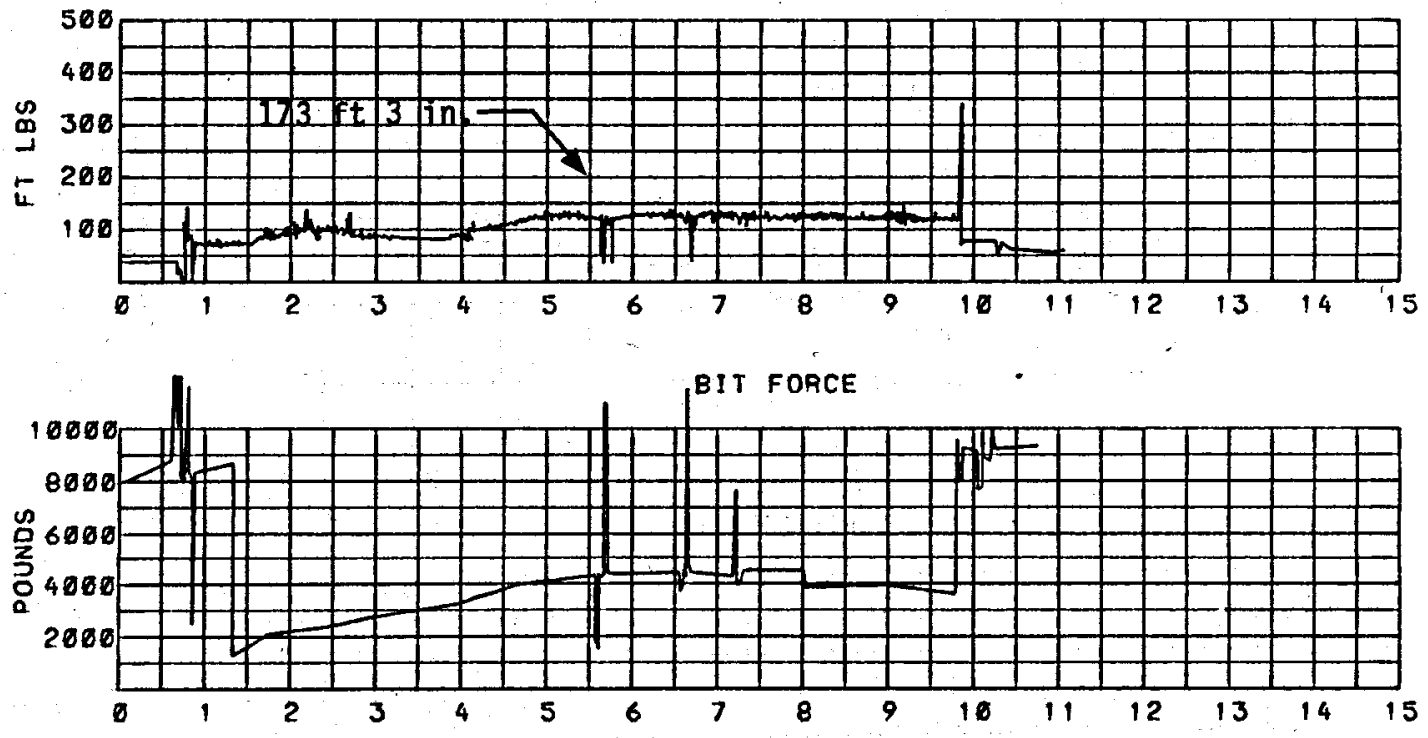

TIME IN MINUTES FROM $18 \quad 16 \quad 12 \quad 00 \quad 1979$

Figure C-13b. Drilling with Jet Drag Bit in Hole 79-4 Showing High-Frequency Drill Pressure and RPM Components 
MAGMA TAPE 7

DRILL SPEED
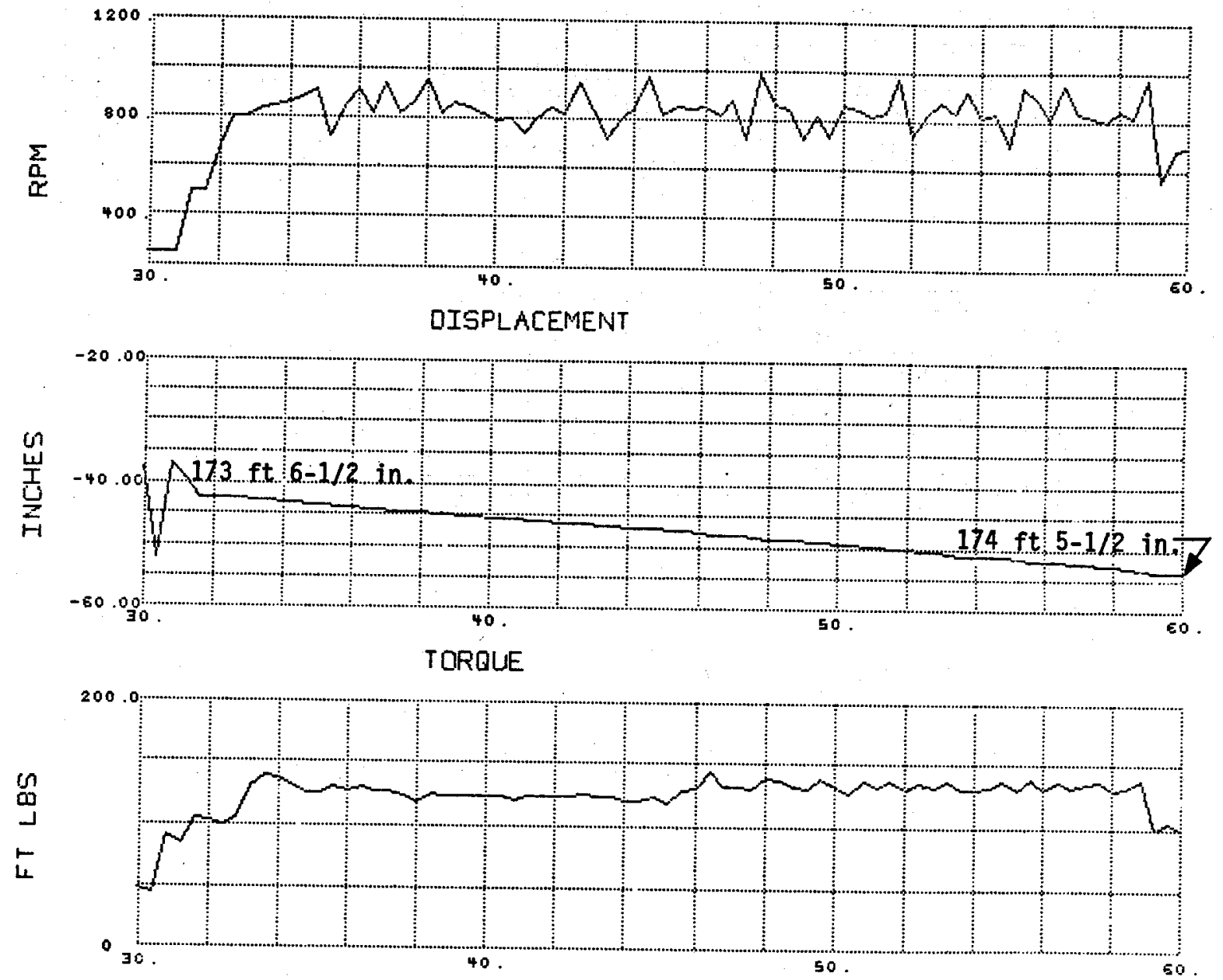

BIT FORICE

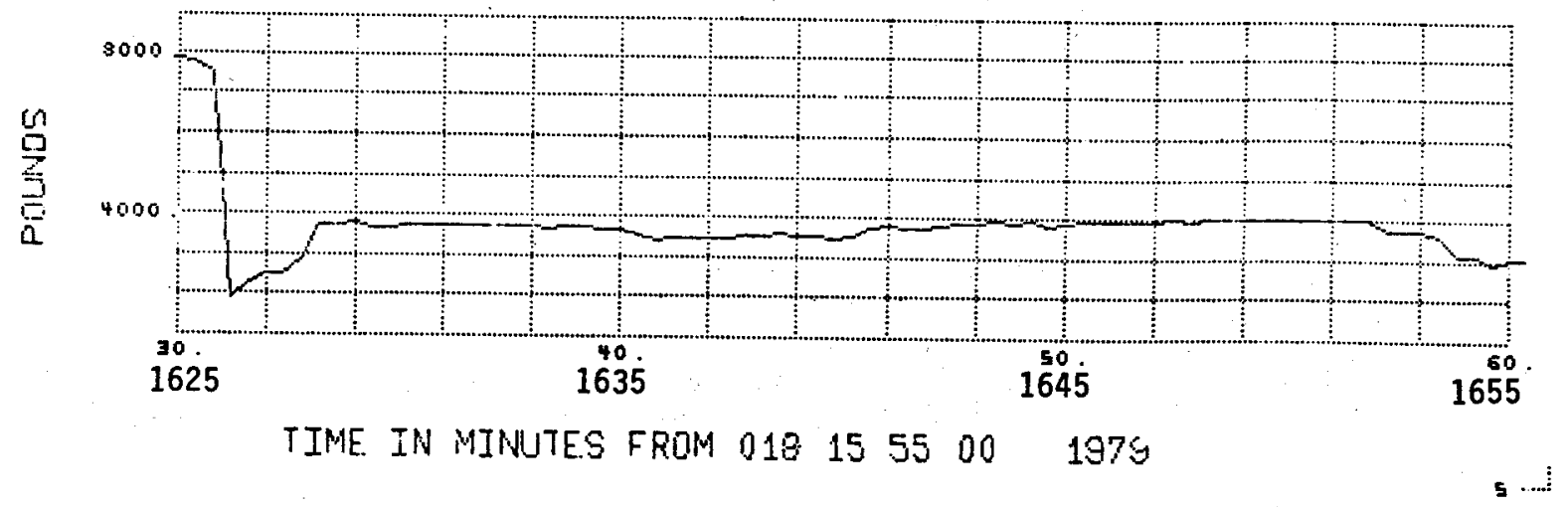

Figure C-14. Drilling with Jet Drag Bit in Hole 79-4 below Casing (three-wing jet drag bit) 
MAGMA TAPE 7

WATER FLOY METER 1
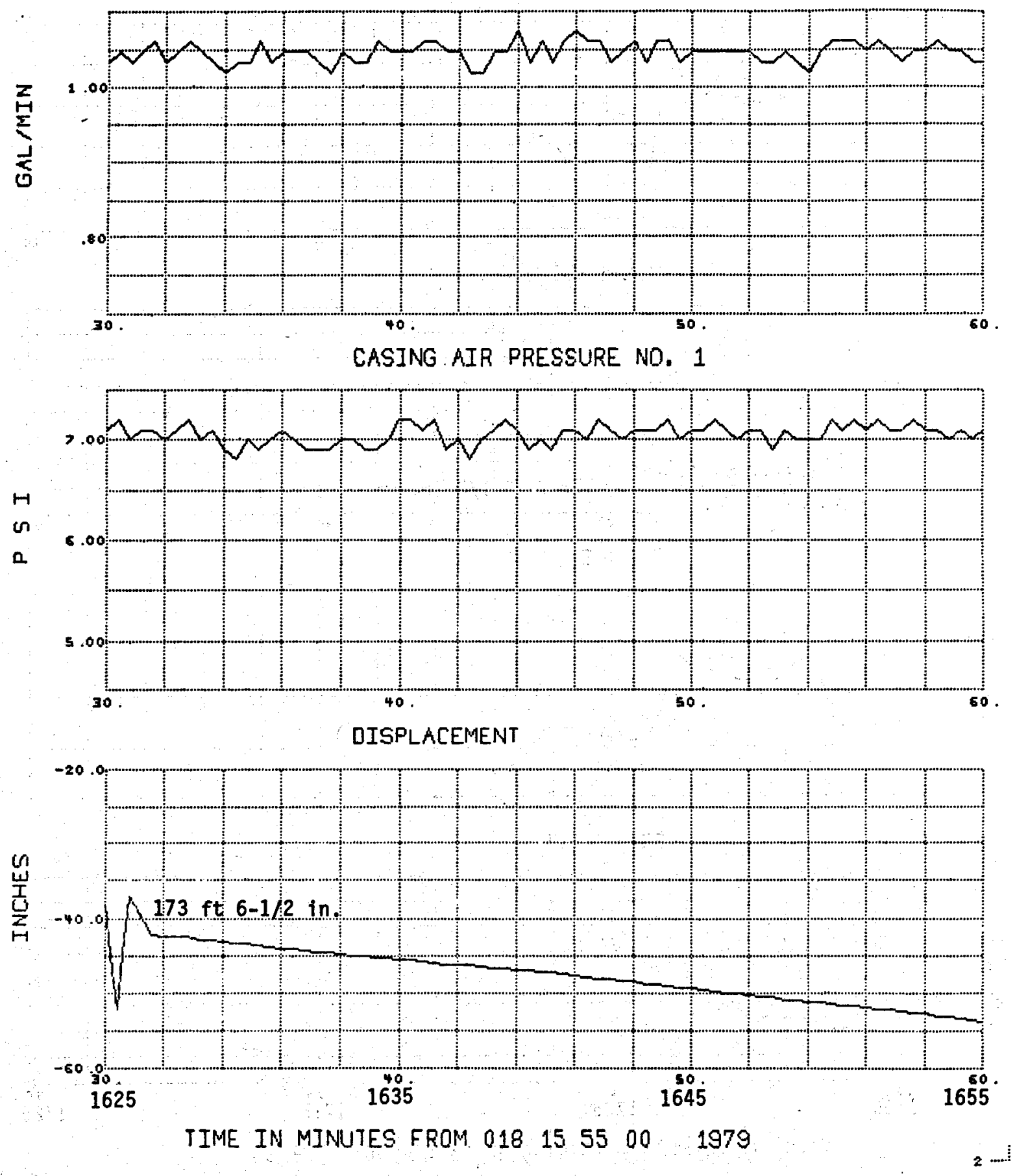

Figure C-14a. Casing Air Pressure and water Flow Rate.Jet Drag Bit Drilling in Hole 79-4 
MAGMA TAPE 7

DRILL SPEED
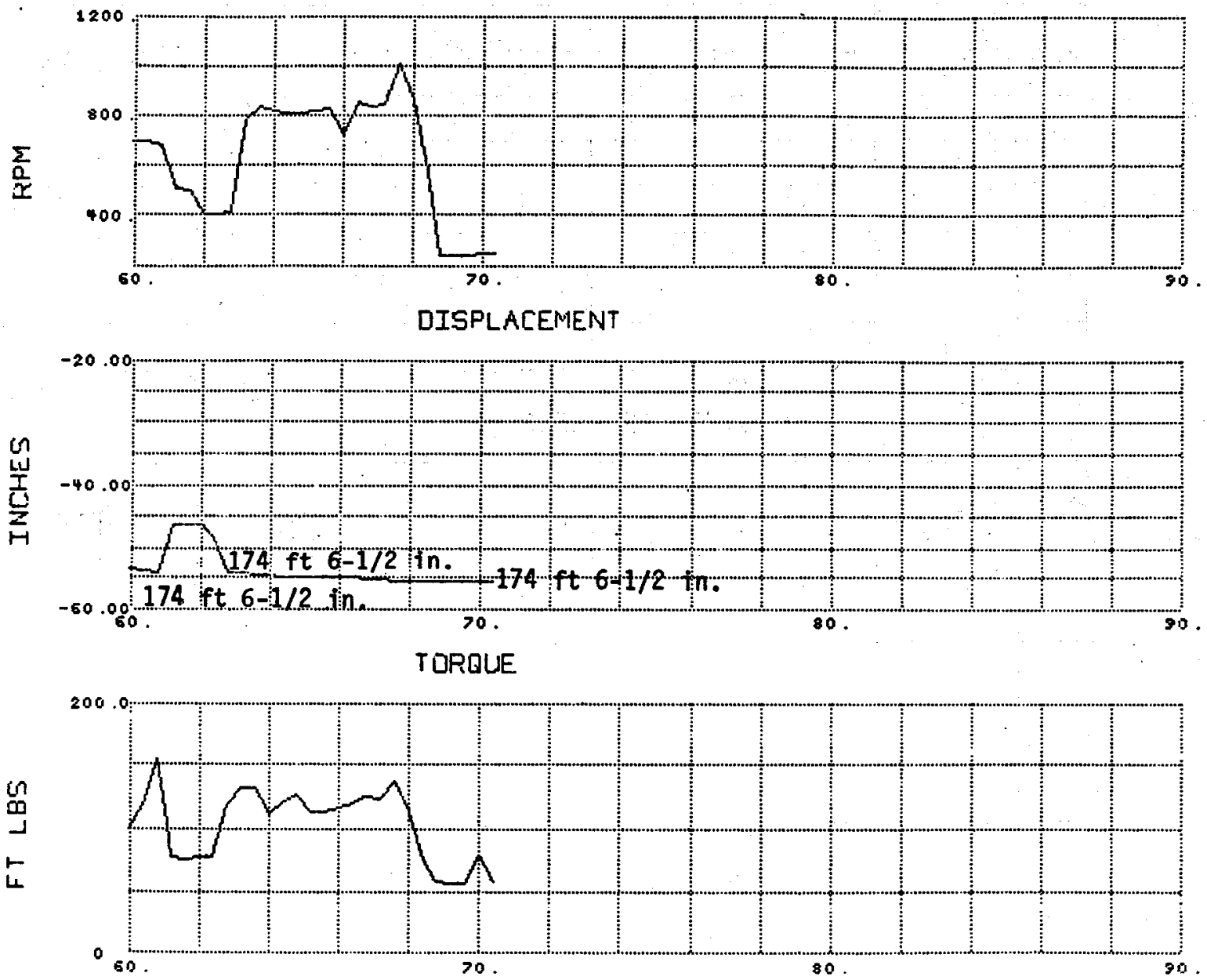

BIT FDRCE

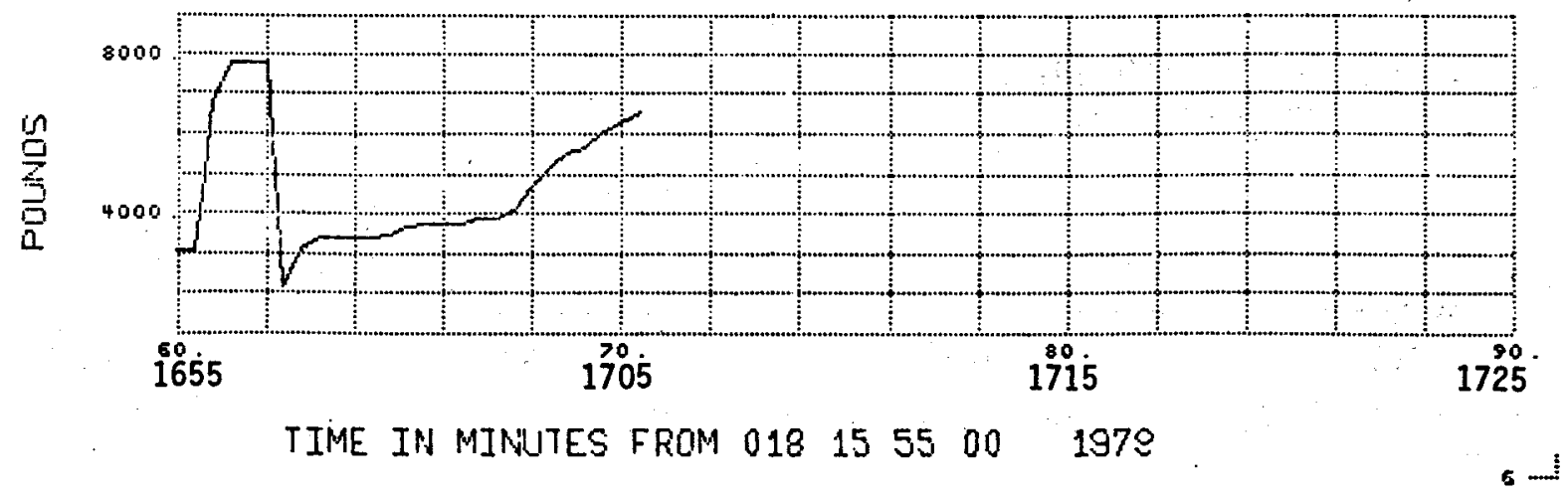

Figure C-15. Drilling with Jet Drag Bit in Hole 79-4 below Casing (three-wing jet drag bit) 
MAGMA TAPE 7

WATER FLOW METER 1
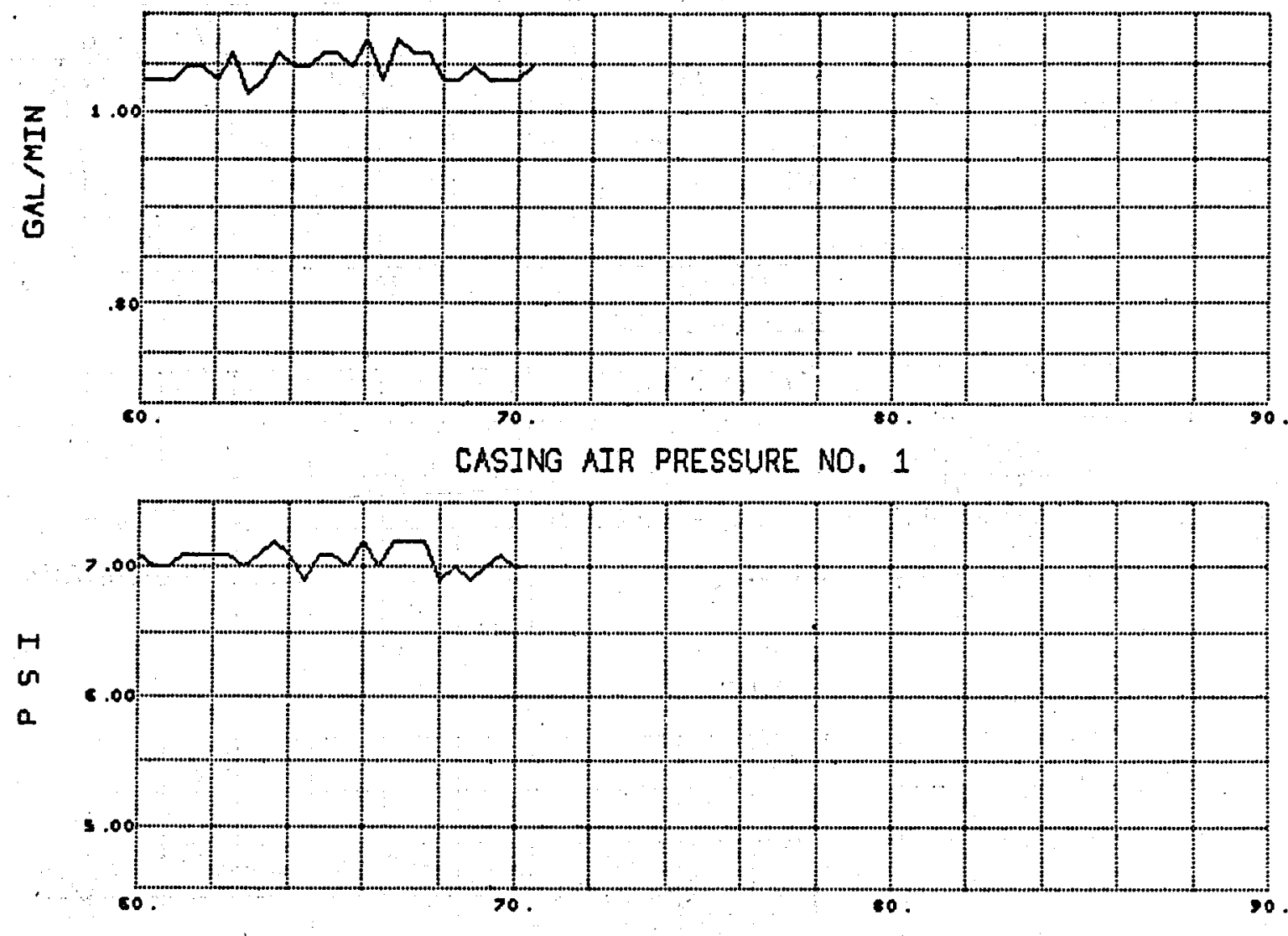

DISPLACEMENT

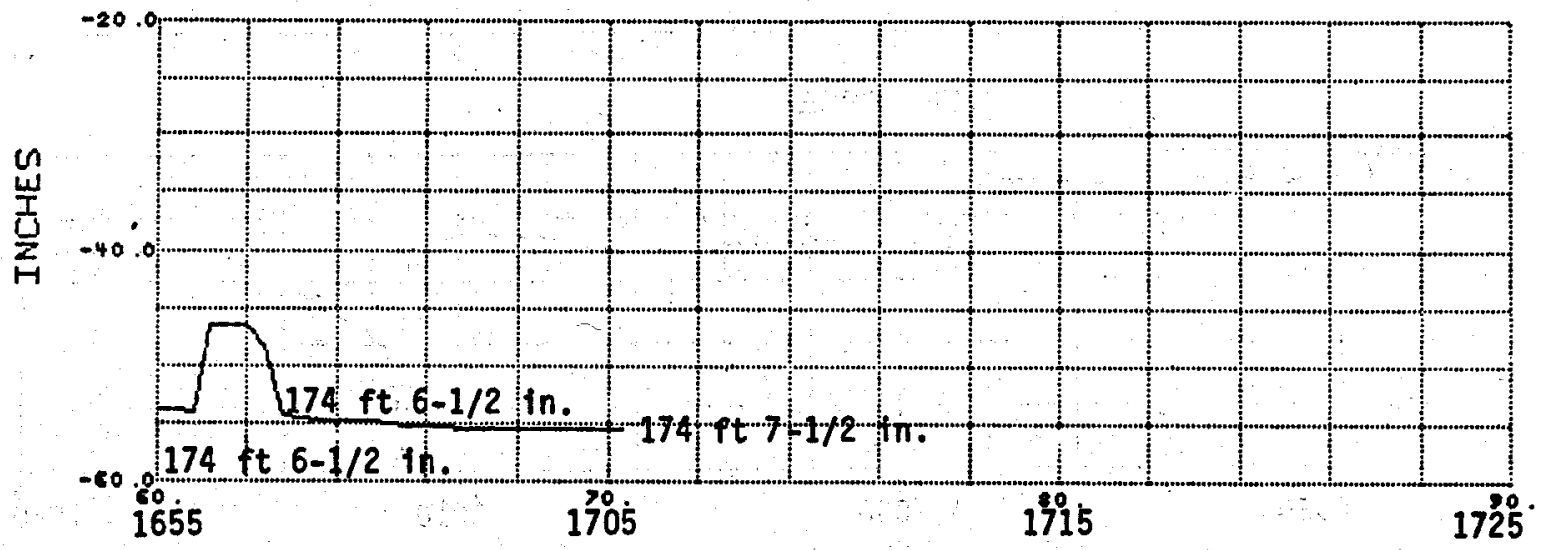

TIME IN MINUTES FROM 018 15 55 00 1979

Figure C-15a. Casing Air Pressure and Water Flow Rates -Jet Drag Bit Drilling in Hole 79-4 
MAGMA TAPE 7

DRILL SPEED
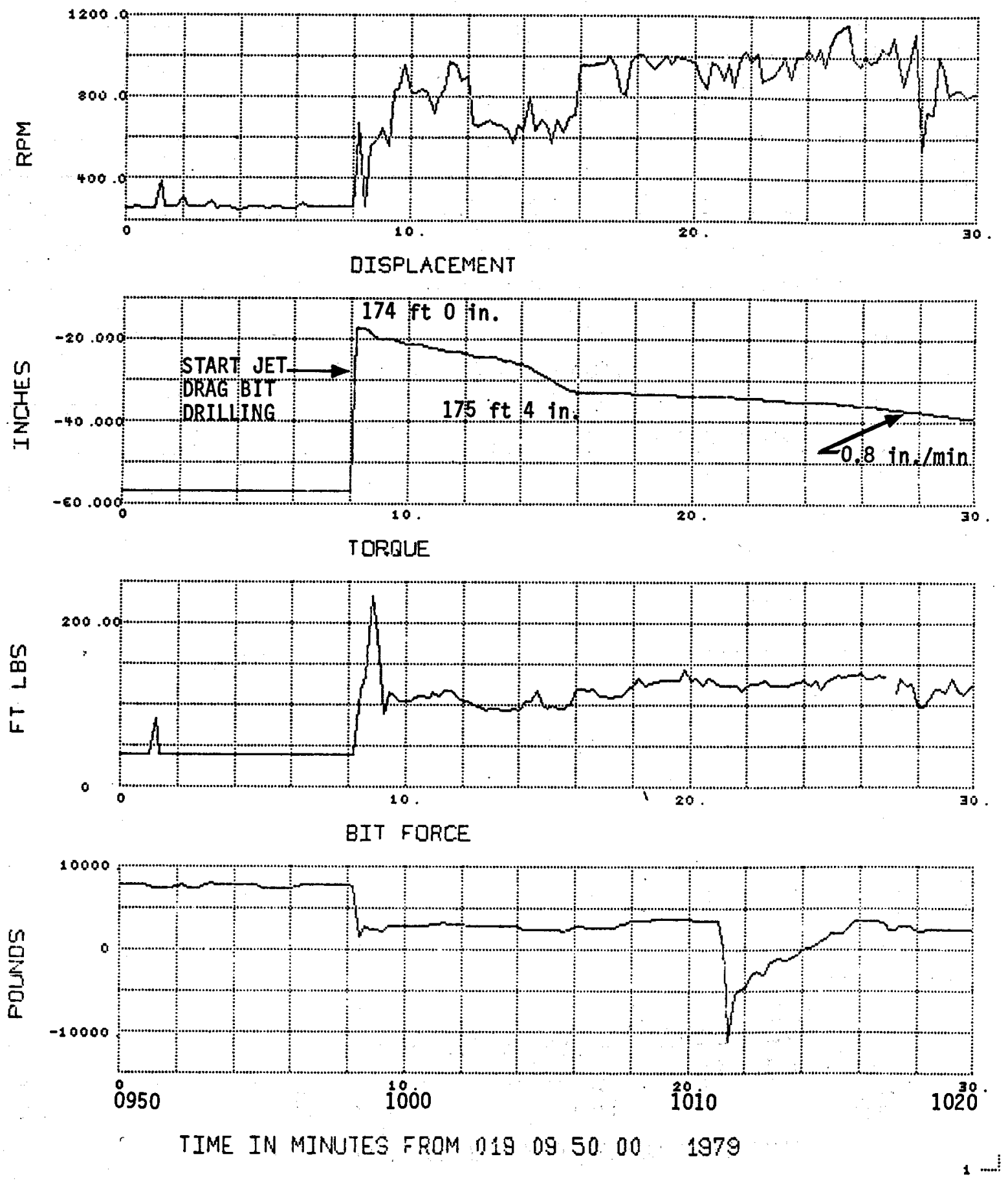

Figure C-16. Jet Drag Bit Drilling in Hole 79-4 
DRILL SPEED

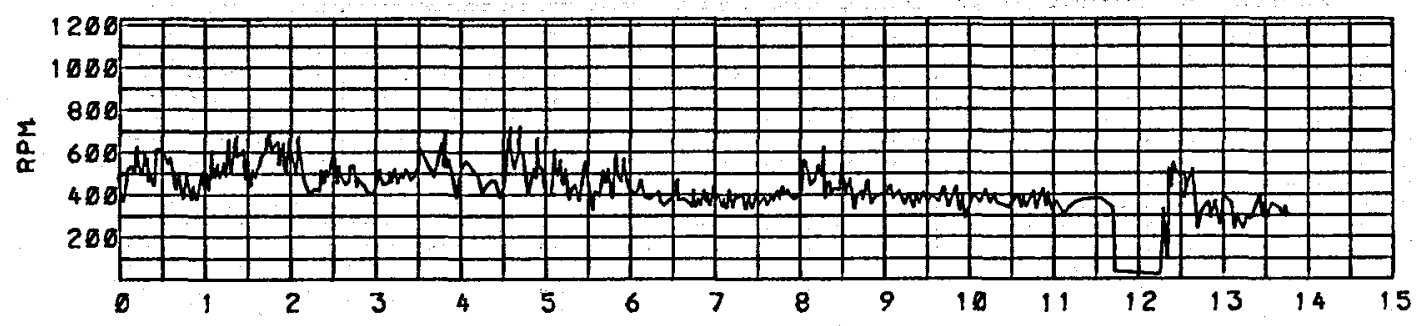

DISPLACEMENT

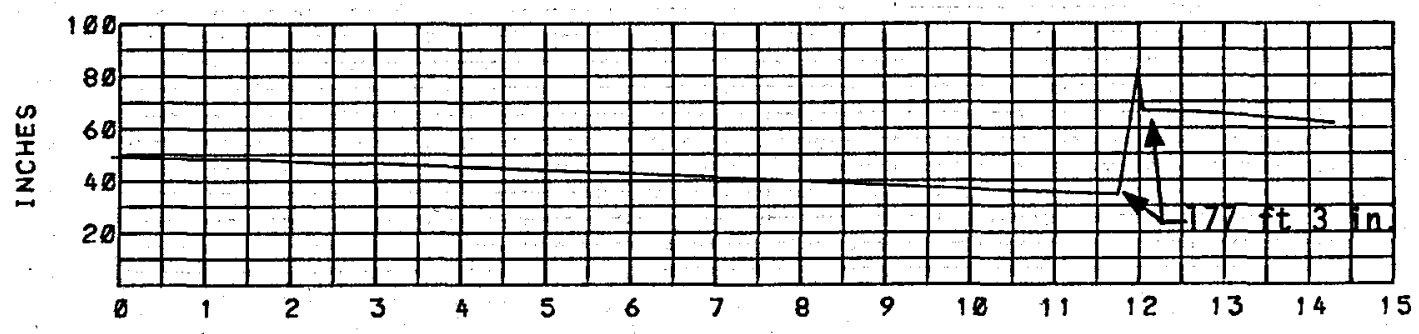

TORQUE

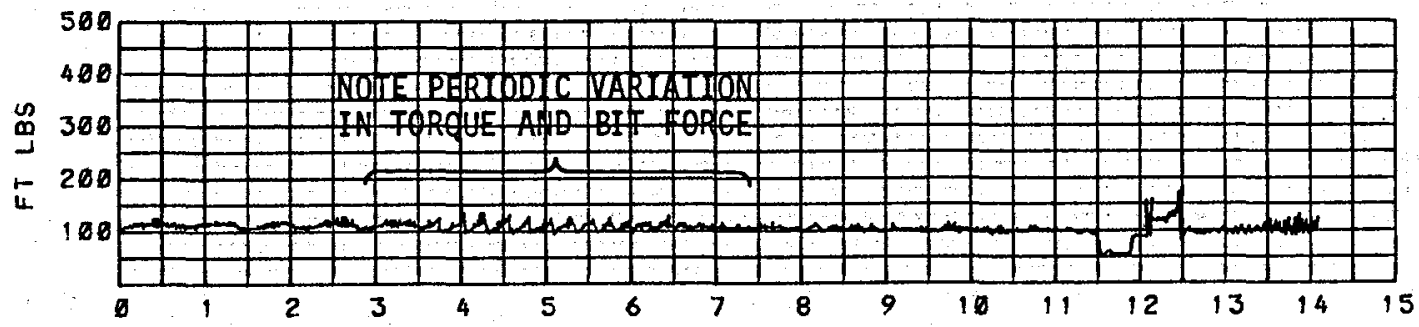

BIT FORCE

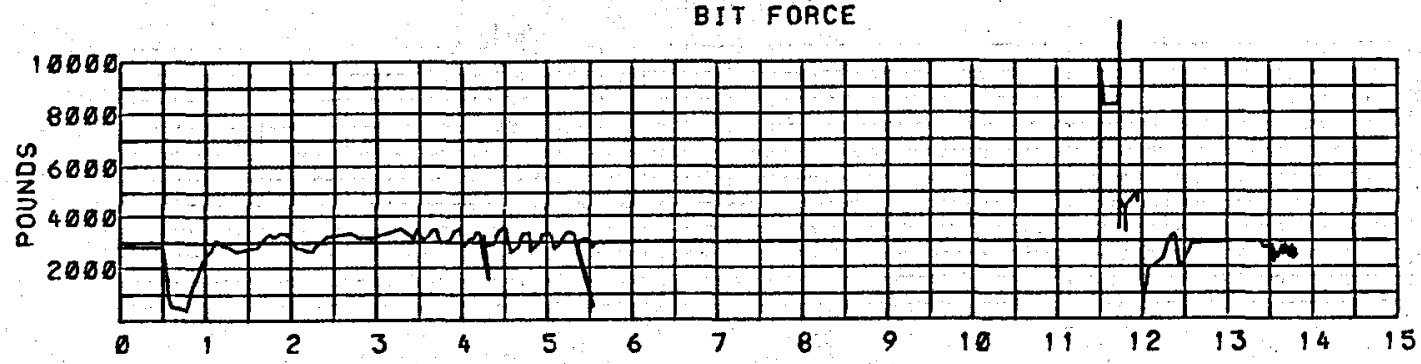

TIME IN MINUTES FROM $1910 \quad 23001979$

Figure C-17. Drilling with Jet Drag Bit in Hole 79-4

(reproduced strip chart record) 
DRILL SPEED

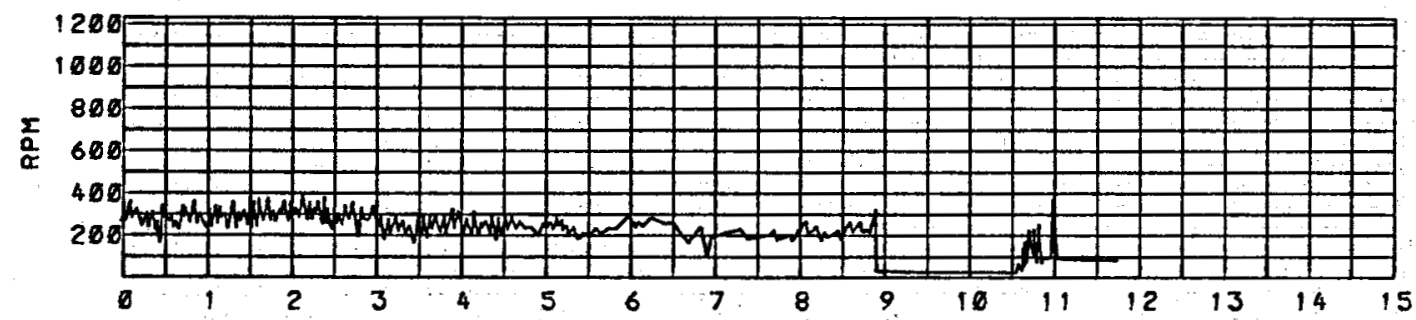

DISPLACEMENT
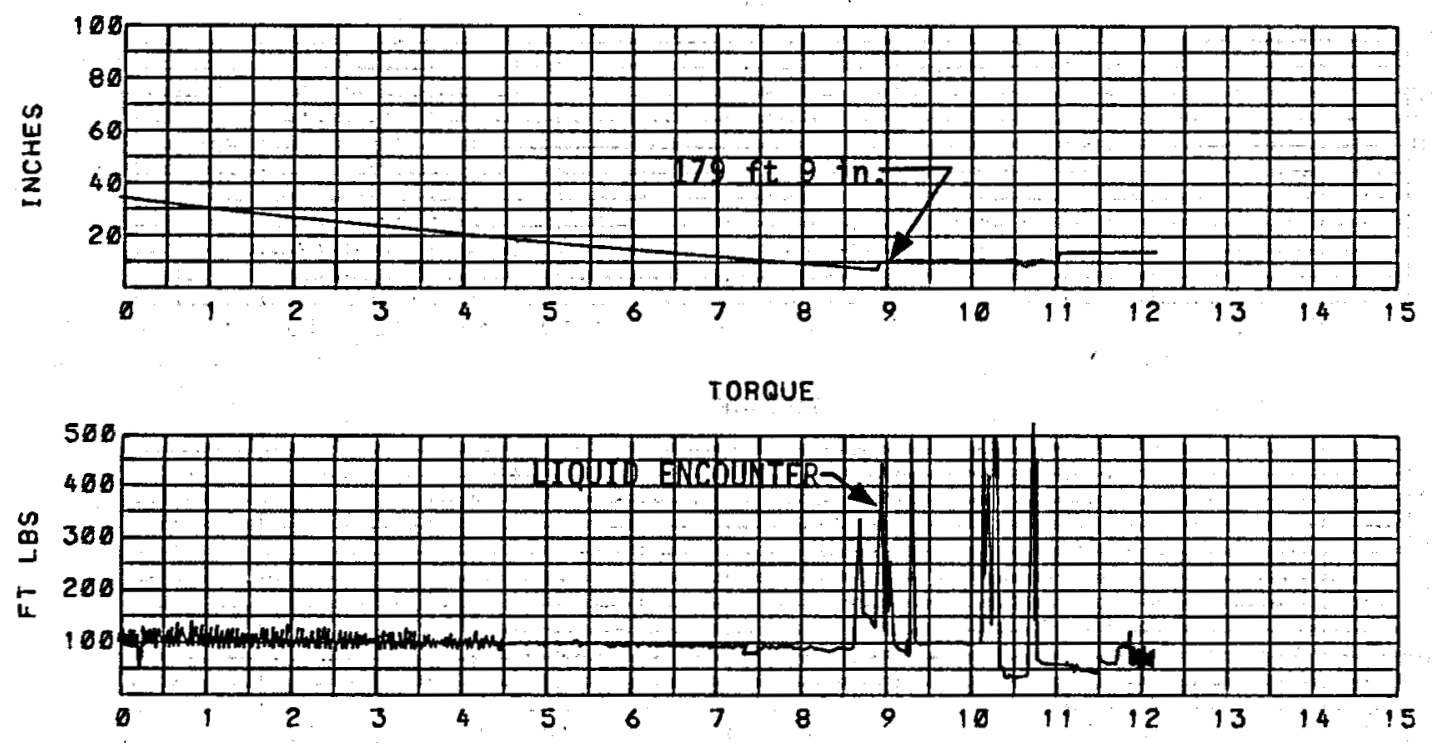

BIT FORCE

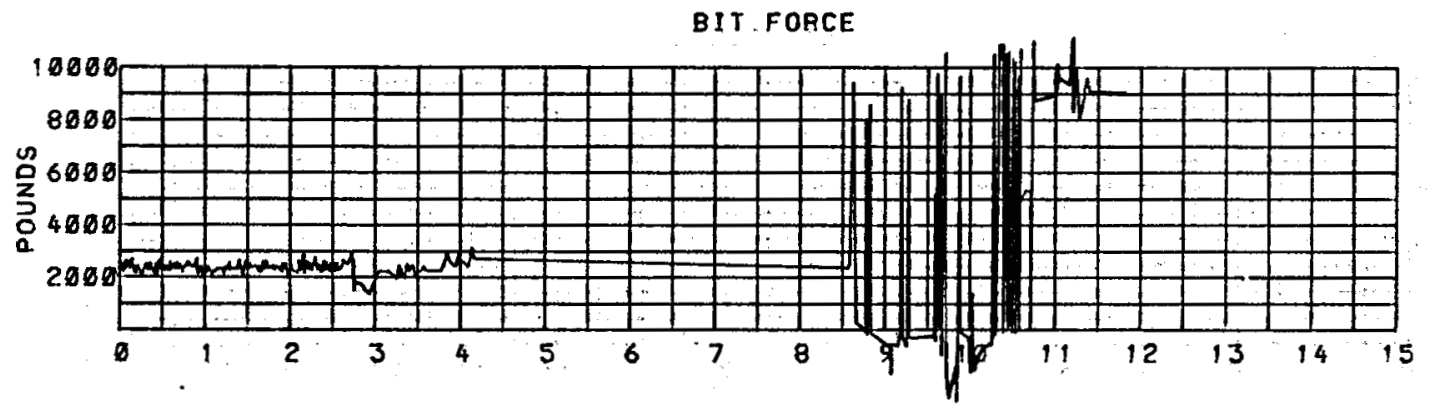

TIME IN MINUTES FROM 19, $10,37 \quad 00 \quad 1979$

Figure C-18. Drilling with Jet Drag Bit in Hole 79-4 to Liquid Encounter at $179 \mathrm{ft} 9$ inches (reproduced strip chart record) 
DRILL SPEED
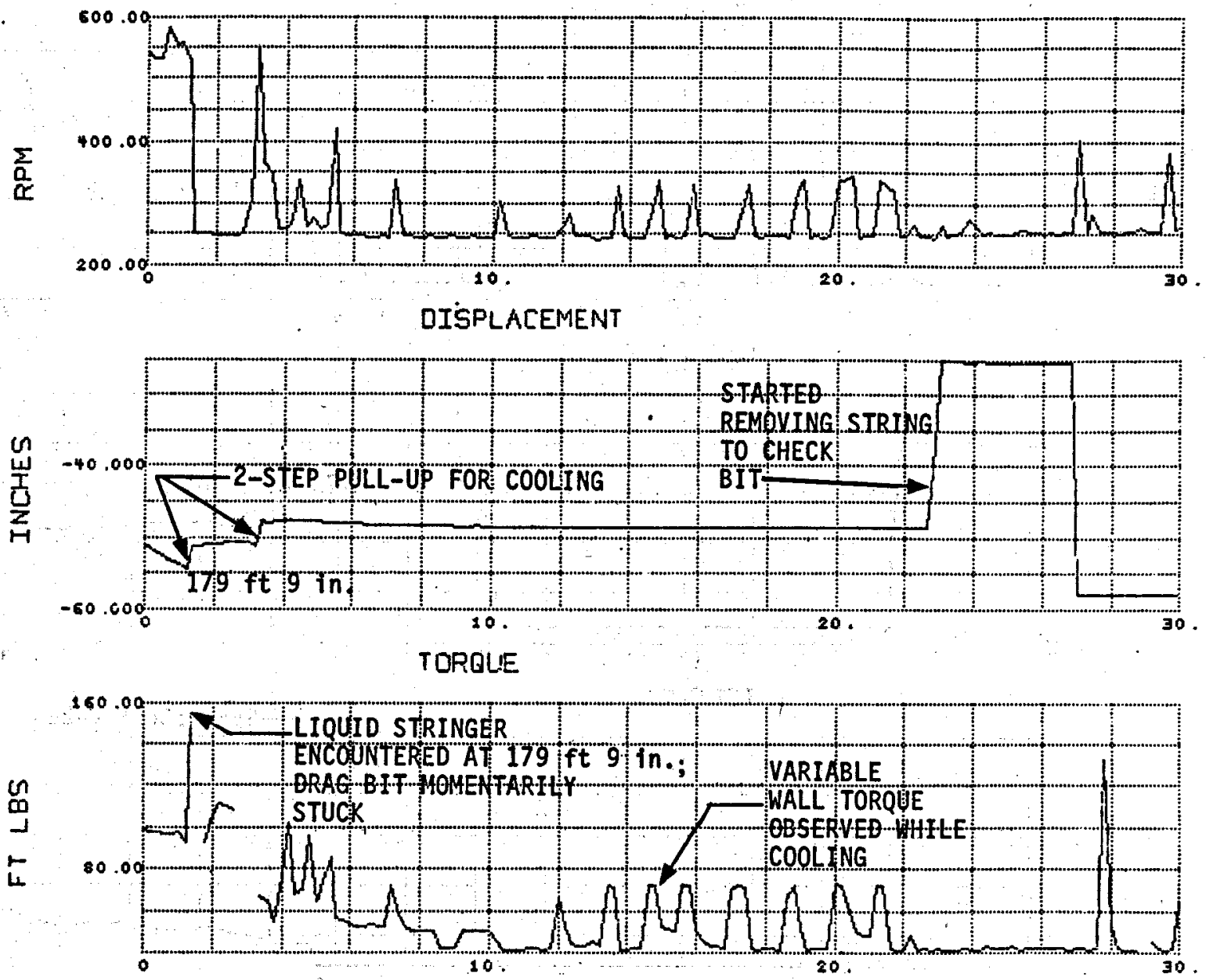

BIT FORCE

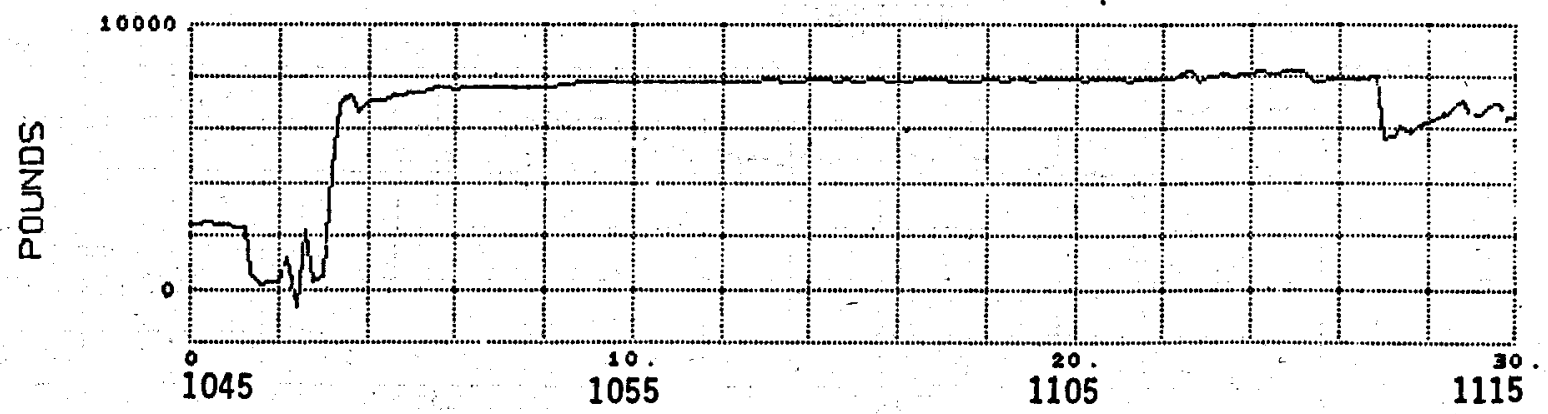

TIME IN MINUTES FROM $019 \quad 1045 \quad 00 \quad 1979$

1.

Figure C-19. Jet Drag Bit Drilling Stopped by Liquid Stinger at $179 \mathrm{ft} 9$ inches (three-wing jet drag bit) 
MAGMA TAPE 8

DRILL SPEED
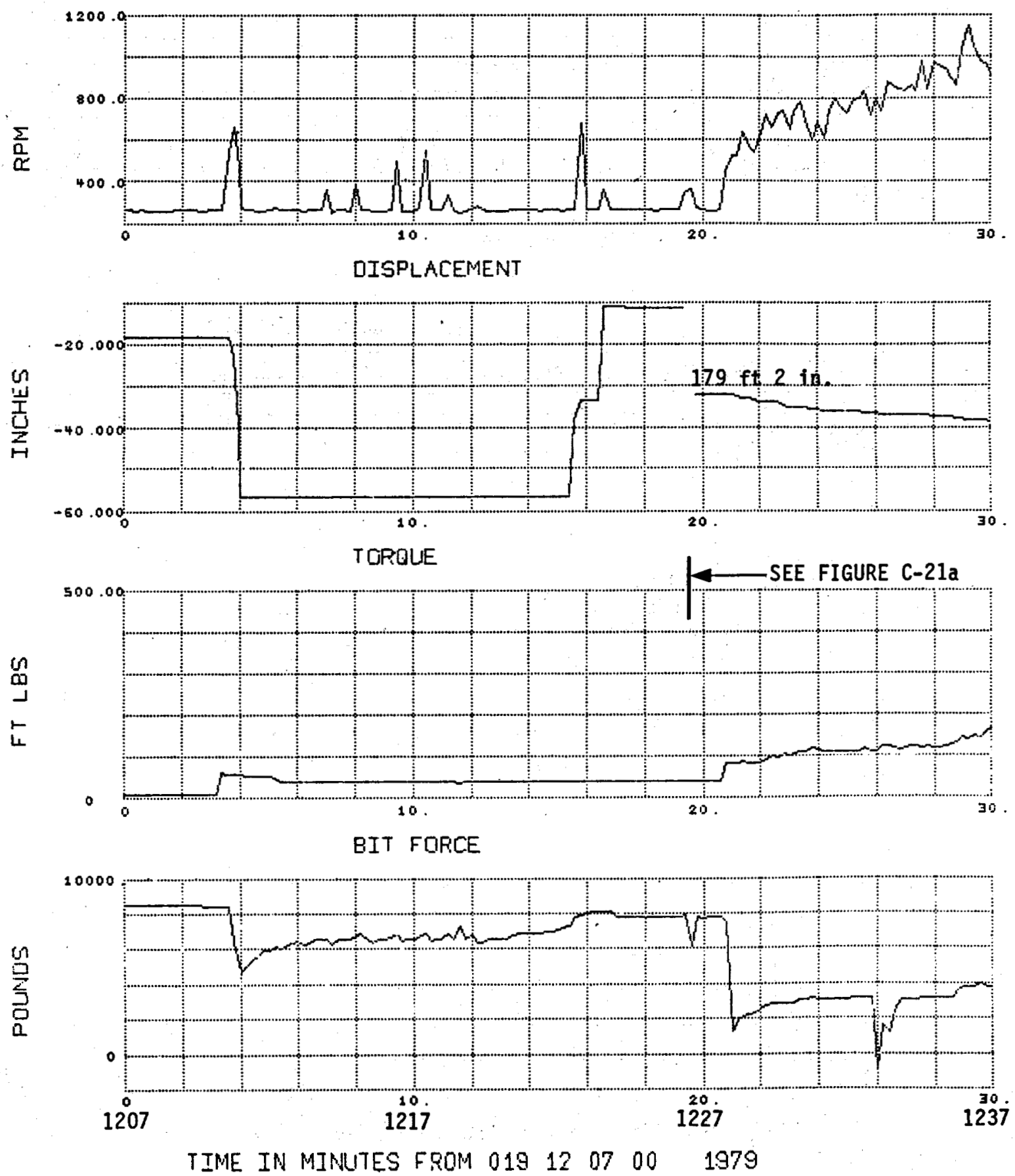

Figure C-20. Jet Drag Bit Drilling -- Second Liquid Encounter at 179 ft 9 inches in Hole 79-4 (three-wing jet drag bit) 
MAGMA TAPE 8

DRILL SPEED
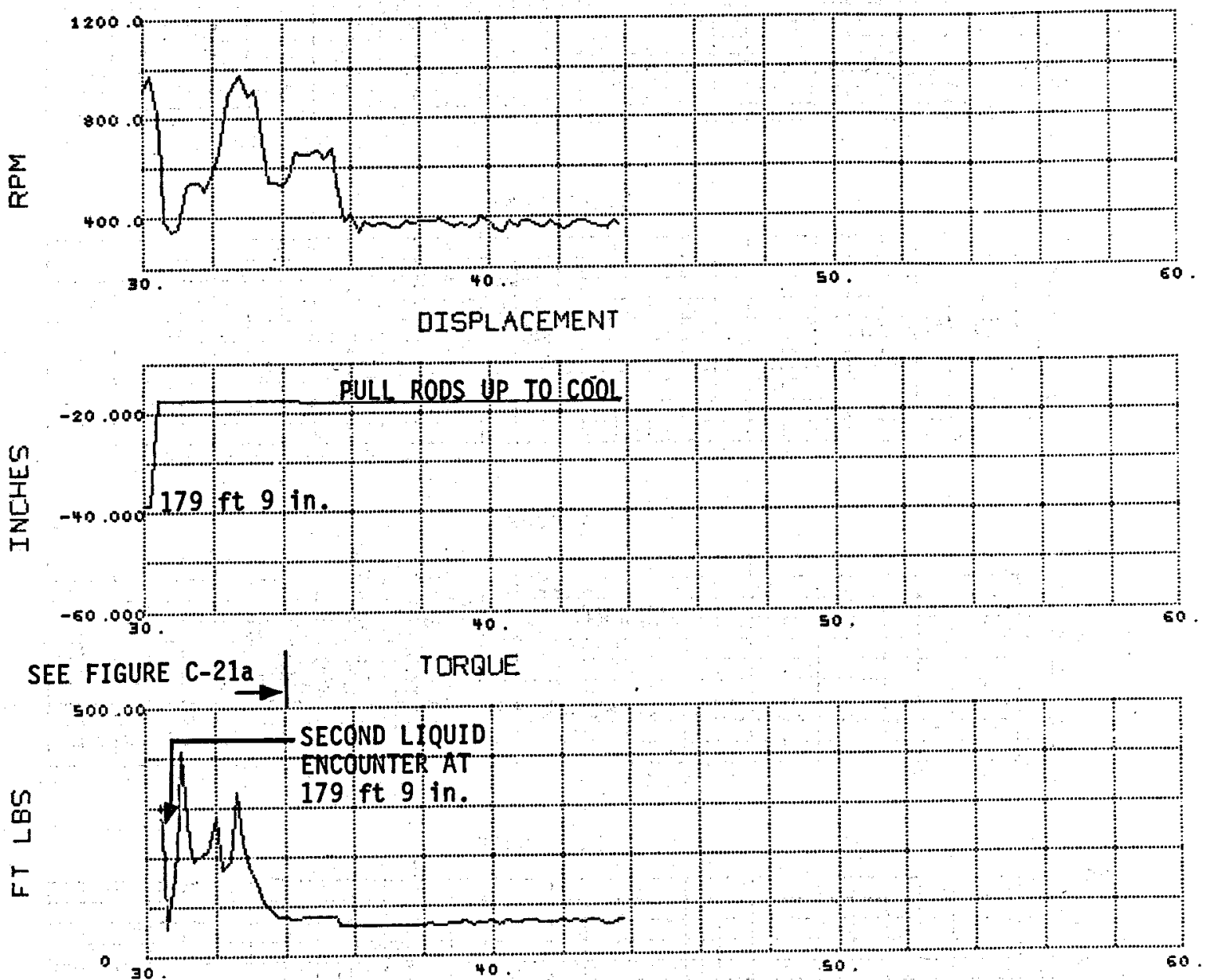

BIT FORCE

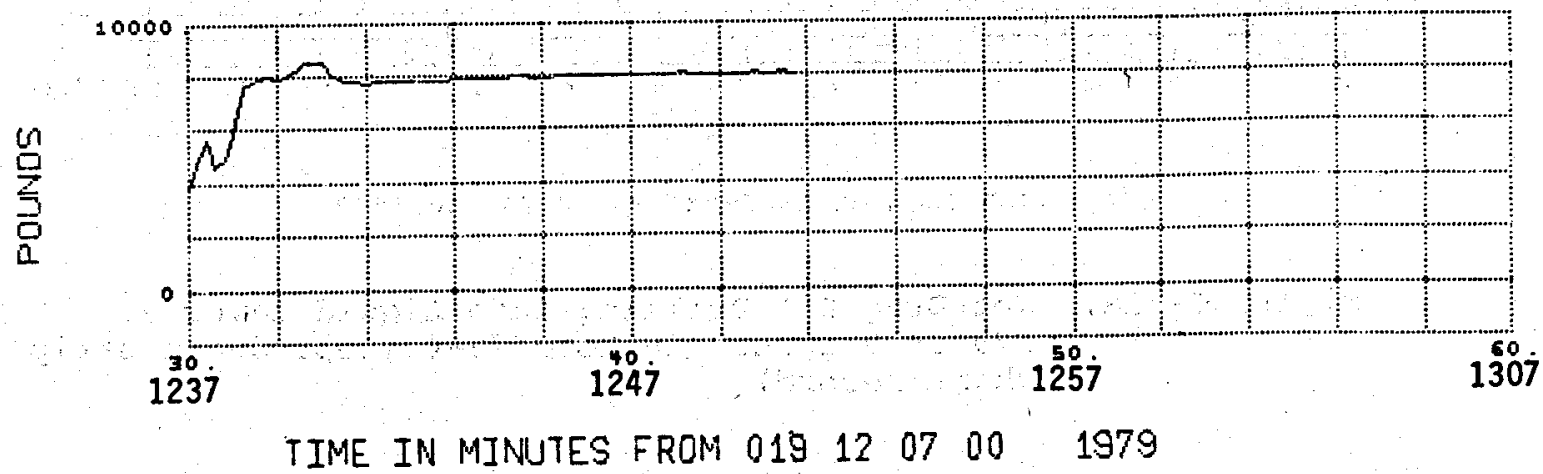

Figure C-21. Jet Drag Bit Drilling -- Second Liquid Encounter at 179 ft 9 inches in Hole 79-4 (three-wing jet drag bit) 
DRILL SPEED

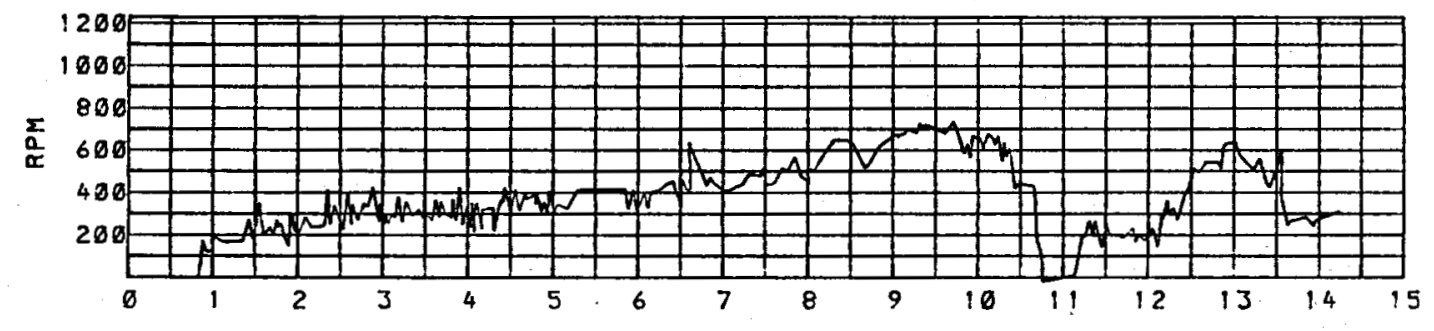

DISPLACEMENT

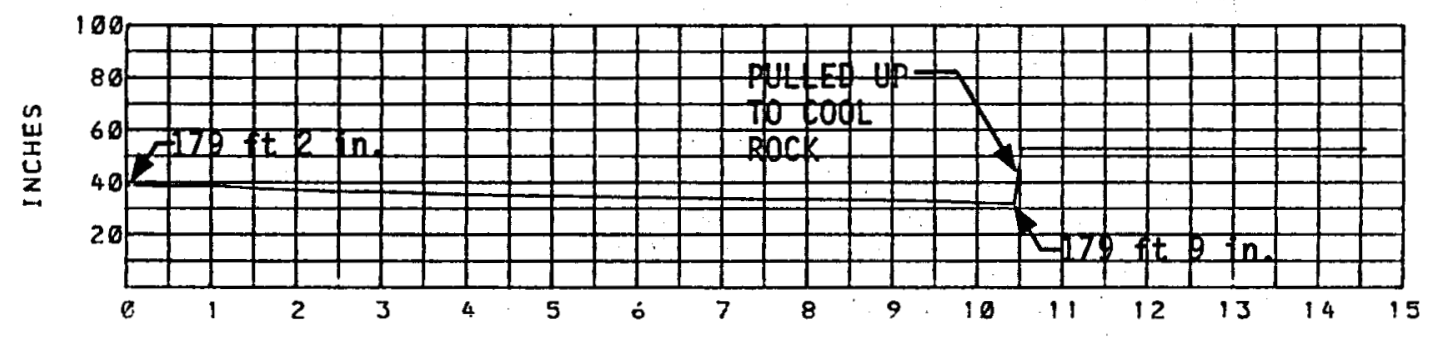

TOROUE
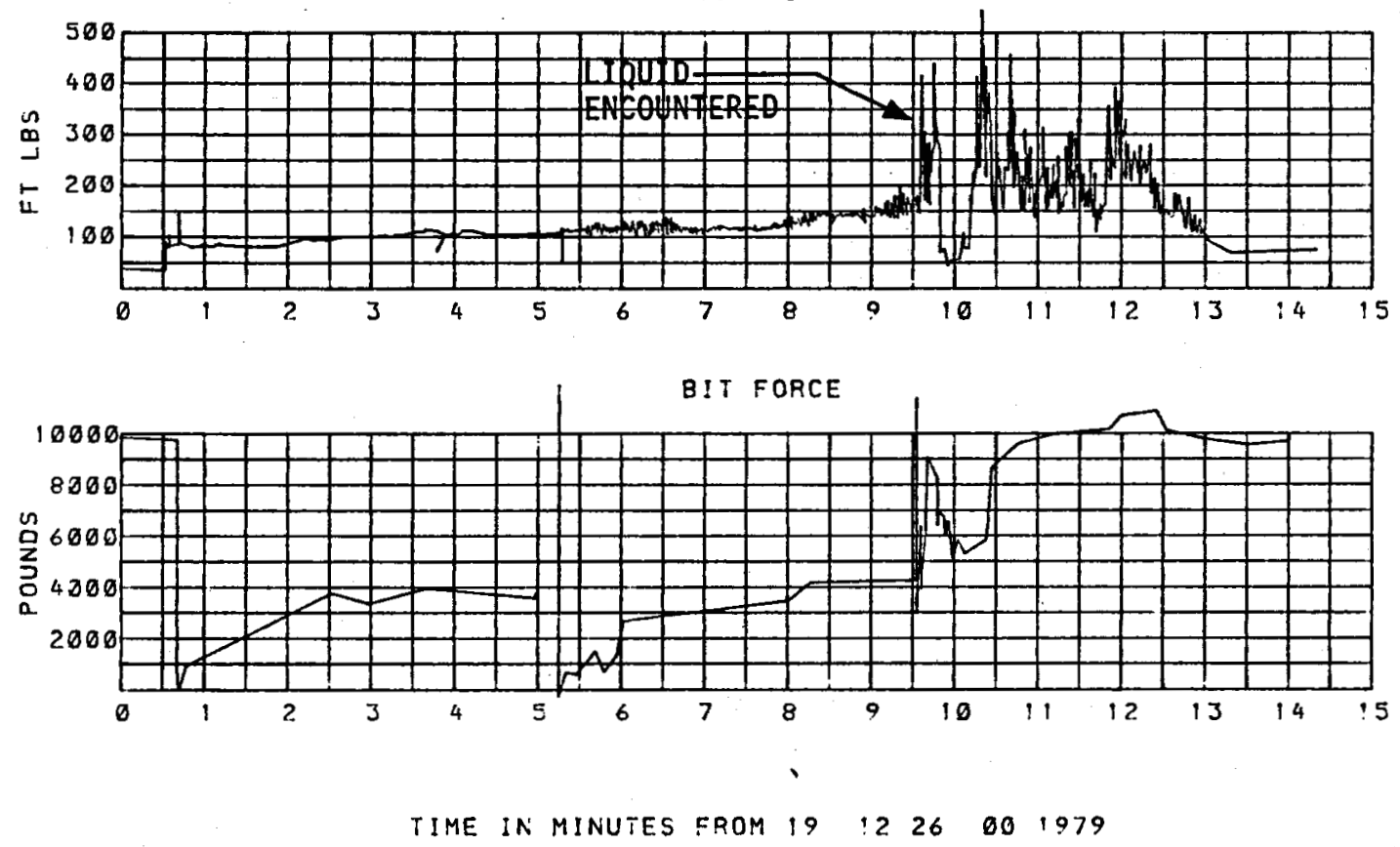

Figure C-2la. Jet Drag Bit Drilling into Liquid Layer at $179 \mathrm{ft} 9$ inches in Hole 79-4 (reproduced strip chart record) 

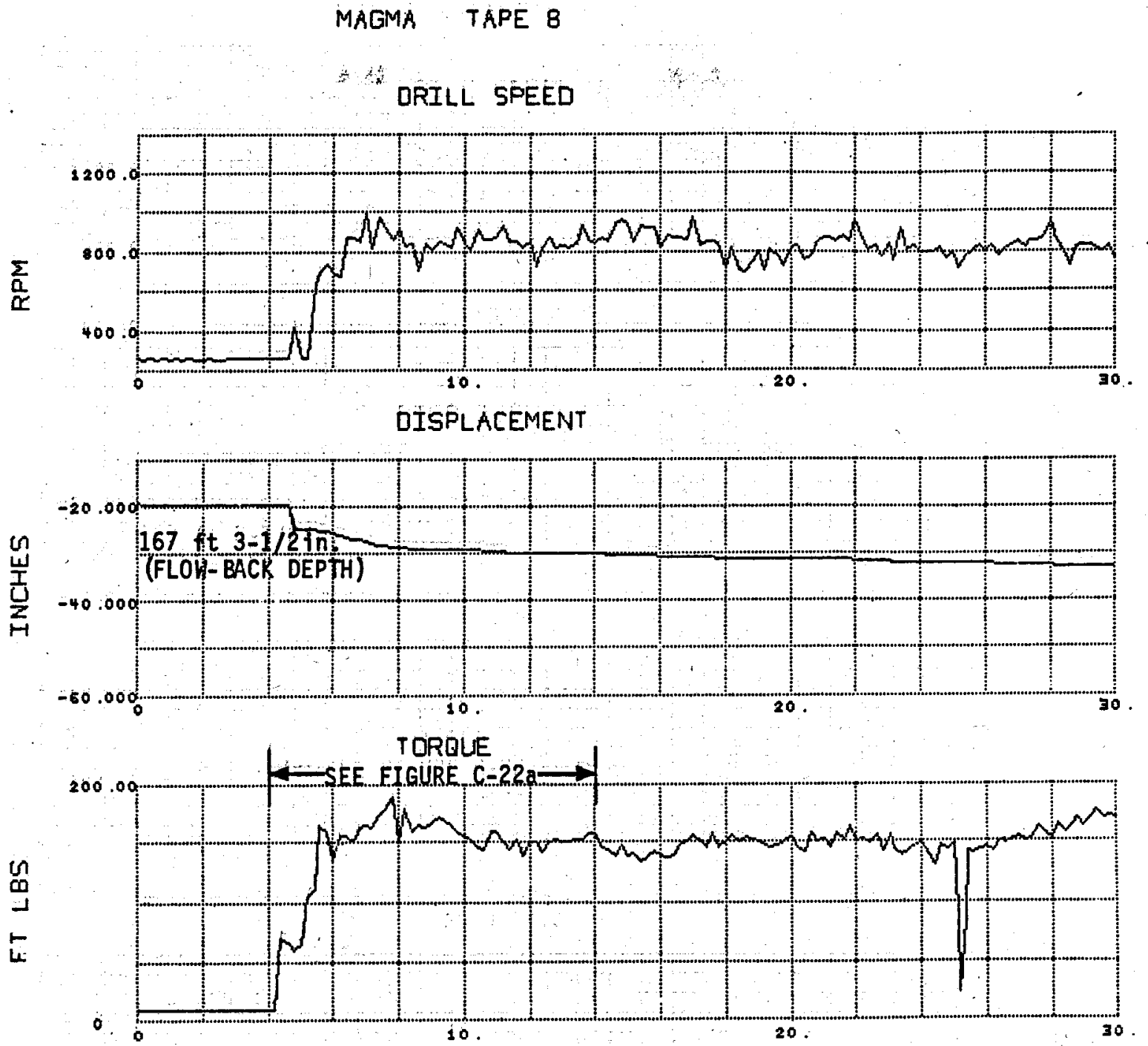

BIT FORCE

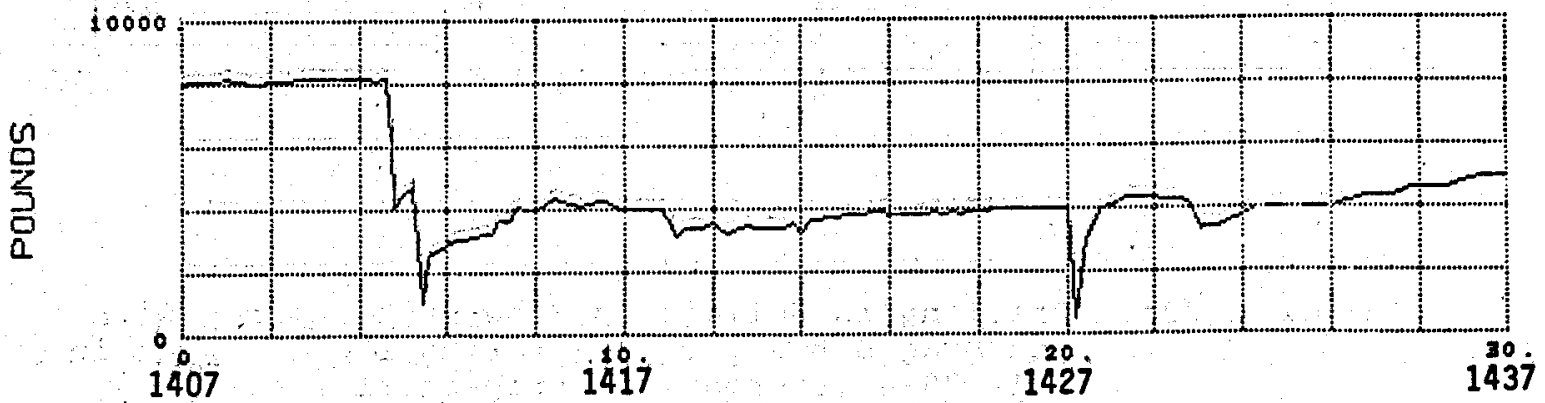

TIME IN MINUTES FROM 01914 O7 00 1979

Figure C-22. Jet Drag Bit Drilling into Flow-Back Chimney from 179 ft 9 inches Liquid Encounter in Hole 79-4 (three-wing jet drag bit) 
ORILL SPEED
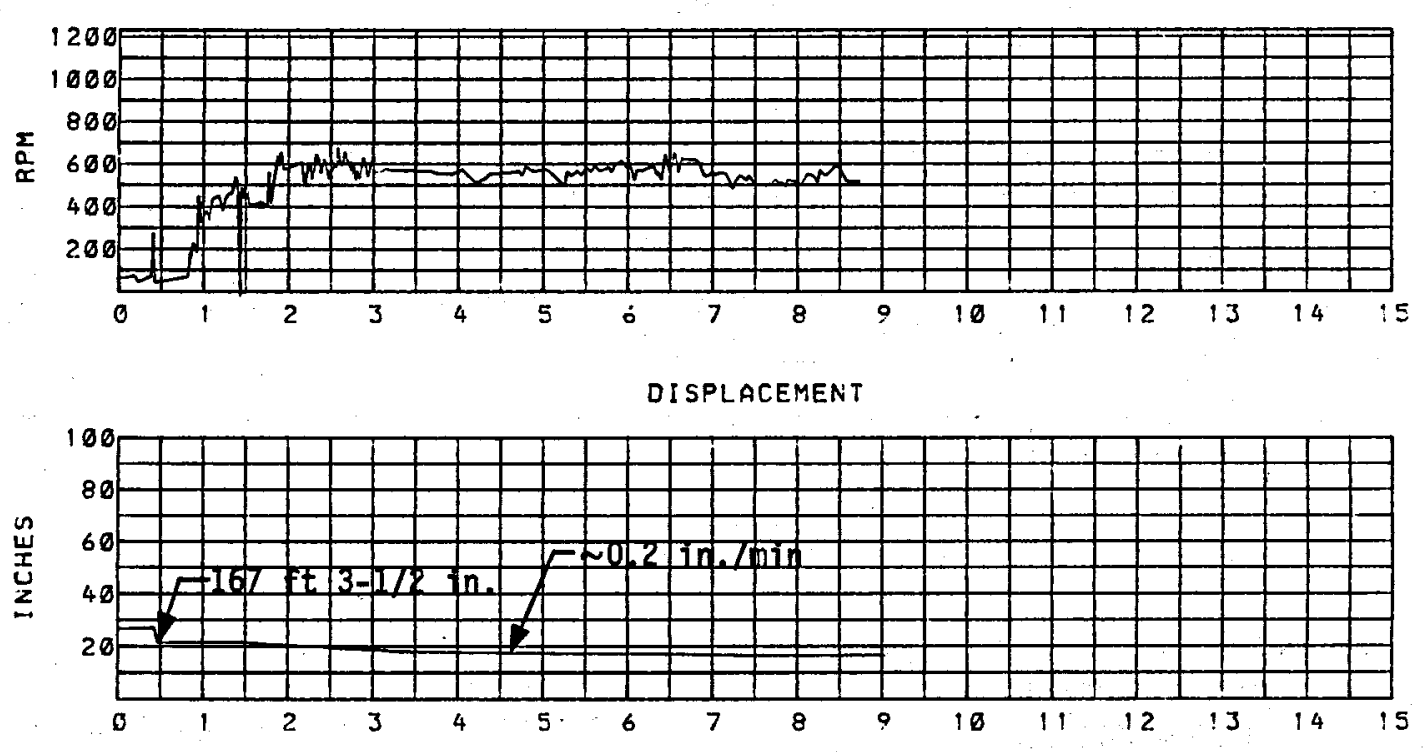

TOROJE
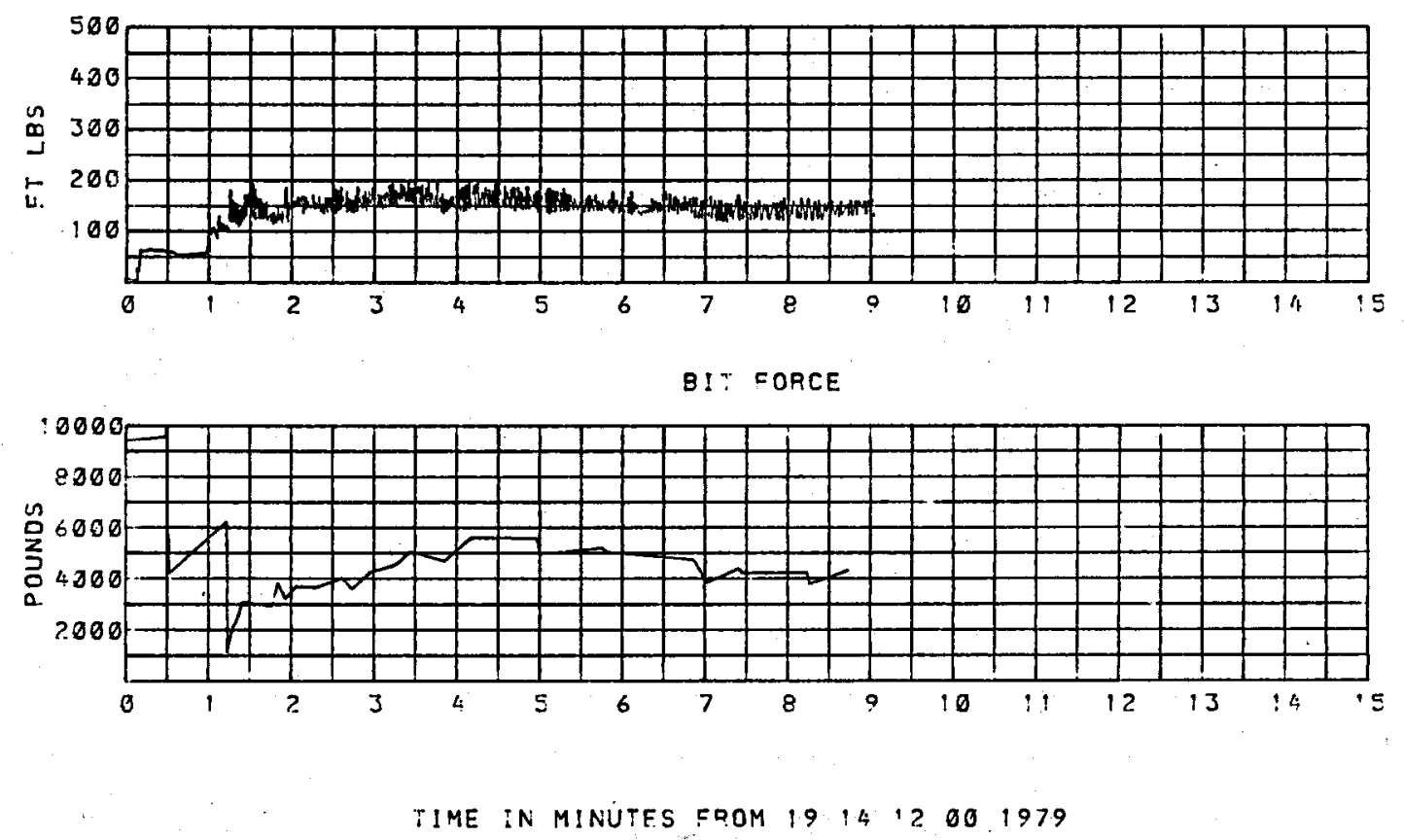

Figure C-22a. Drilling in Solidified Flow-Back Chimney with Jet Drag Bit after penetrating Liquid Layer in Hole 79-4 (reproduced strip chart record) 
MAGMA TAFE 8

DRILL SPEED

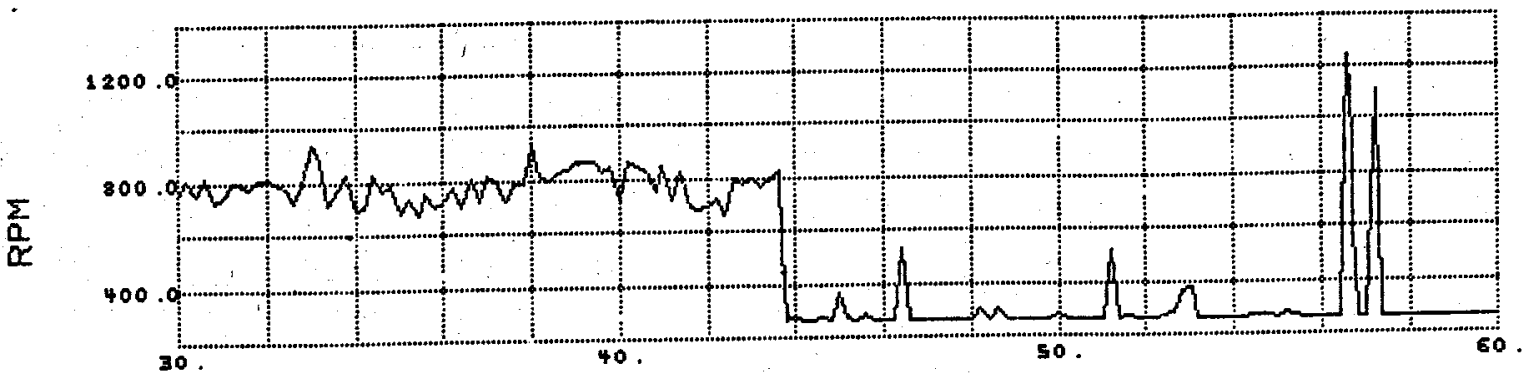

DISPLACEMENT
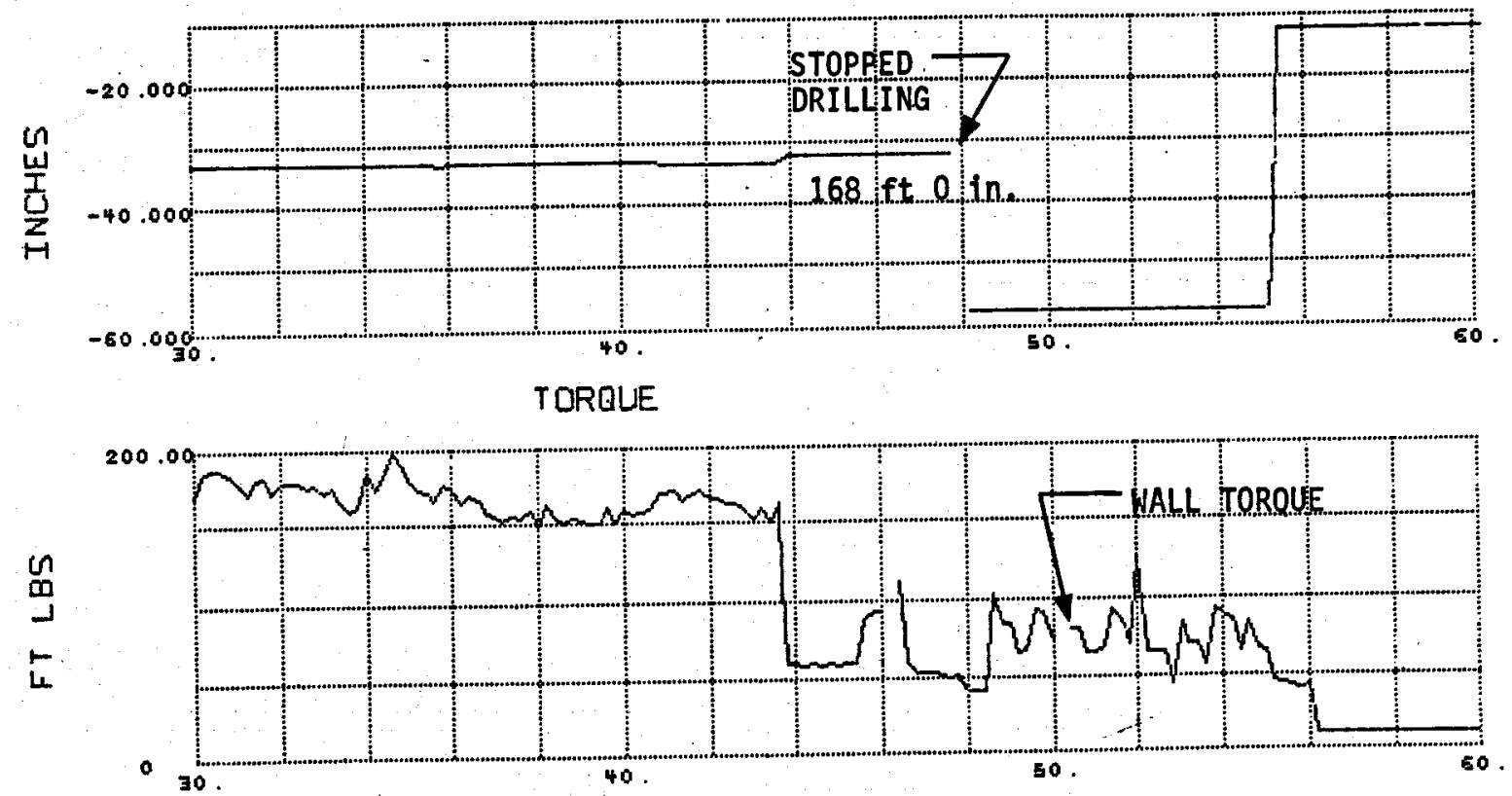

BIT FORCE

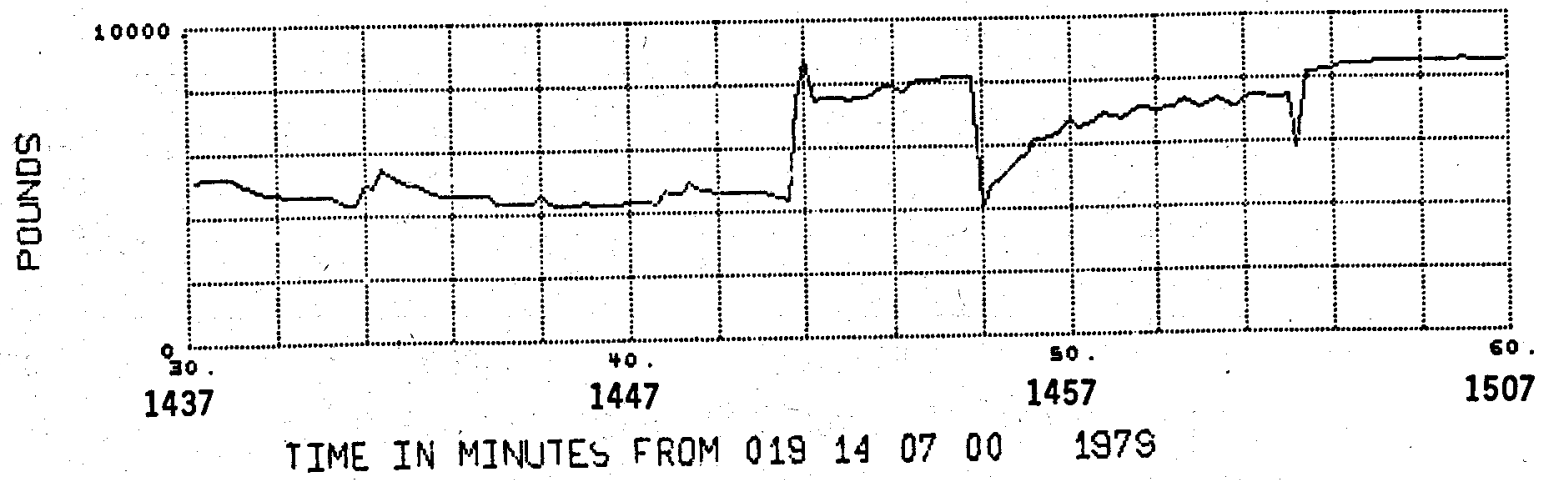
Figure C-23. Jet Drag Bit Drilling into Flow-Back Chimney from
179 ft 9 inches Liquid Encounter in Hole 79-4 (three-wing jet drag bit) 
MAGMA TAPE 8

DRILL SPEED
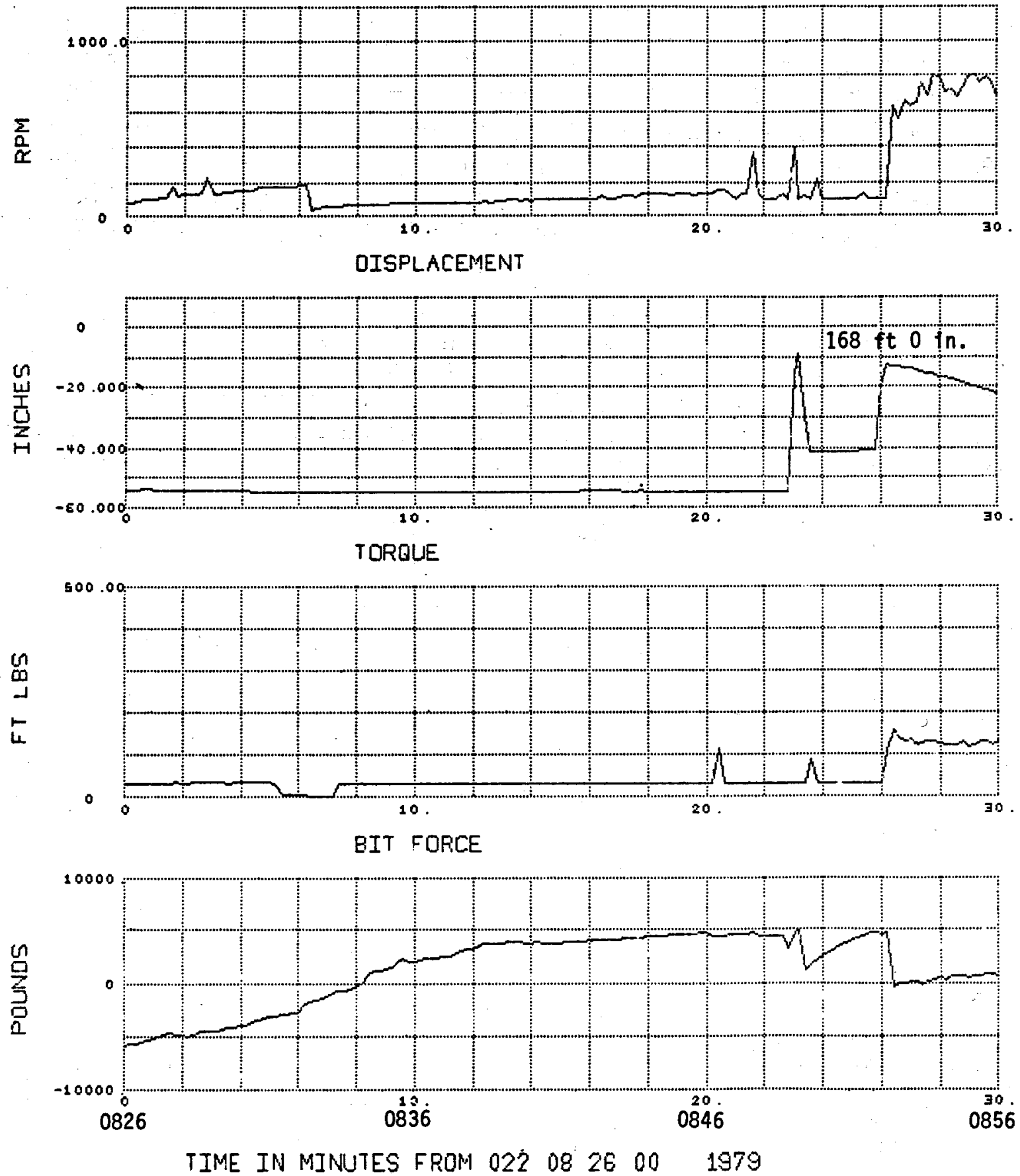

Figure C-24. Drilling into Flow-Back Chimney from Liquid Encounter at $179 \mathrm{ft} 9$ inches with BQ Core Bit in Hole 79-4 (BQ -- 2.36 inches diameter -wireline coring equipment) 
MAGMA TAPE 8

DRILL SFEED
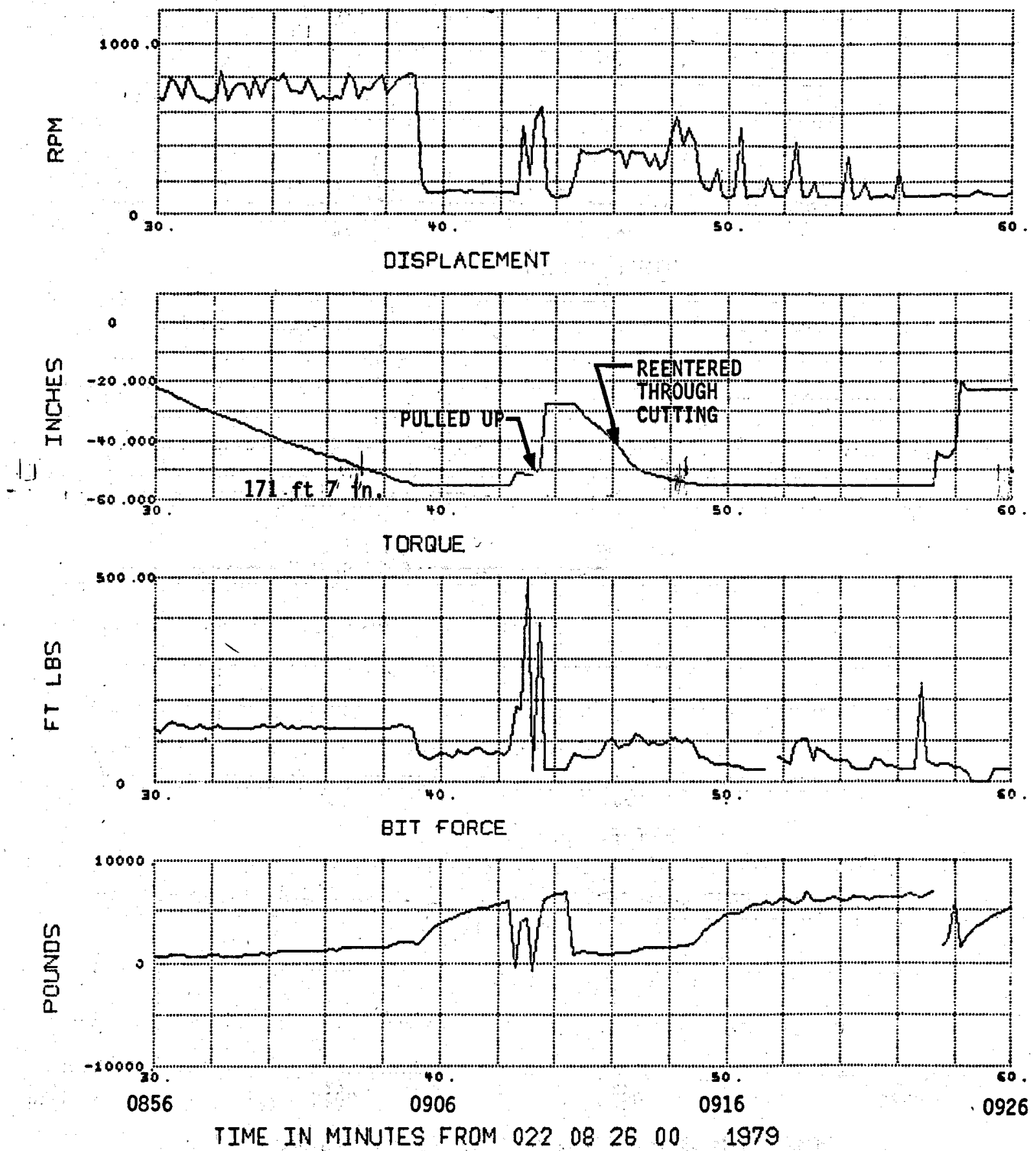

Figure C-25. Drilling into Flow-Back Chimney from Liquid Encounter at $179 \mathrm{ft} 9$ inches with $B Q$ Core Bit in Hole 79-4 (BQ - 2.36 inches diameter -wireline coring equipment) 
MAGMA TAPE 8
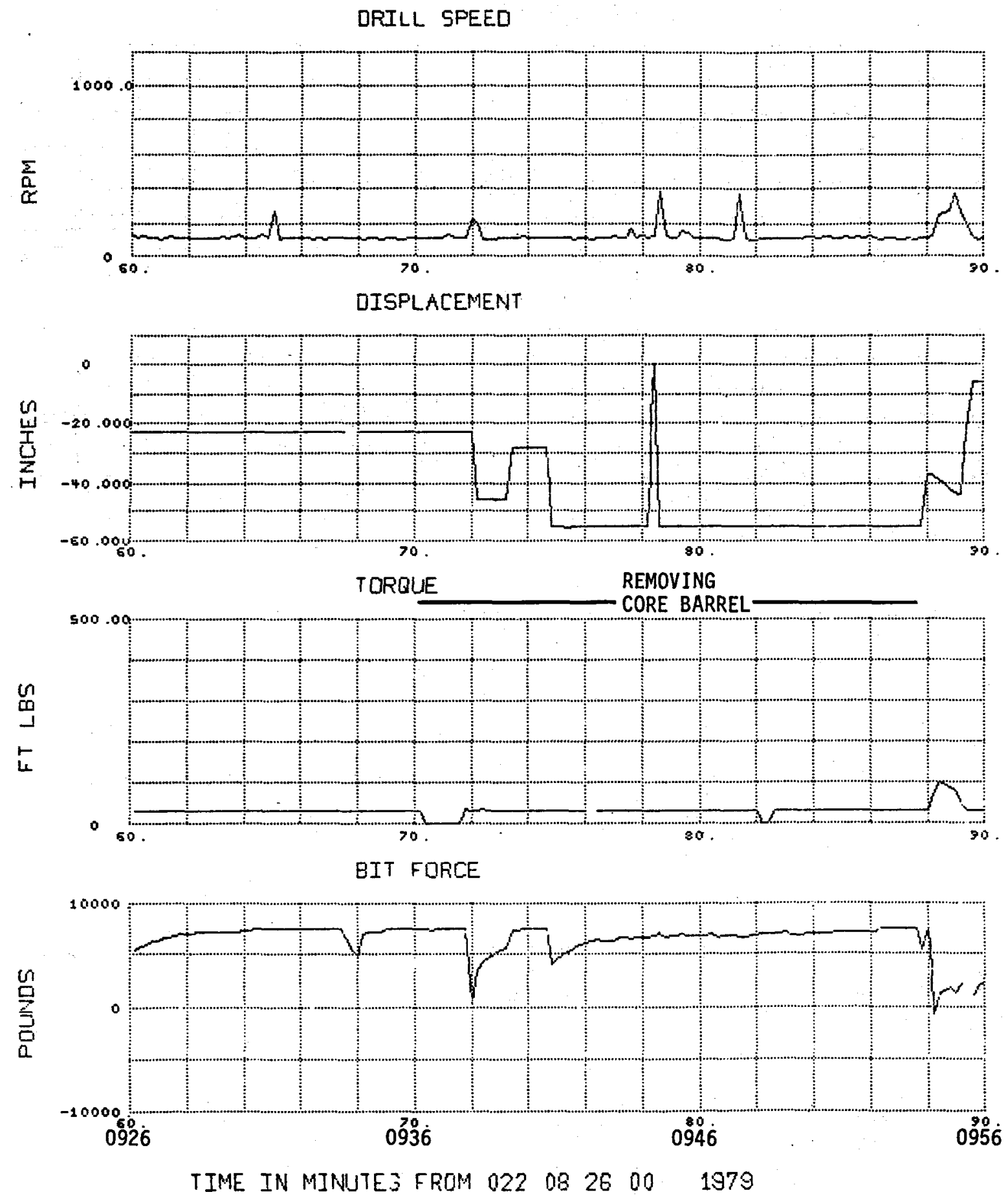

Figure C-26. Drilling into Flow-Back Chimney from Liquid Encounter at 179 ft 9 inches with BQ Core Bit in Hole 79-4 
MAGMA TAPE 8

DRILL SPEED
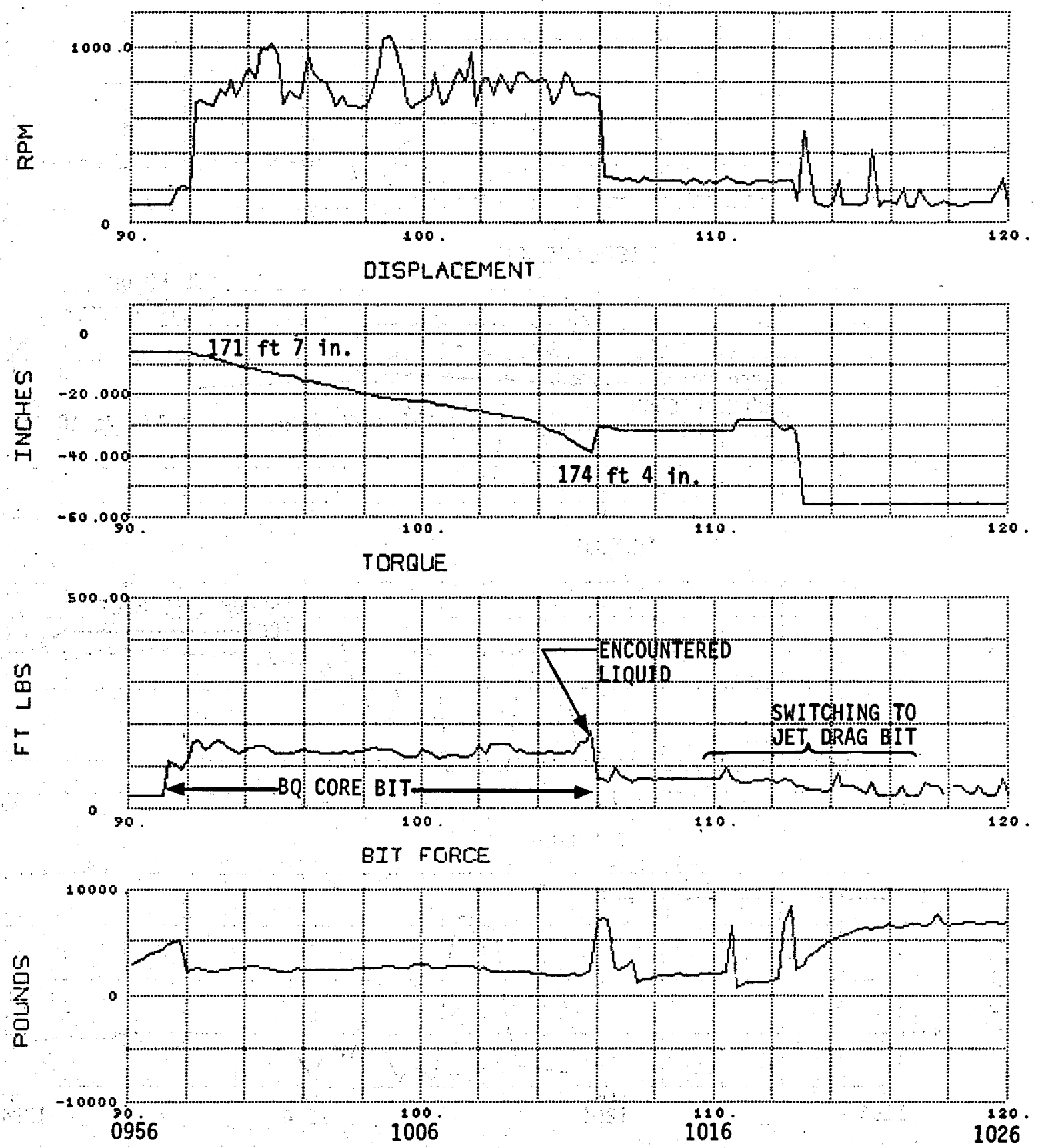

TIME IN MINUTES FROM 022 DQ 26 OO 1979

Figure C-27. Drilling into Flow-Back Chimney from Liquid Encounter at 179: ft 9, inches with BQ Core Bit in Hole 79-4 (BQ - 2.36 inches diameter -wireline coring equipment) 
MAGMA TAPE 8

DRILL SPEED
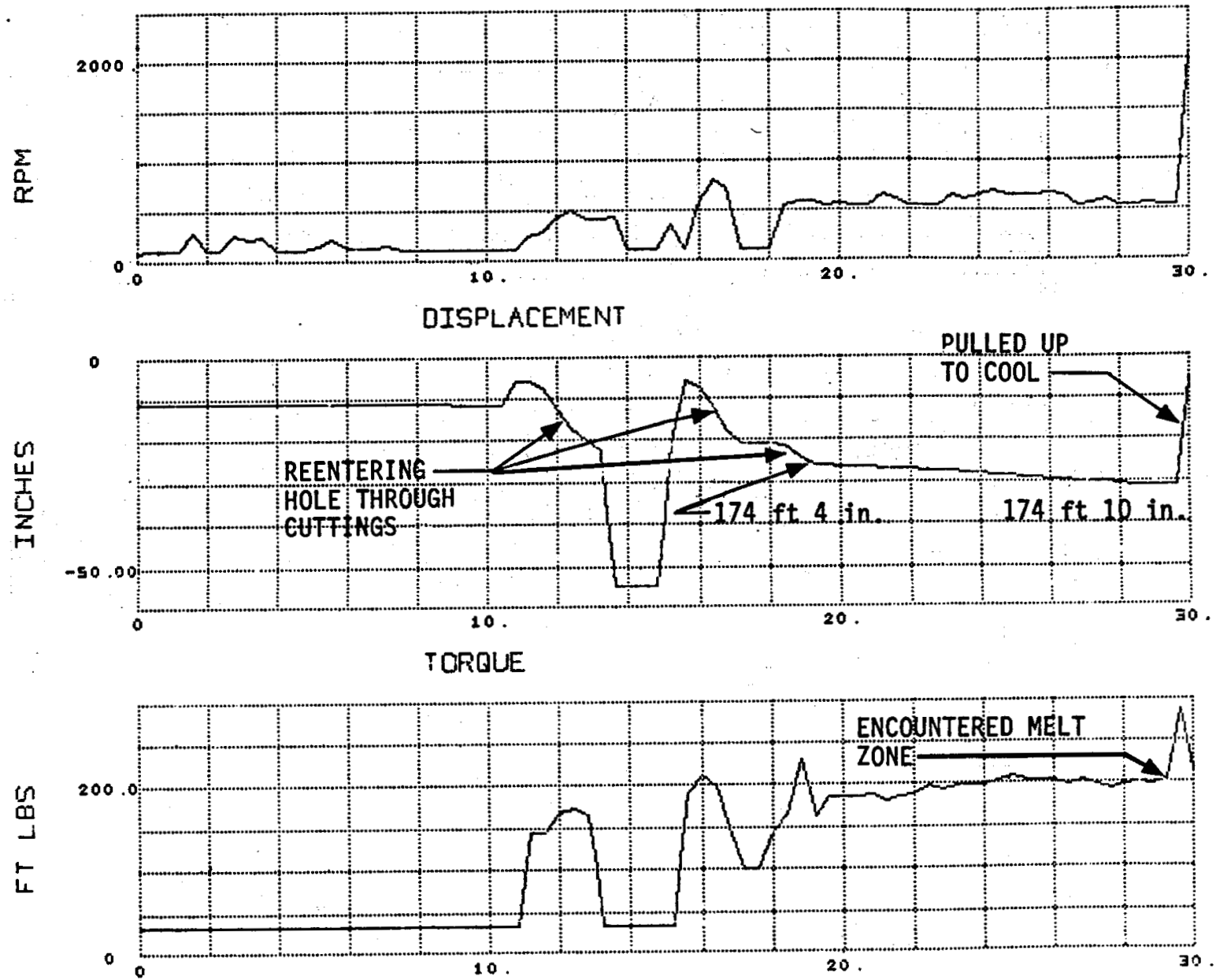

BIT FORCE

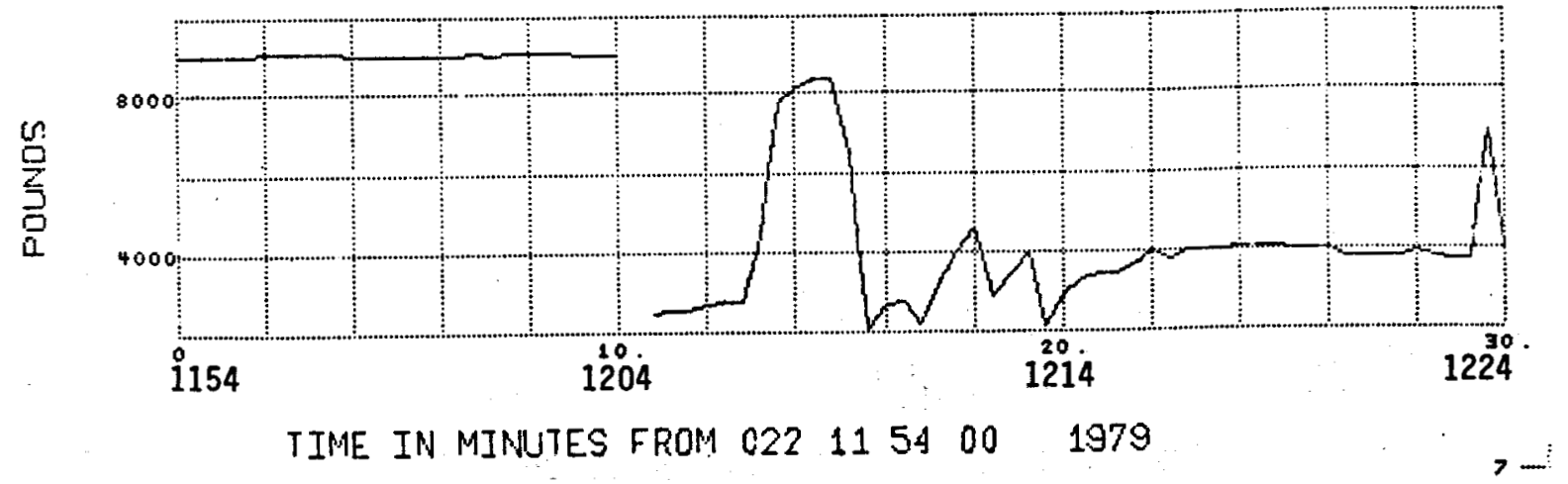

Figure C-28. Drilling into Flow-Back Chimney from Liquid Encounter at $179 \mathrm{ft} 9$ inches with Jet Drag Bit in Hole 79-4 (three-wing jet drag bit) 
MAGMA TAPE 8

W WATER FLOW METER 1
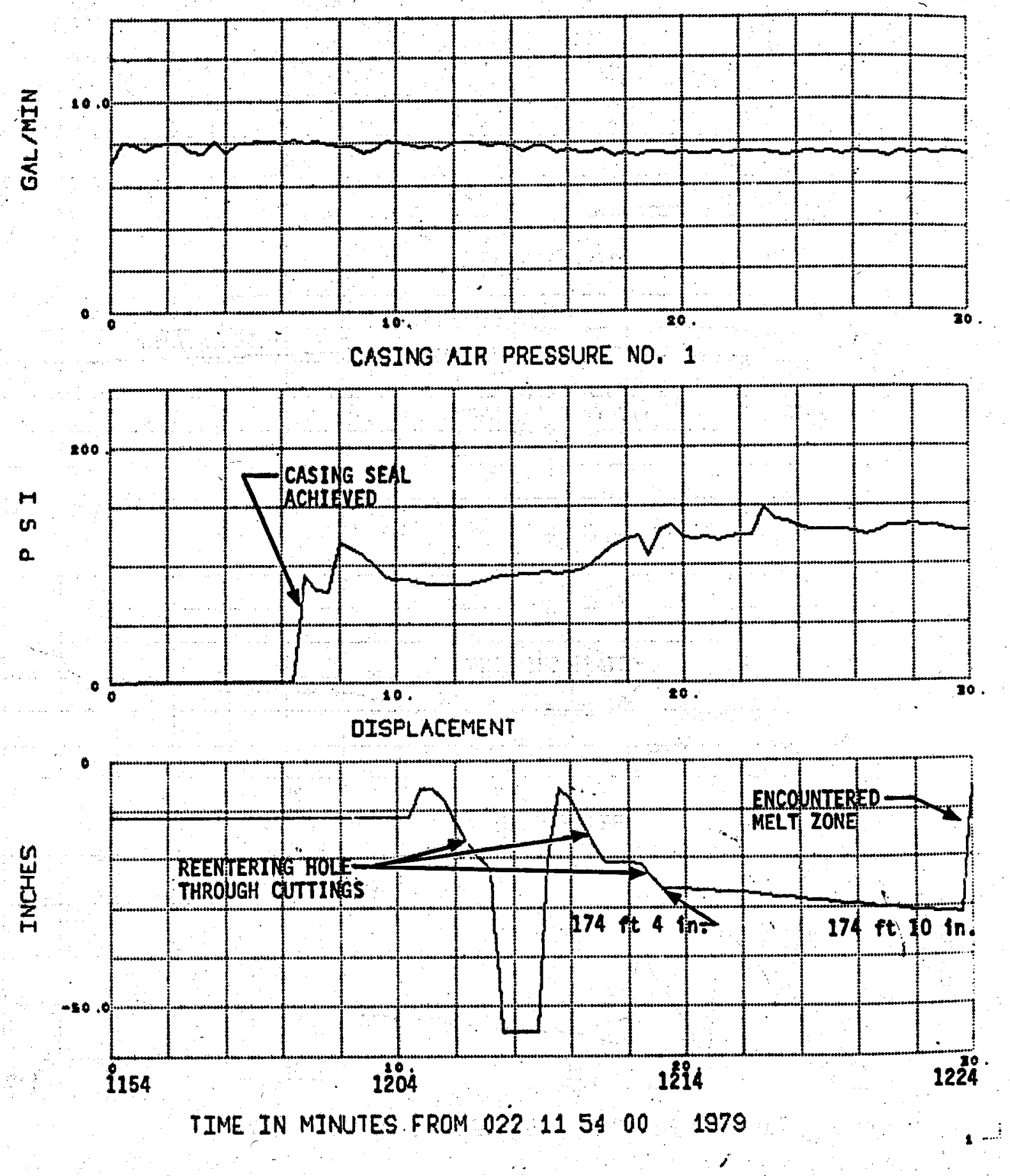

Figure C-2Ba. Casing Air Pressure and Cooling Water Flow while Drilling in Hole $79-4$ with Jet Drag Bit 
MAGMA TAPE 8

DRILL SPEED
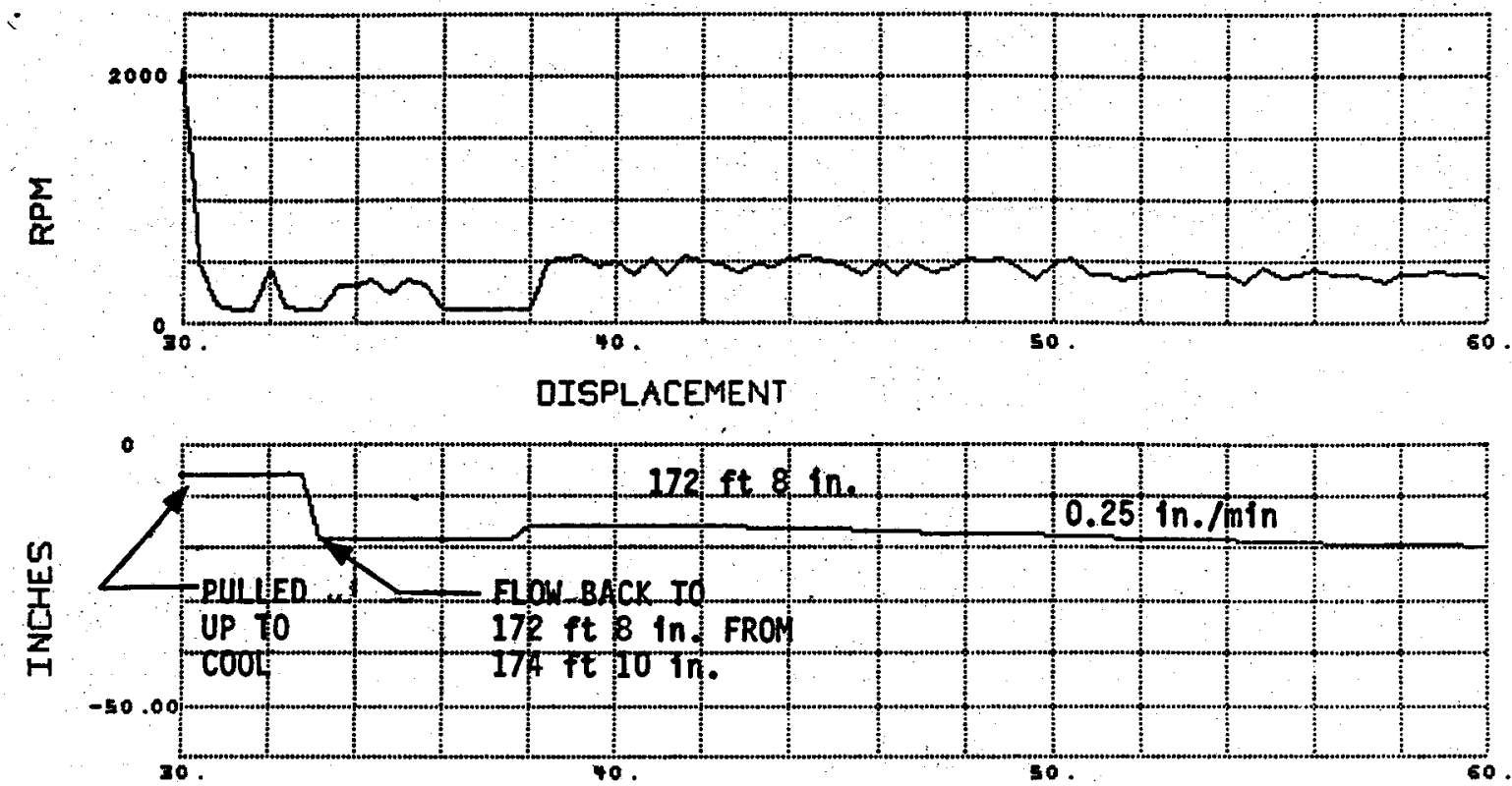

TORQUE

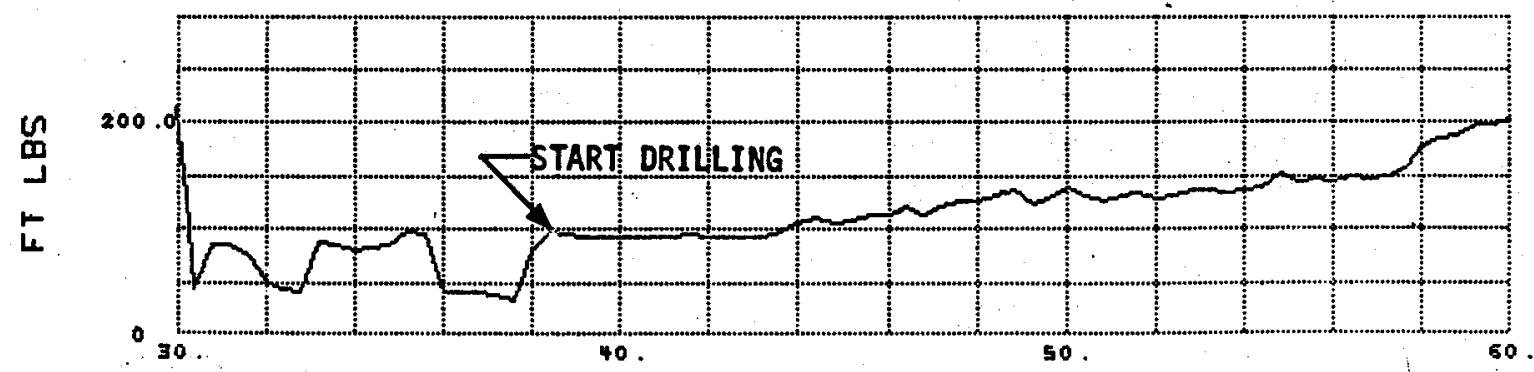

BIT FORCE

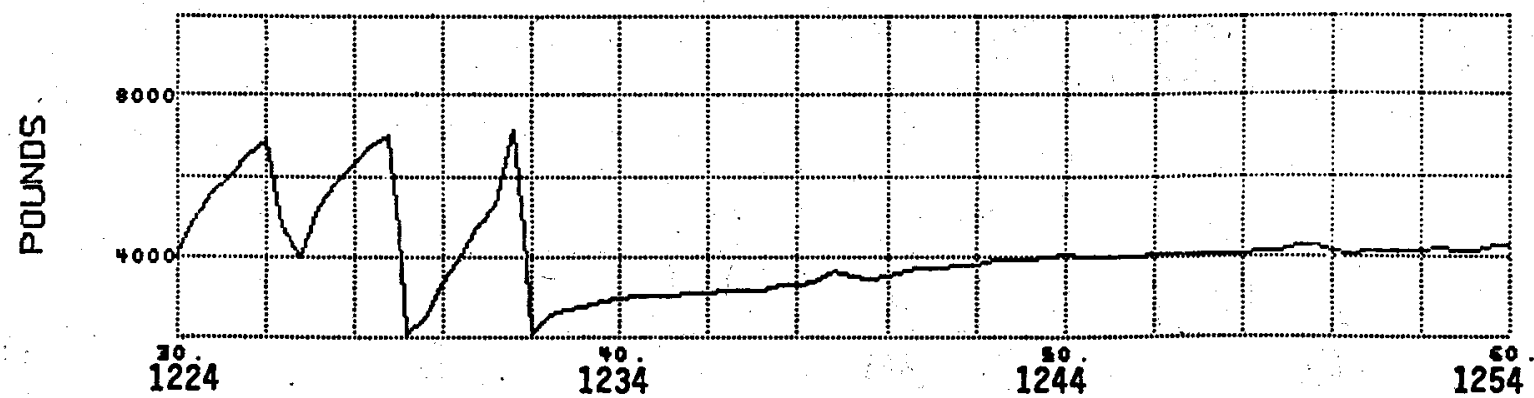

TIME IN MINUTES FROM $022115400 \quad 1979$

Figure C-29. Drilling into Flow-Back Chimney from Liquid Encounter at $179 \mathrm{ft} 9$ inches with Jet Drag Bit in Hole 79-4 (three-wing jet drag bit) 
MAGMA TAPE 8
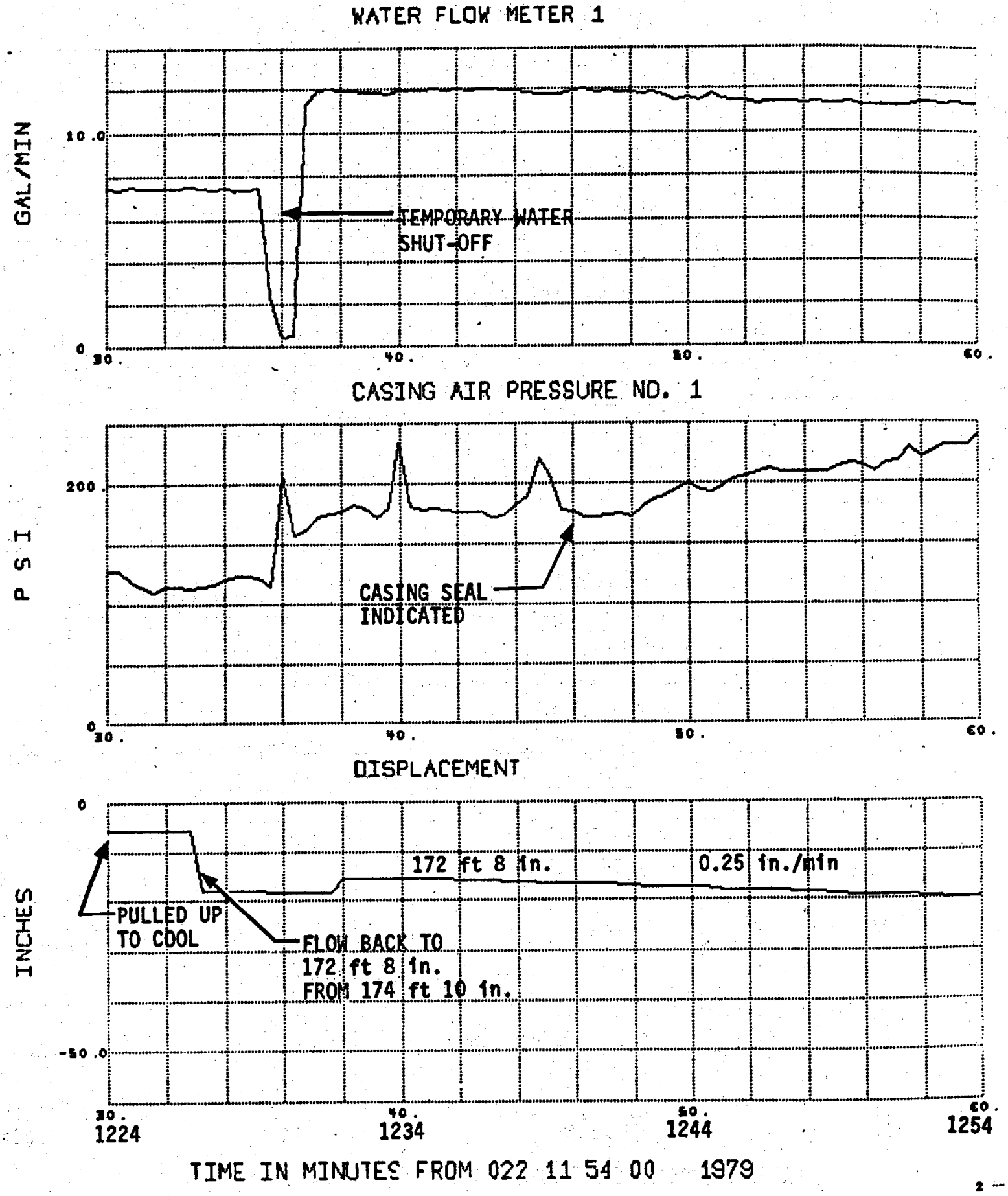

Figure C-29a. Casing Air Pressure and Cooling Water Flow while Drilling in Hole 79-4 with Jet Drag Bit (three-wing jet drag bit) 
MAGMA TAPE 8

DRILL SPEED

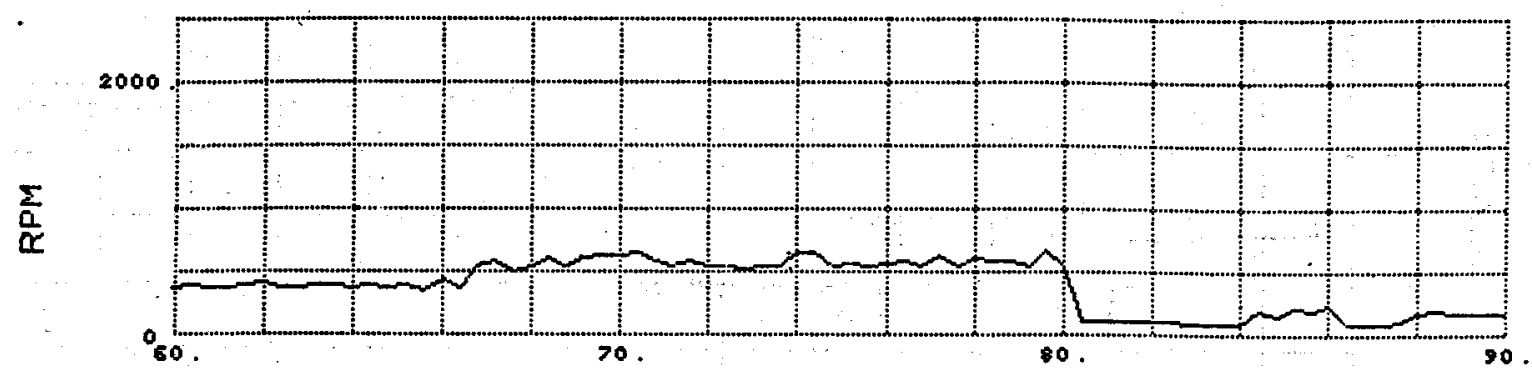

DISPLACEMENT
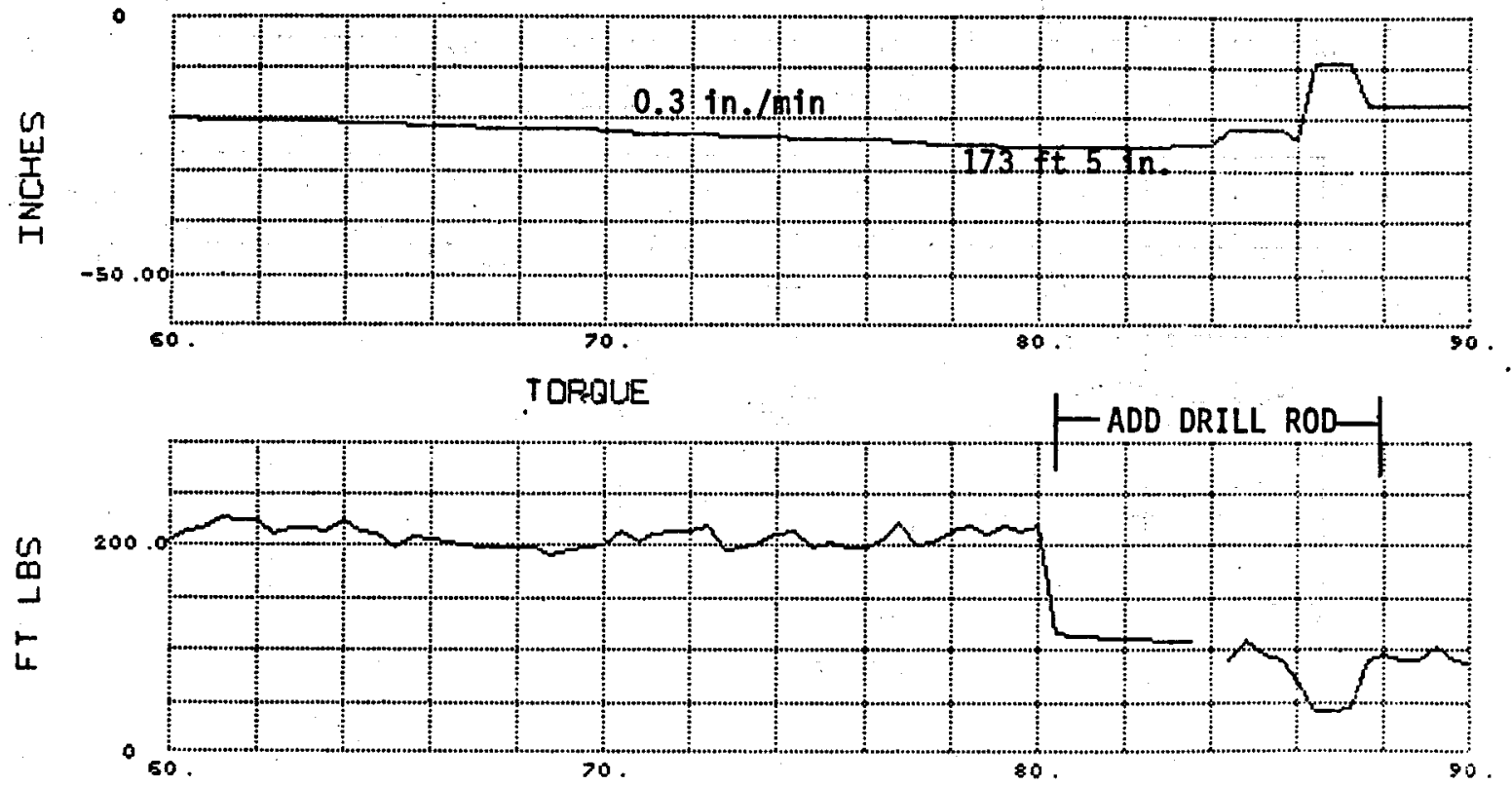

BIT FORCE

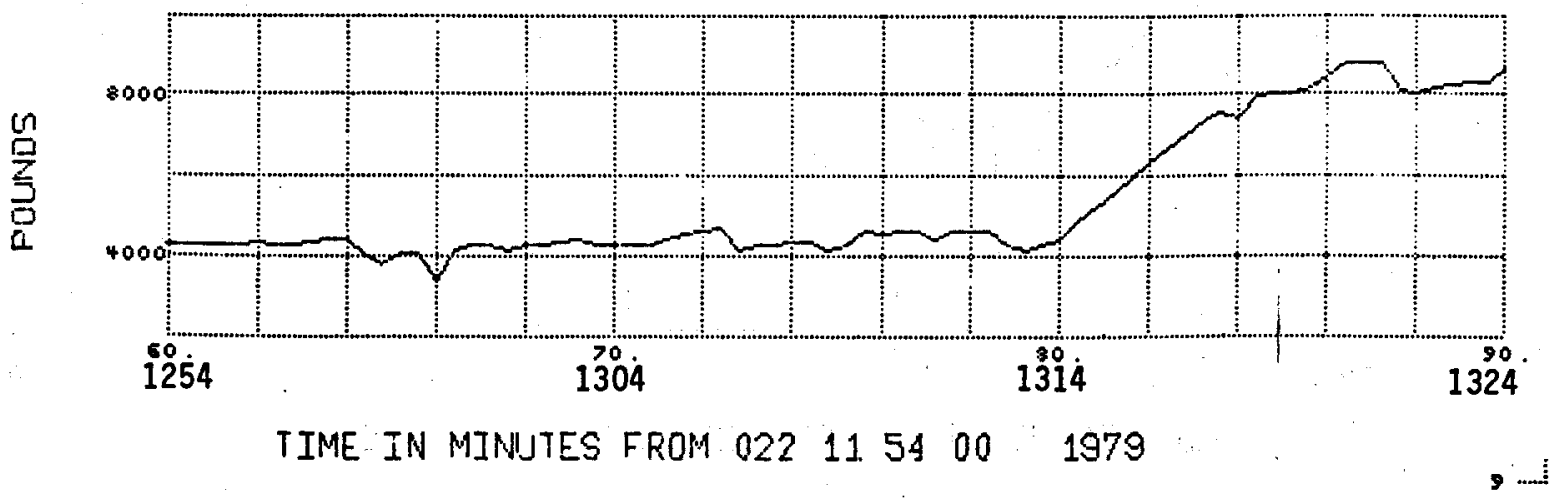

Figure c-30. Drilling into Flow-Back Chimney from Liquid Encounter at $179 \mathrm{ft} 9$ inches with Jet Drag Bit in Hole 79-4 (three-wing jet drag bit) 
MAGMA TAPE 8

WRTER FLOW METER 1
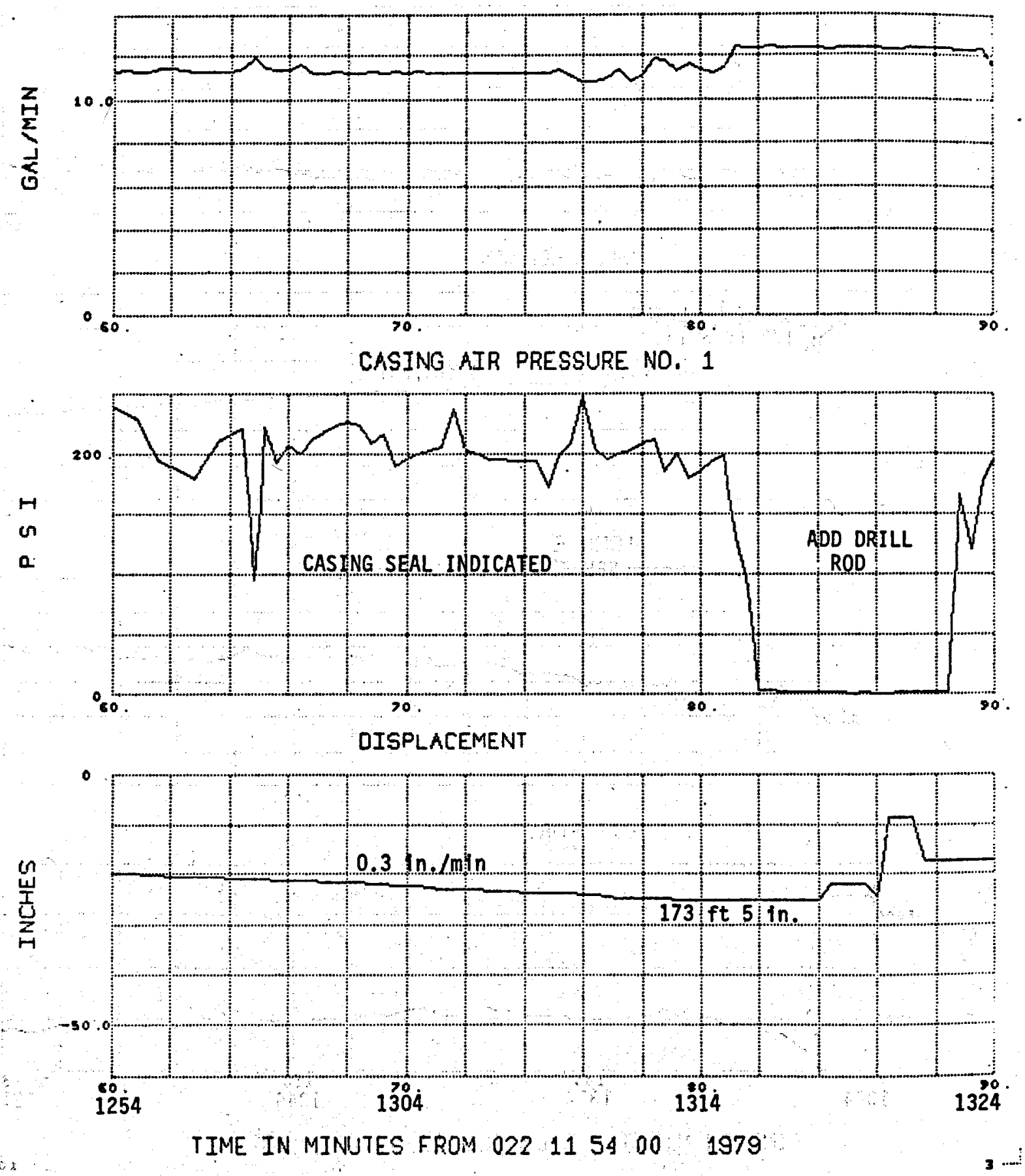

Figure C-30a. Casing Air Pressure and Cooling water Flow while Drilling in Hole 79-4 with Jet Drag Bit 
MAGMA TAPE 8

DRILL SPEE[
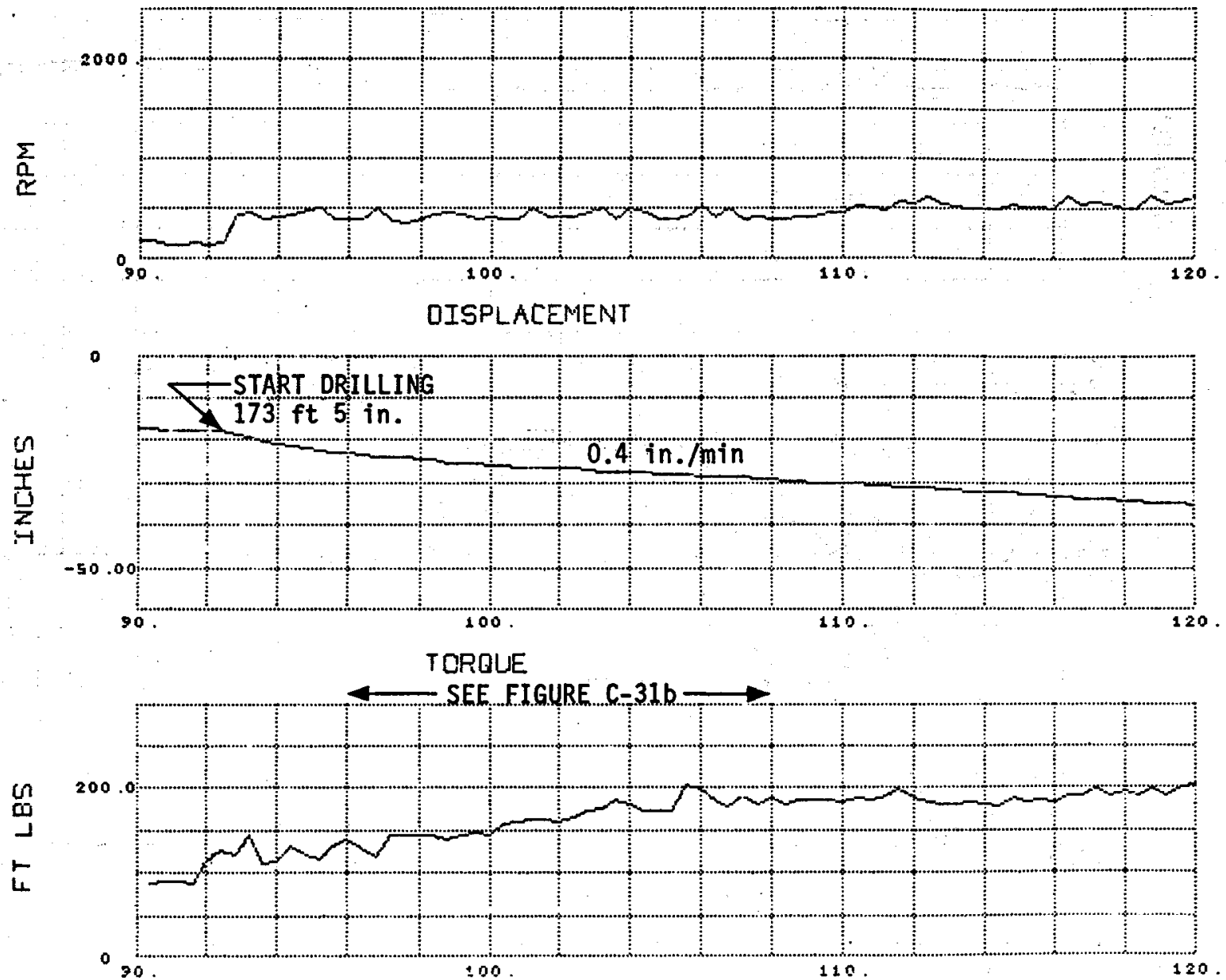

BIT FQRCE

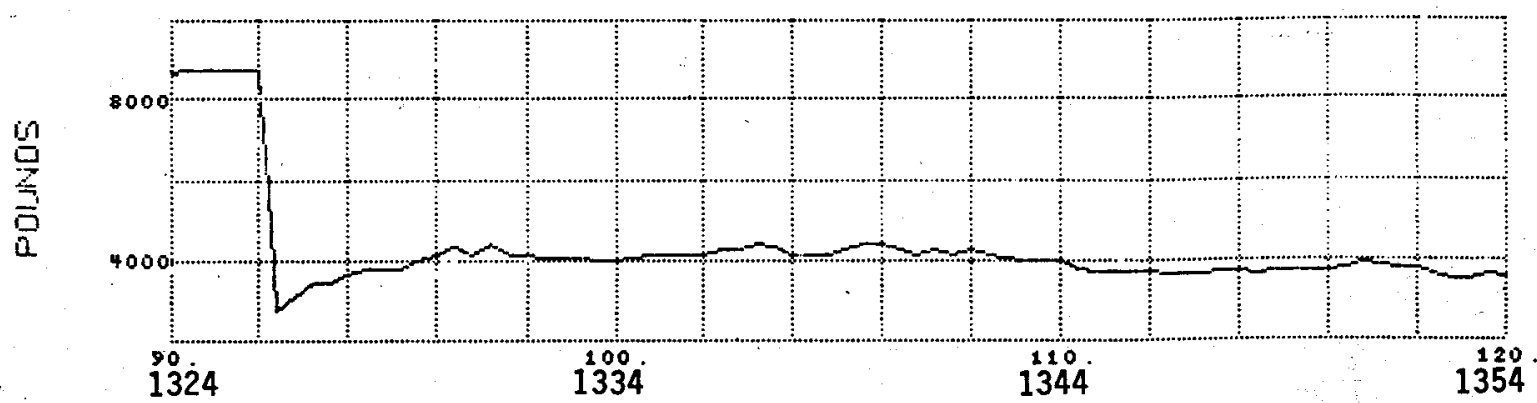

TIME IN MINUTES FROM $022115 \%$ 00: 1979

$10-1$

Figure C-31. Drilling into Flow-Back Chimney from Liquid Encounter at $179 \mathrm{ft} 9$ inches with Jet Drag Bit in Hole 79-4 (three-wing jet drag bit) 

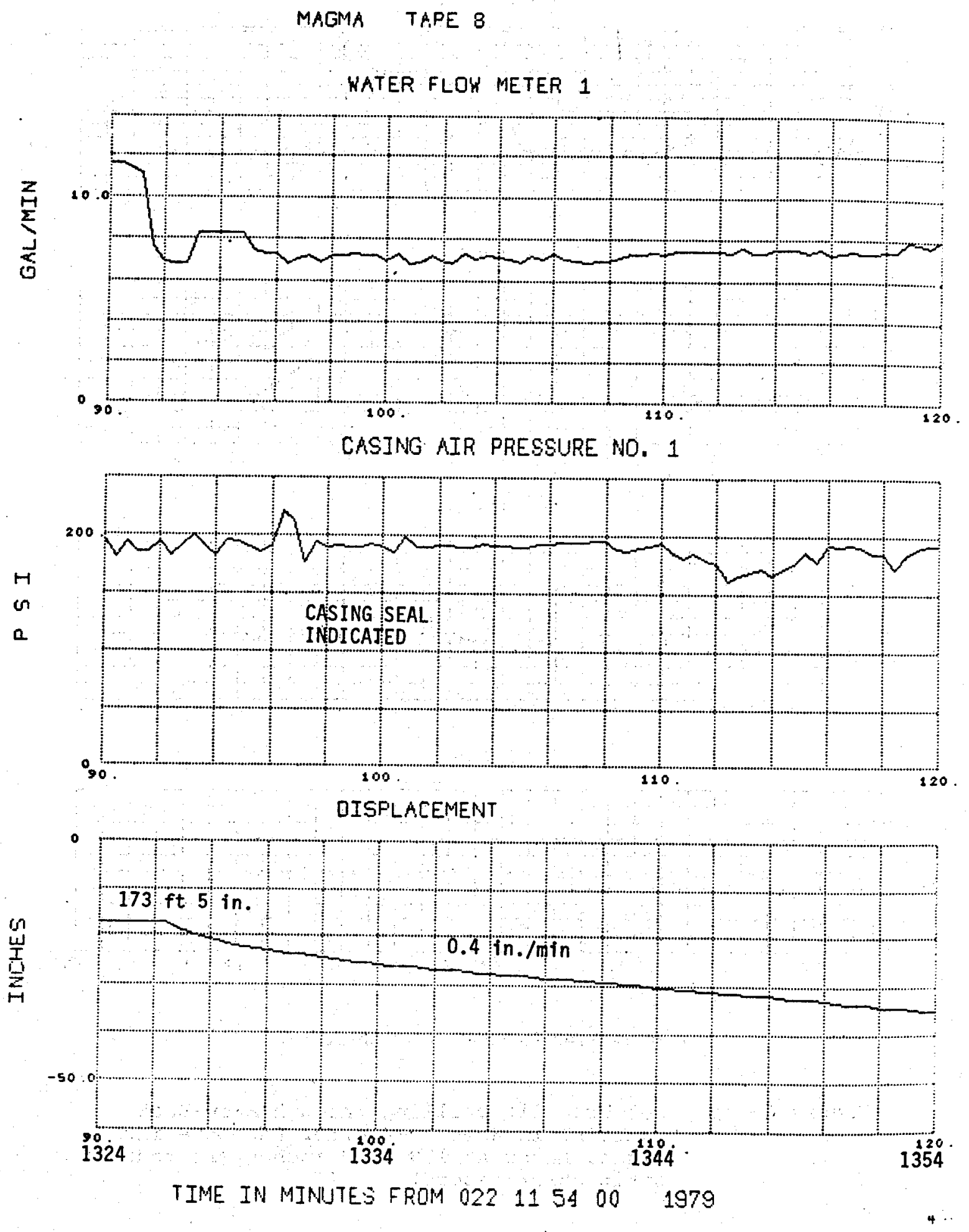

Figure C-3la. Casing Air Pressure and Cooling water Flow while Drilling in Hole 79-4 with Jet Drag Bit 
DRILL SPEED
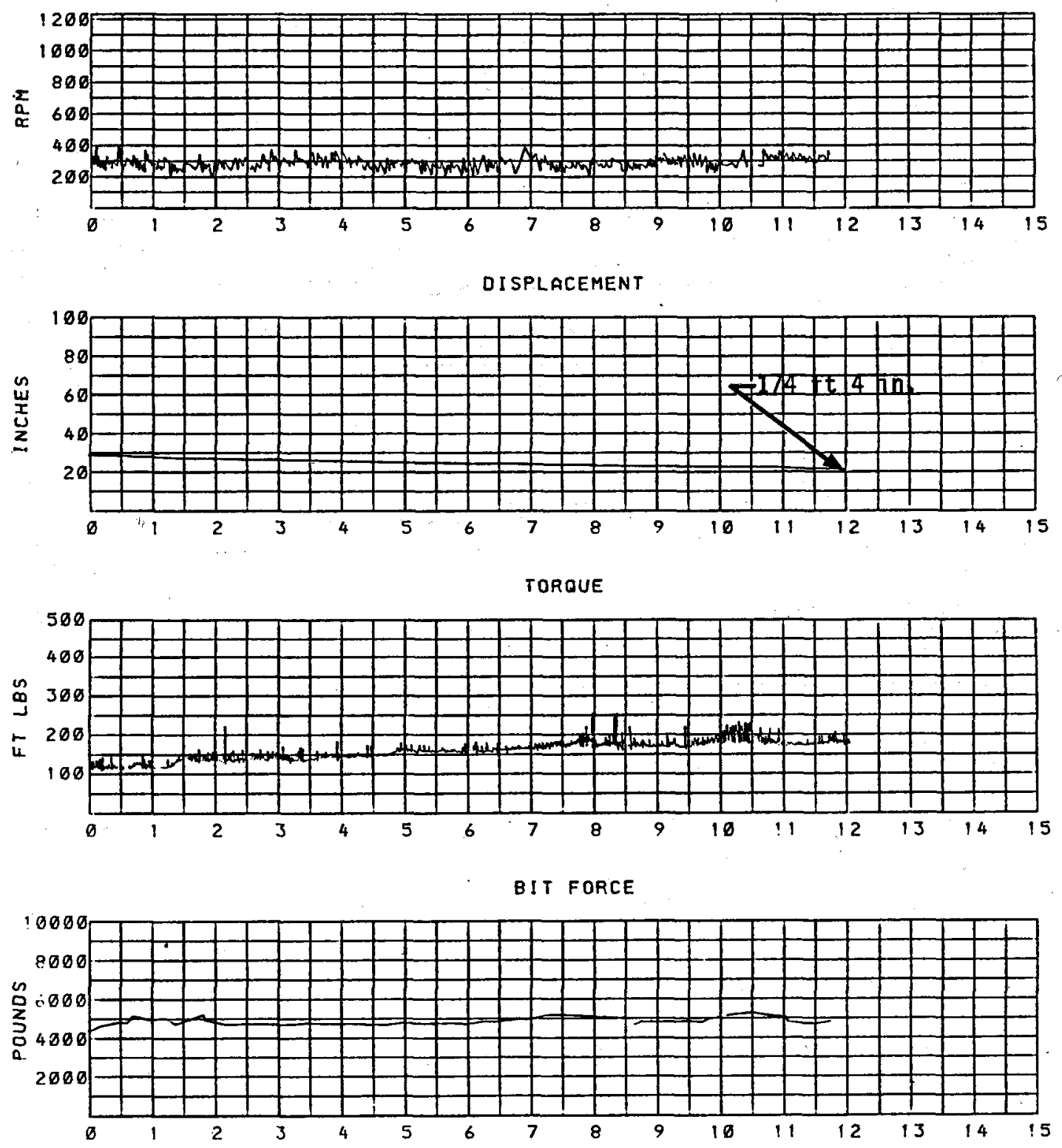

TIME IN MINUTES FROM $22 \quad 13 \quad 30 \quad 00 \quad 1979$

Figure C-3lb. Jet Drag Bit Drilling through Flow-Back Material in Hole 79-4 after Encountering Liquid Layer at $179 \mathrm{ft} 9$ inches (reproduced strip chart record) 


\section{MAGMA TAPE 8}

DRILL SPEED
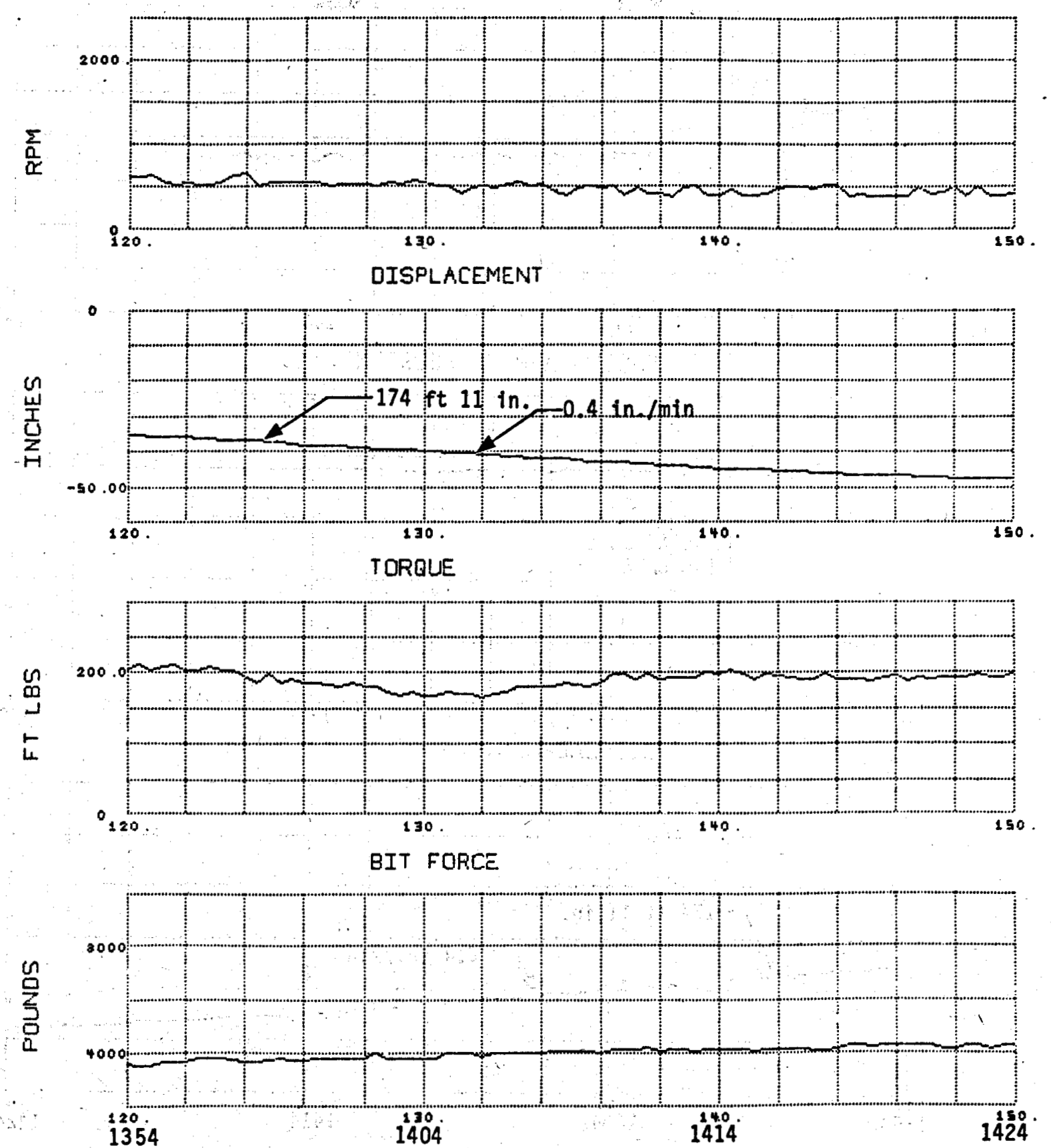

TIME IN MINUTES FROM $022 \quad 115400 \quad 1979$

$11 \ldots$

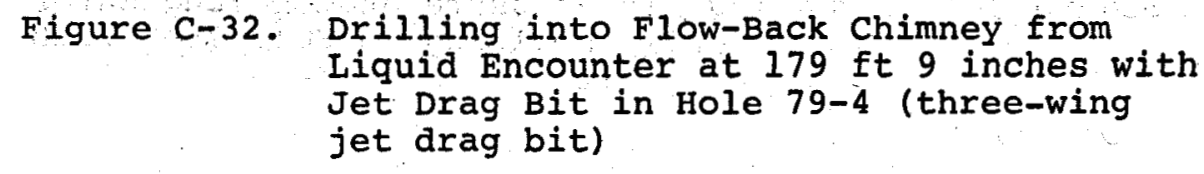


MAGMA TAPE 8

WATER FLOH METER 1

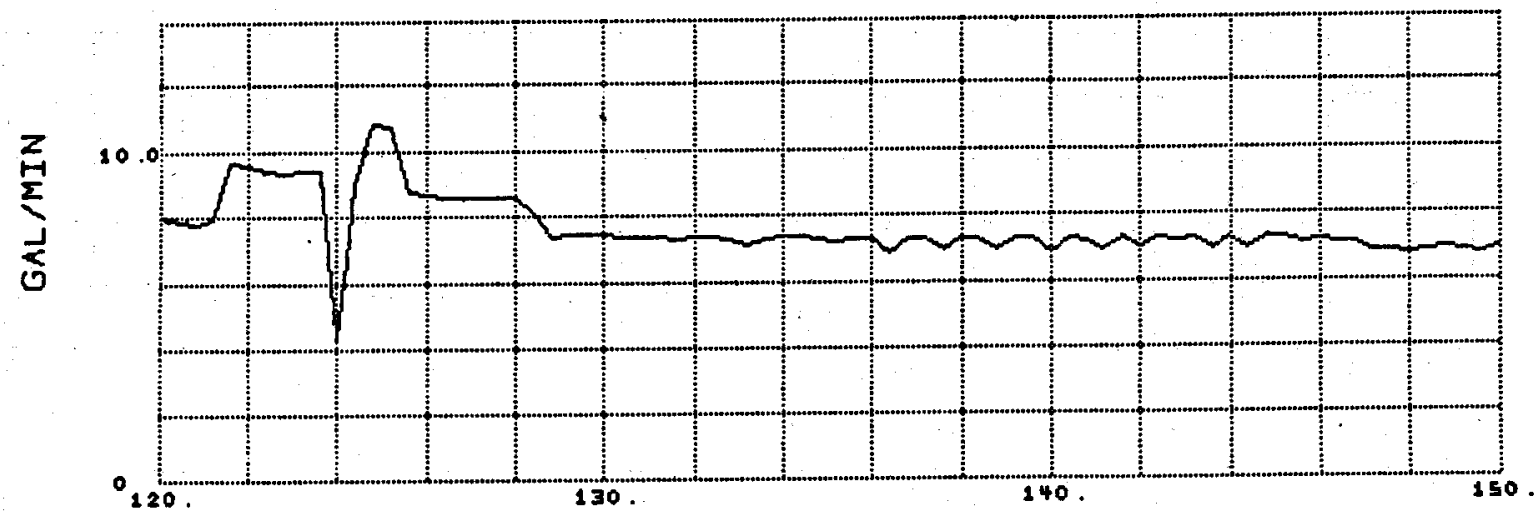

CASING AIR PRESSURE NO. 1
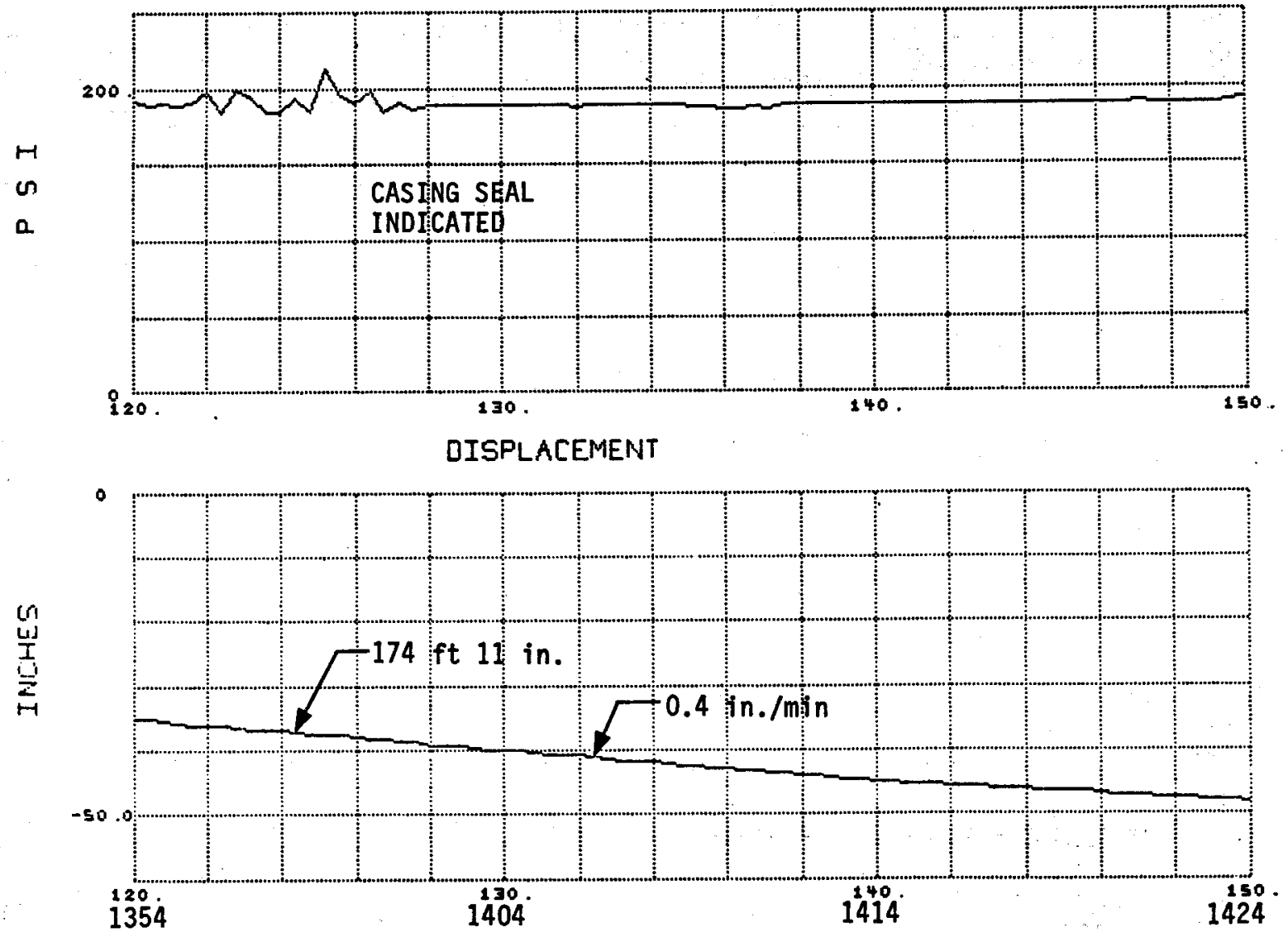

TIME IN MINIJTES FROM $022 \quad 1154 \quad 00 \quad 1979$

5

Figure C-32a. Casing Air Pressure and Cooling Water Flow while Drilling in Hole 79-4 with Jet Drag Bit 
MAGMA TAPE 8

DRILL SPEED
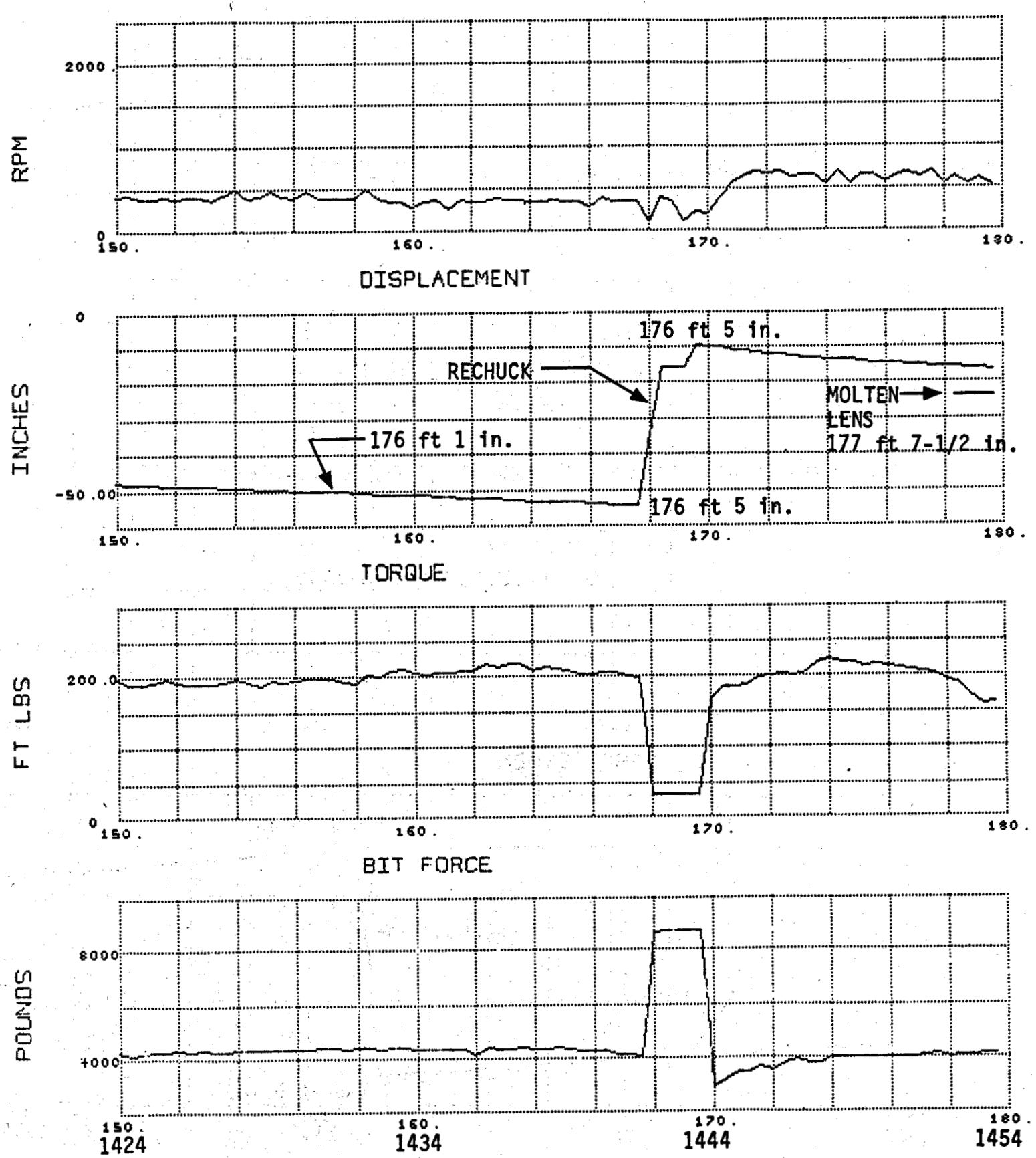

TIME IN MINUTES FROM $022 \cdot 1154 \quad 00 \quad 1979$

Figure C-33. Drilling into Flow-Back Chimney from Liquid Encounter at 179 ft 9 inches with Jet Drag Bit in Hole 79-4 (three-wing jet drag bit) 

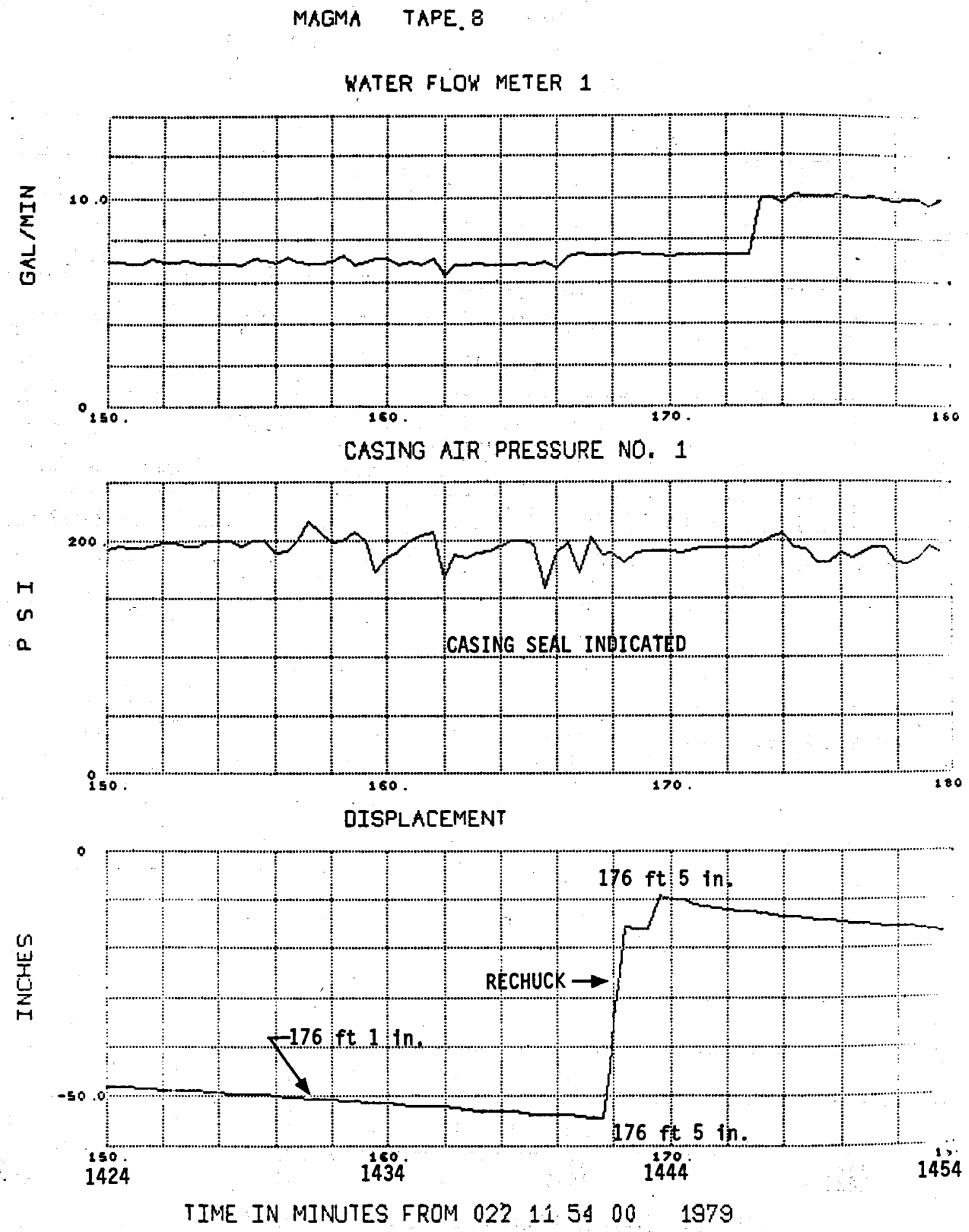

Figure C-33a. Casing Air Pressure and Cooling Water Flow Rate while Drilling in Hole 79-4 with Jet Drag Bit (three-wing jet drag bit) 


\section{MAGMA TAFE 9}

DRILL SPEED

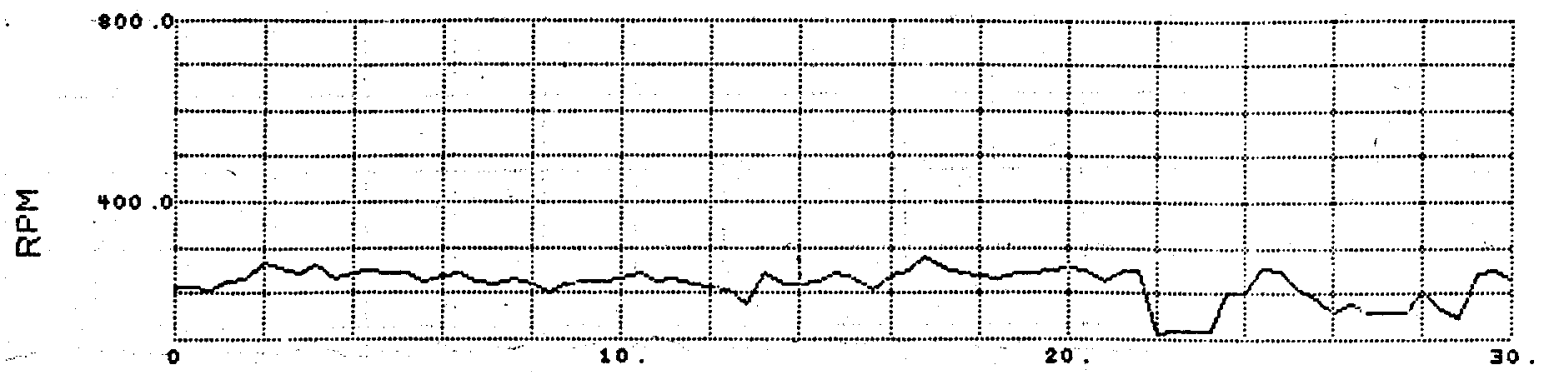

DISPLACEMENT

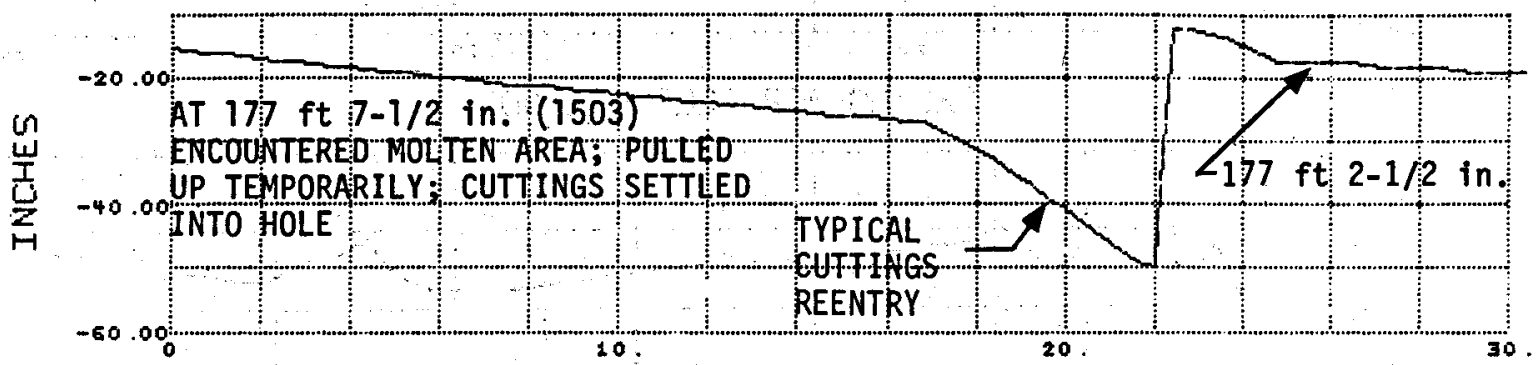

TORGUE

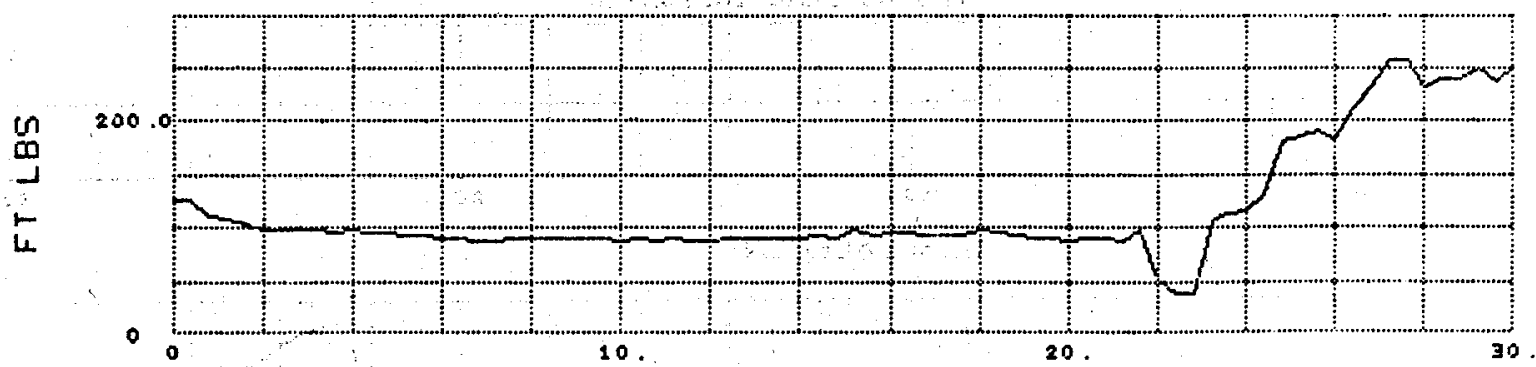

BIT FORCE

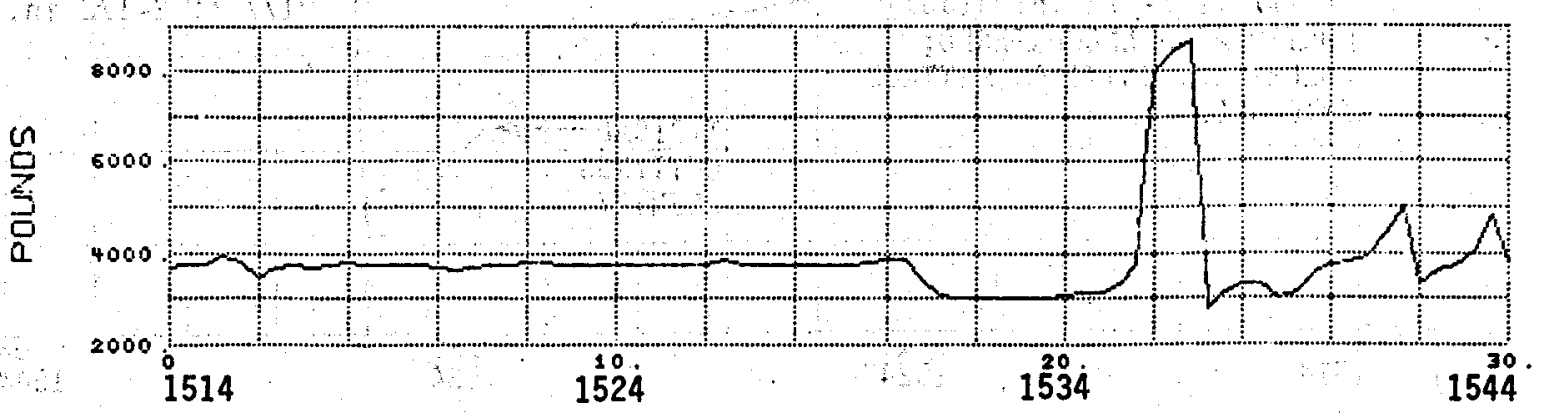

TIME IN MINUTES FROM $022 \quad 1514 \quad 00 \quad 1979$

$6+\frac{1}{10}$

Figure C-34. Drilling into Flow-Back Chimney from Liquid

Encounter at 179 ft 9 inches with Jet Drag

Bit in Hole 79-4 (three-wing jet drag bit) 
MAGMA TAPE 9

WATER FLOW METER 1
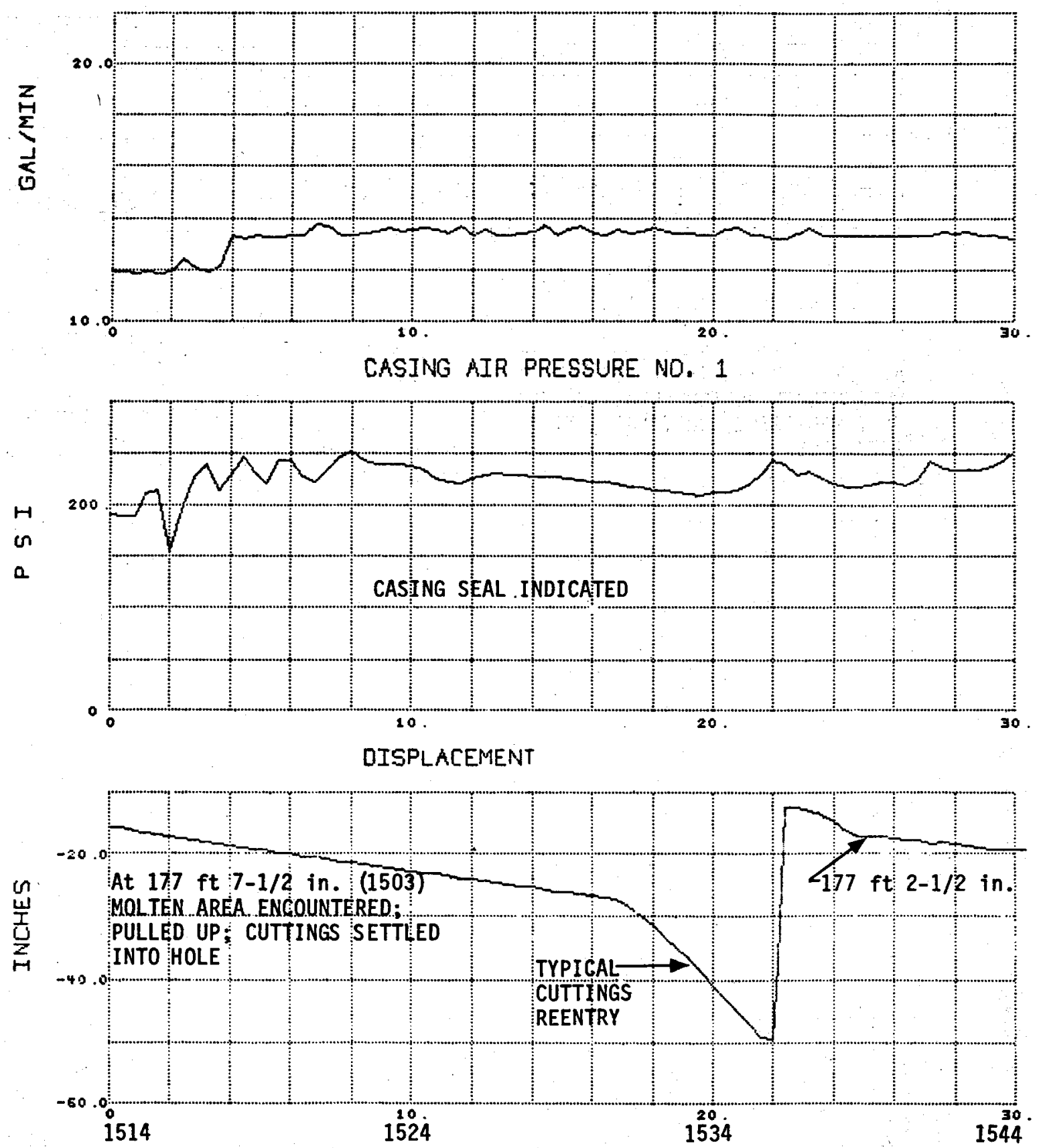

TIME IN MINUTES FROM $022 \quad 15 \quad 14 \quad 00 \quad 1979$

$1 \ldots$

Figure C-34a. Casing Air Pressure and Cooling Water Flow while Drilling in Hole 79-4 with Jet Drag Bit 

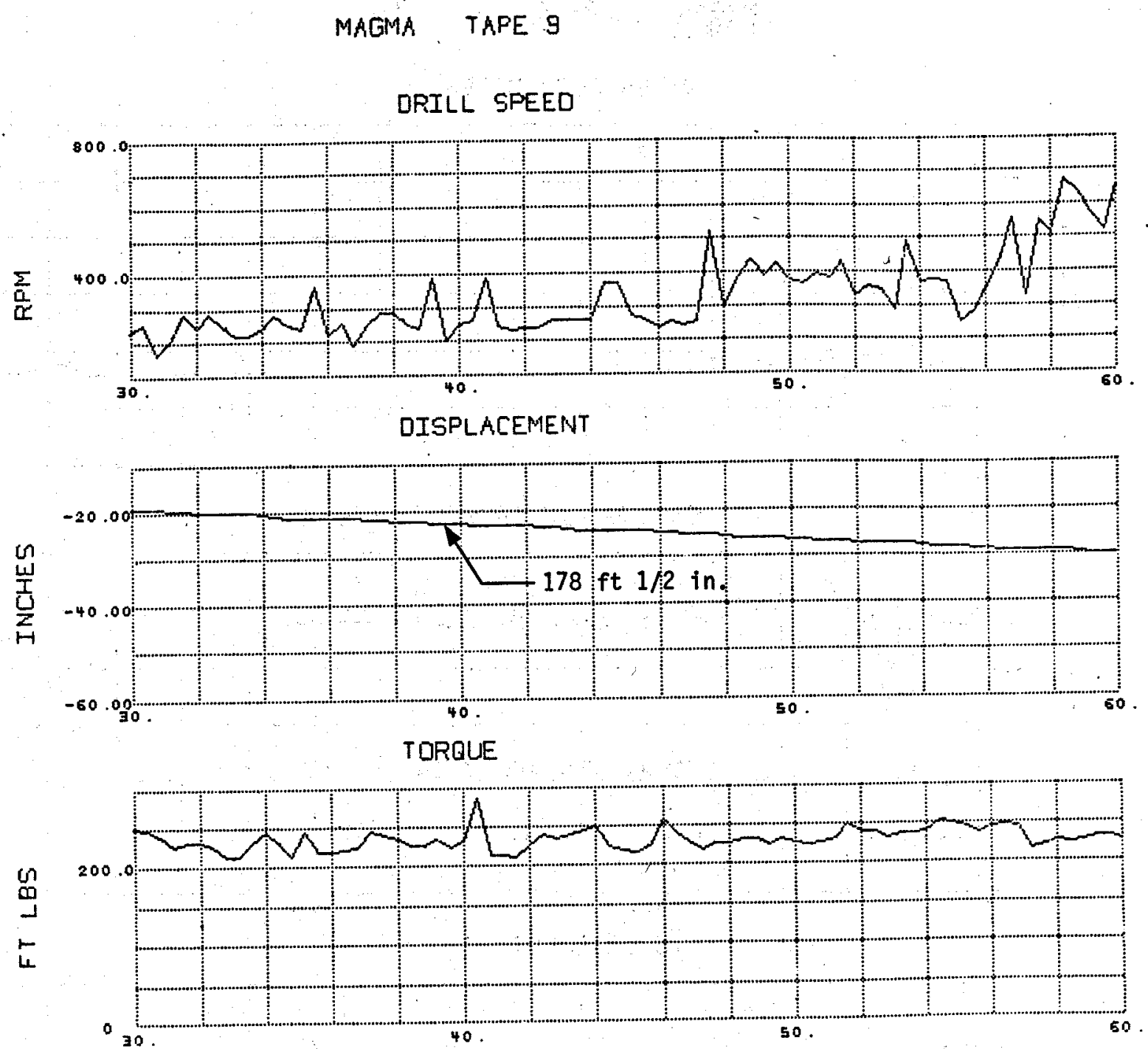

BIT FDRCE

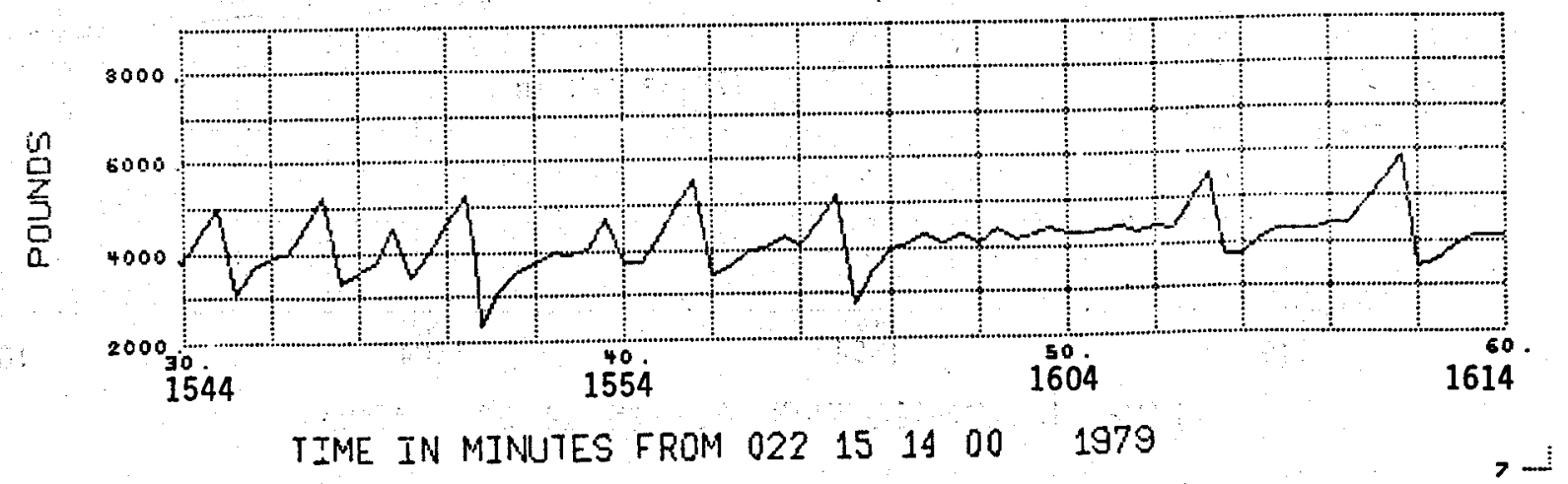

Figure C-35. Drilling in Flow-Back Chimney from Liquid Encounter at $179 \mathrm{ft} 9$ inches with Jet Drag Bit in Hole 79-4 (three-wing jet drag bit) 
MAGMA TAPE. 9

WATER FLOK METER 1
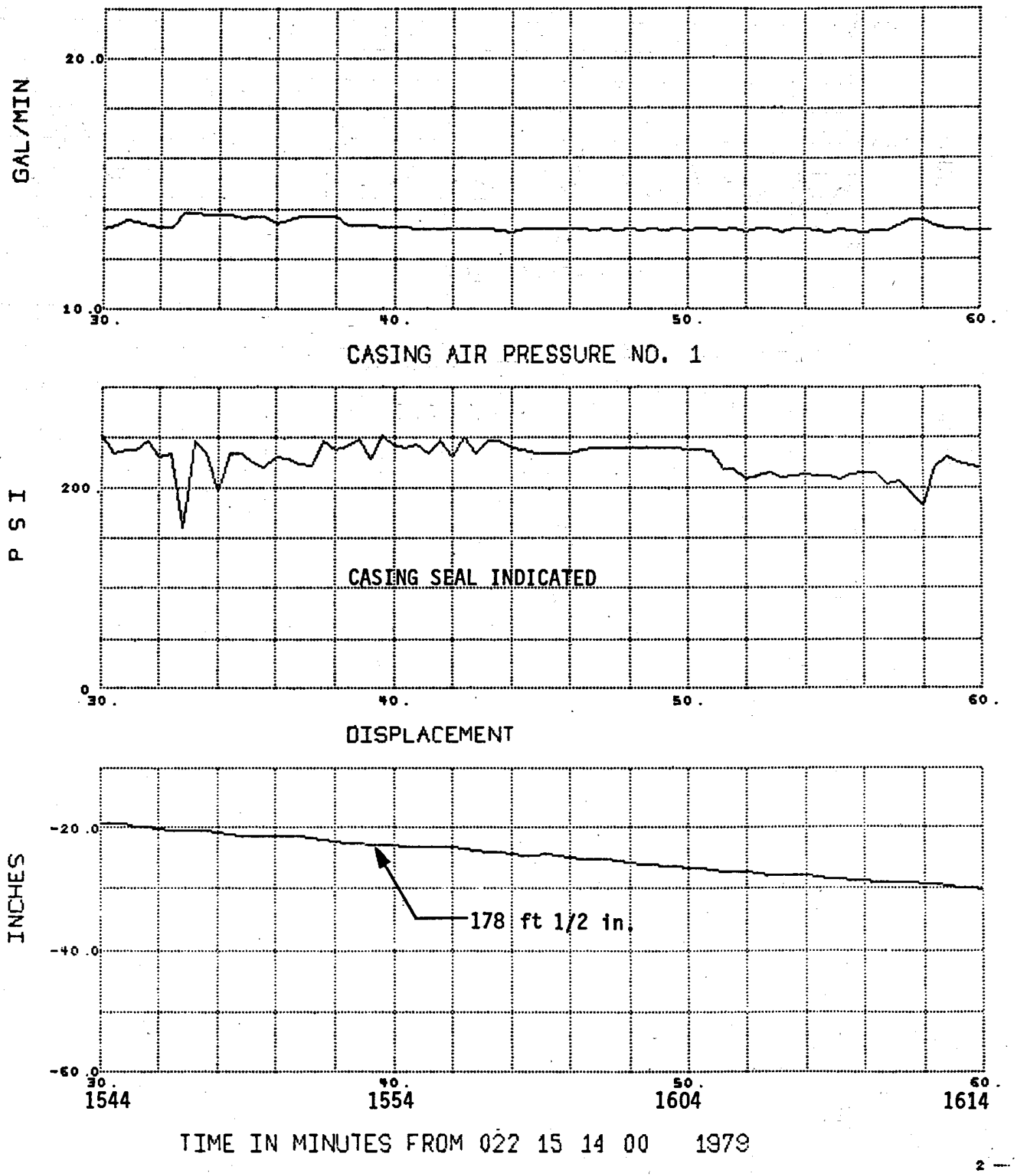

Figure C-35a. Casing Air Pressure and Cooling Water Flow while Drilling in Hole 79-4 with Jet Drag Bit 
DRILL SPEED
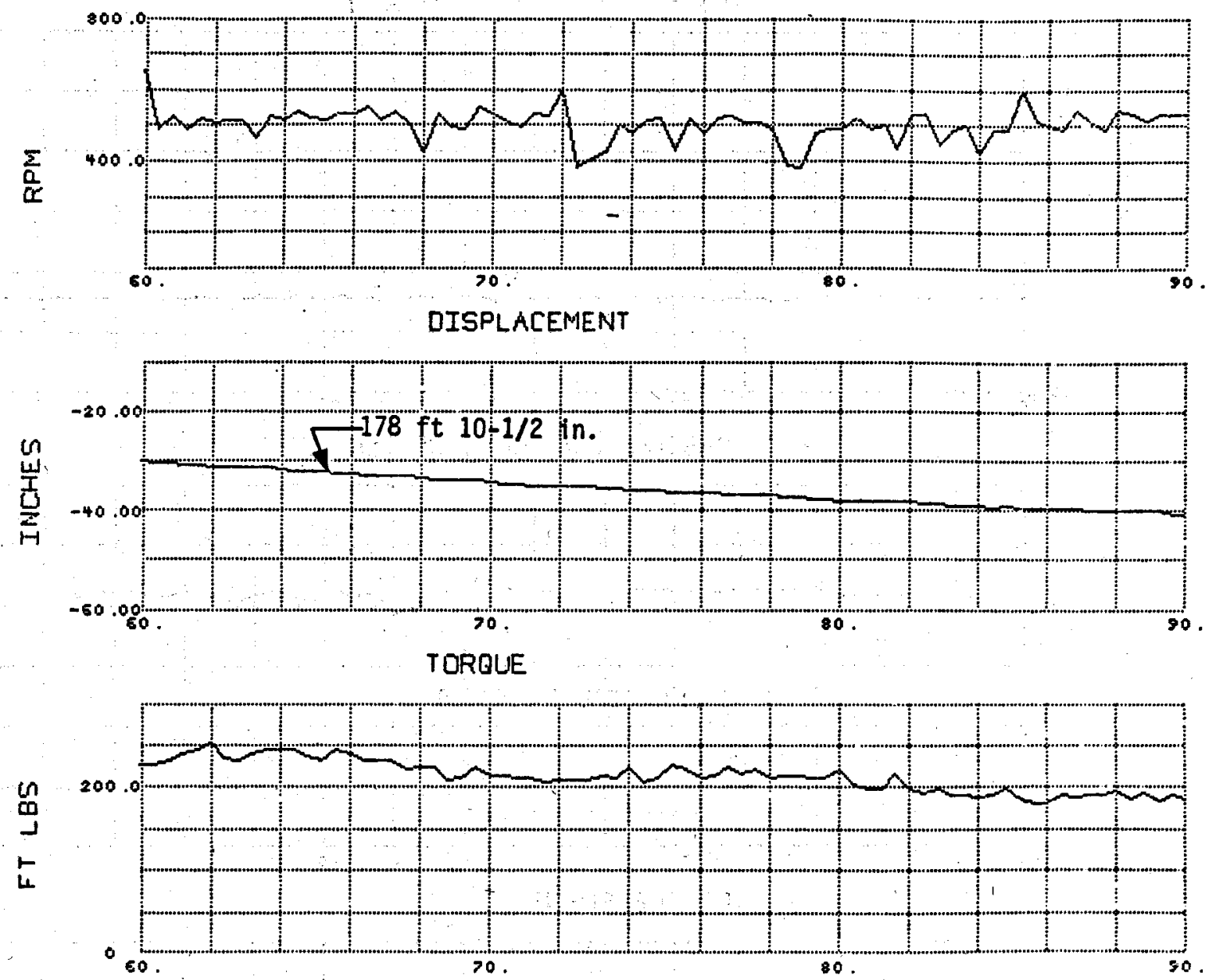

BIT FDRCE
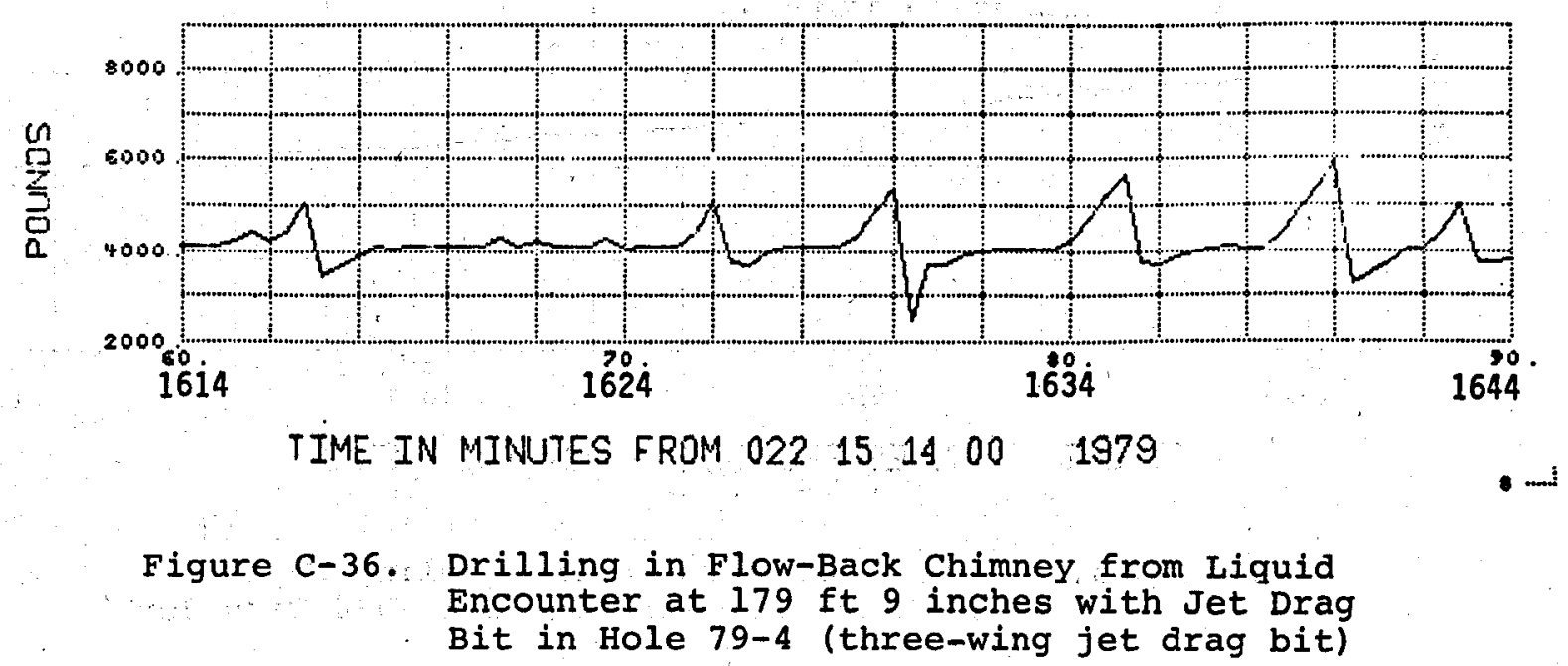
MAGMA TAPE 9

WATER FLOW METER 1
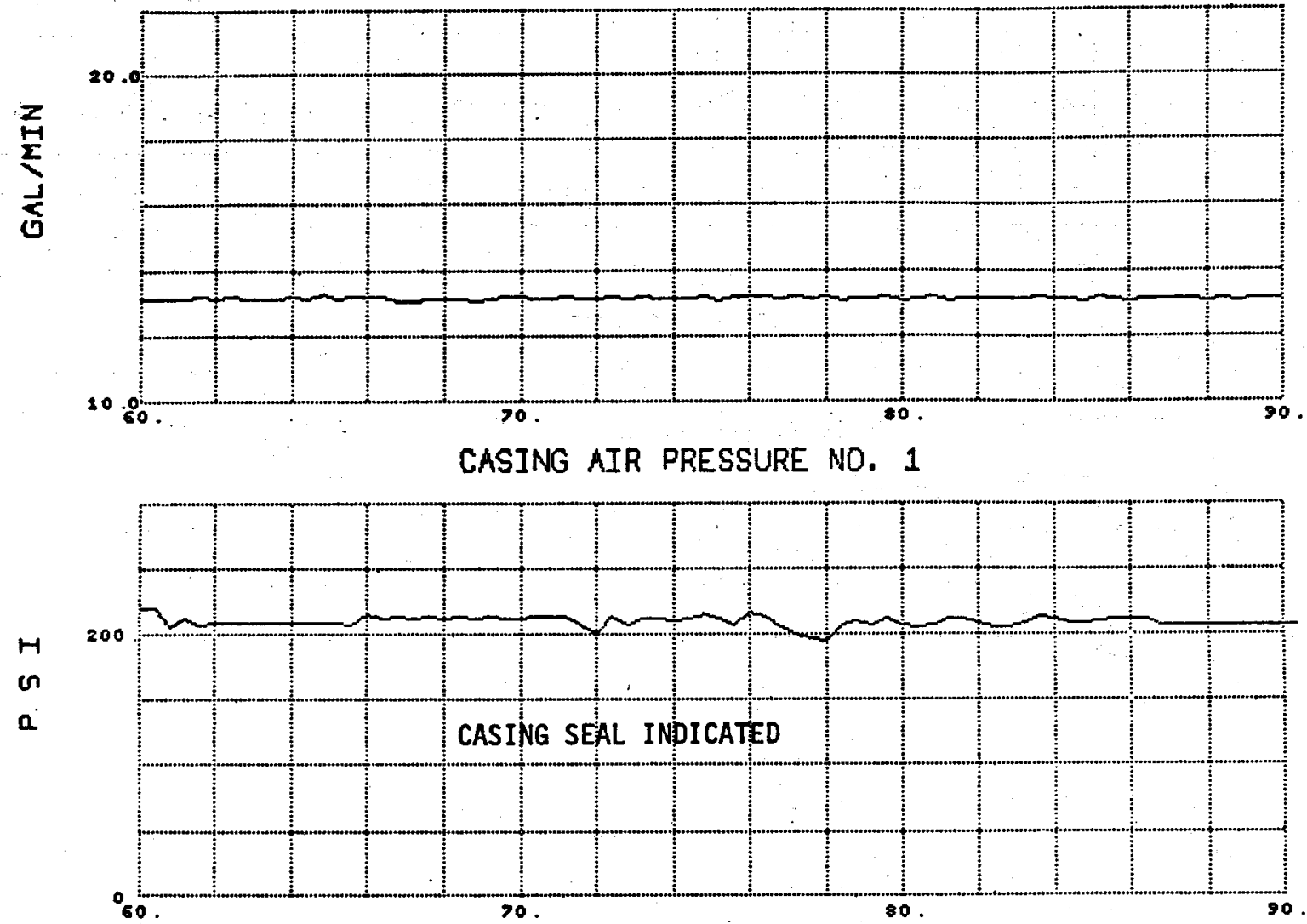

DISPLACEMENT

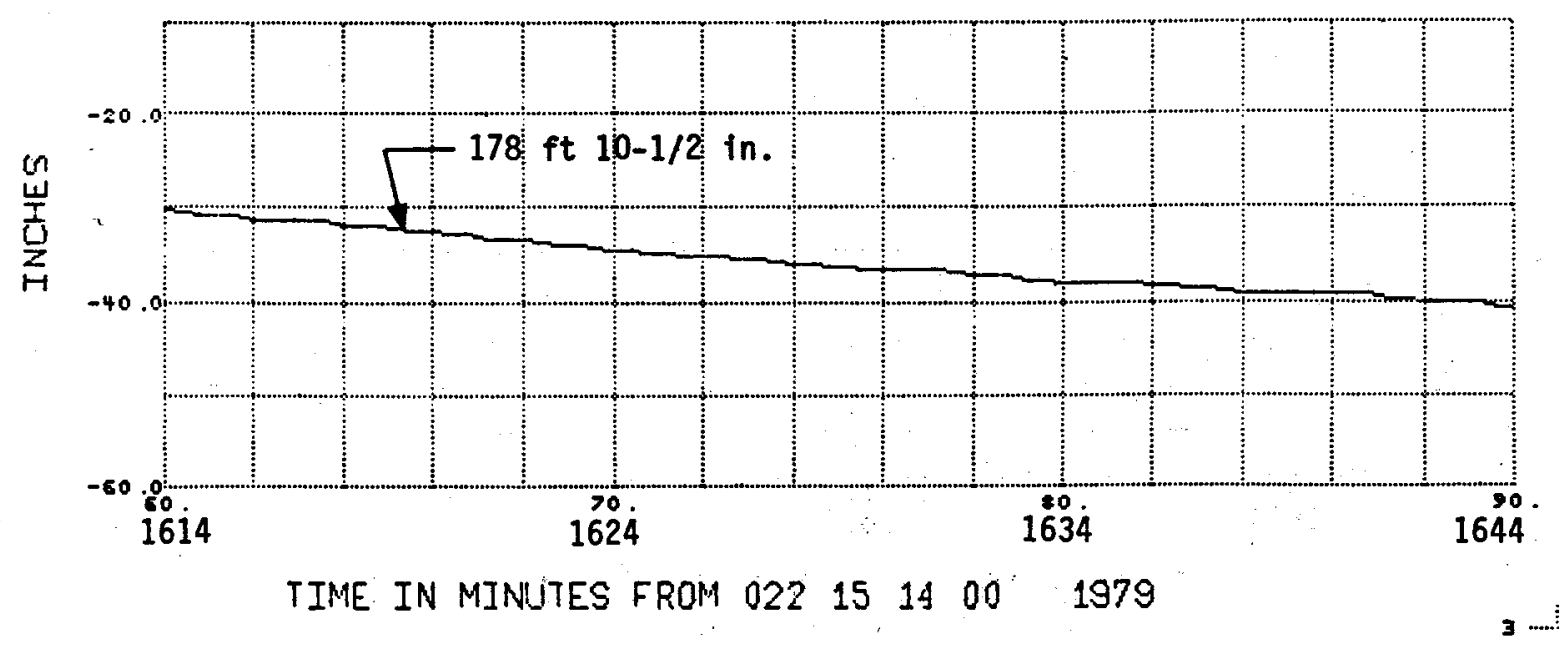

Figure C-36a. Casing Air Pressure and Cooling Water Flow while Drilling in Hole 79-4 with Jet Drag Bit 
MAGMA TAPE 9

DRILL SPEED
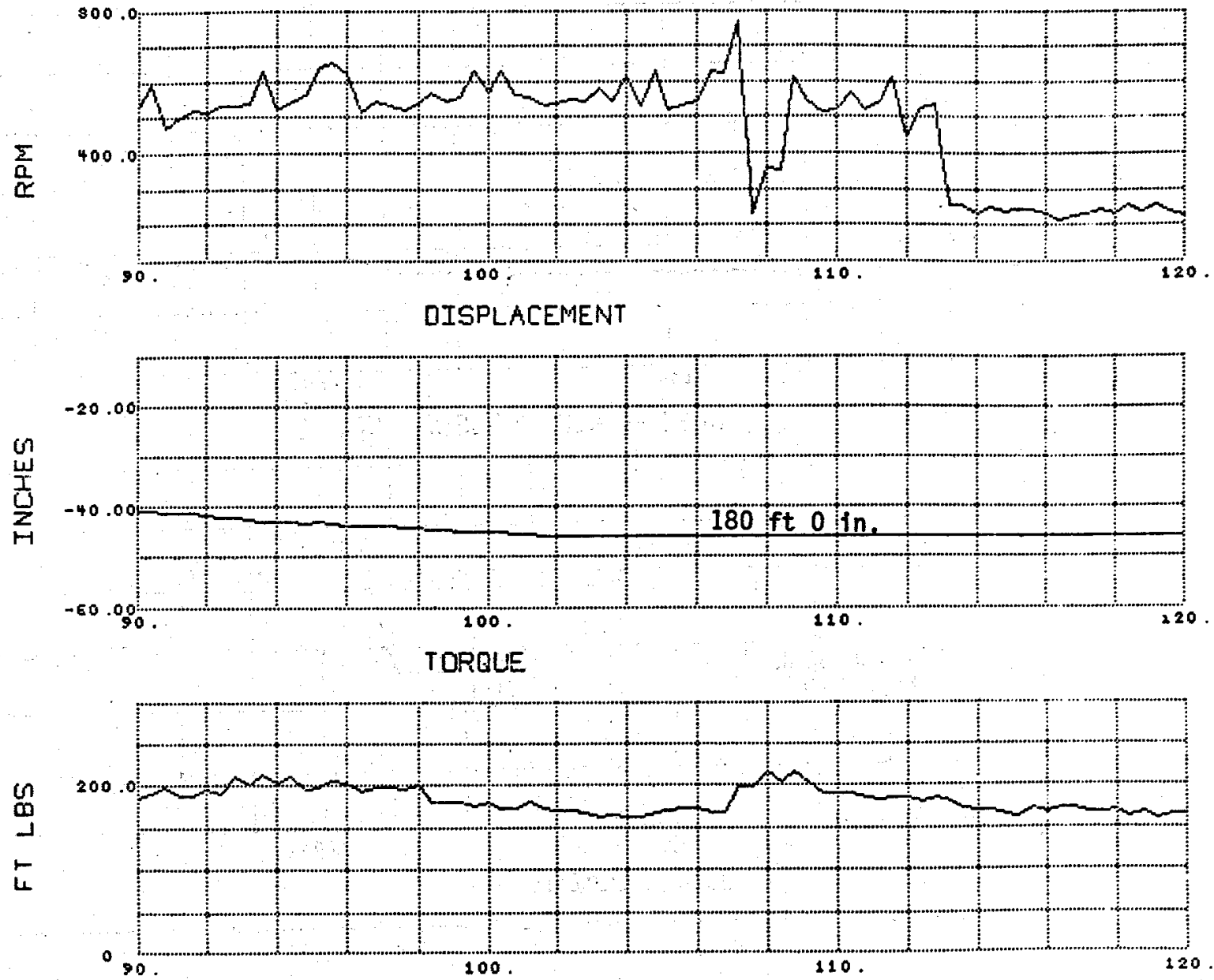

BIT FORCE

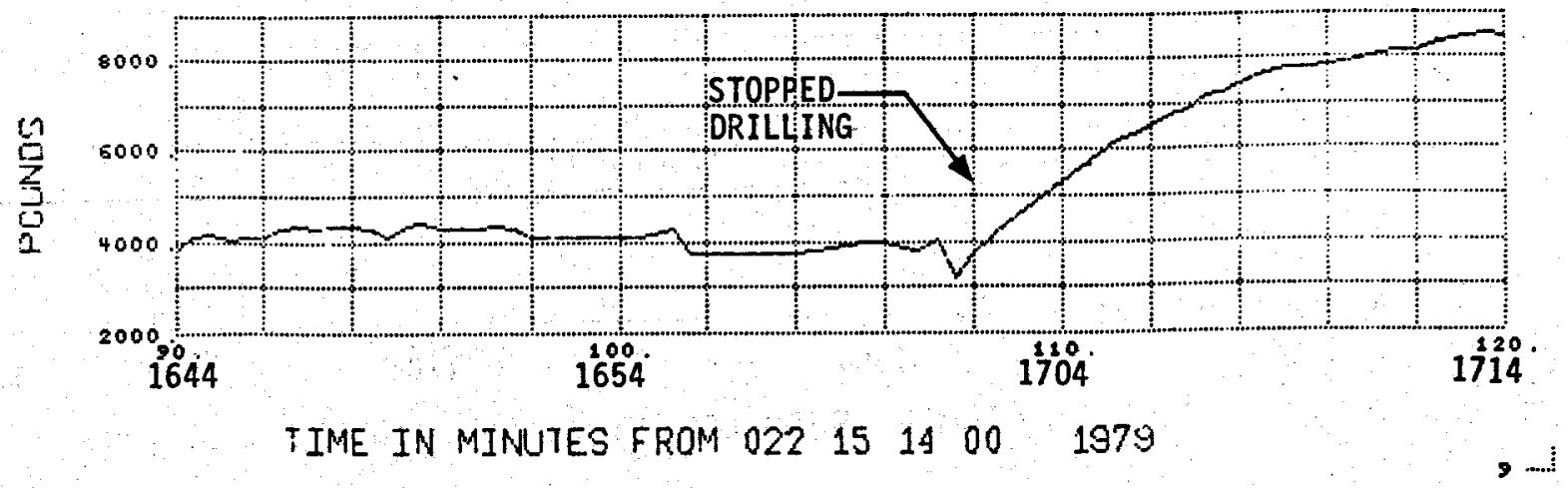

Figure C-37. Drilling through 179 ft 9 inches Melt zone in Hole 79-4 with Jet Drag Bit (three-wing jet drag bit) 
MAGMA TAPE 9

WATER FLOW METER 1
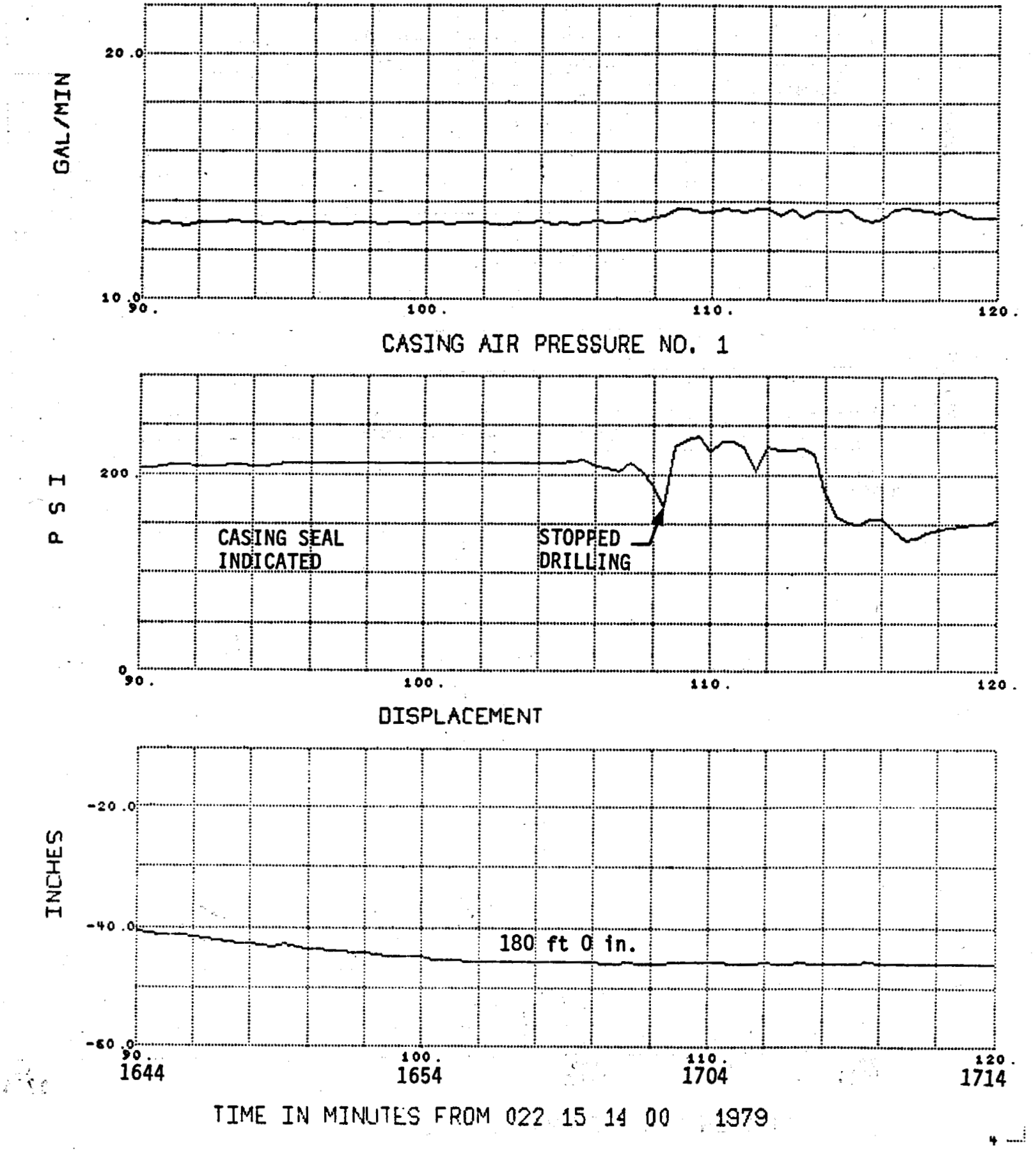

Figure C-37a. Casing Air Pressure and Cooling Water Flow while Drilling in Hole 79-4 with Jet Drag Bit 
MAGMA TAPE 9

DRILL SPEED
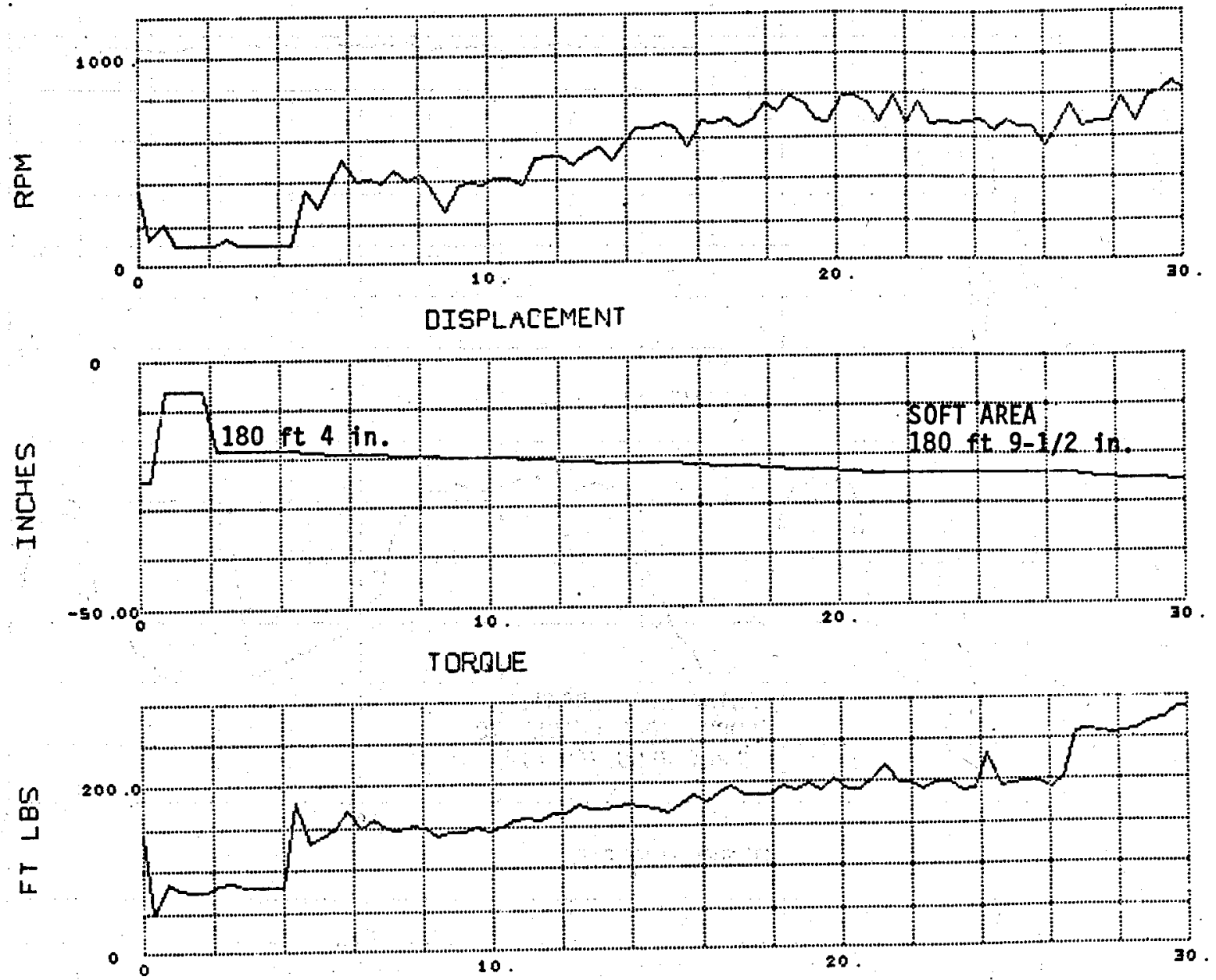

BIT FORCE

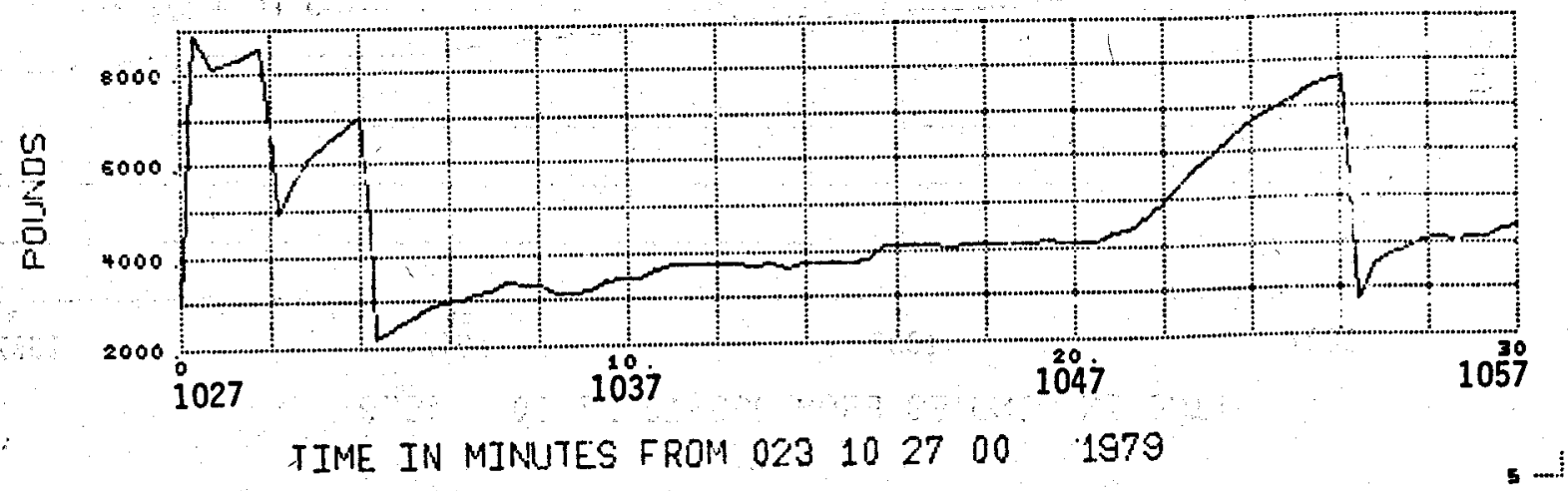

Figure $\mathrm{C}-38$. Drilling in original Rock below $179 \mathrm{ft} 9$ inches Melt Zone in Hole 79-4 with Jet Drag Bit (threewing jet drag bit) 
MAGMA TAPE 9
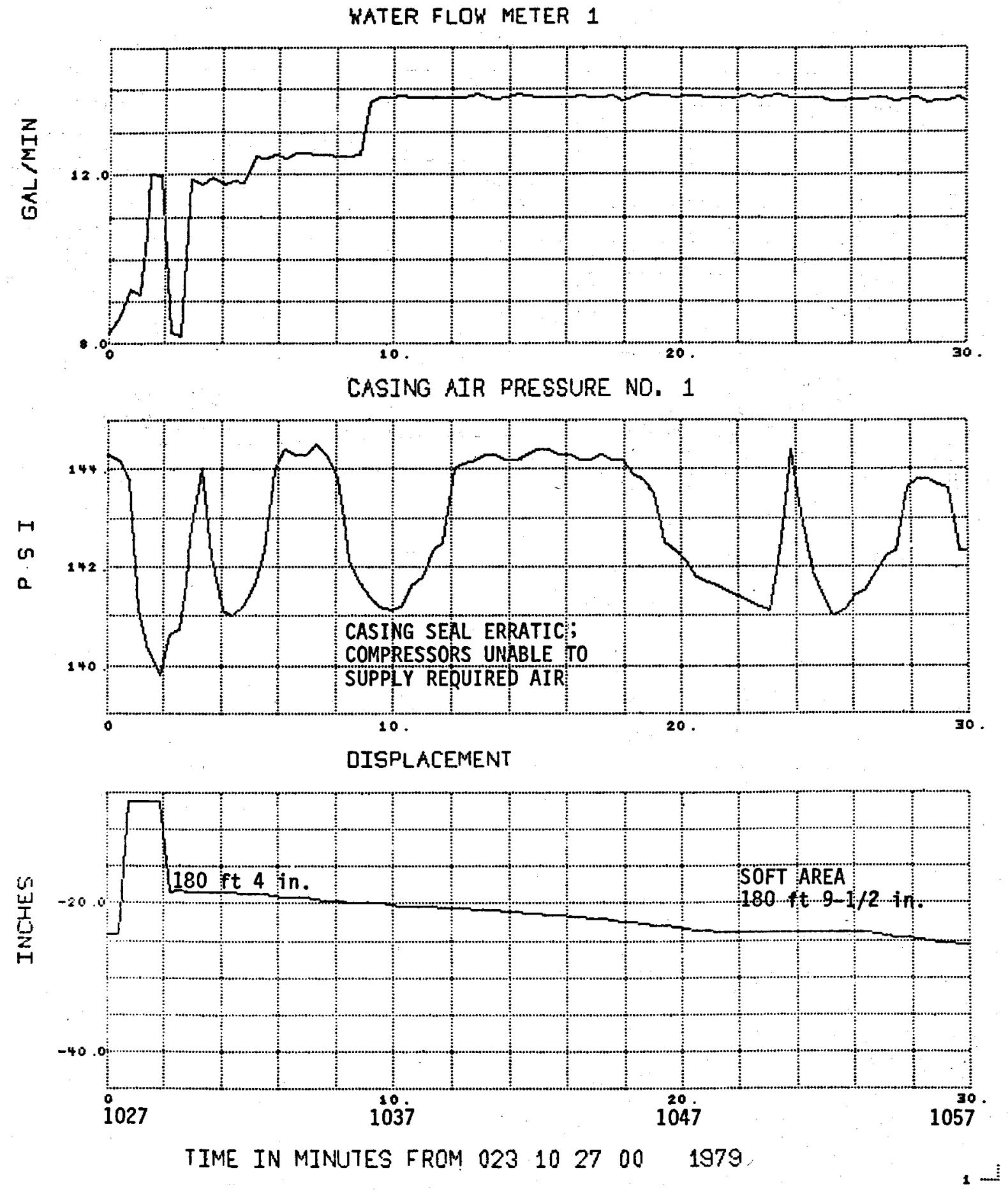

Figure C-38a. Casing Air Pressure and Cooling Water Flow while Drilling in Hole 79-4 with Jet Drag Bit 

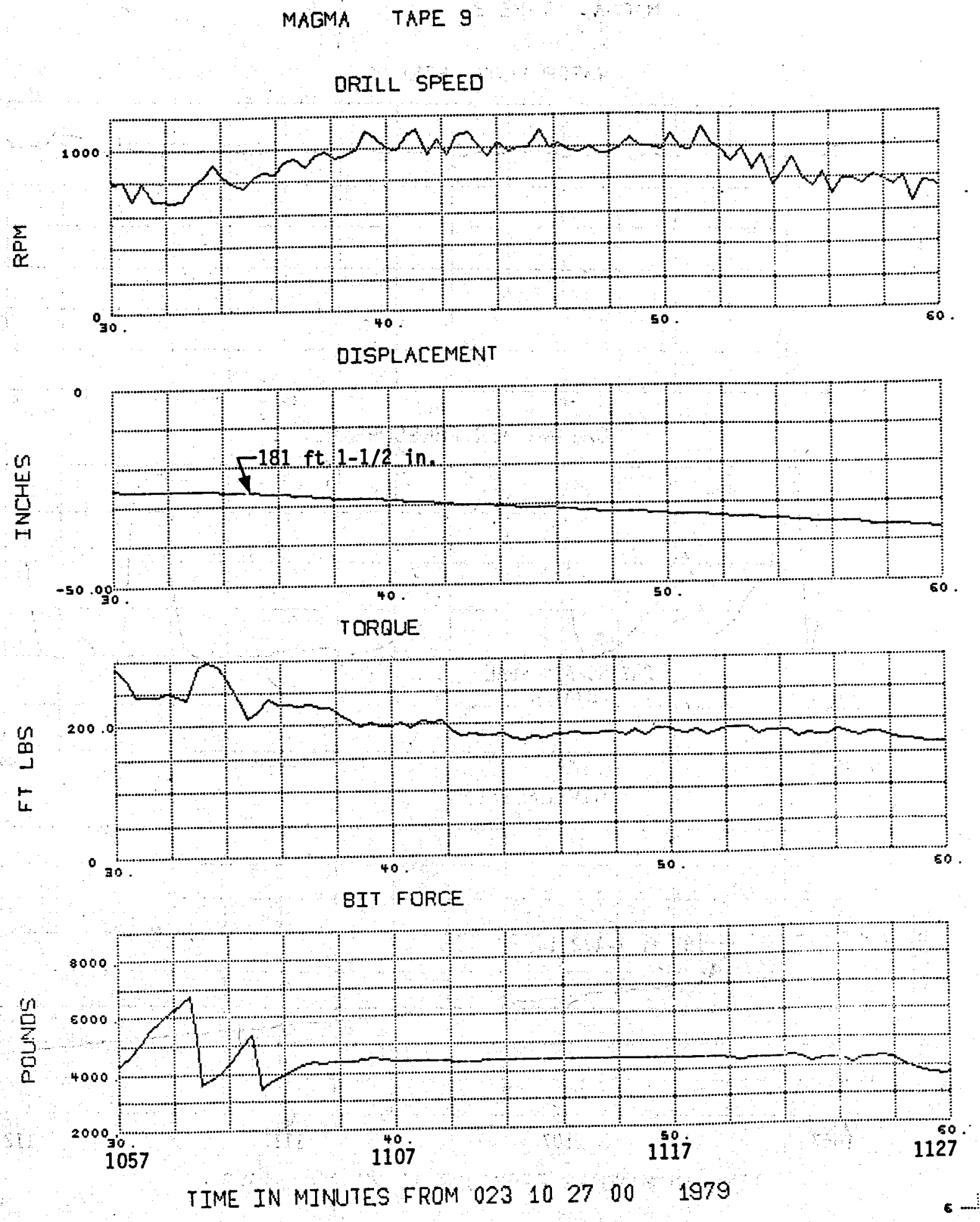

Figure C-39. Drilling in Original kock below $179 \mathrm{ft} 9$ inches
Melt Zone in Hole $79-4$ with Jet Drag Bit (three-
wing drag bit) 
MAGMA TAPE 9

WATER FLOW METER 1

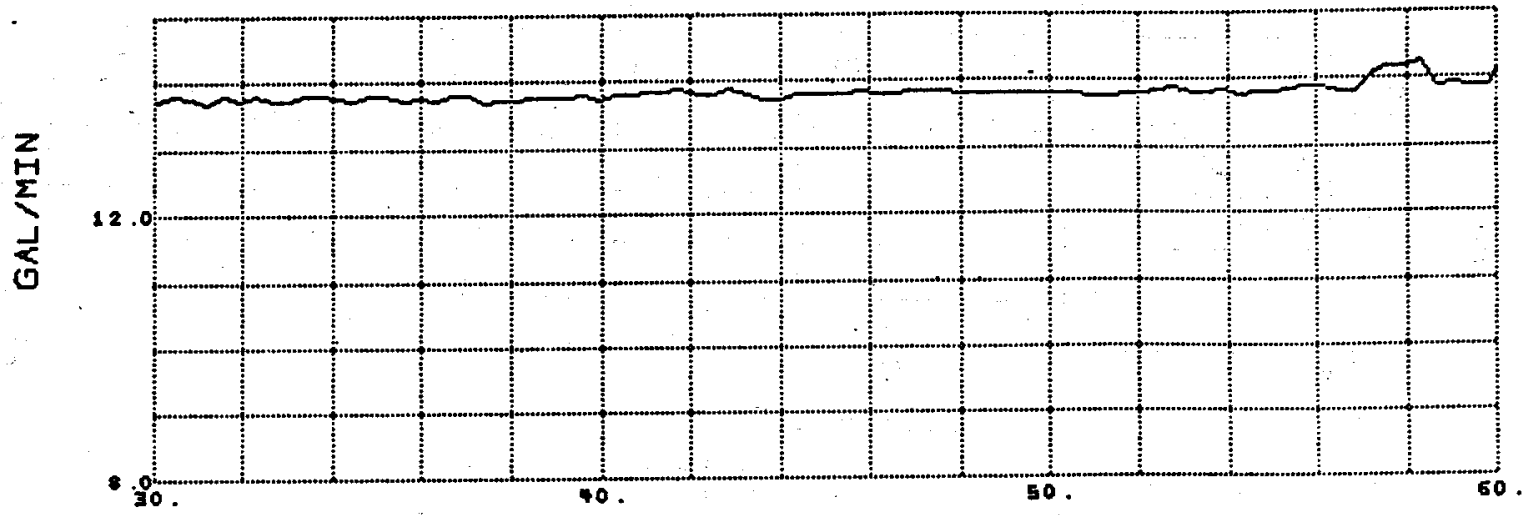

CASING AIR PRESSURE NO. 1

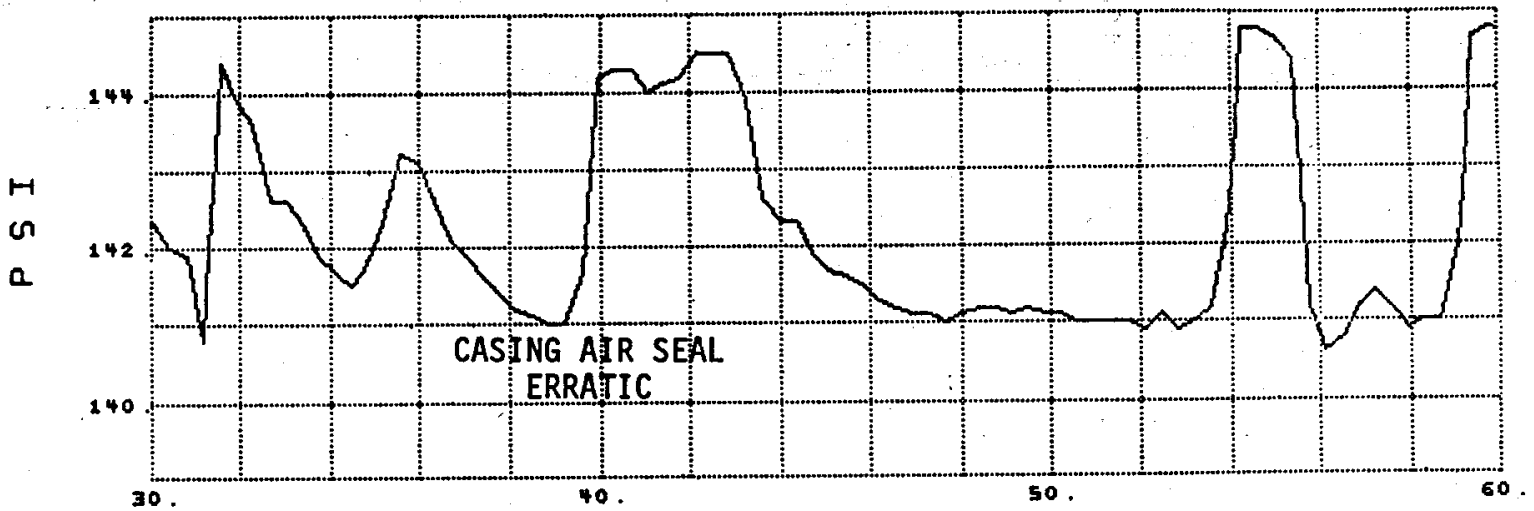

DISPLACEMENT

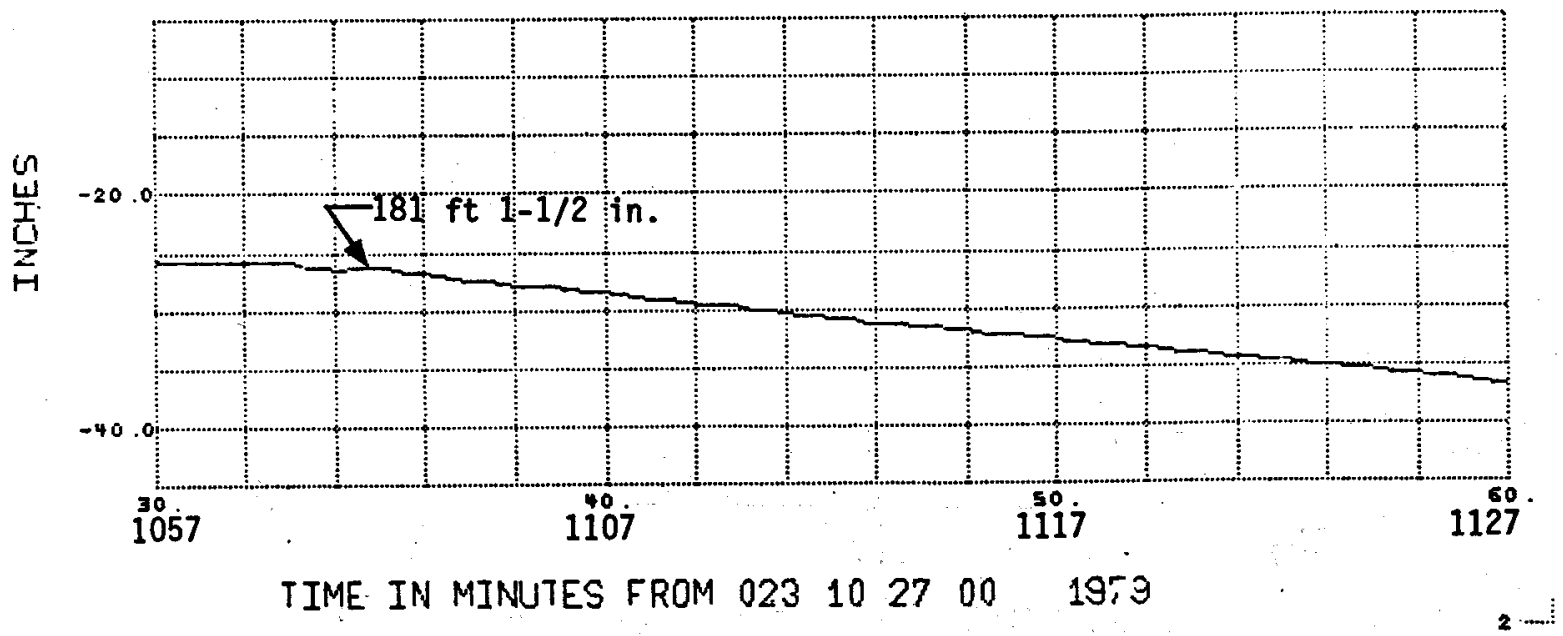

Figure C-39a. Casing Air Pressure and Cooling Water Flow while Drilling in Hole 79-4 with Jet Drag Bit 


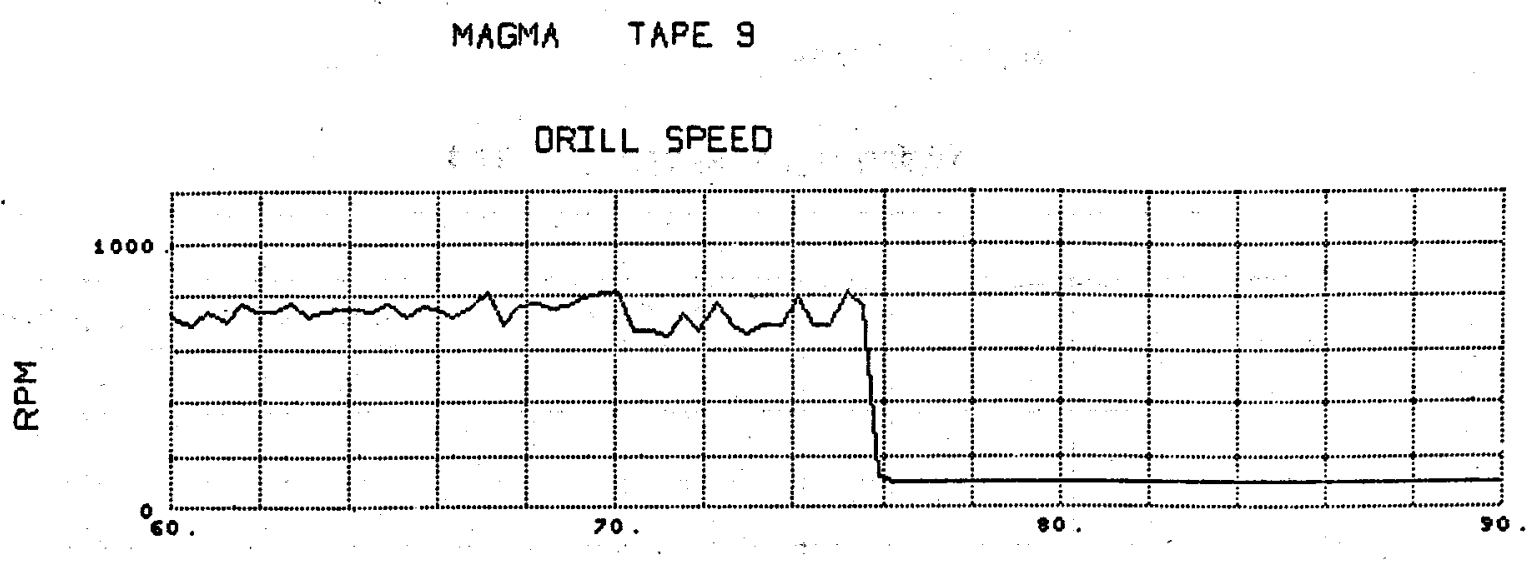

OISPLACEMENT
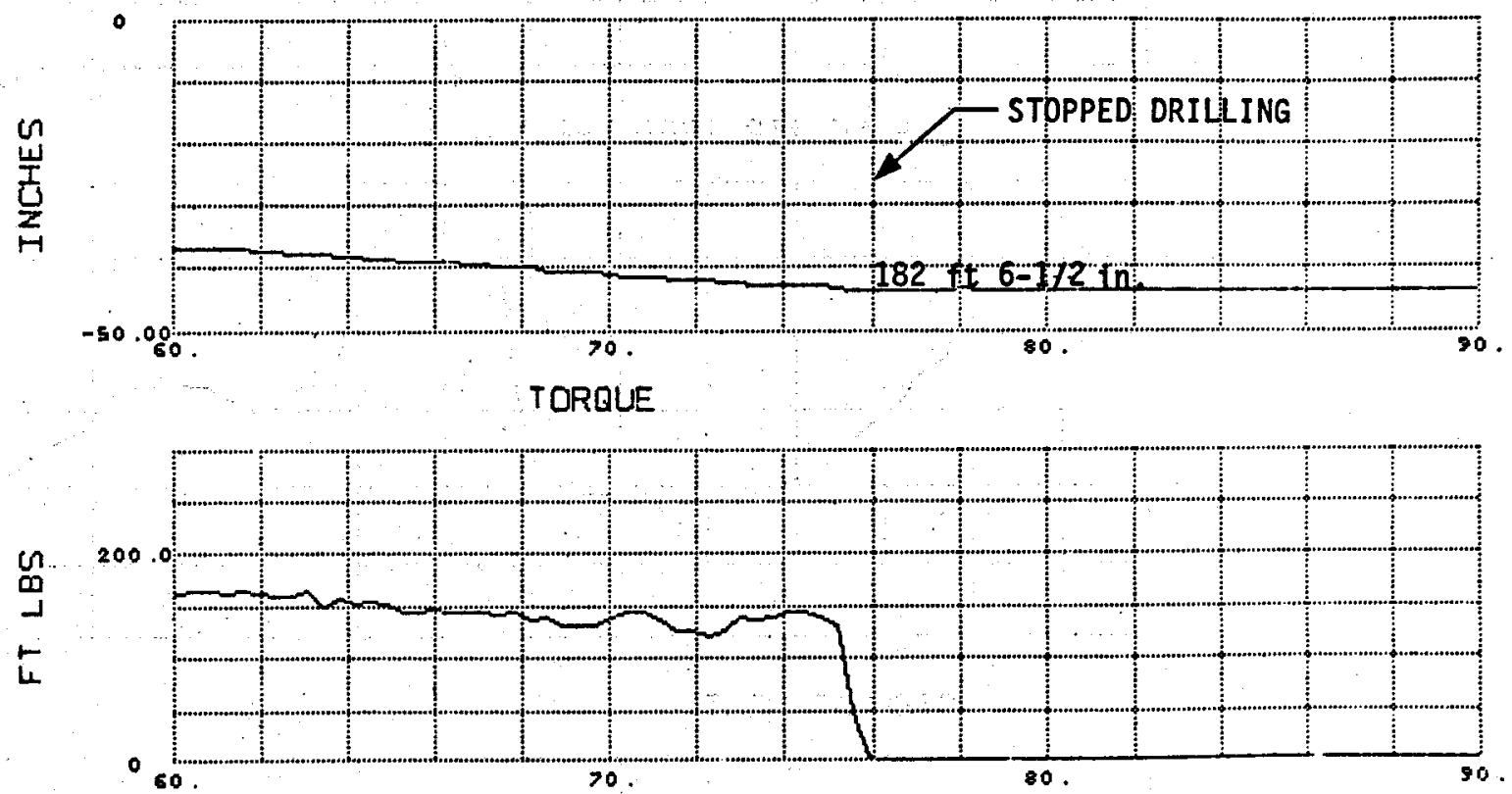

BIT FORCE

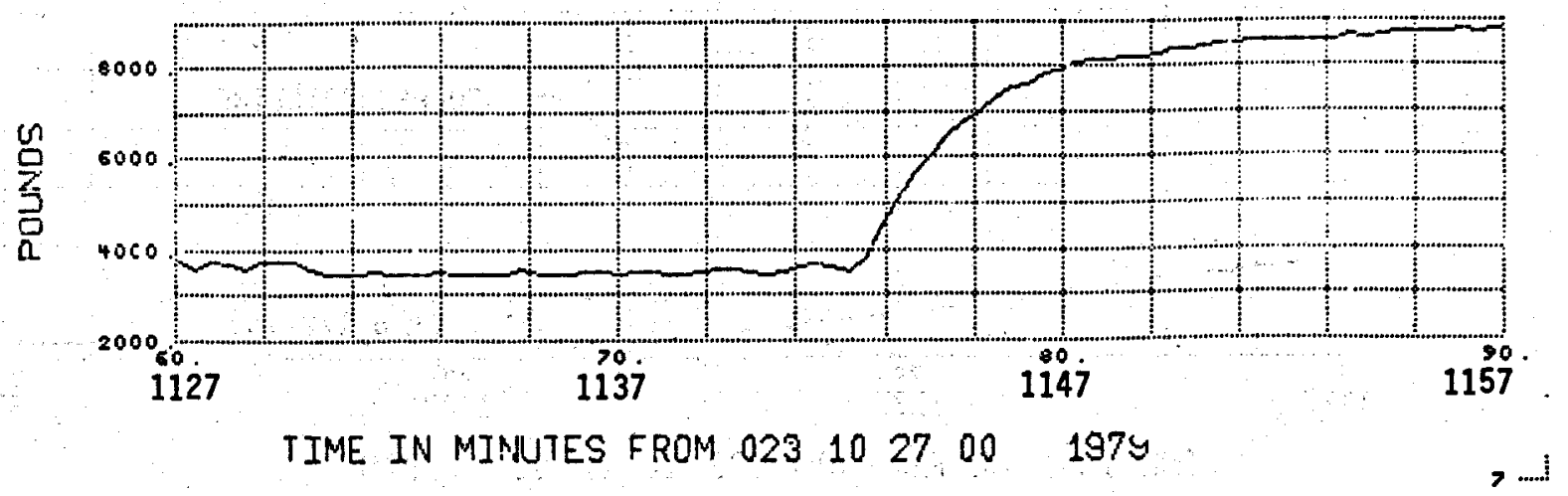

Figure C-40. Drilling in Original Rock below $179 \mathrm{ft} 9$ inches Melt zone in Hole 79-4 with Jet Drag Bit (threewing jet drag bit) 

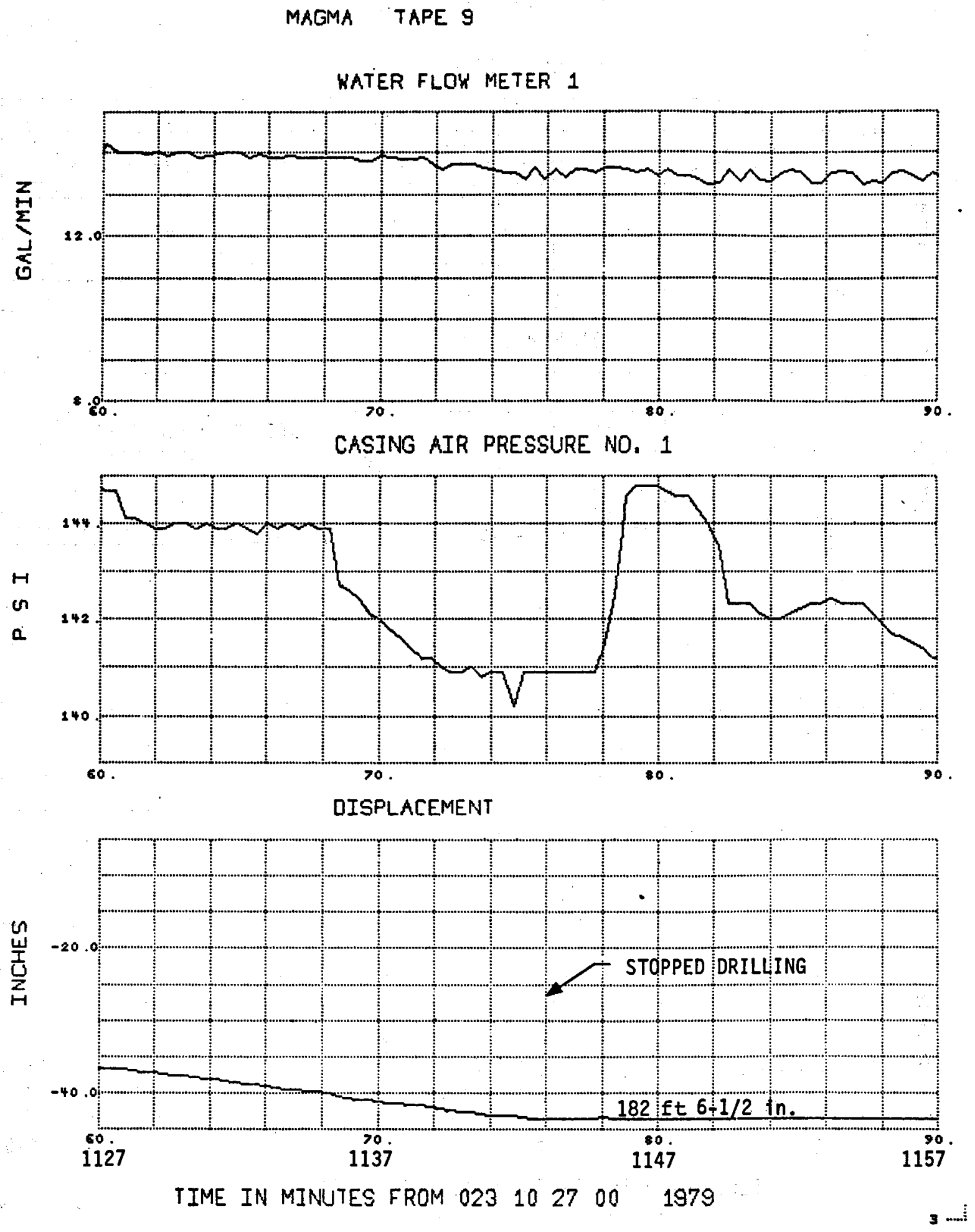

Figure C-40a. Casing Air Pressure and Cooling Water Flow while Drilling in Hole 79-4 with Jet Drag Bit 
MAGMA TAPE 9

ORILL SPEED
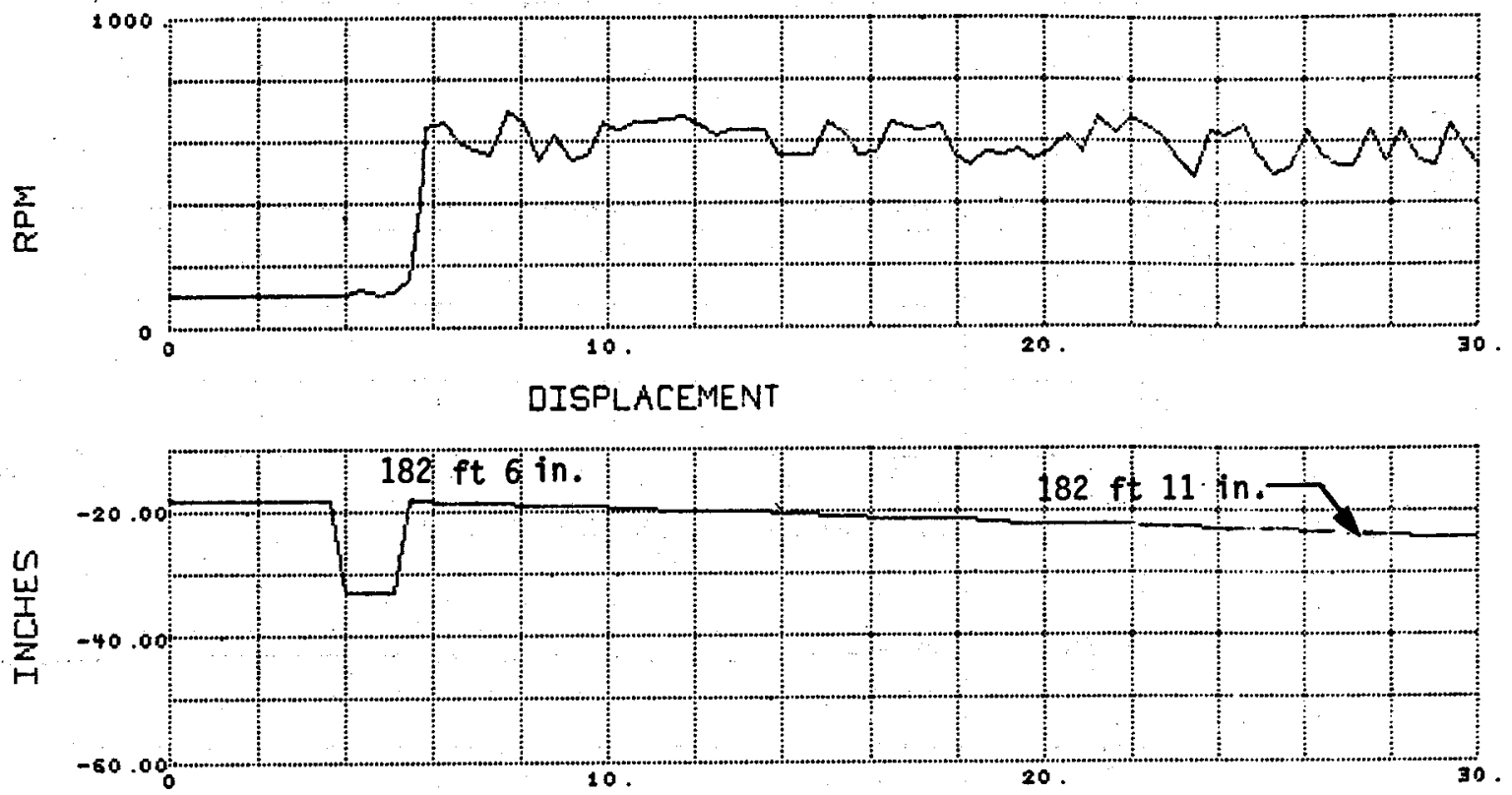

TORQQUE

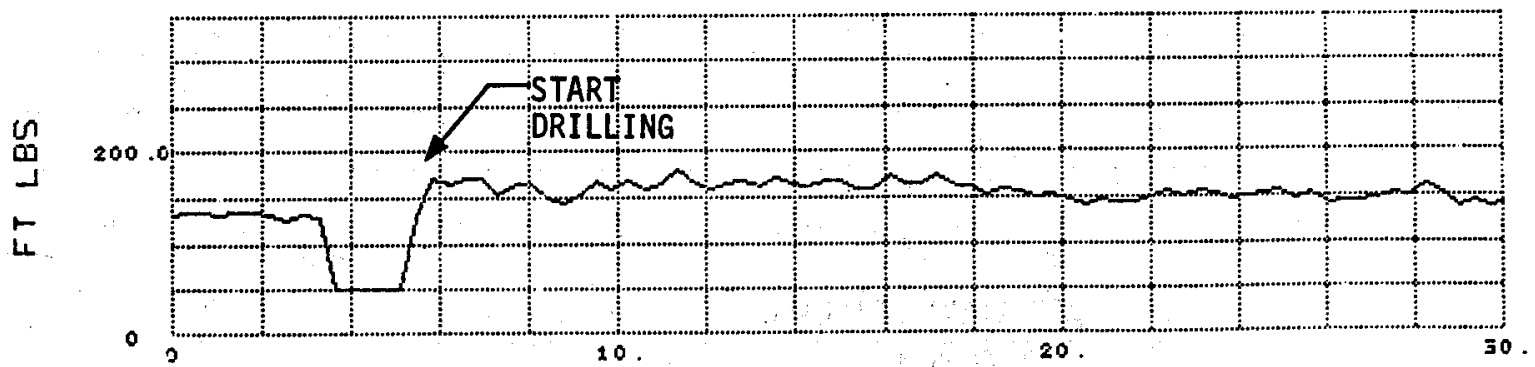

BIT FORCE

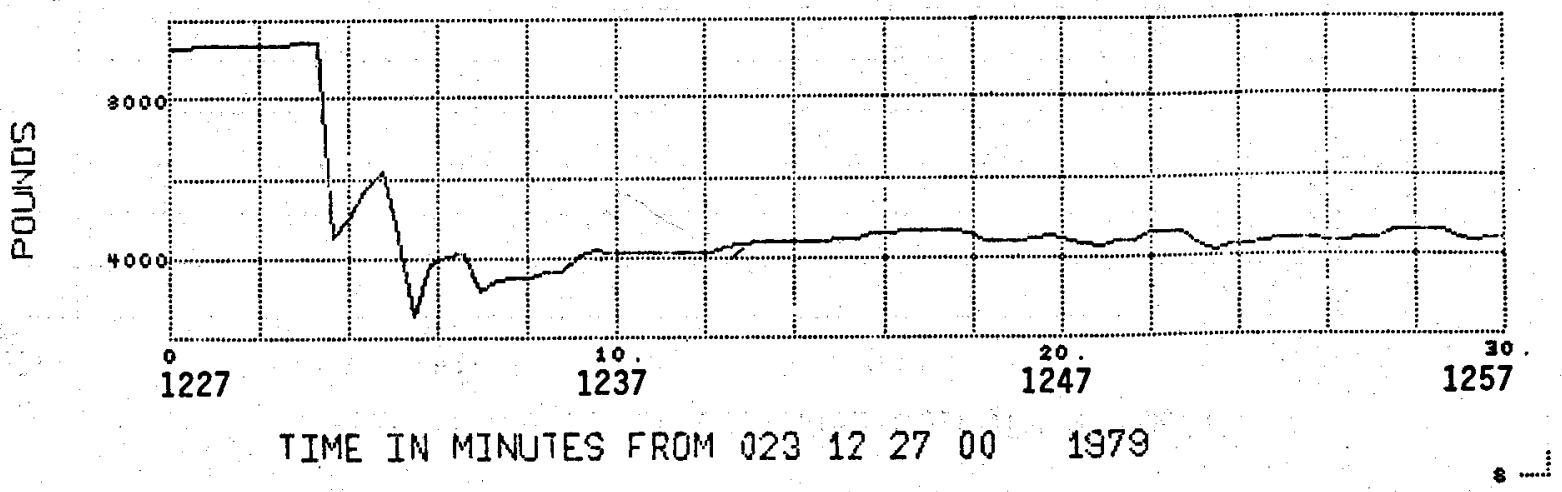

Figure C-41. Drilling in Original Rock below 179 ft 9 inches Melt Zone in Hole 79-4 with Jet Drag Bit 

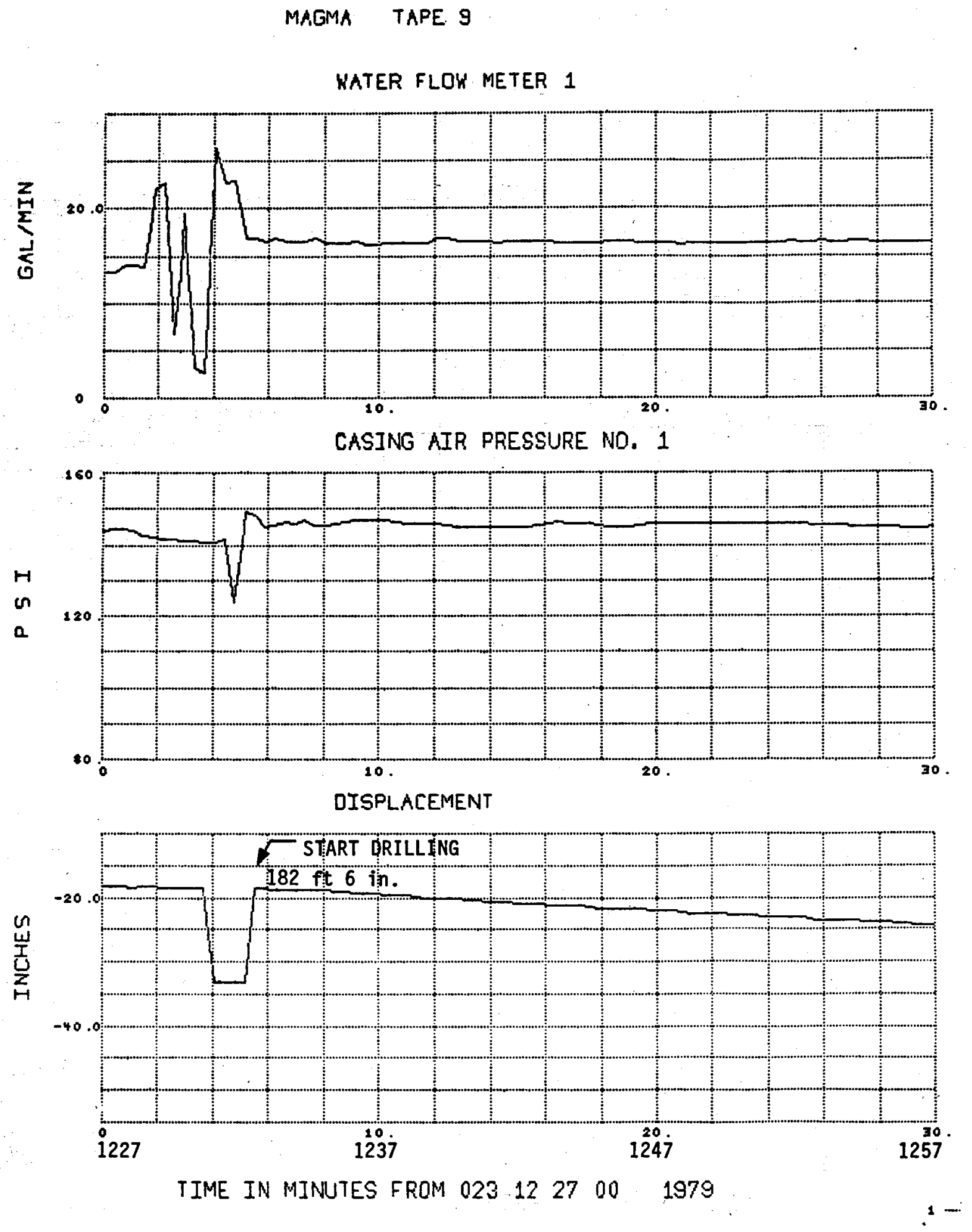

Figure C-4la. Casing Air Pressure and Cooling Water Flow while Drilling in Hole 79-4 with Jet Drag Bit 


\section{MAGMA TAPE 9}

DRILL SPEED

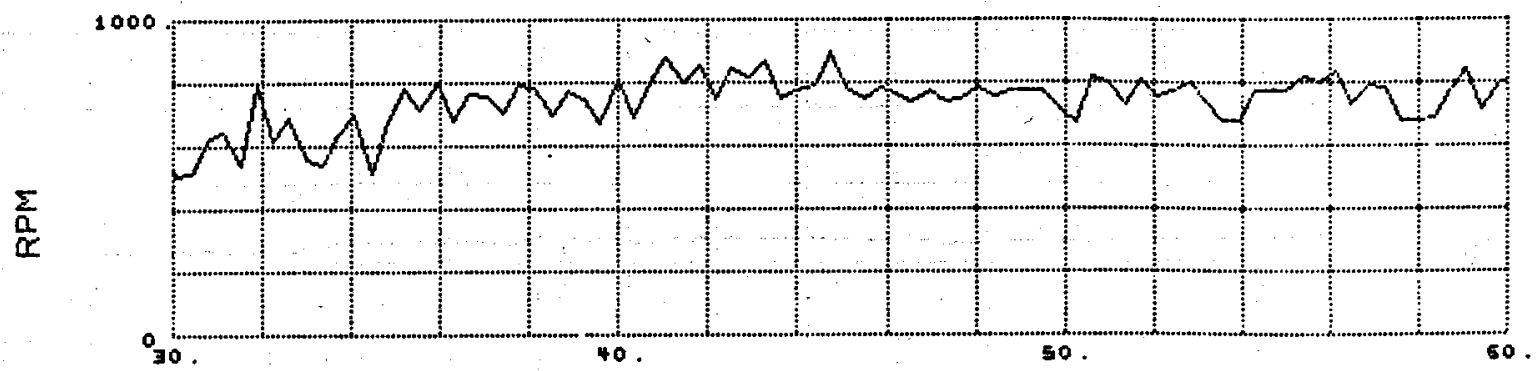

DISPLACEMENT

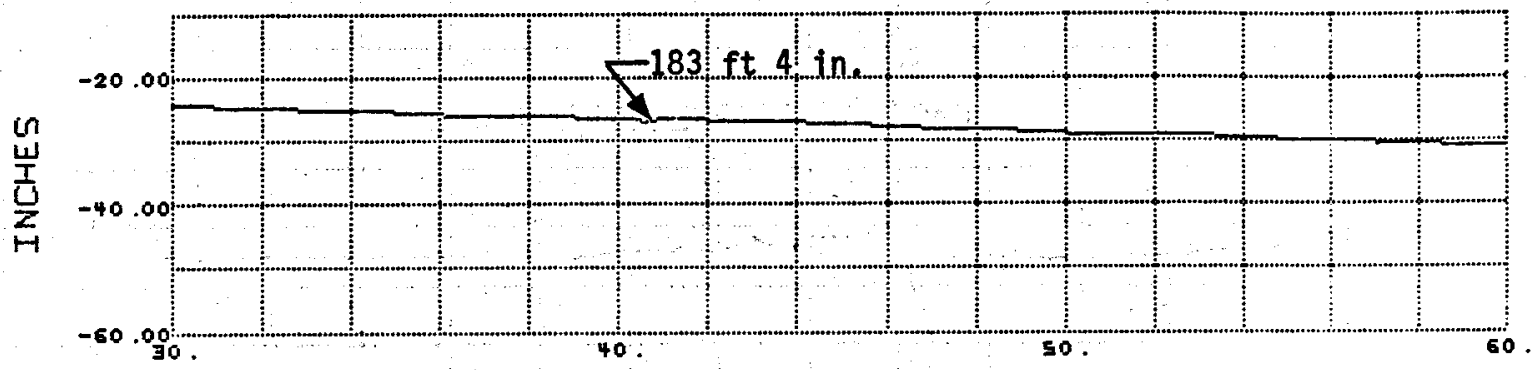

TORQUE

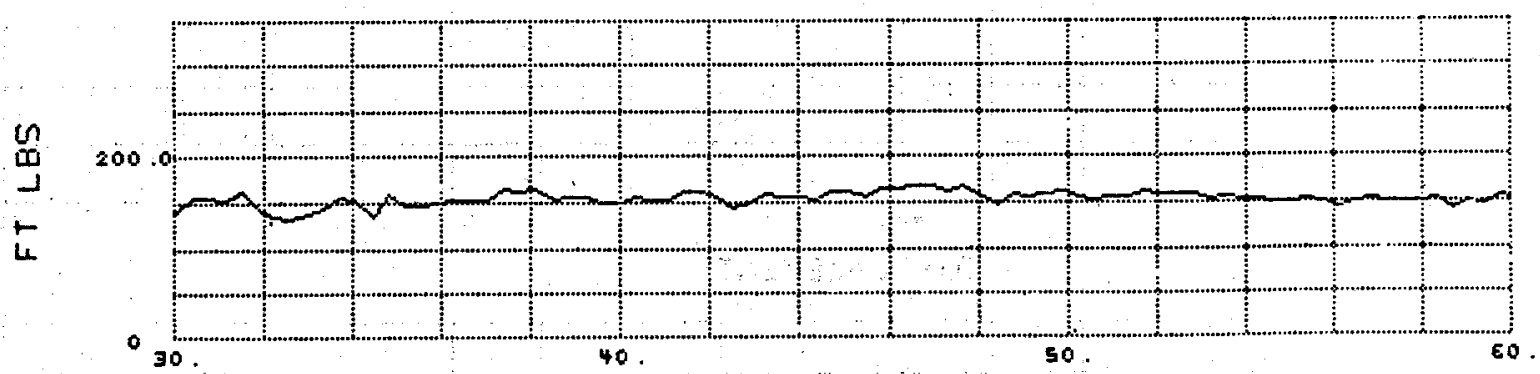

BIT FORCE

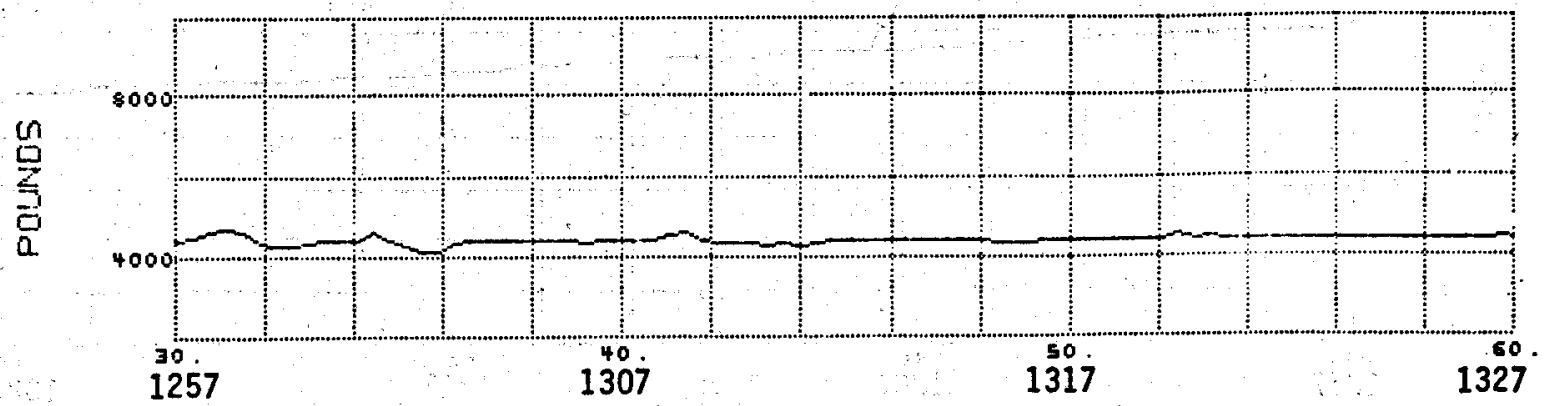

TIME IN MINUTES FROM $023 \quad 12 \quad 2700,1979$

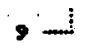

Figure c-42. Drilling in original Rock below 179 ft 9 inches Melt zone in Hole 79-4 with Jet Drag Bit (threewing jet drag bit) 
MAGMA TAPE 9

WATER FLOW METER 1
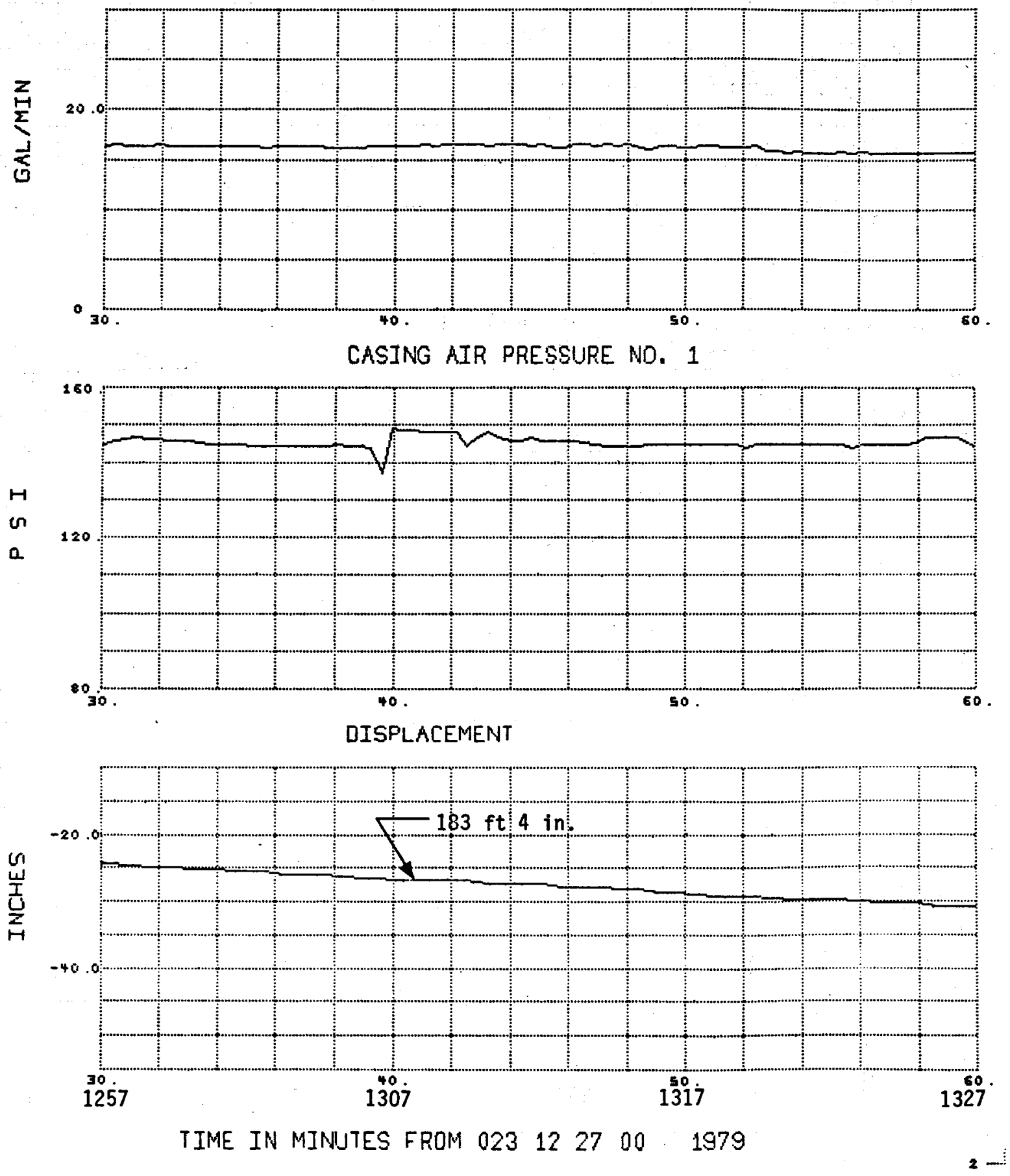

Figure C-42a. Casing Air Pressure and Cooling Water Flow while Drilling in Hole 79-4 with Jet Drag Bit 
MAGMA. TAPE 9

DRILL SPEED
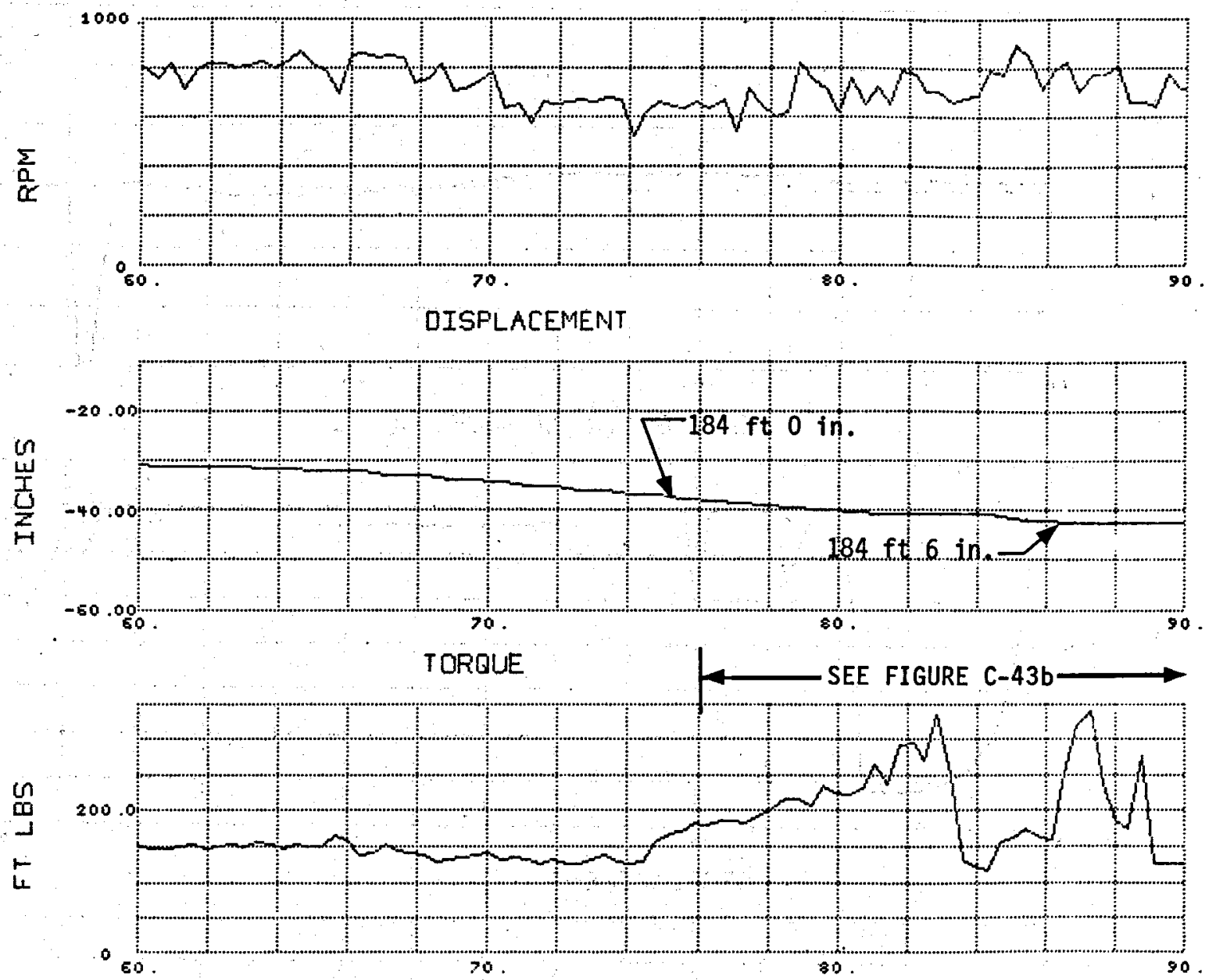

BIT FORCE

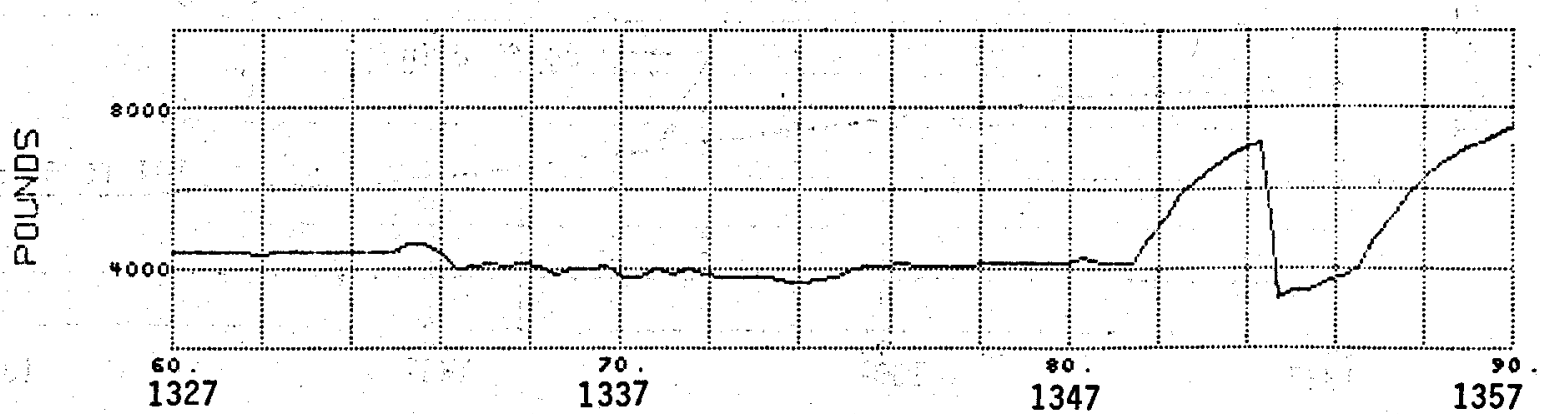

TIME IN MINUTES FROM $023 \quad 12 \quad 27 \quad 00 \quad 1979$

$10 \ldots$

Figure C-43. Drilling in Hole $79-4$ with Jet Drag Bit Approaching Plastic Layers (three-wing jet drag bit) 
MAGMA TAPE 9

WATER FLOK METER 1
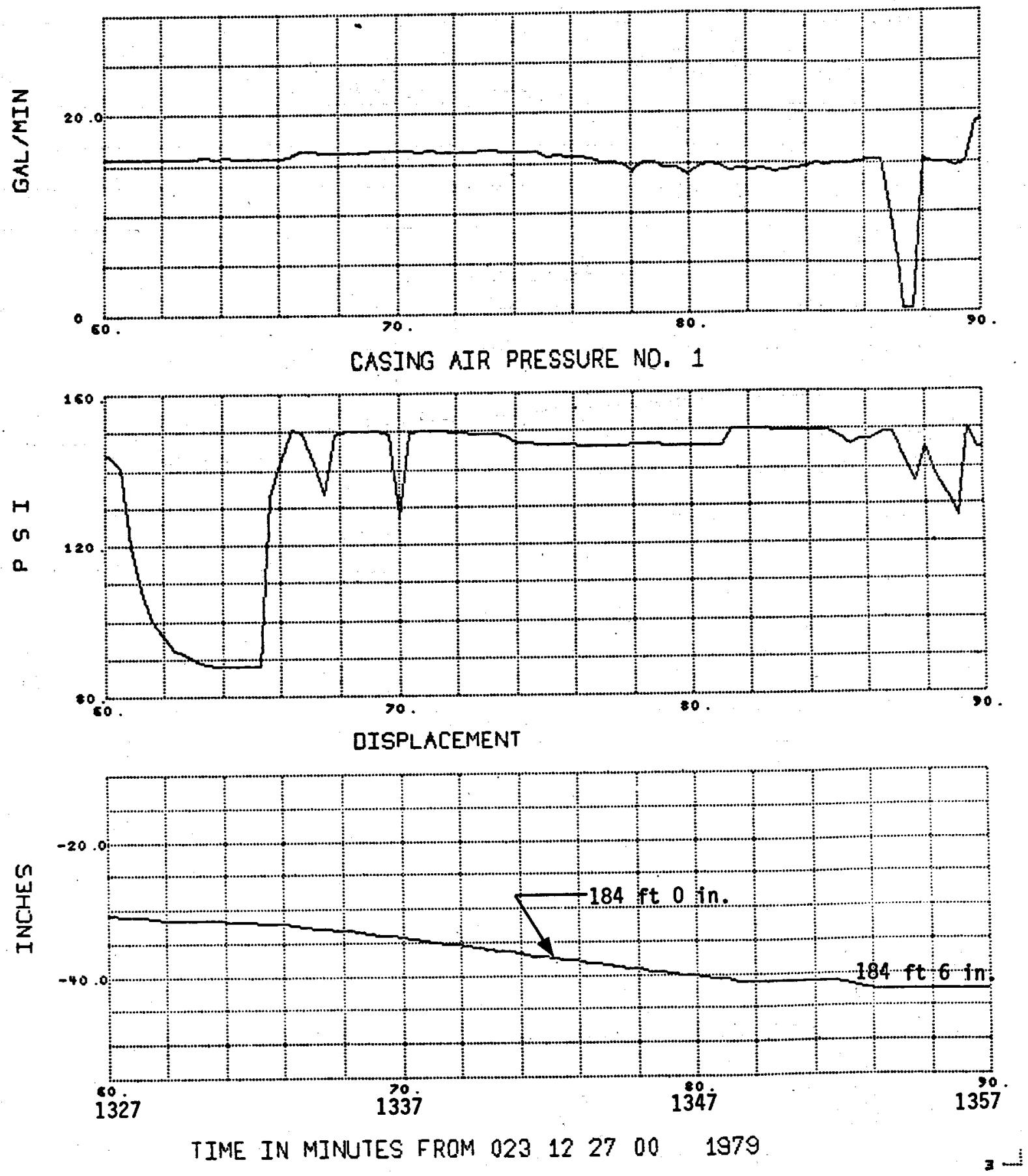

Figure C-43a. Casing Air Pressure and Cooling Water Flow
while Drilling in Hole 79-4 with Jet Drag Bit 
DRILL SPEED

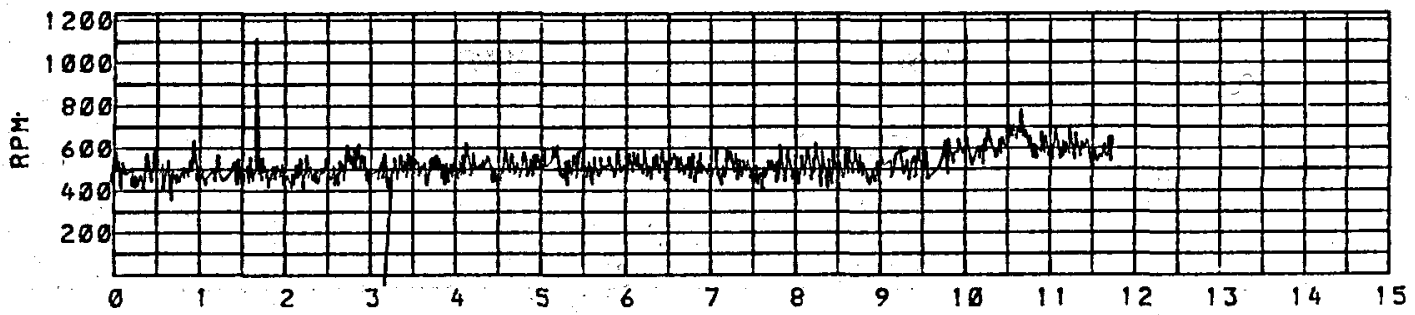

DISPLACEMENT

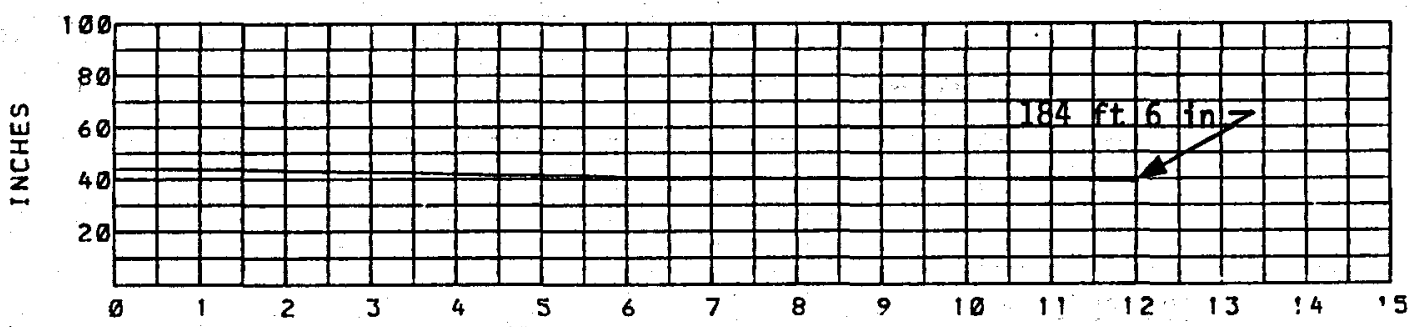

TOROUE

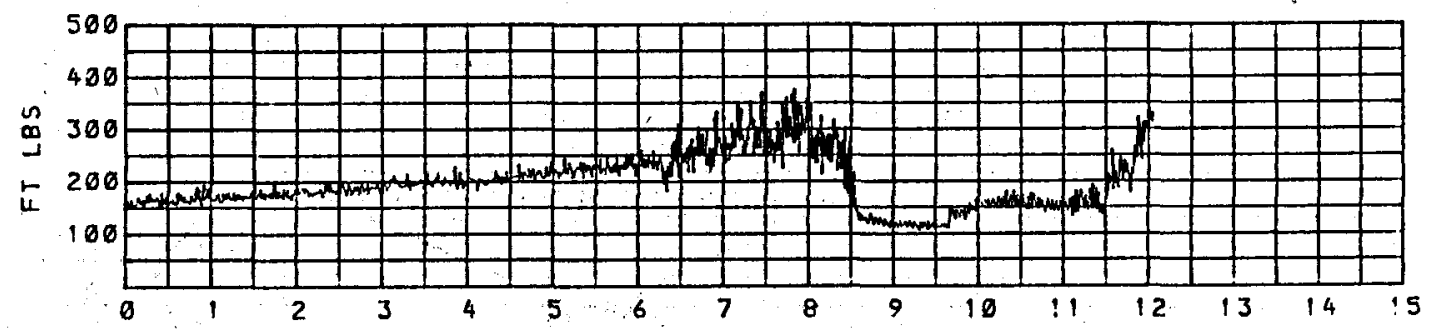

BIT FORCE

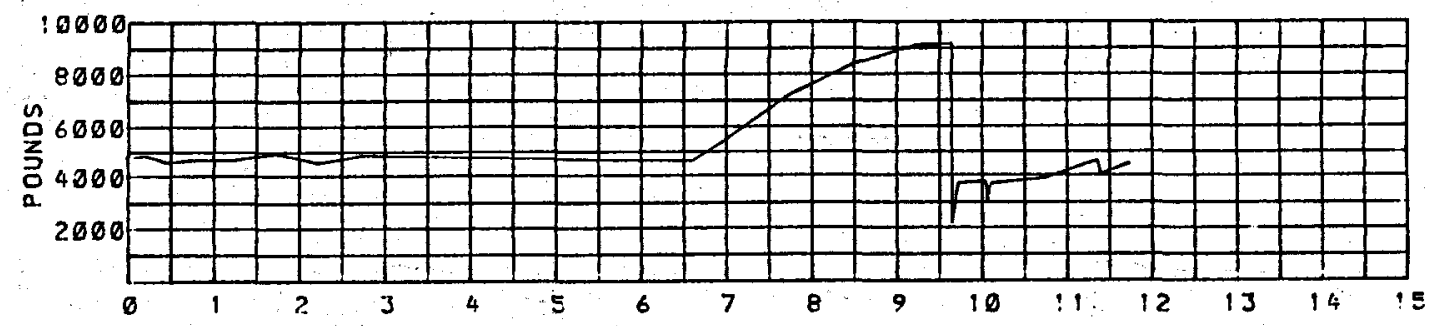

TIME IN MINUTES FROM $23 \quad 13 \quad 43001979$

Figure c-43b. Drilling with Jet Drag Bit into Liquid Layer at $184 \mathrm{ft} 0$ inches in Hole 79-4; Near Maximum Depth Attained (reproduced strip chart record) 
MAGMA TAPE 9

DRILL SPEED
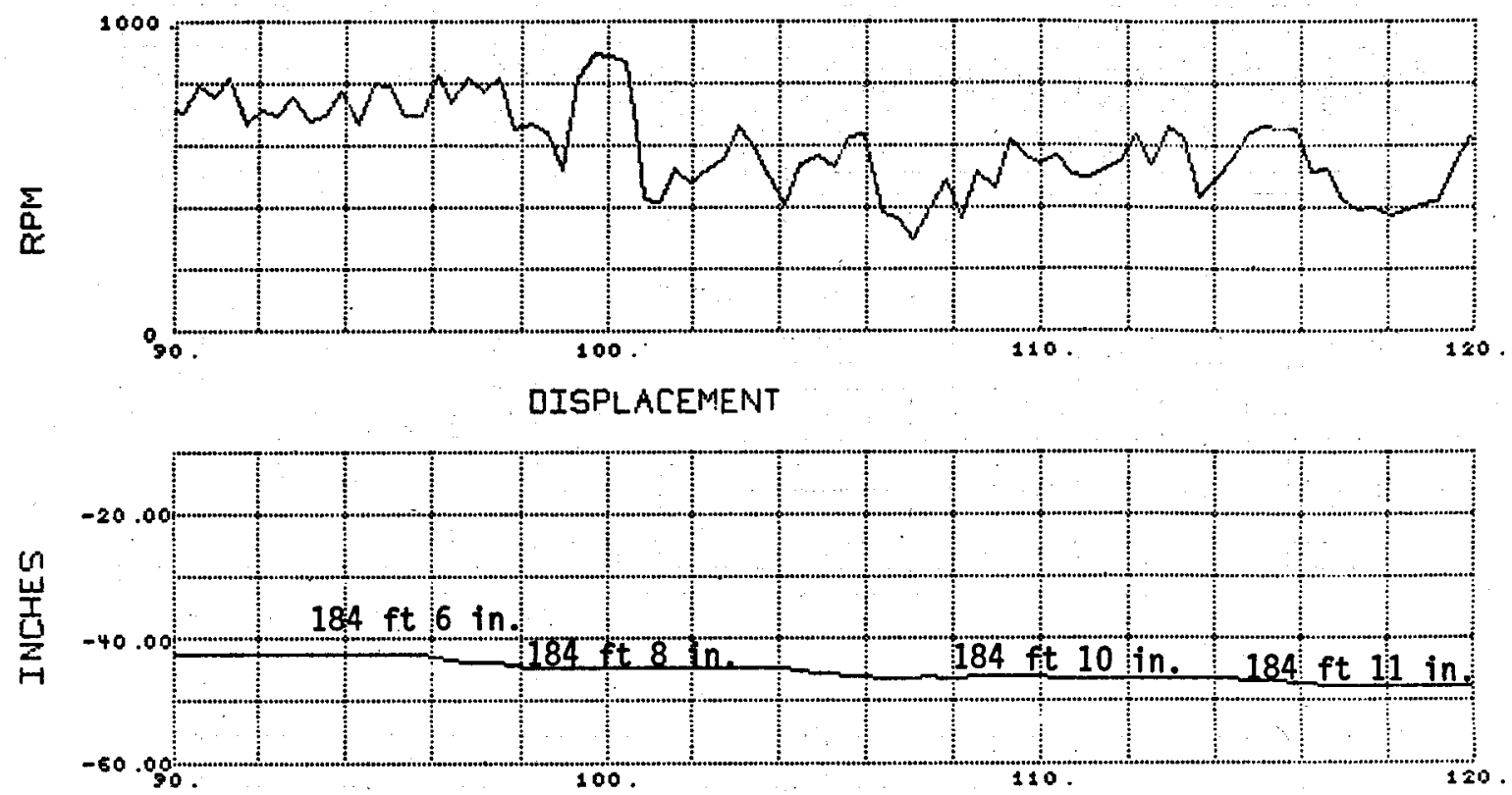

TORQUE

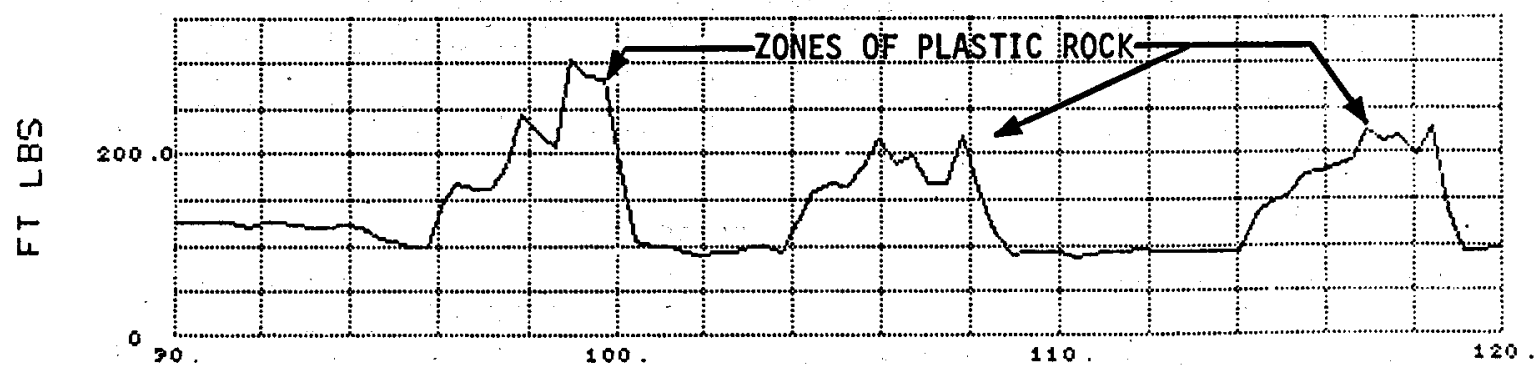

BIT FORCE

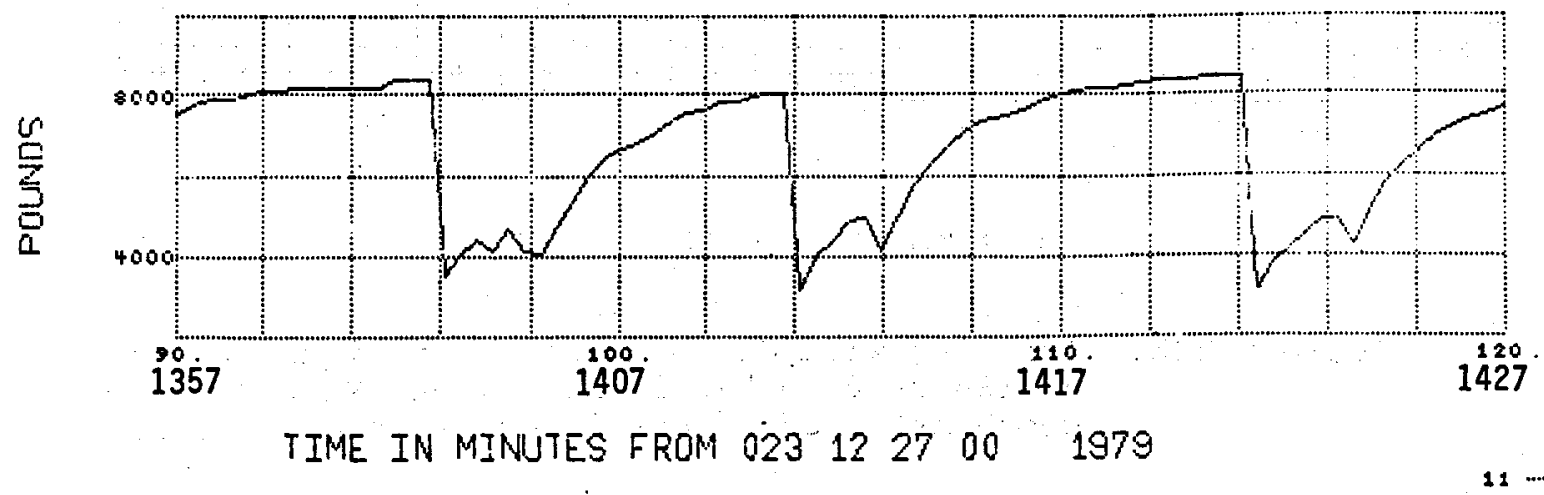

Figure C-44. Drilling through Plastic Zones in Hole 79-4 with Jet Drag Bit (three-wing jet drag bit) 


\section{MAGMA TAPE 9}
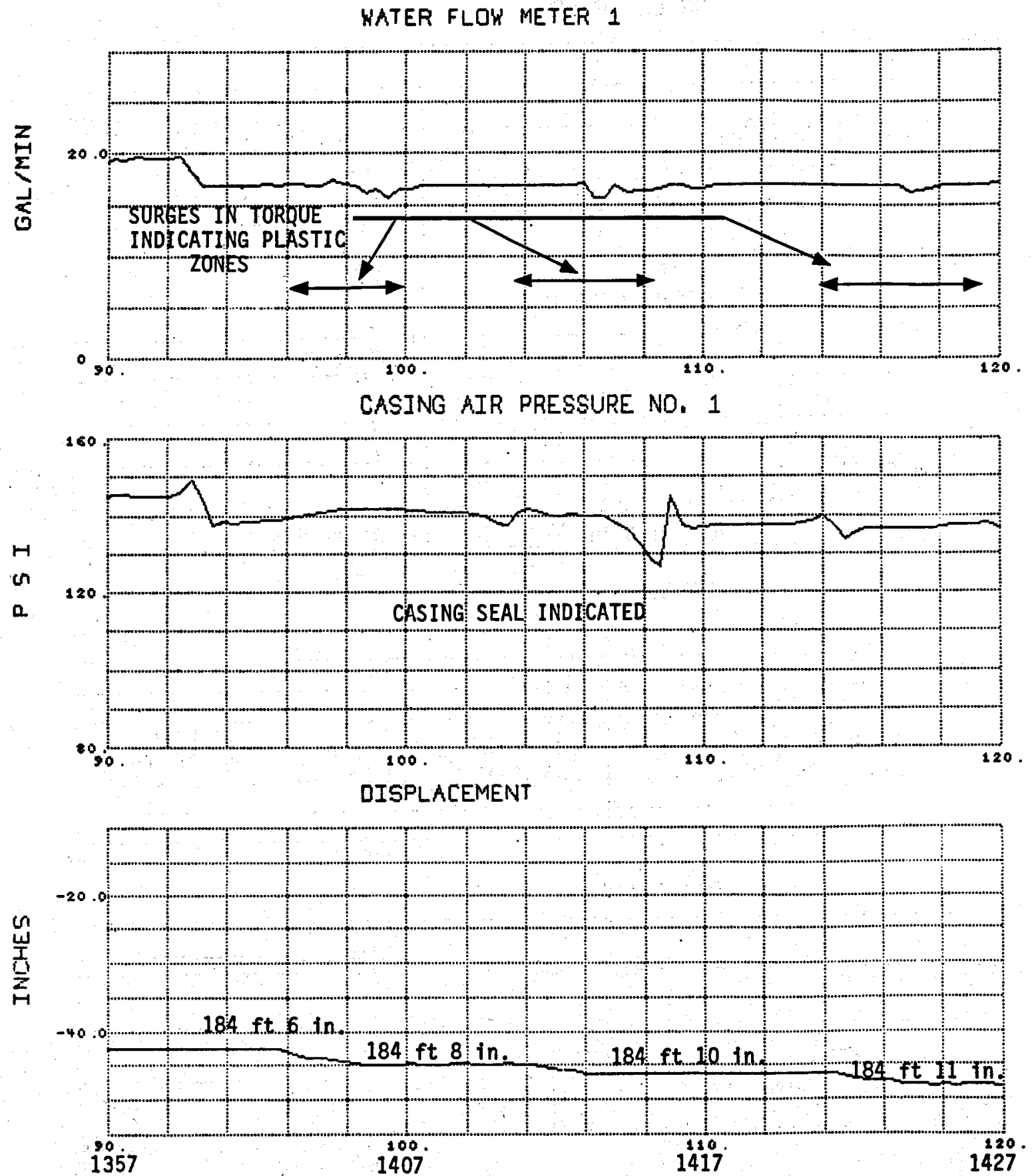

TIME IN MIMUTTES FROM $023 \quad 12 \quad 27 \quad 00 \quad 1979$

Figure C-44a. Casing Air Pressure and Cooling Water Flow while Drilling through Plastic zones in Hole 79-4 with Jet Drag Bit 
MAGMA TAPE 9
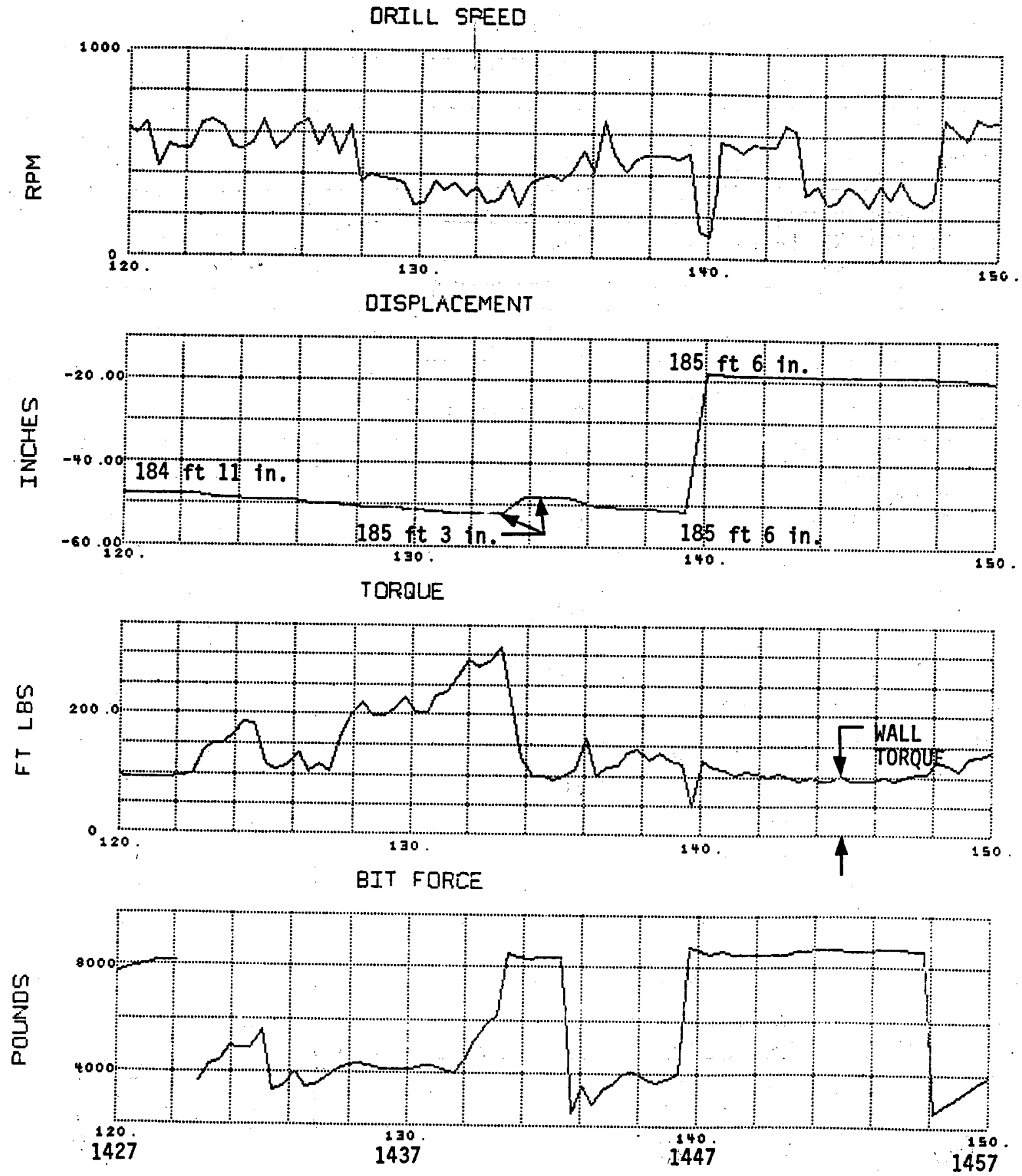

TIME IN MINUTES FROM $023 \quad 12 \quad 27 \cdot 00 \quad 1979$

$12 \ldots$

Figure C-45. Drilling through Plastic zones in Hole 79-4 with Jet Drag Bit (three-wing jet drag bit) 
MAGMA TAPE 9

WATER FLOW METER 1
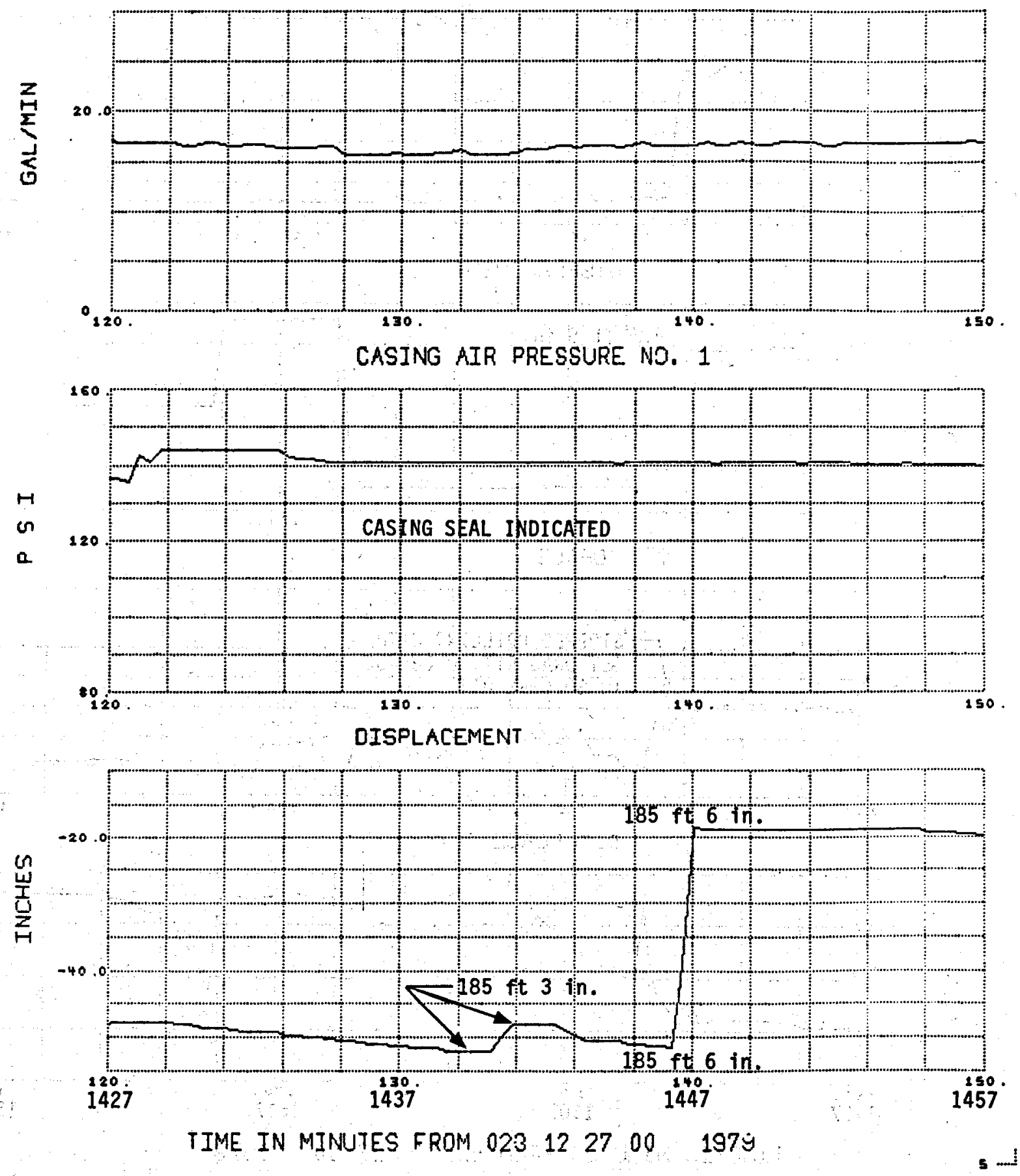

Figure C-45a. Casing Air Pressure and Cooling water while Drilling through Plastic zones in Hole 79-4 with Jet Drag Bit 
MAGMA TAPE 9

DRILL SPEED
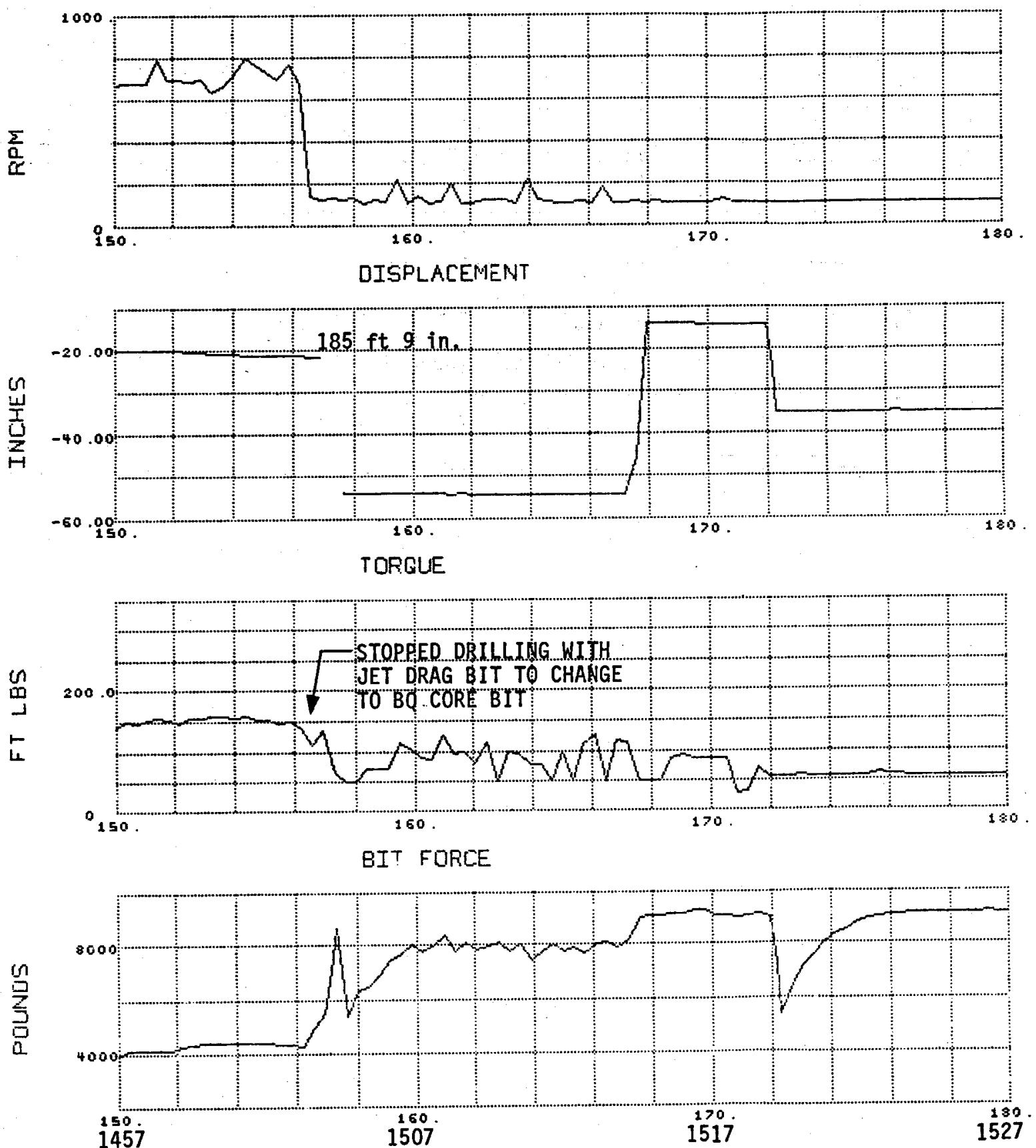

TIME IN MINUTES FROM $023: 2 \quad 27$ DO 1979

$13 \ldots$

Figure C-46. Changing from Jet Drag Bit to BQ Core Bit
to Obtain Core Sample 

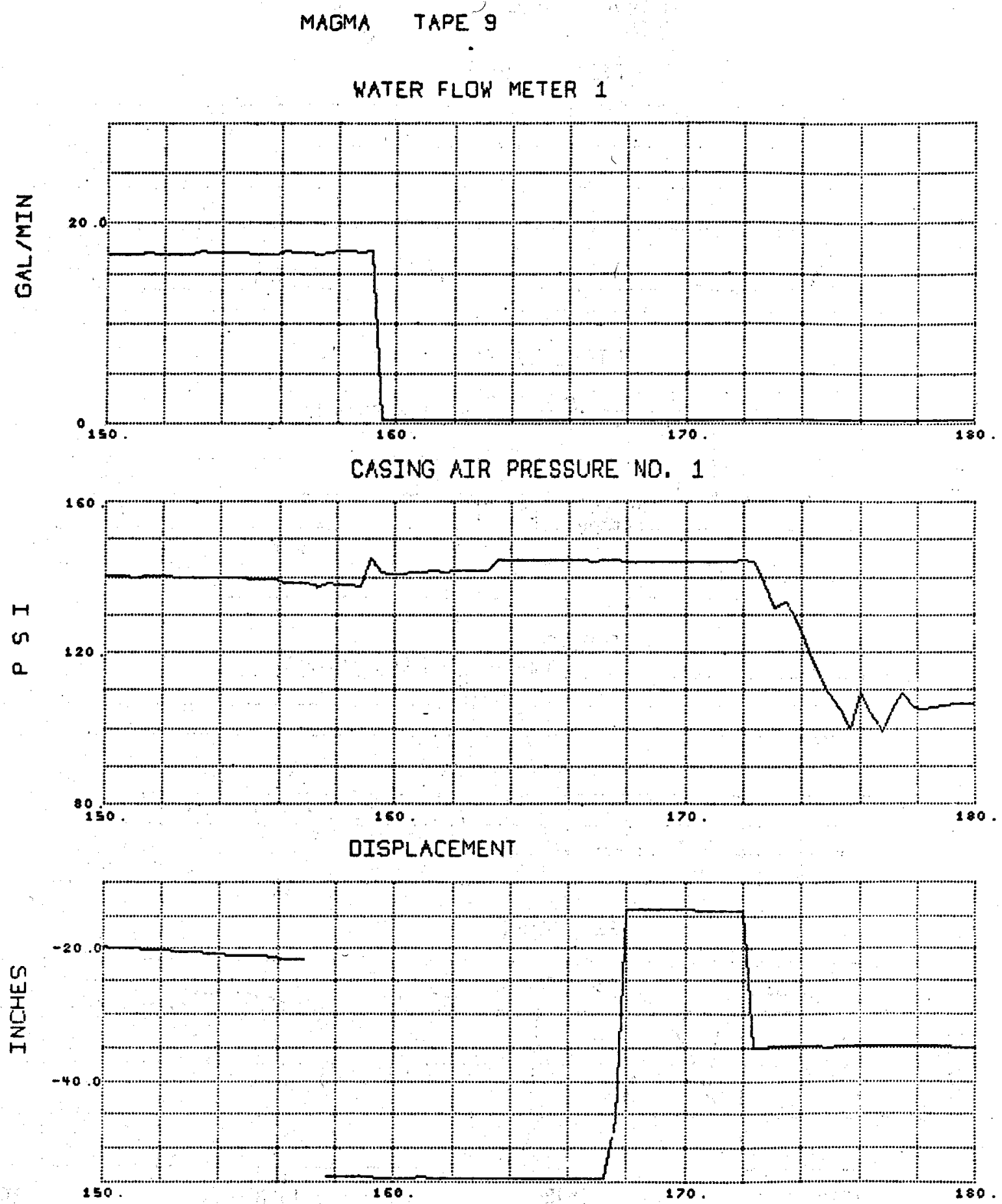

TIME IN MINUTES FROM $02312 \quad 2700 \quad 1973$

$6 .+1$

Figure $C-46 a$ 
MAGMA TAPE 10

QRILL SPEED
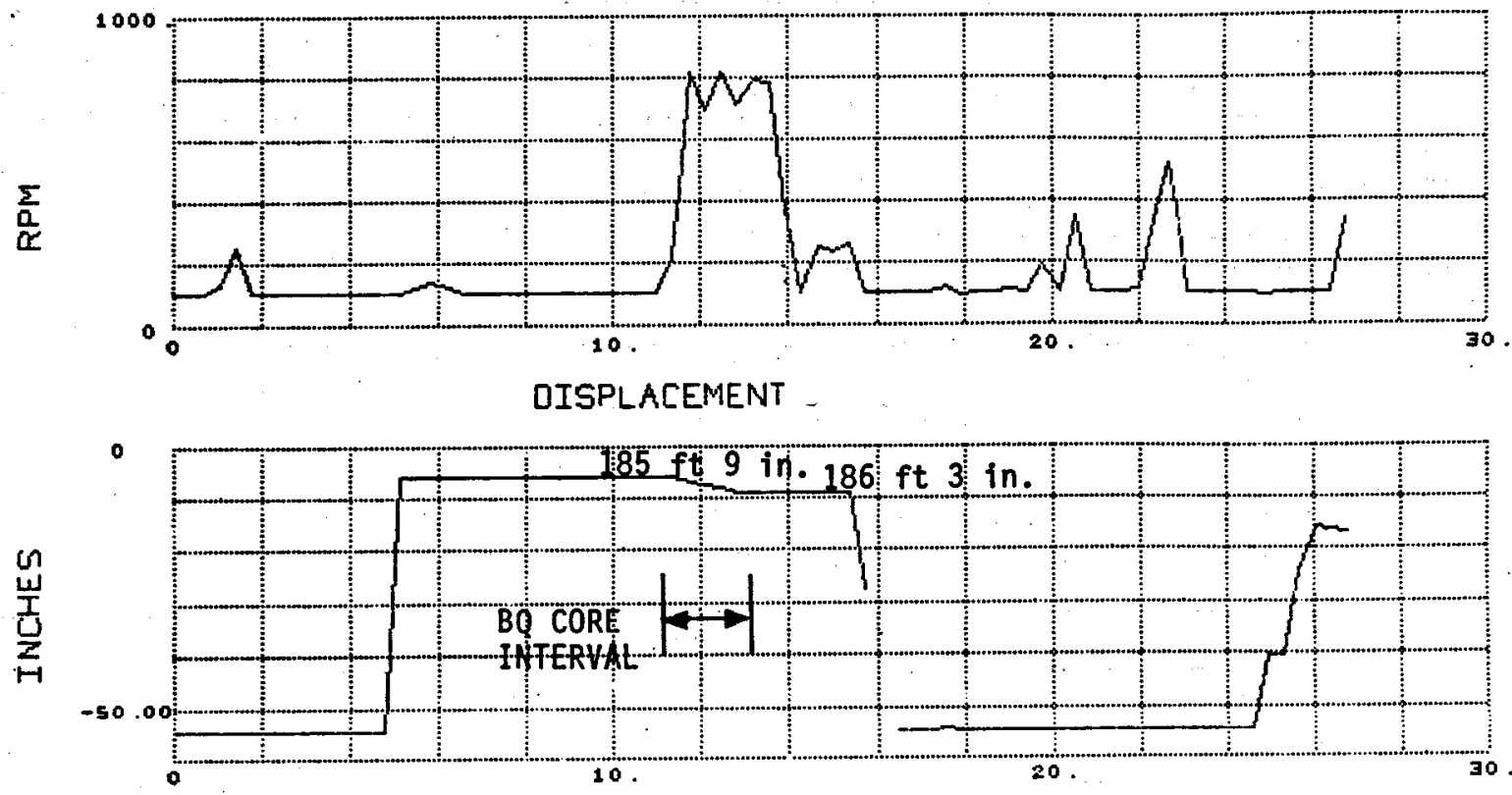

TORQUE

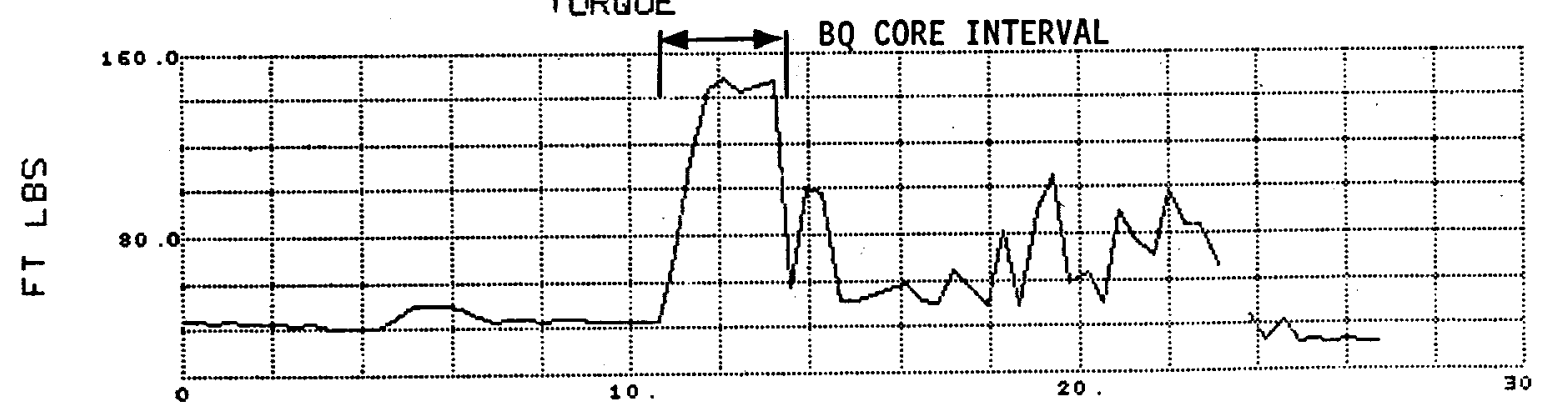

BIT FORCE

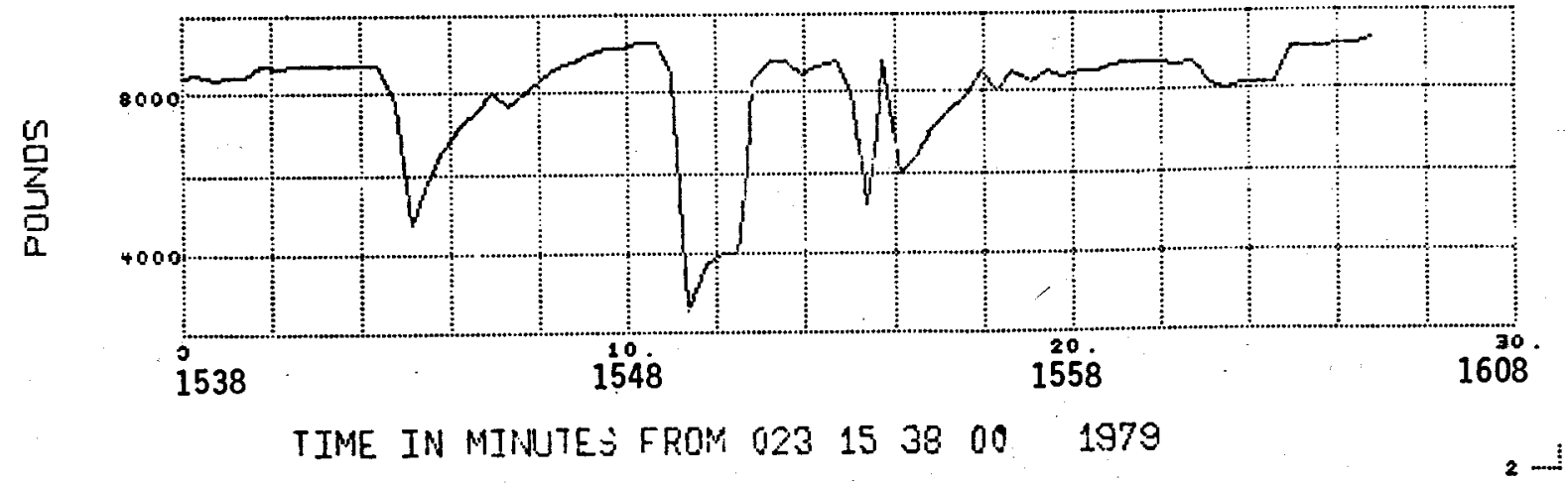

Figure C-47. Drilling in Hole 79-4 at $186 \mathrm{ft}$ for BQ Core Sample (BQ -- 2.36 inches diameter -- wireline coring equipment) 


\section{MAGMA TAPE 10}

DRILL SPEED
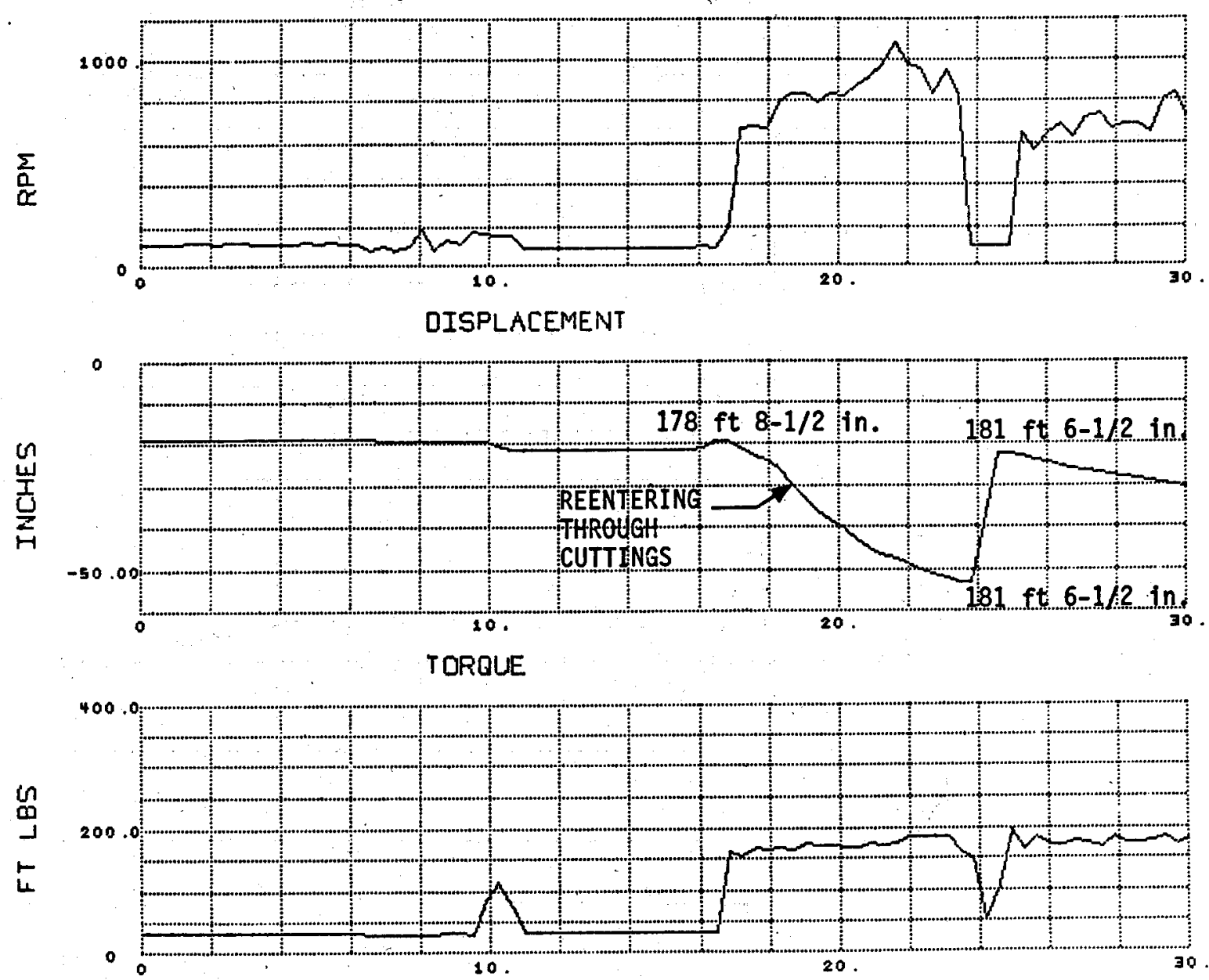

BIT FORCE

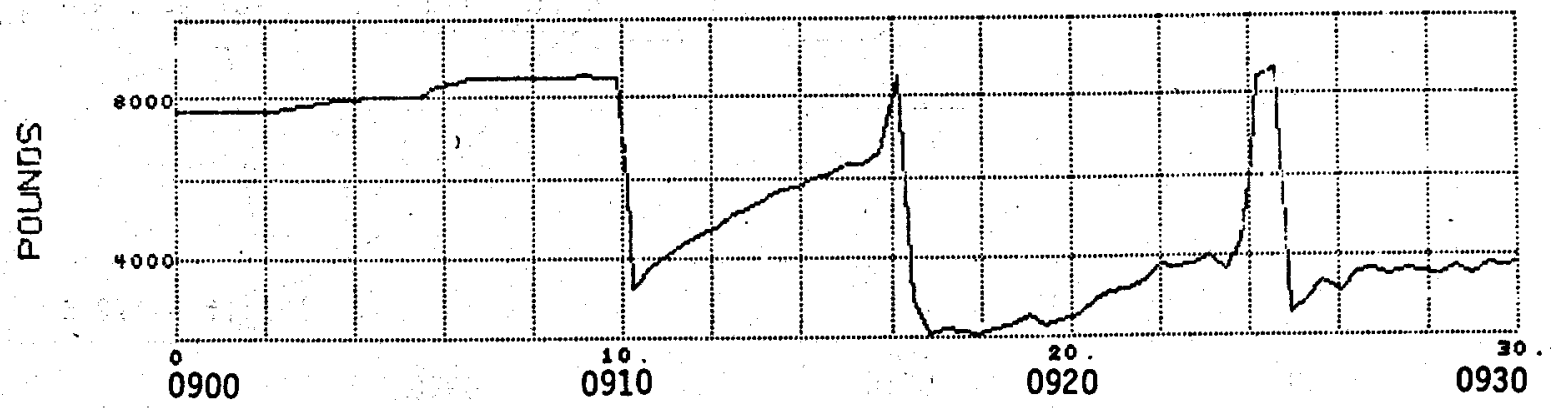

TIME IN MINUTES FROM 024 09 00 00 1979

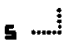

Figure C-48. Reentering Hole 79-4 through Cuttings with Jet Drag Bit (three-wing jet drag bit) 

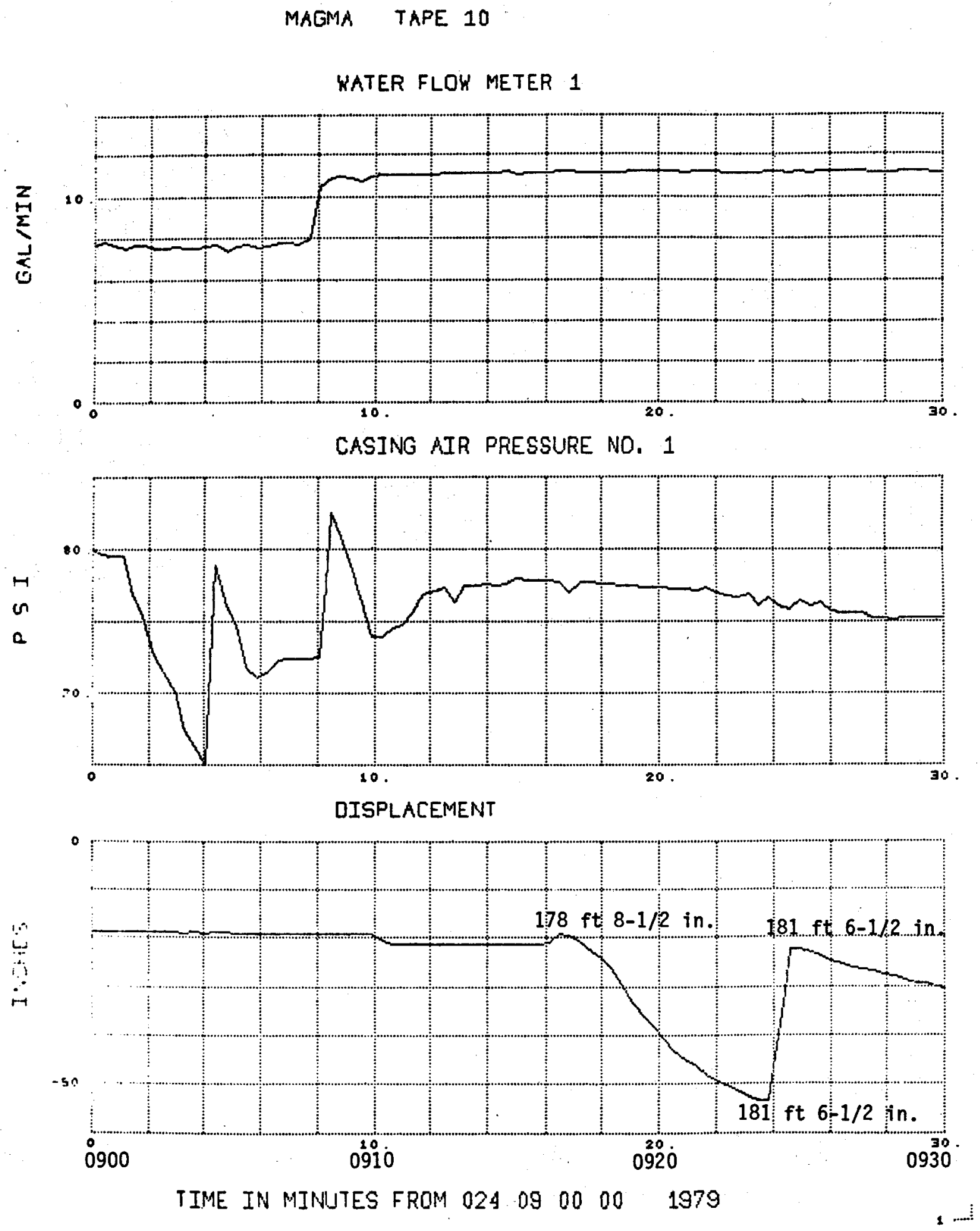

Figure C-48a. Reentering Hole 79-4 through Cuttings with Jet Drag Bit 
MAGMA TAPE 10

ORILL SPEED
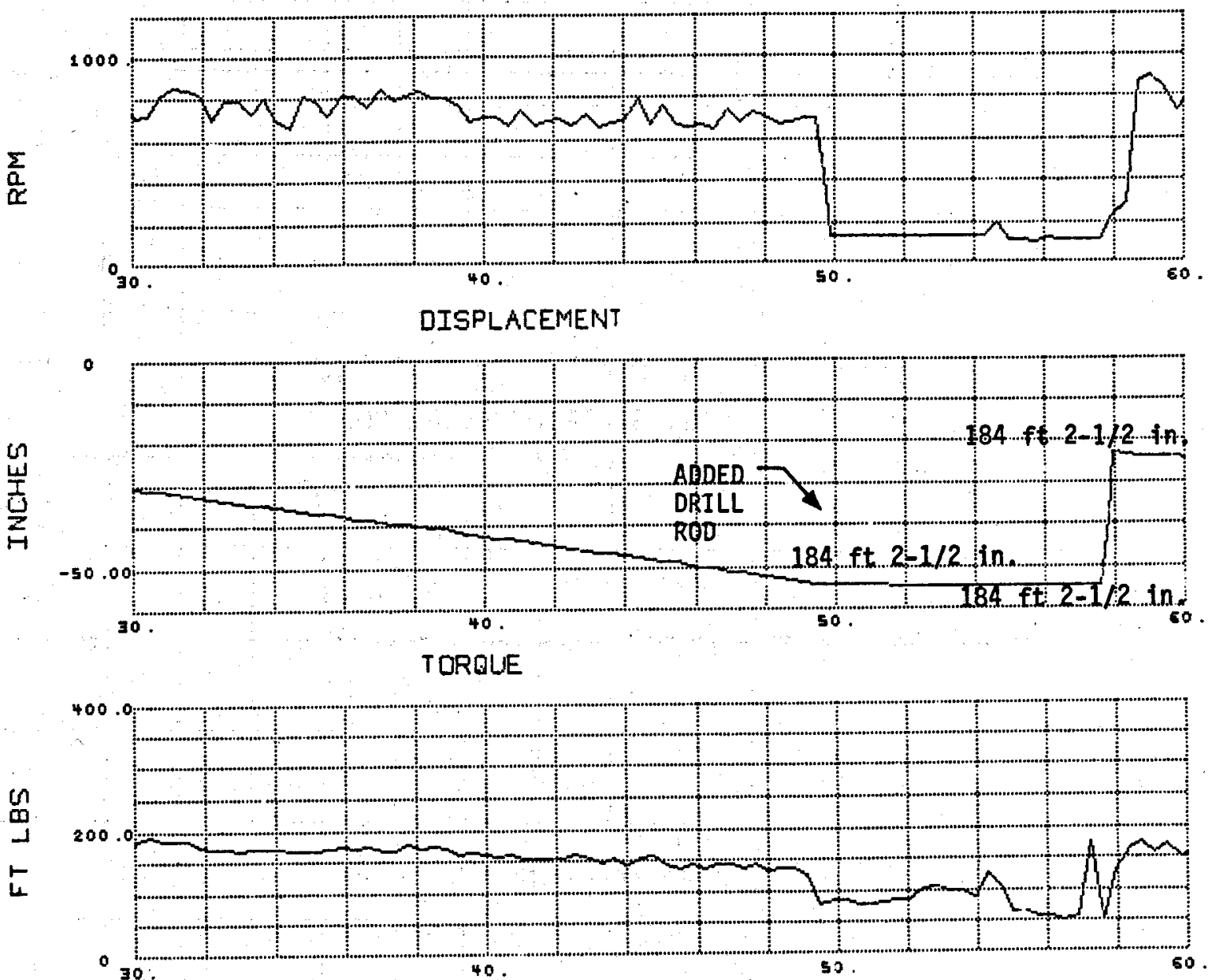

BIT FORCE

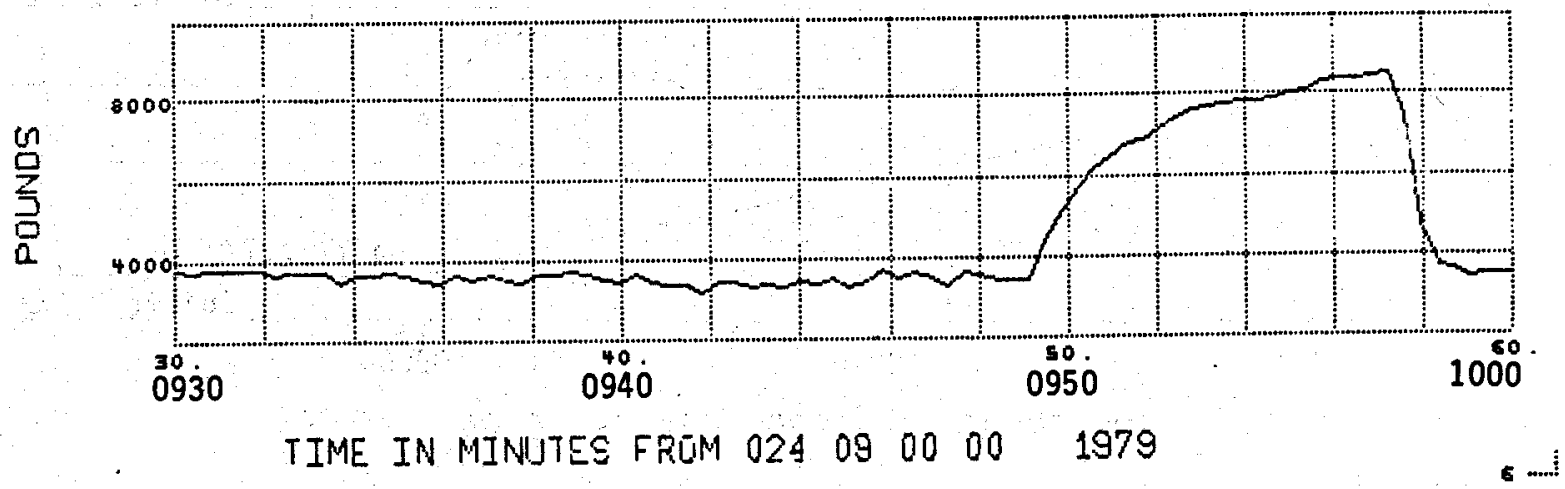

Figure C-49. Drilling Back into $79-4$ with Jet Drag Bit after Obtaining BQ Core Sample 
MAGMA TAPE 10

WATER FLOW METER 1
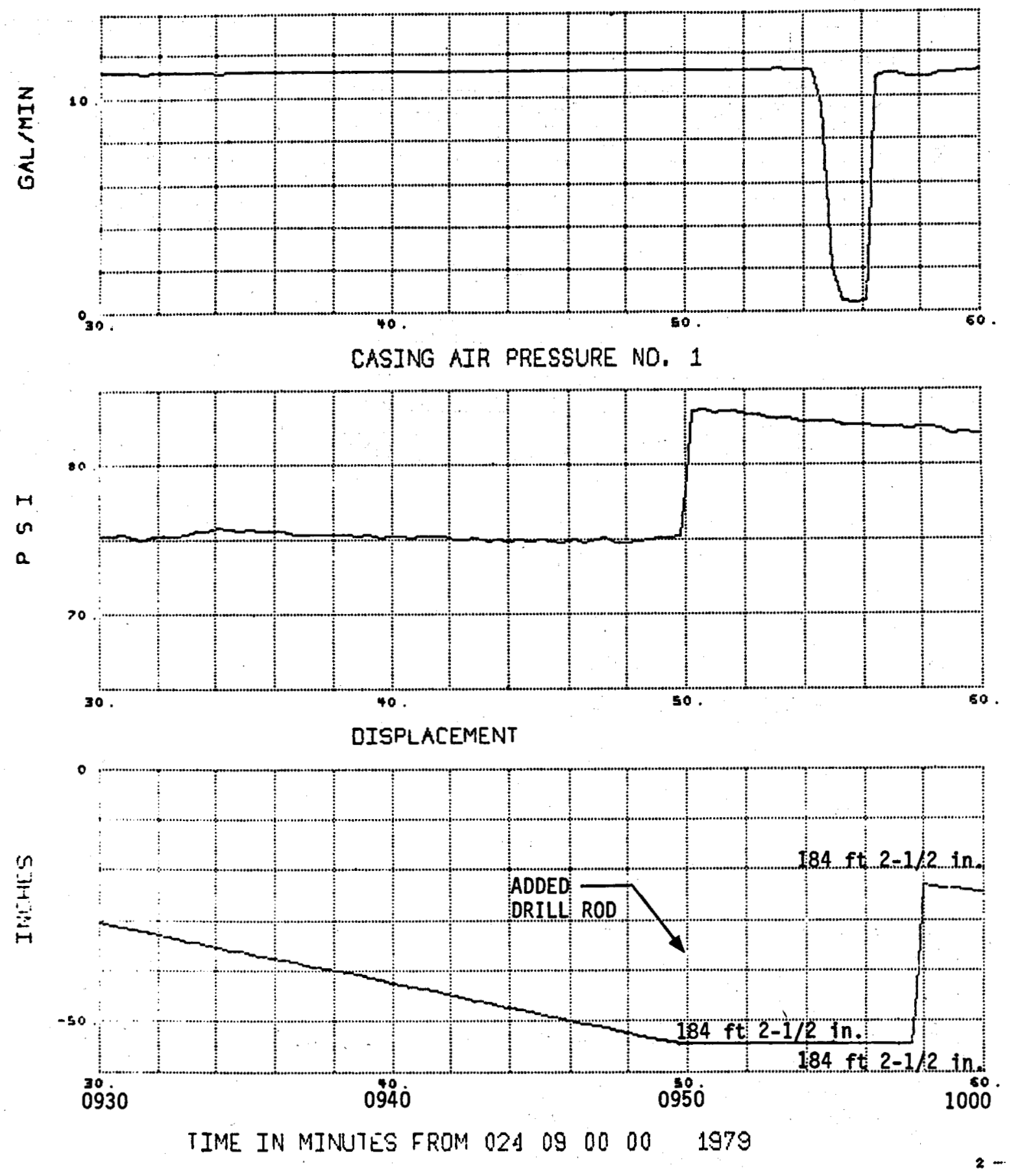

Figure C-49a. Casing Air Pressure and Cooling Water Flow while Reeentering Hole 79-4 with Jet Drag Bit after Obtaining BQ Core Sample 
MAGMA TAPE 10
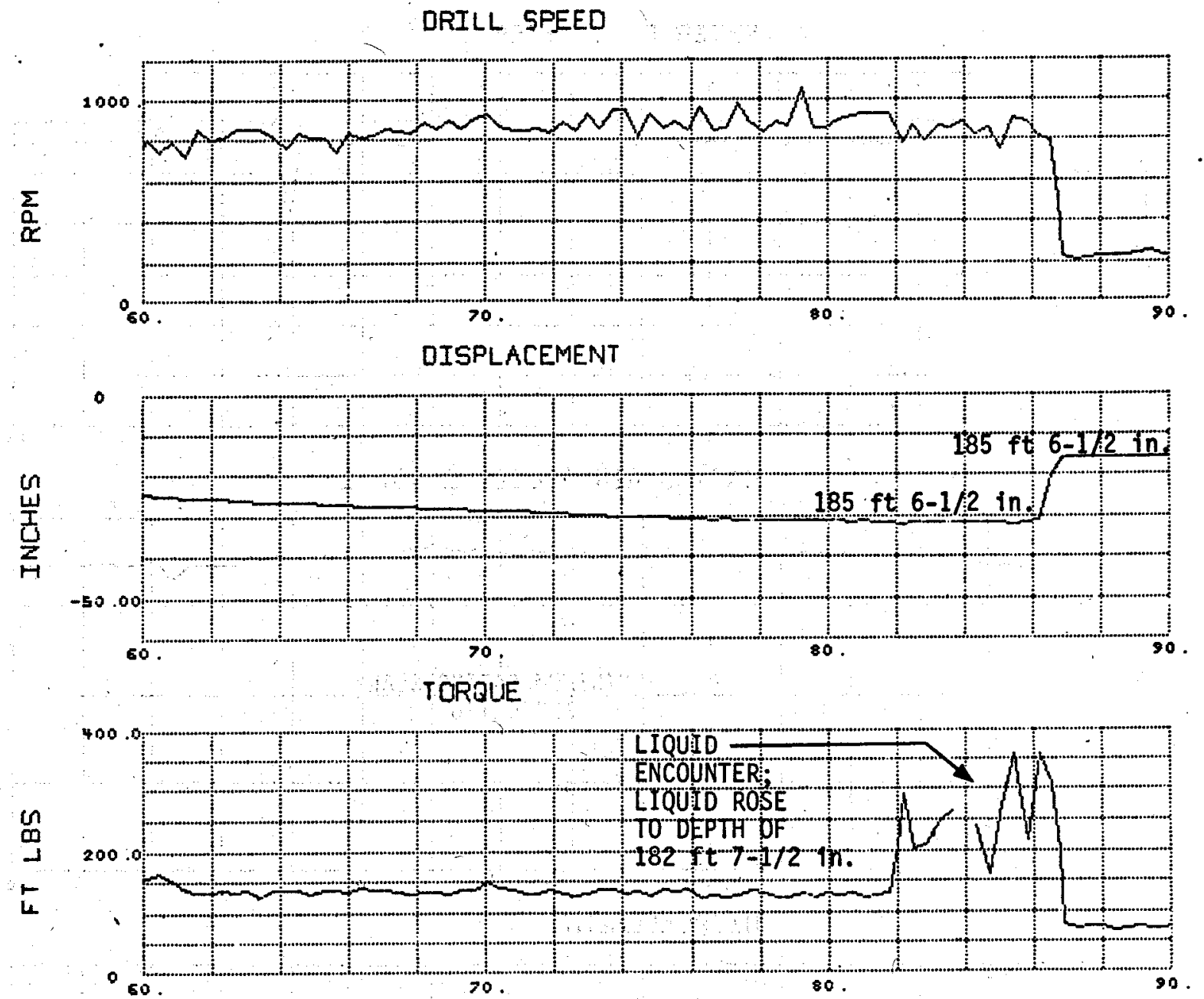

BIT FDRCE

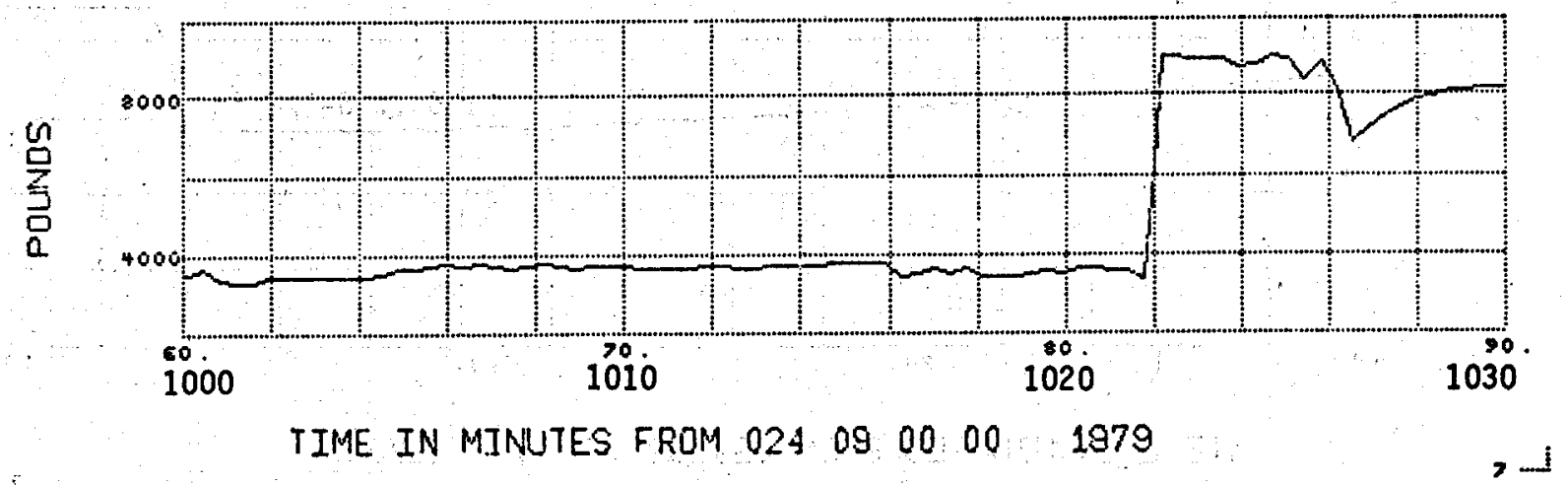

Figure C-50. Drilling into Final Liquid Layer in Hole 79-4 with Jet Drag Bit 
MAGMA TAPE 10

WATER FLOW METER 1
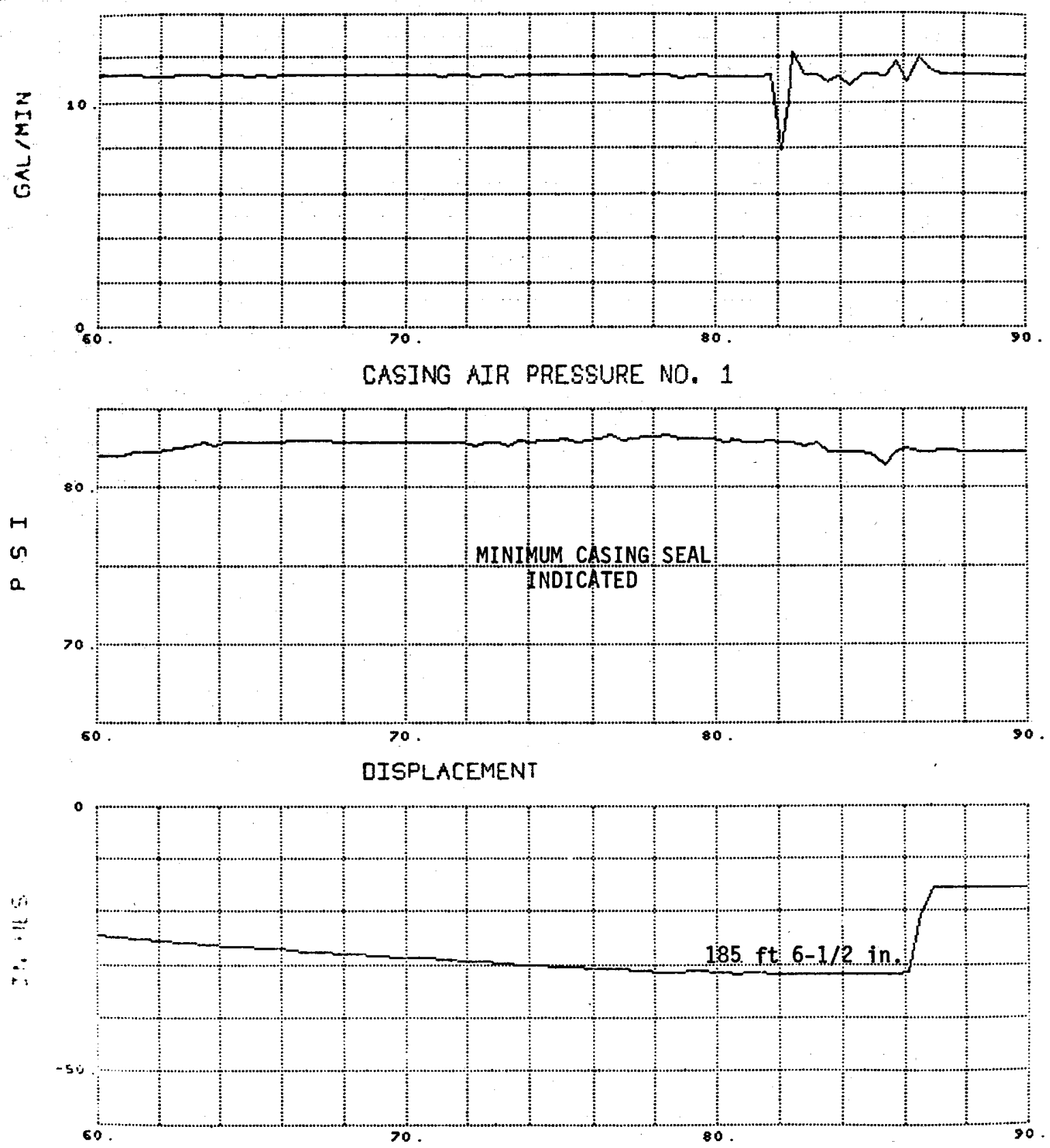

TIME IN MINUTES FROM $02409 \quad 00 \quad 00 \quad 1979$

Figure C-50a. Casing Air Pressure and Cooling Water Flow during Encounter with Final Liquid Layer in Hole 79-4 
APPENDIX D

Drilling Records for Reentry Jet Drilling in Hole 79-1 


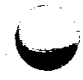

- 
Hole 79-1 was drilled to a depth of 202 feet between December 20, 1978, and January 1, 1979, using conventional HQ wireline coring equipment. At 202 feet, some difficulty was encountered in drilling, and the hole was abandoned for more préssing work. on January 24, 1979, the hole was reentered, and arilling commenced at a new bottom-hole depth of 165 feet 1 inch. Core drilling with conventional HQ wireline proceeded slowly ( $<5$ feet per day net) to 183 feet 7 inches on January 24 , when equipment was changed to commence the jet core arilling. The conventional Ho wireline drilling was frequently interrupted by plastic or liquid rock plugging water passages and forcing the drill string to be withdrawn for clearing. It was during this period that core length considerably in excess of the drilled interval was recovered as the plastic rock oozed its way into the rotating core barrel.

During the jet core bit drilling, the pressure of the high-velocity cooling water stream was supplied to the bit and controlled by varying the speed of the positive displacement pump used to supply drilling water. The water pressure indicated by the pump sight gauge was hand-recorded. The drill functions were recorded on the strip chart recorders only. Jet core drilling proceeded slowly (1/2 to 1 inch per minute) but steadily for about 15 feet, at which point the accumulation of cuttings threatened to stick the drill rod, and jet drilling was stopped.

Figures D-1 through D-17 show the recordings of the drill function data for the period when conventional drilling was performed. Figures D-18 through D-26 show the recorded drill functions after switching to the jet core drill. 
DRILL SPEED
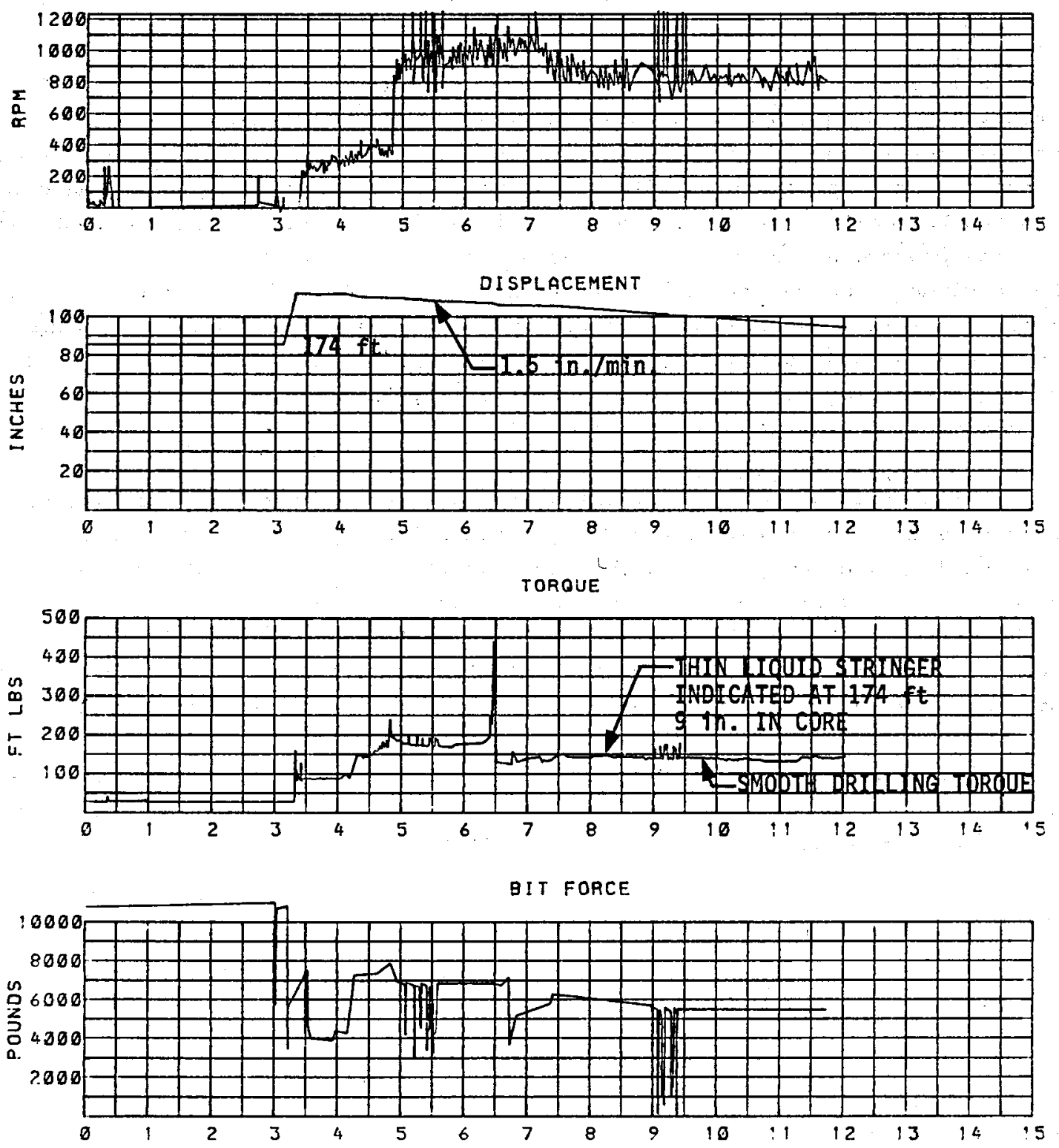

TIME IN MINUTES FROM 25 I5 $11 \quad 00 \quad 1979$

Figure D-1. Drilling with Conventional HQ Core Bit during Reentry into Hole 79-1 
DRILL SPEED
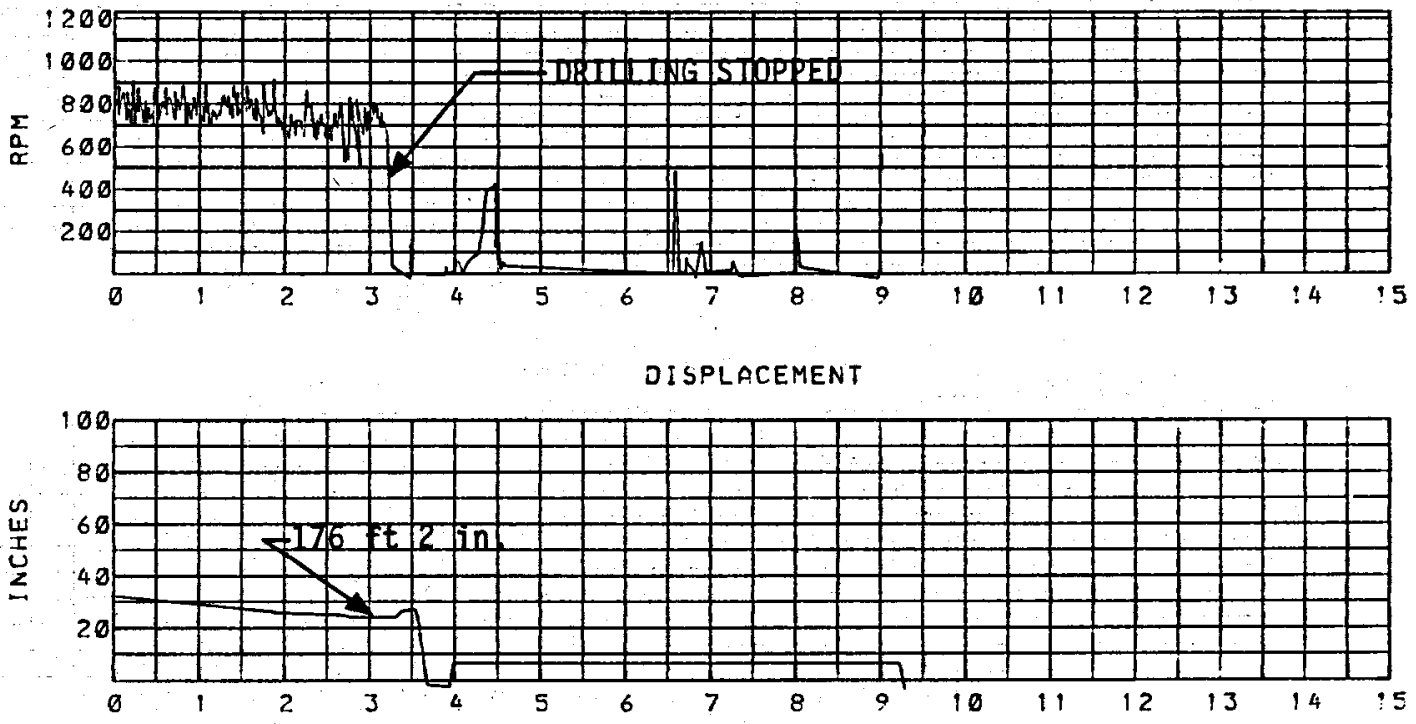

TOROUE
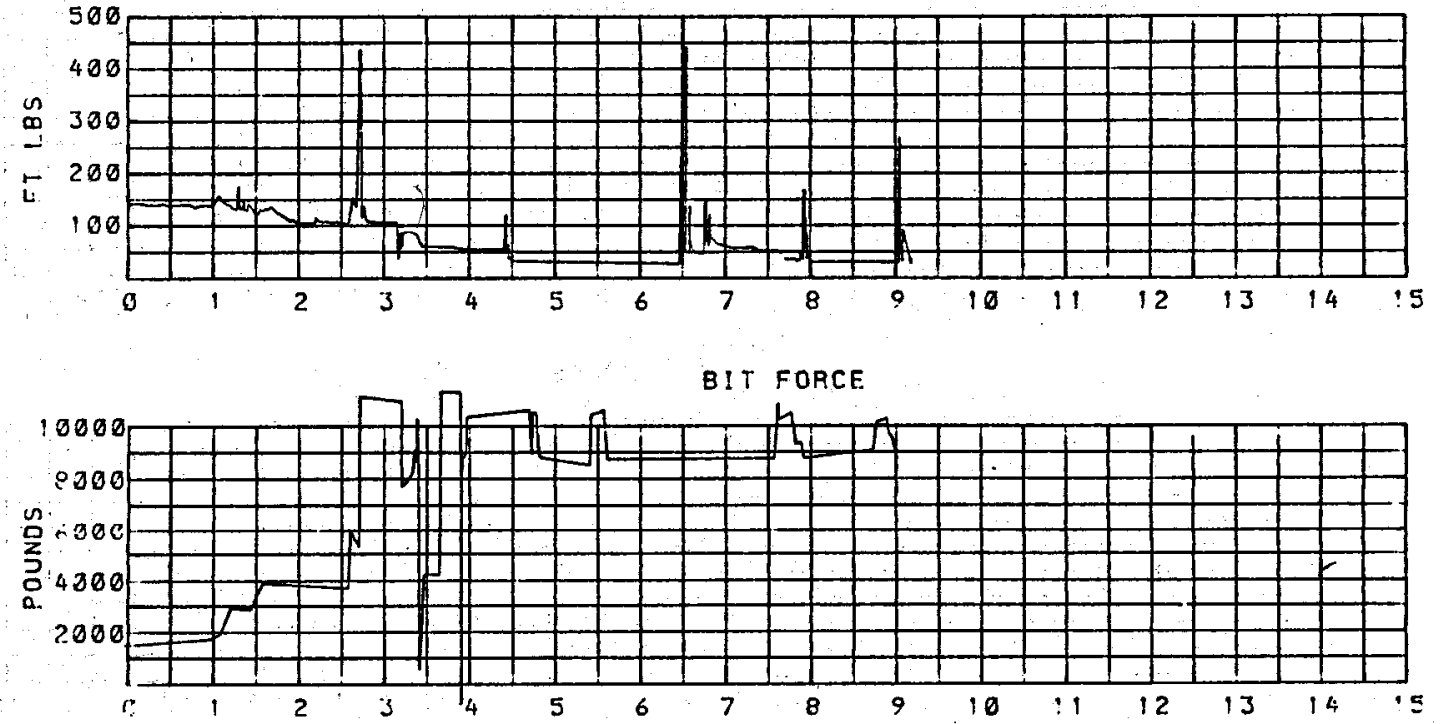

TIME IN MINUTES FROM 25 15:23 301979

Figure D-2, Drilling with Conventional HQ Core Bit during Reentry into Hole 79-1 
DRILL SPEED
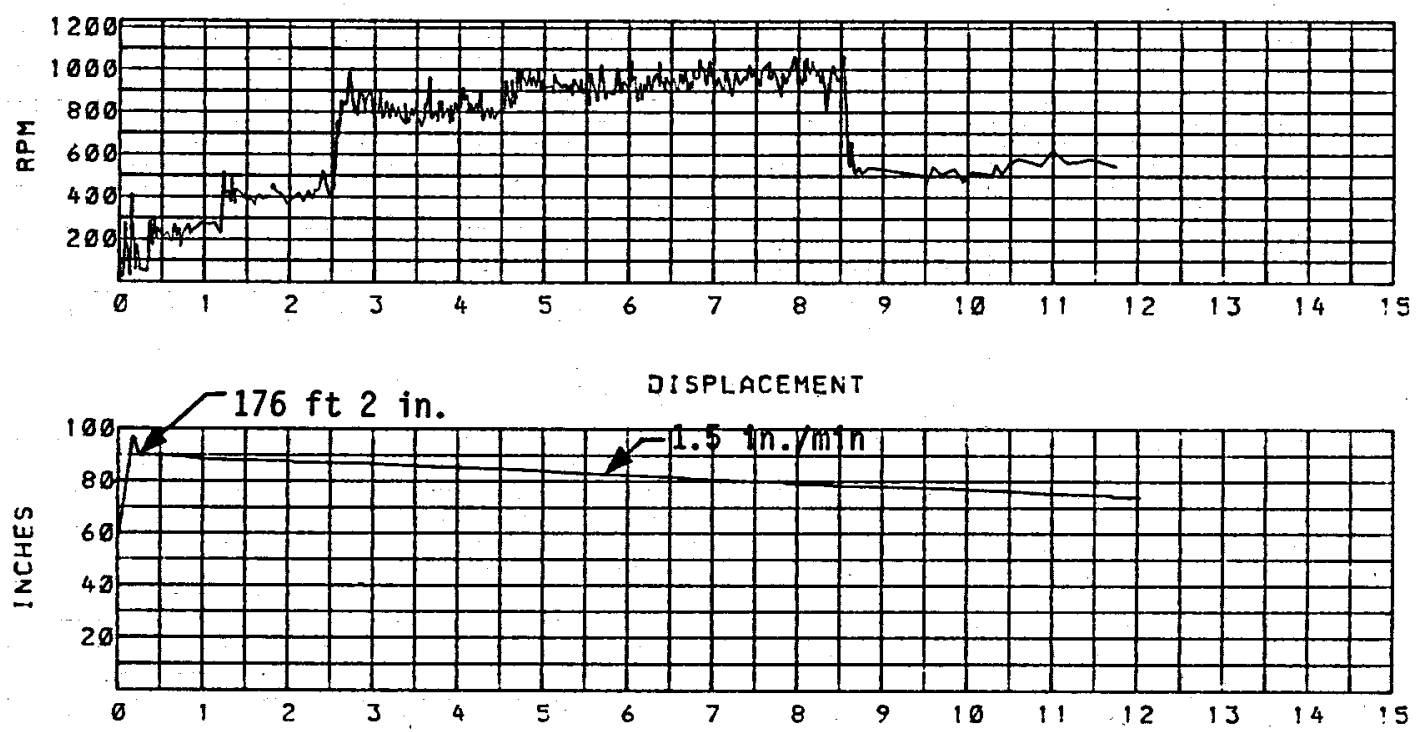

TOROUE

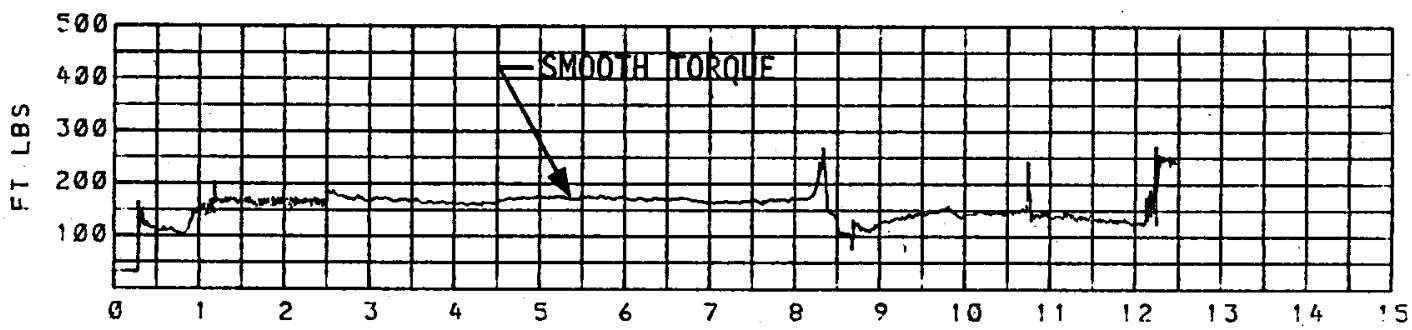

BIT FORCE

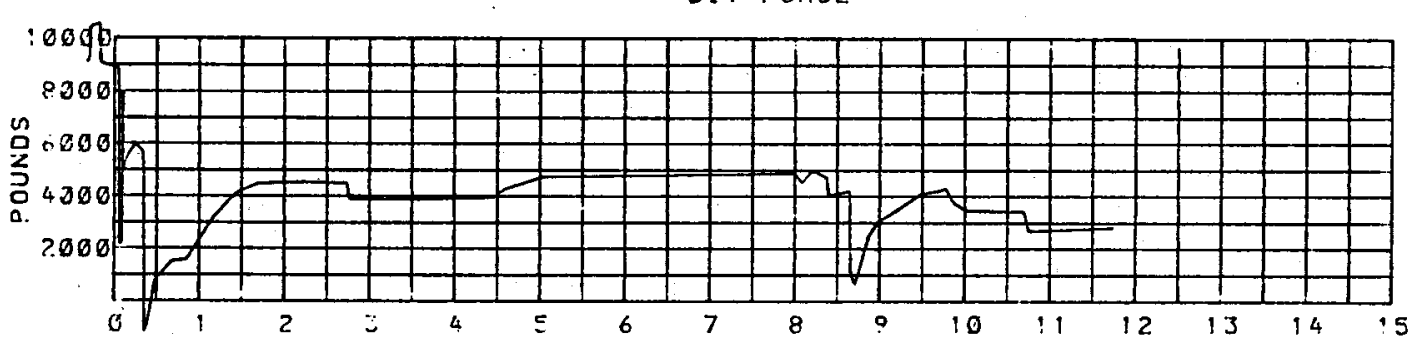

TIME IN MINUTES FPOM $2608 \quad 4,001979$

Figure D-3. Drilling with Conventional HQ Core Bit during Reentry into Hole 79-1 
DRILL SPEED
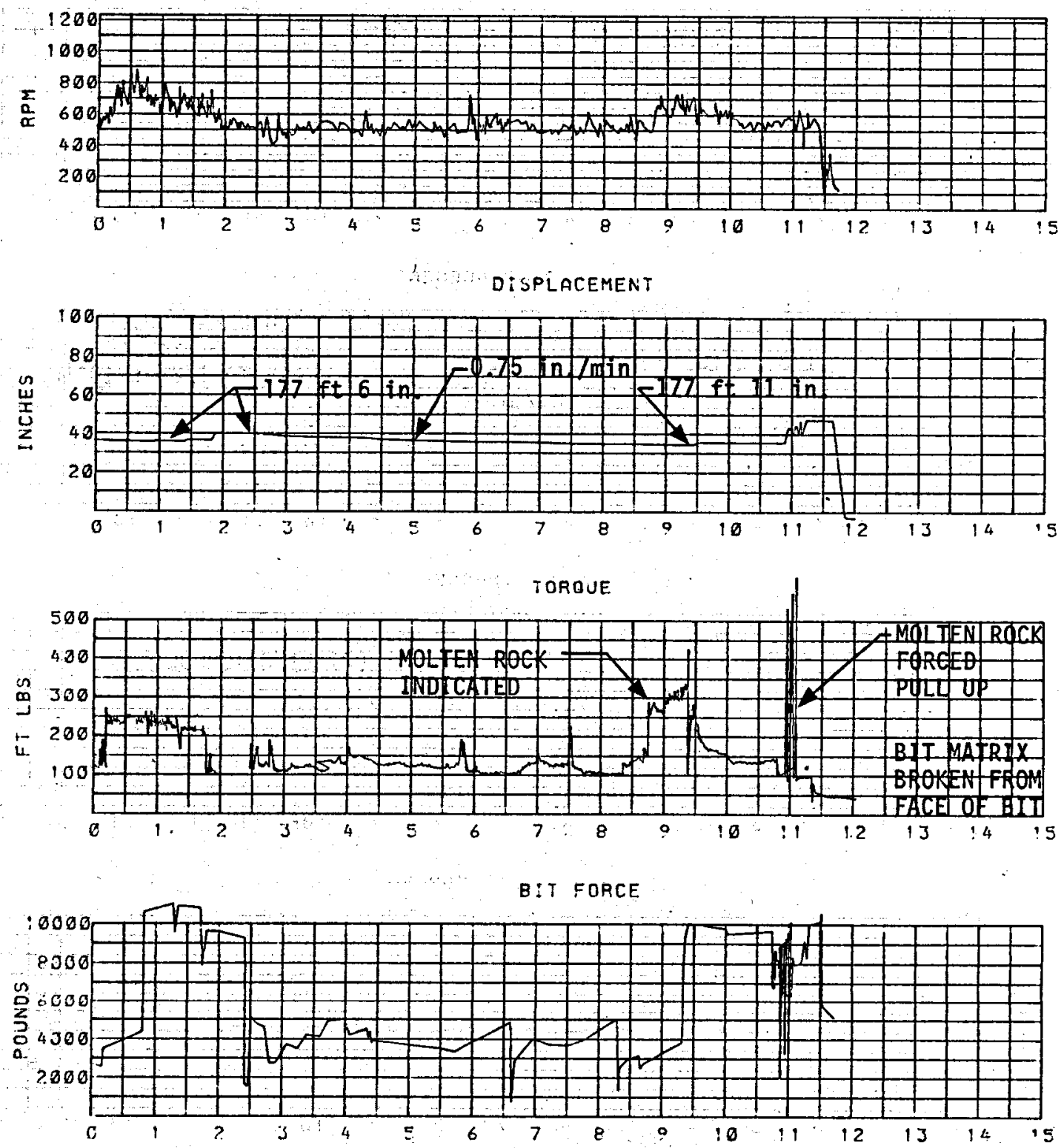

IIME IN MINUTES FOOM 26 O8 53001979

Figure D-4. Drilling with Conventional Ho Core Bit during Reentry into Hole 79-1 
DRILL SPEED

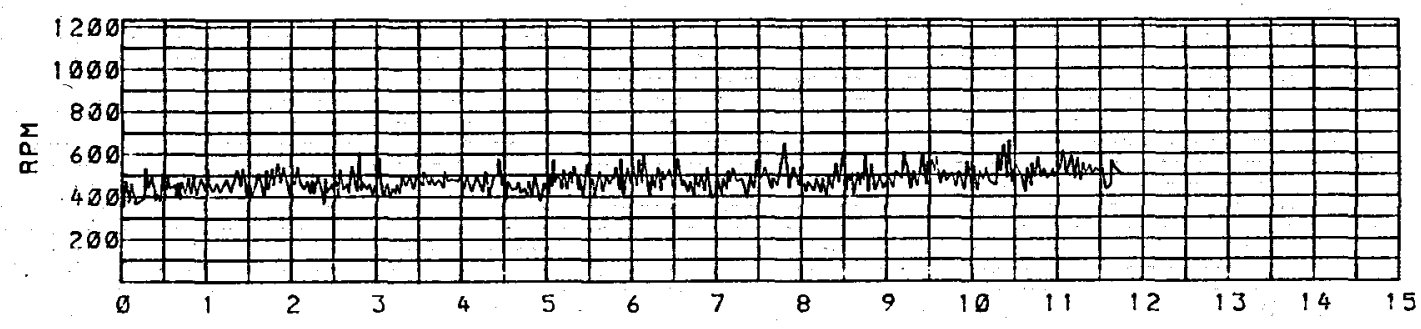

DISPLACEMENT
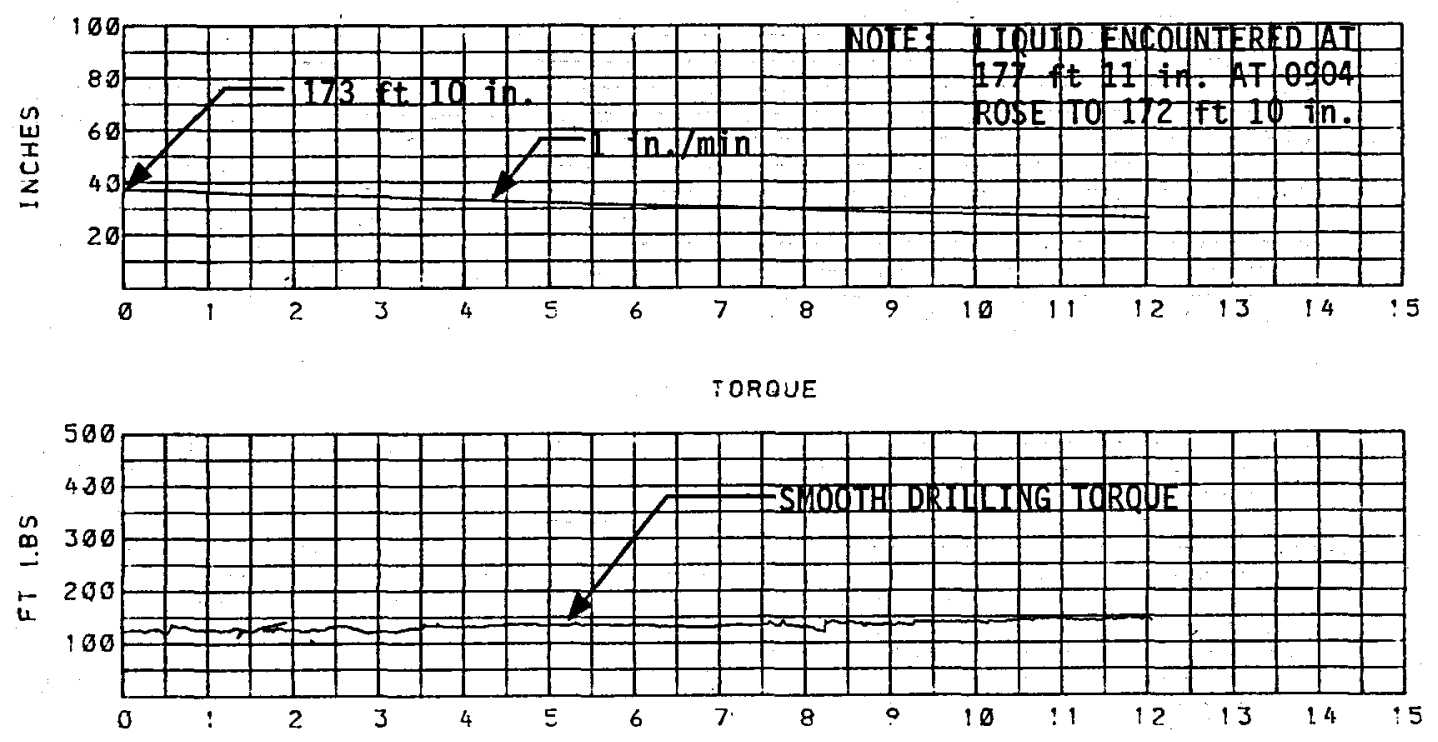

BIT FORCE

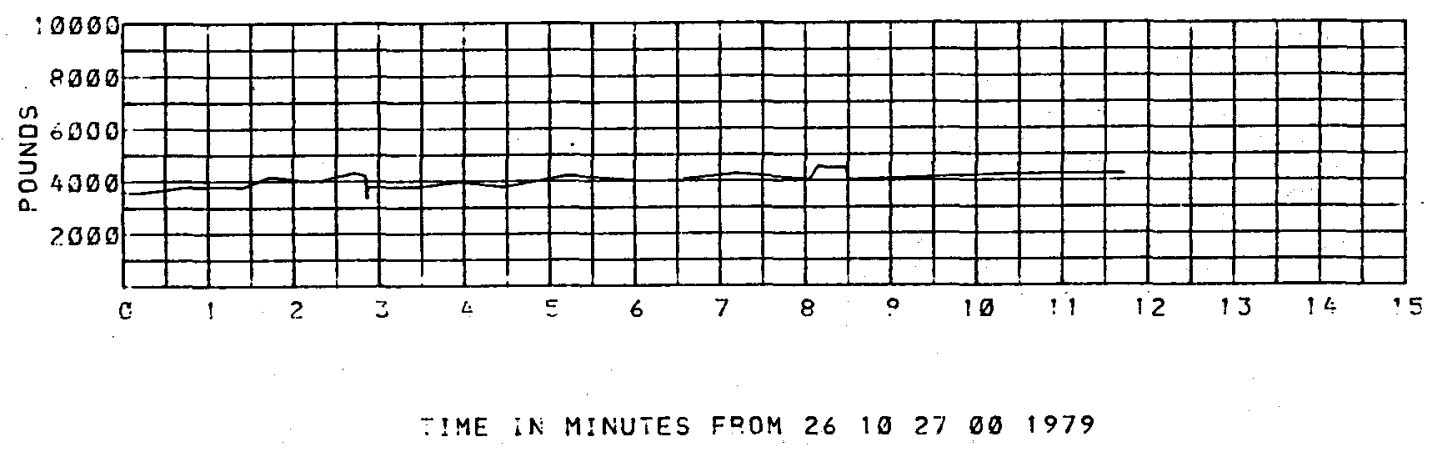

Figure D-5. Drilling with Conventional HQ Core Bit during Reentry into Hole 79-1: Drilling in Flow-Back Column at between $172 \mathrm{ft} 10$ inches and $177 \mathrm{ft}$ 11 inches 
DRILL SPEED

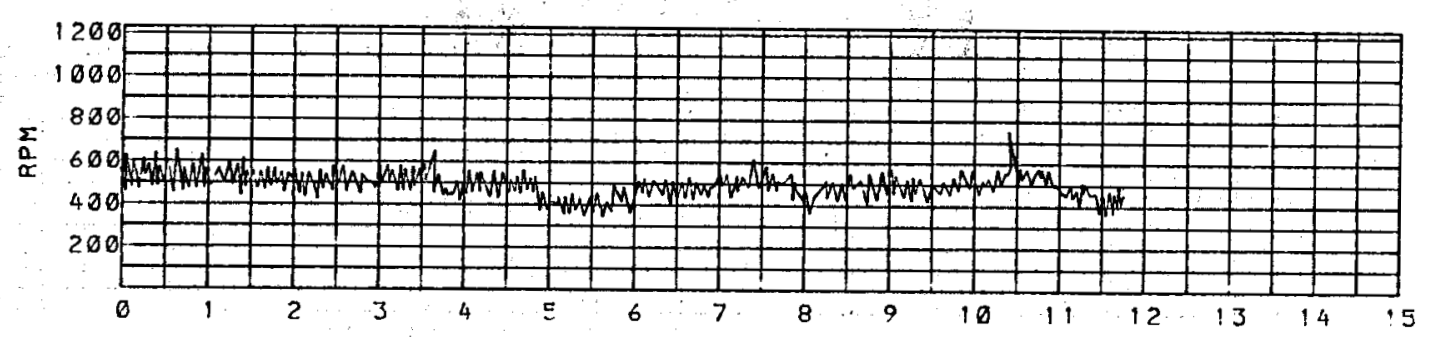

DISPLACEMENT
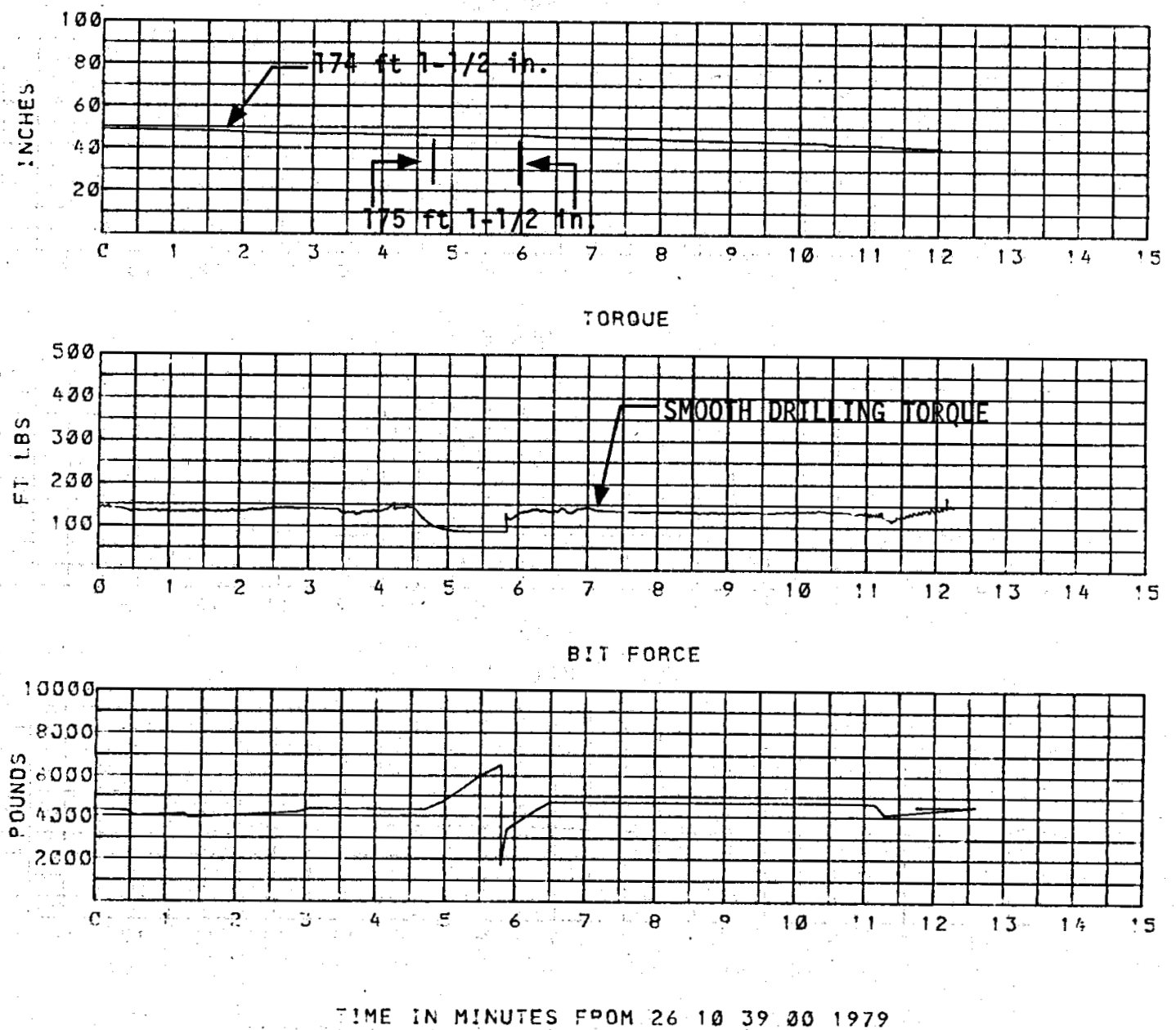

Figure D-6. Drilling with Conventional HQ Core Bit during Reentry into Hole 79-1 
DRILL SPEED

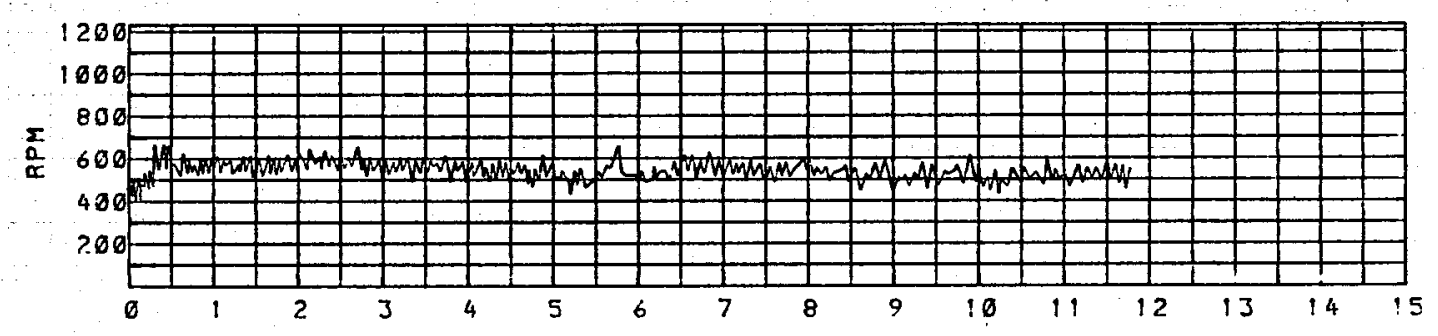

OISPLACEMENT
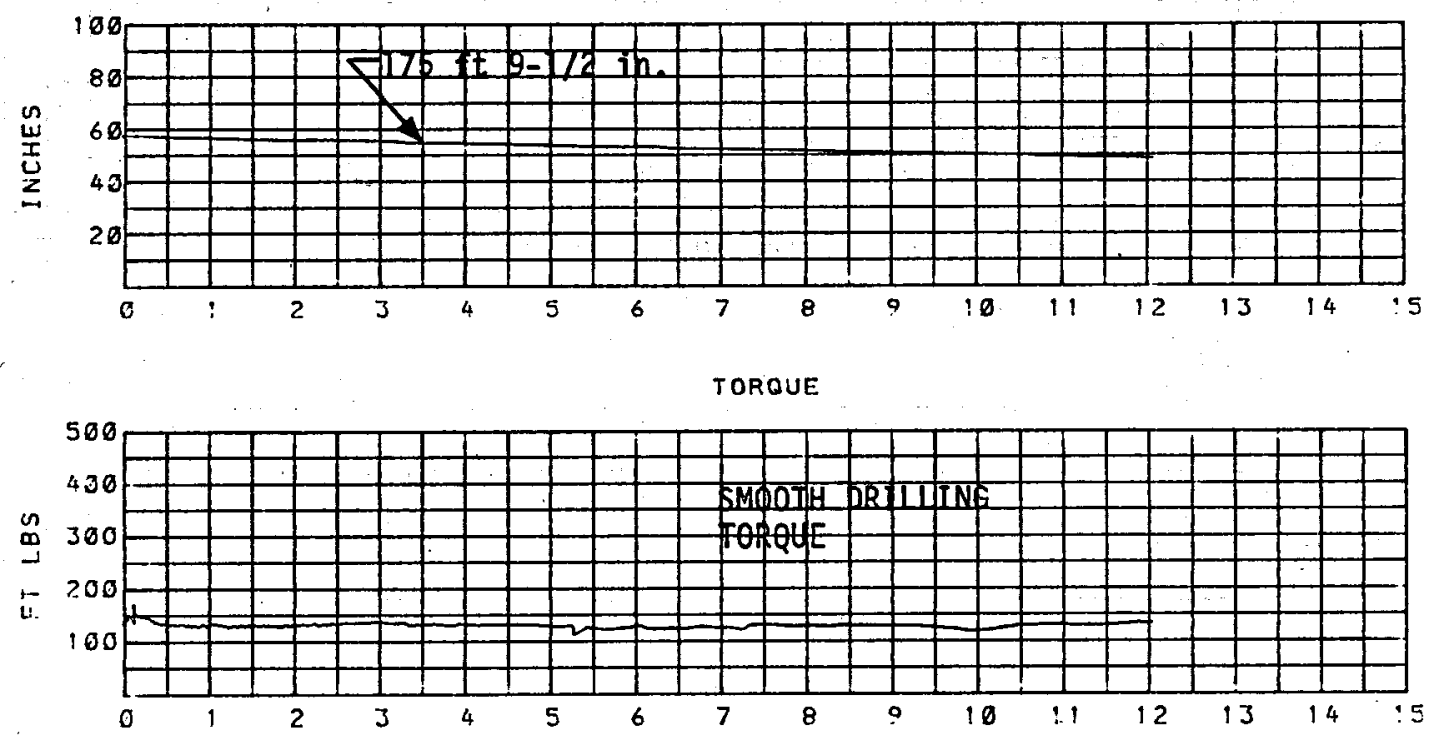

BIT FORCE

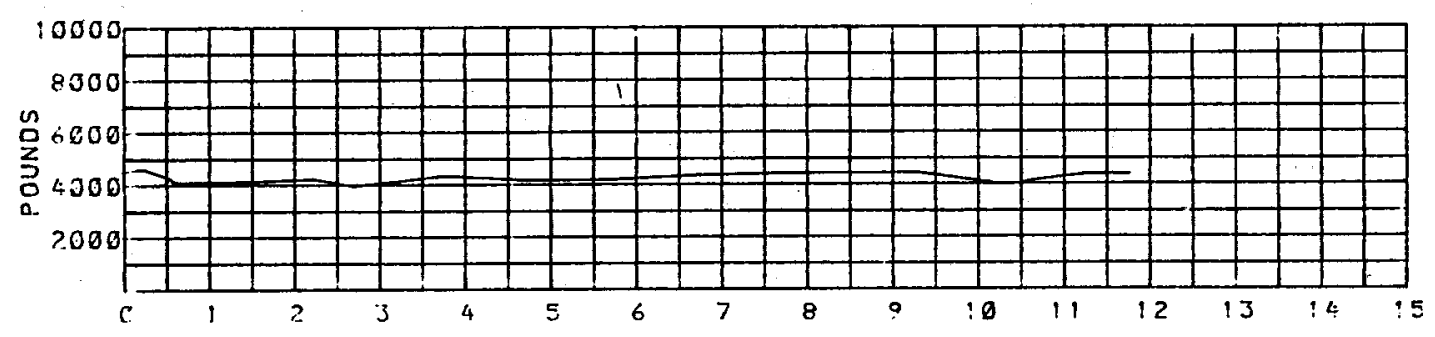

IIME :N MINUTES FROM $26 \quad 1051 \quad 001979$

Figure D-7. Drilling with Conventional HQ Core Bit during Reentry into Hole 79-1: Drilling in Flow-Back Column between $172 \mathrm{ft} 10$ inches and $177 \mathrm{ft}$ 11 inches 
ORILL SPEED

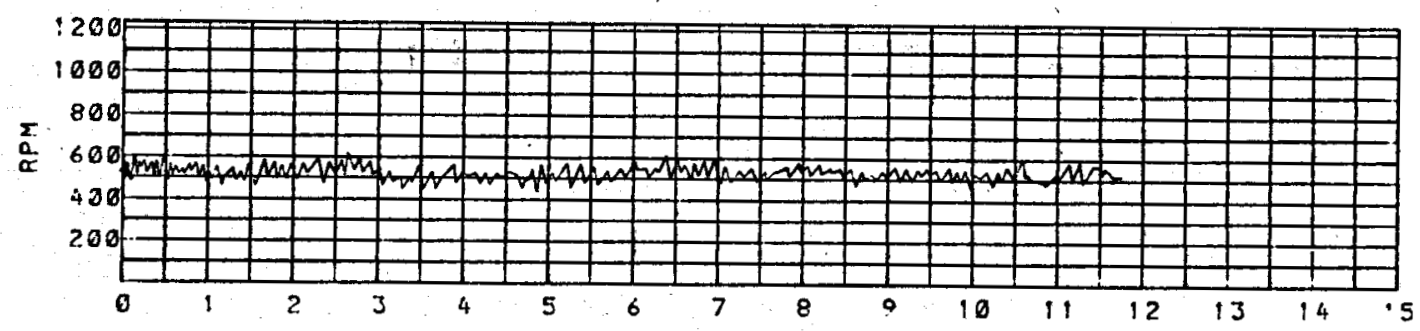

DISPLACEMENT

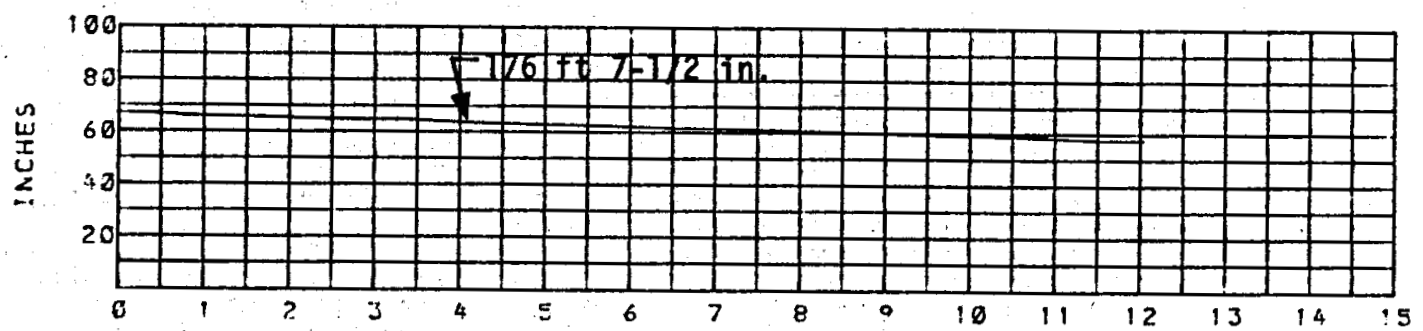

TOROUE

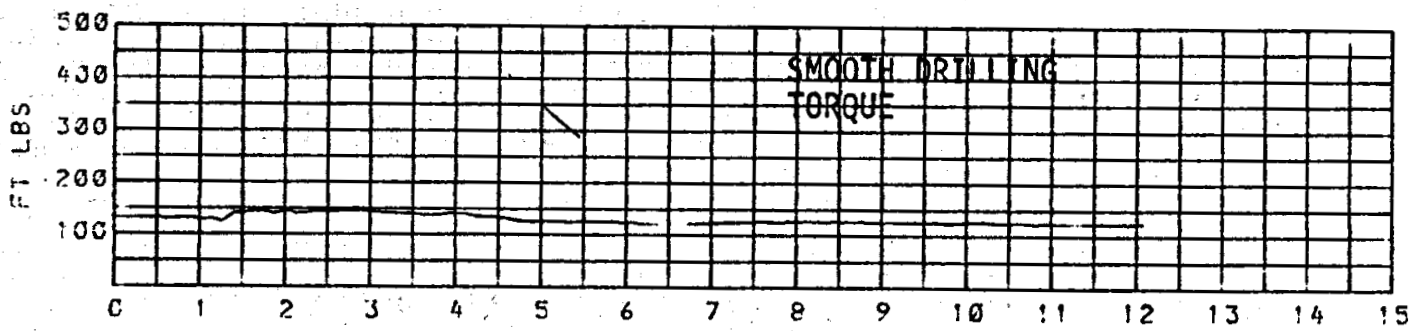

B!T PORCE

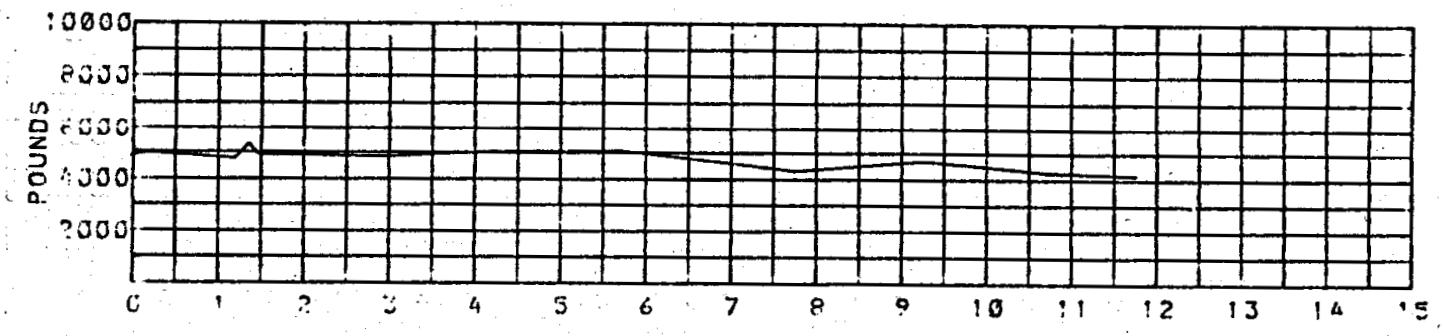

TIME IN MINUTES FQOMM 261103001979

Figure D-8. Drilling with Conventional HQ Core Bit during Reentry into Hole 79-1: Drilling through

Flow-Back Column between $172 \mathrm{ft} 10$ inches and 177. ft 11 inches 
DRILL SPEED
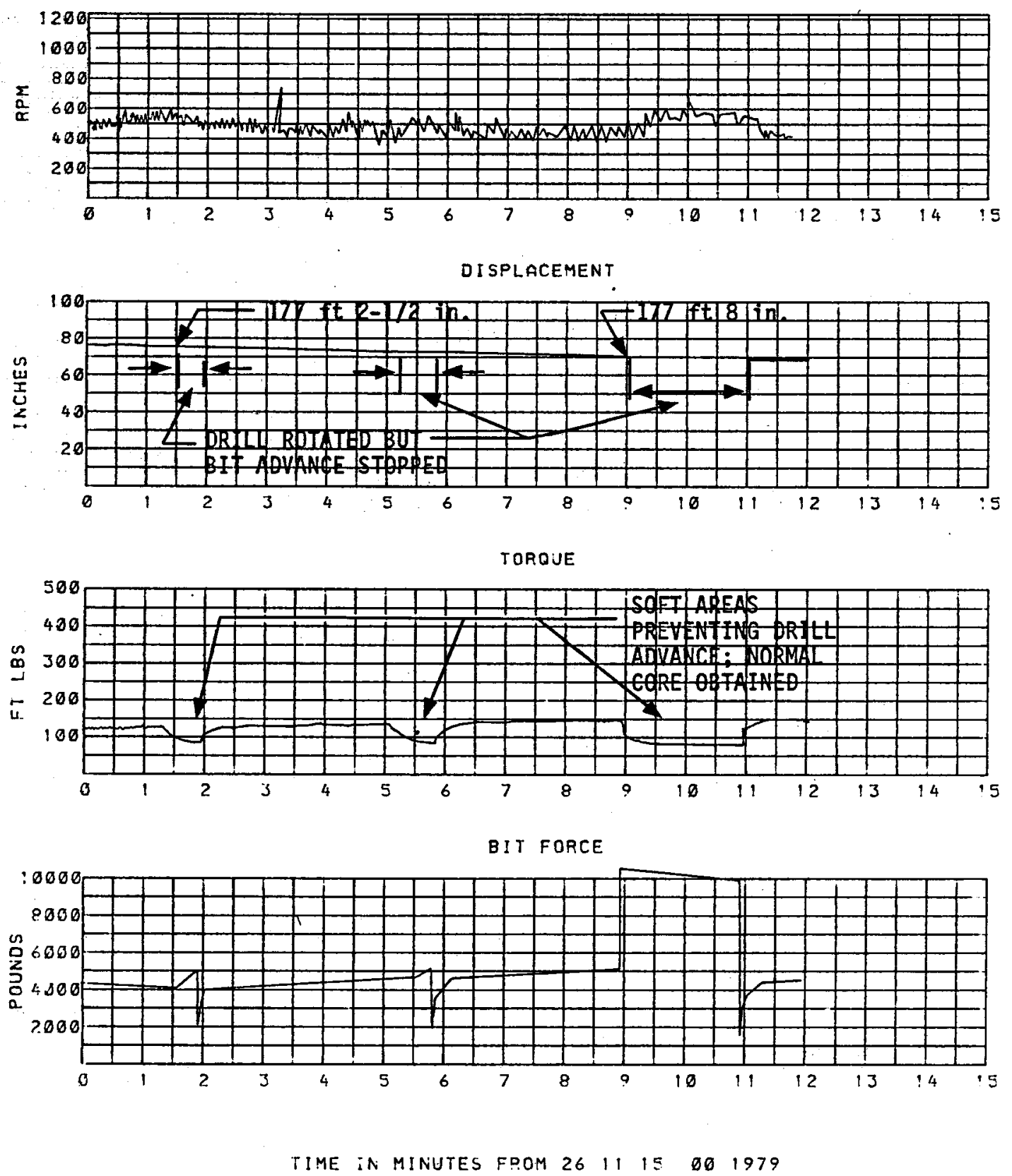

Figure D-9. Drilling with Conventional HQ Core Bit during Reentry into Hole 79-1: Drilling in Lowest Part of Flow-Back column between $172 \mathrm{ft} 10$ inches and $177 \mathrm{ft} 11$ inches 


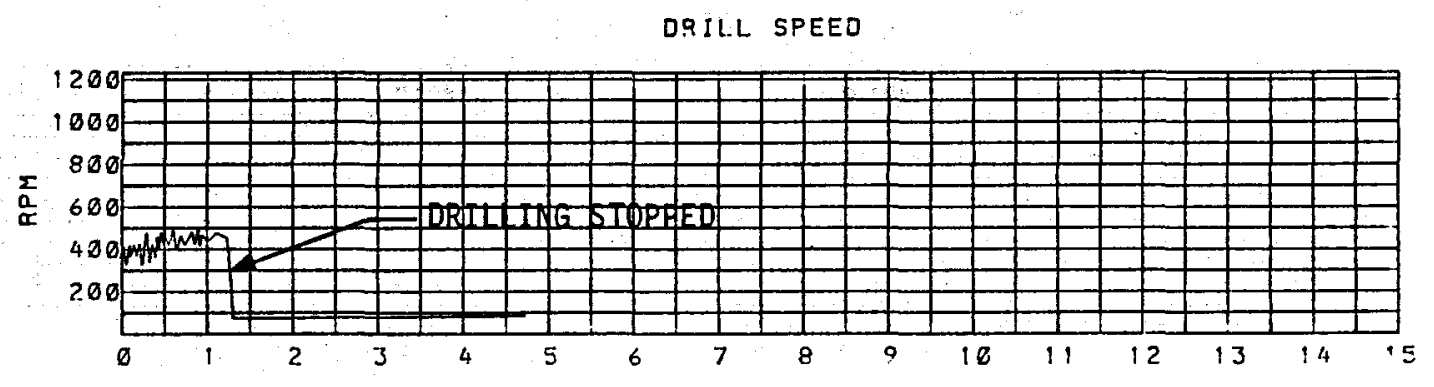

DISPLACEMENT

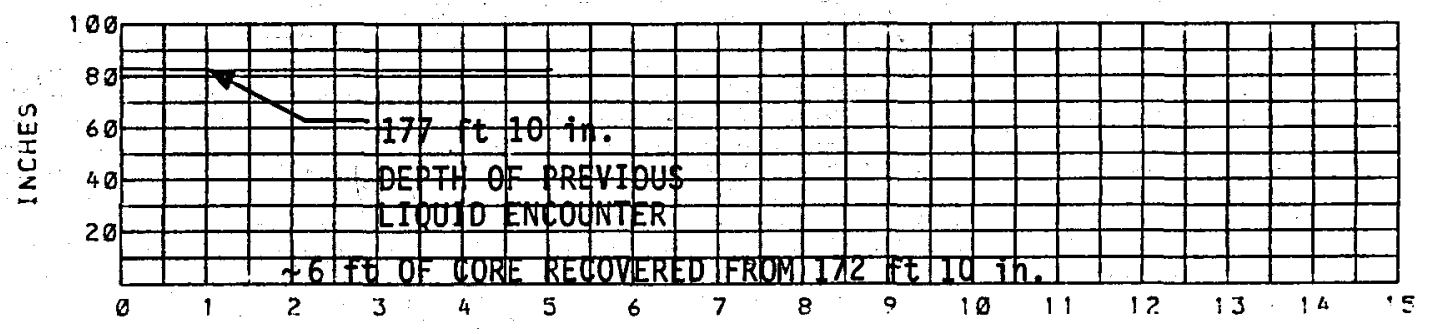

TOROUE

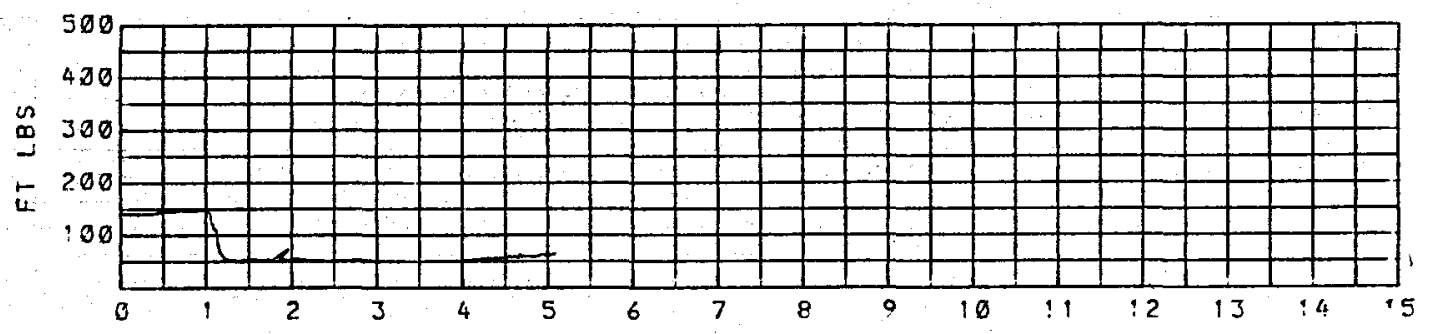

BIT FORCE

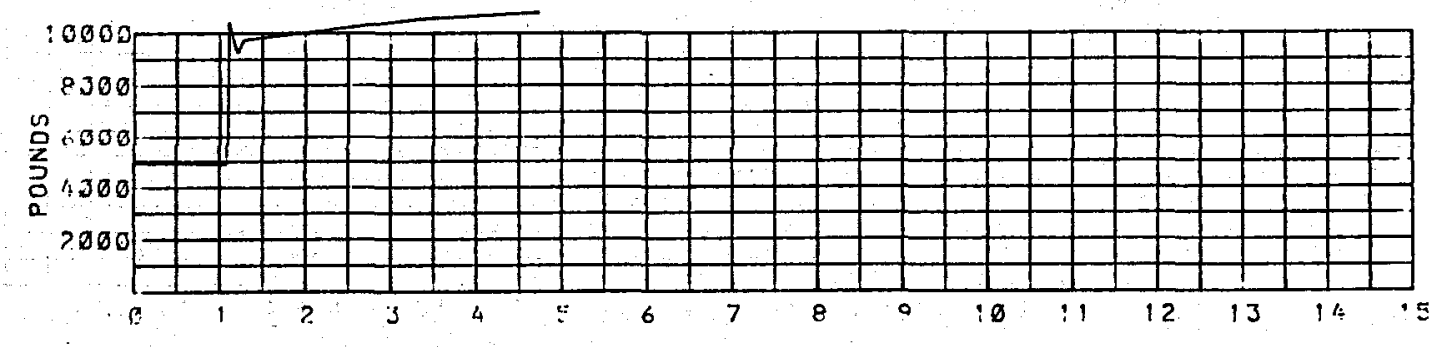

TIME IN MINUTES FPOM $26 \quad 1127 \quad 00 \quad 1979$

Figure D-10. Drilling with Conventional HQ Core Bit during Reentry into Hole 79-1: Drilling to the Bottom of the Flow-Back Chimney between 172 ft 10 inches and 177 ft 11 inches 
DRILL SPEED
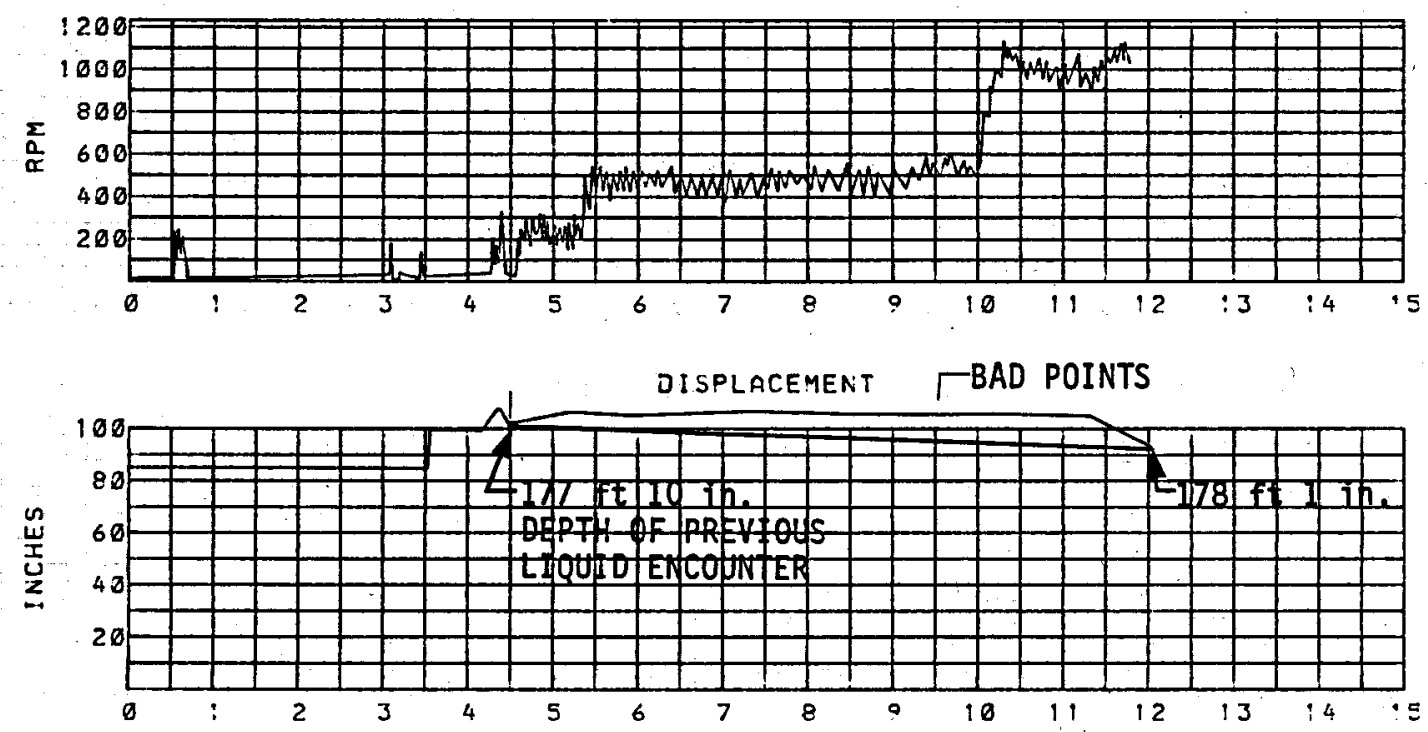

TORQUE
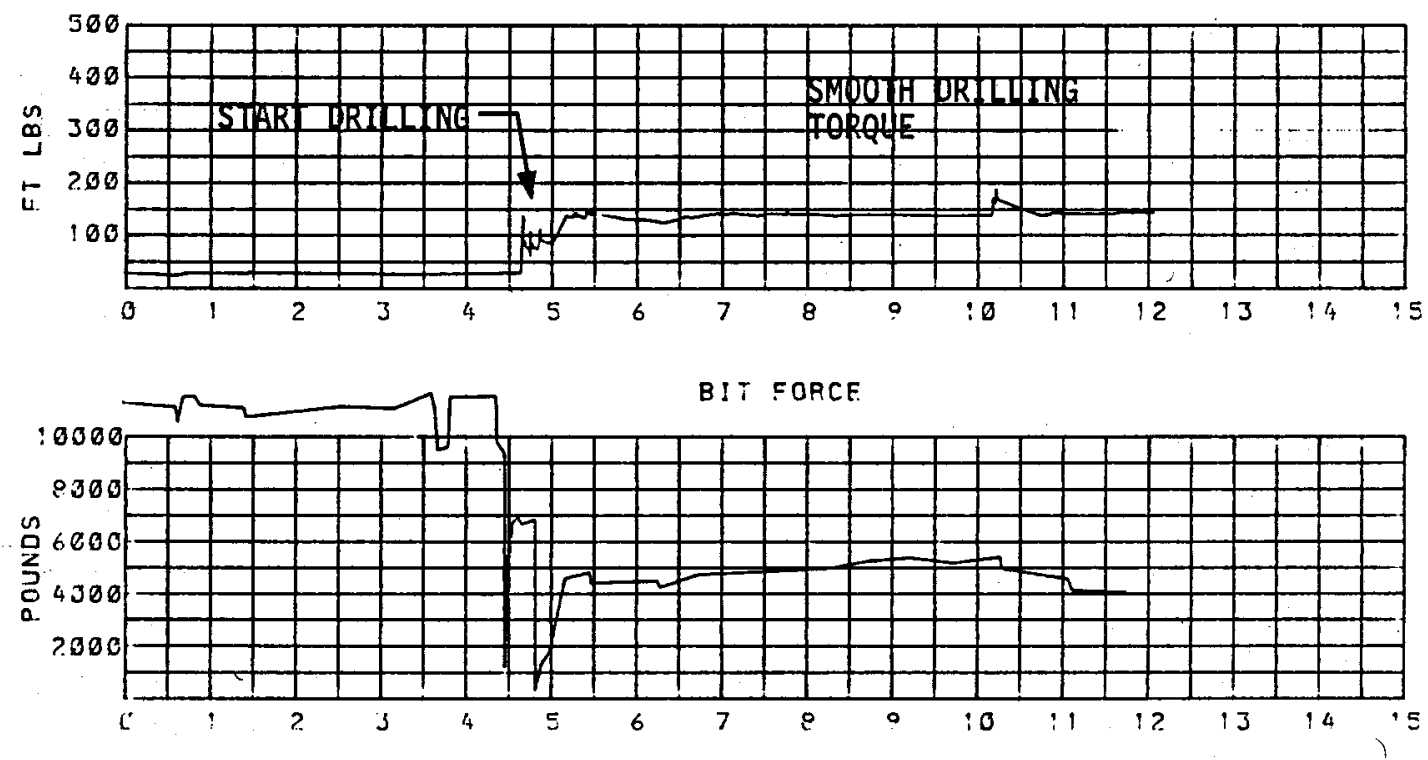

TIME IN MINUTES FDOM $26 \quad 12 \quad 4000 \quad 1979$

Figure D-11. Drilling with Conventional HQ Core Bit during Reentry into Hole 79-1: Drilling Below $177 \mathrm{ft}$ 11 inches Melt Encounter 
DRILL SPEED

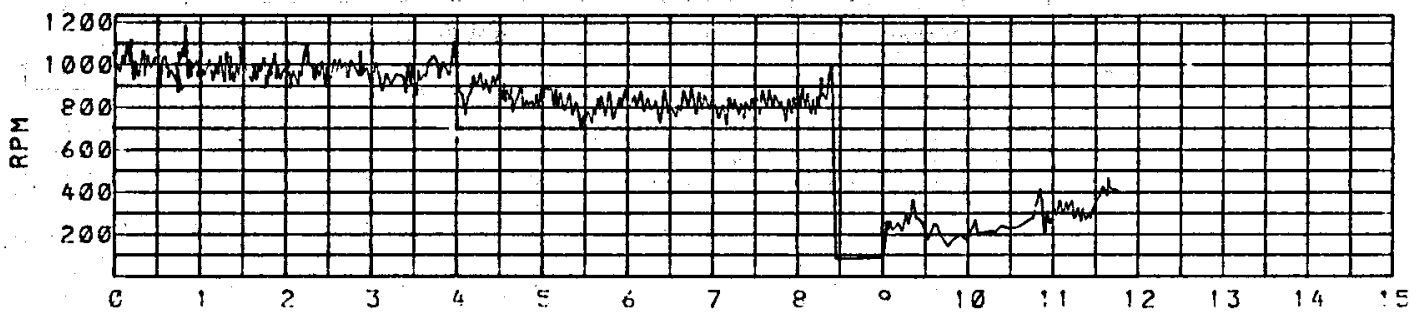

DI SPLACEMENT

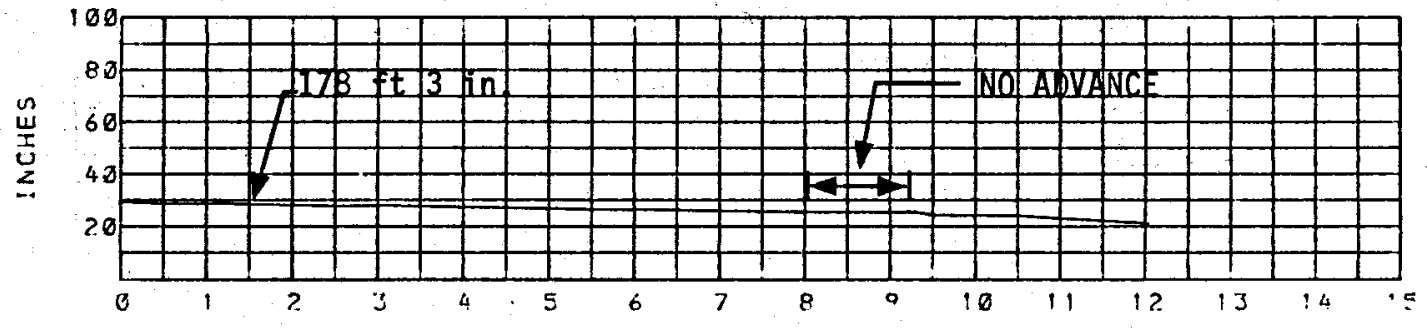

TOROUE
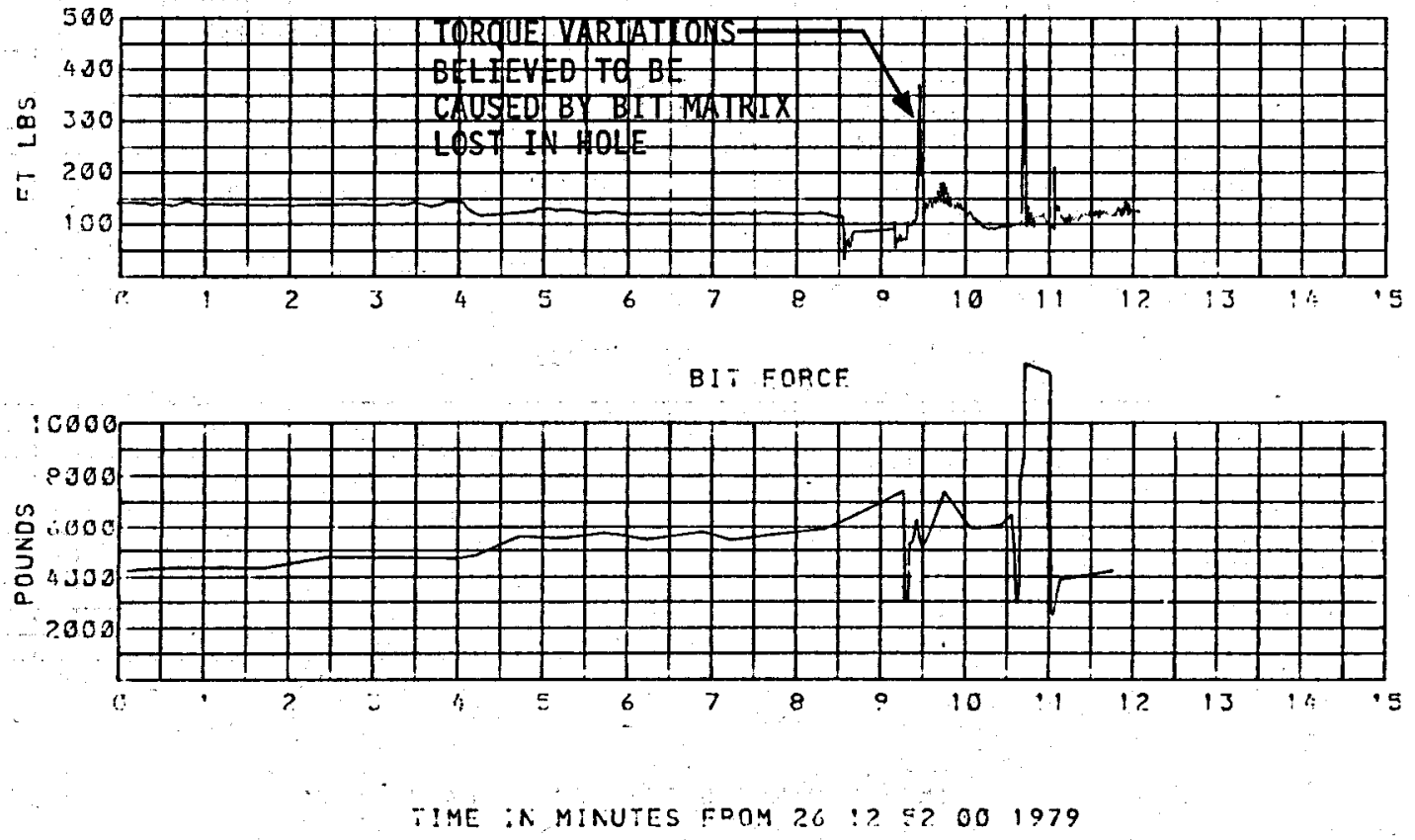

Figure D-12. Drilling with Conventional HQ Core Bit during Reentry into Hole 79-1: Drilling below Melt Encountered at $177 \mathrm{ft} 11$ inches 
DRILL SPEEO

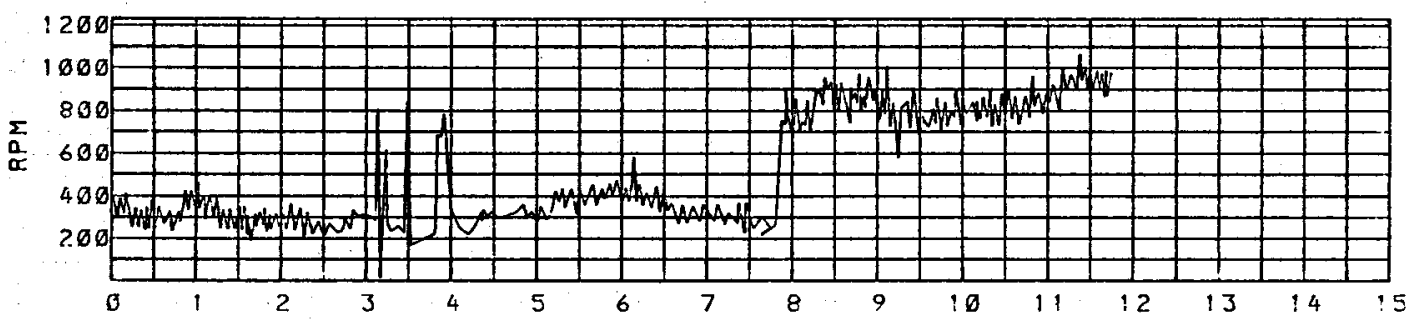

DISPLACEMENT

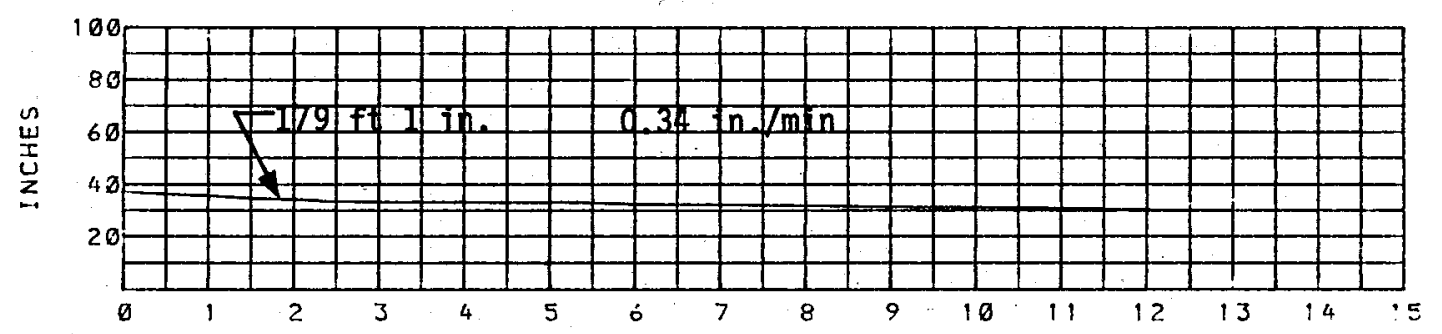

TOROUE

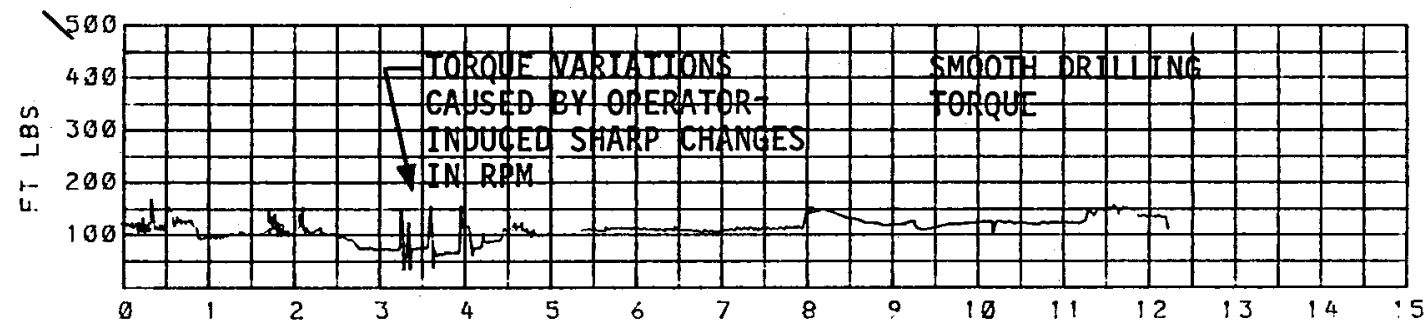

BI? FORCE

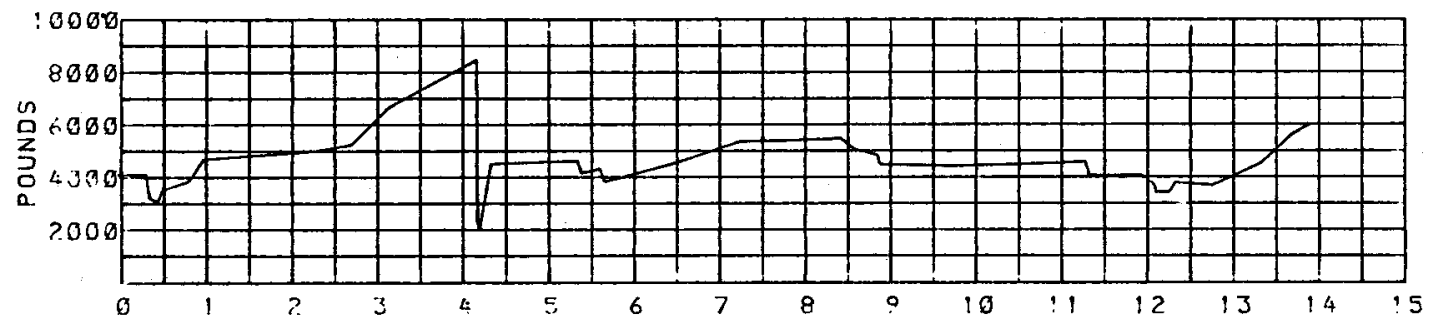

TIME IN MINUTES FDOM $26 \quad 13 \quad 04 \quad 30^{\circ} 1979$

Figure D-13. Drilling with Conventional HQ Core Bit during Reentry into Hole 79-1 

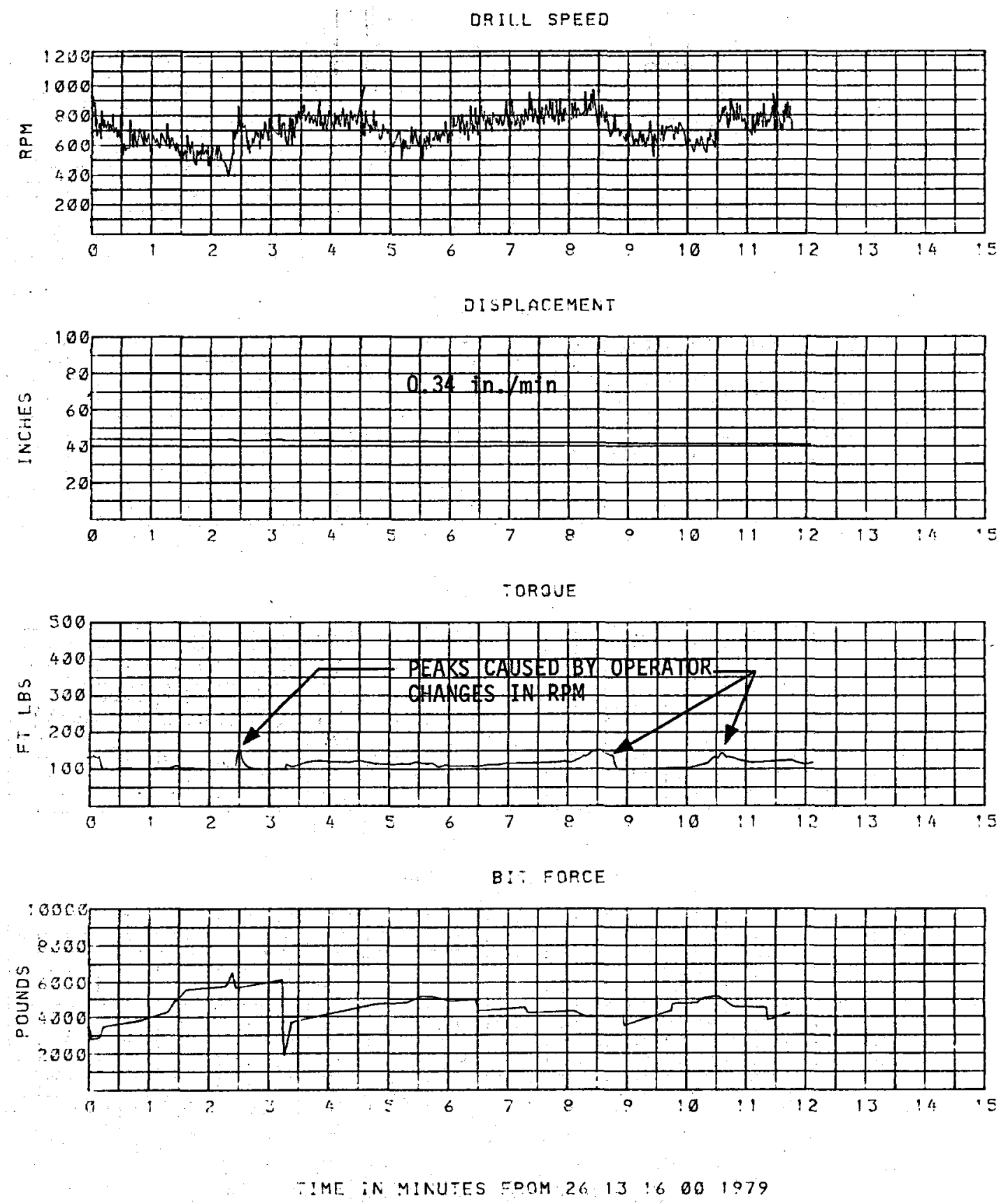

Figure D-14. Drilling with Conventional HQ Core Bit during Reentry into Hole 79-1 
DQILL SPEEO

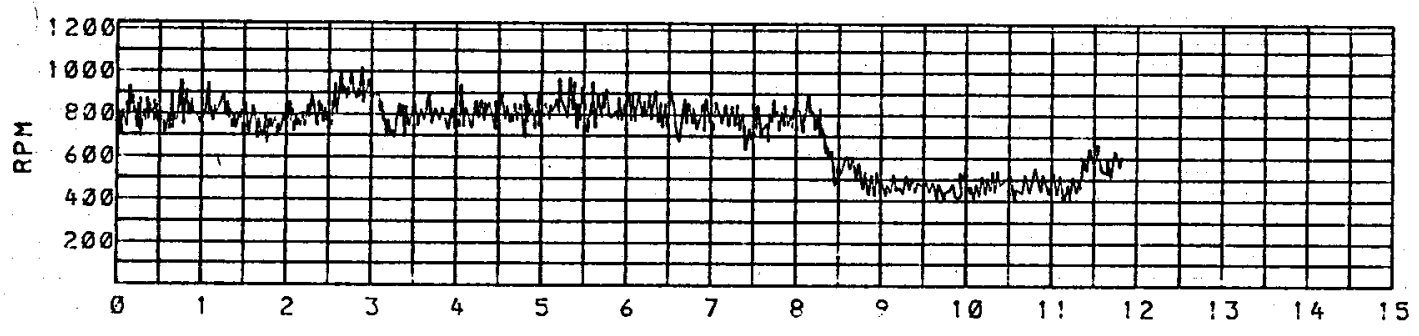

DISPLACEMENT

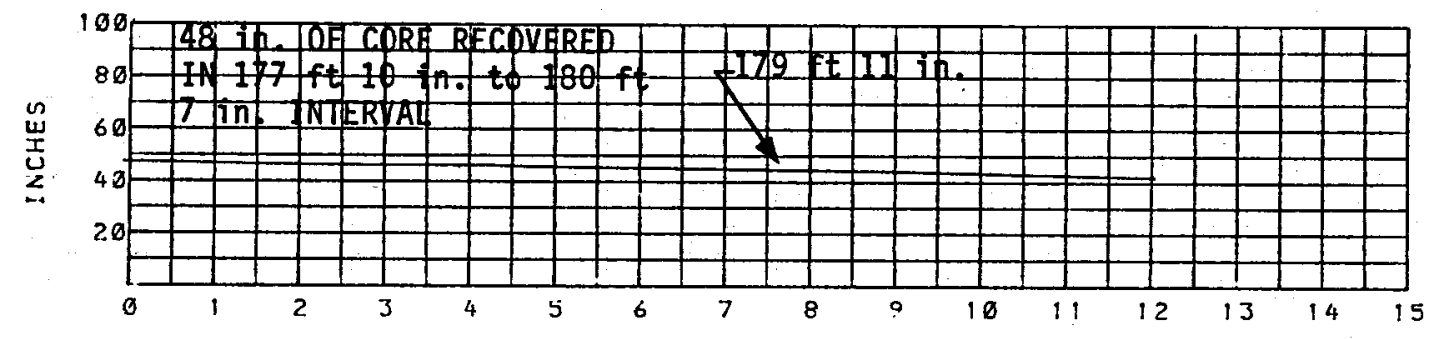

TORQUE

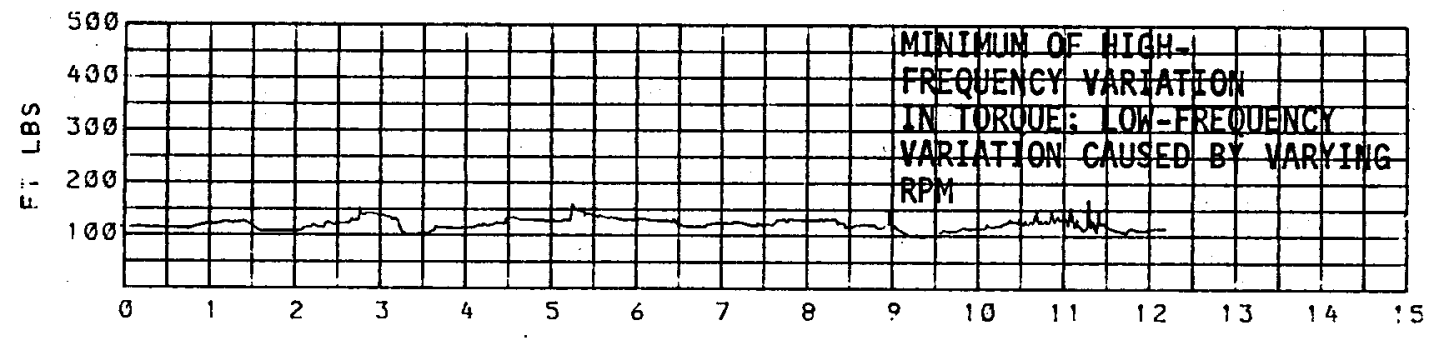

B:T FORCE

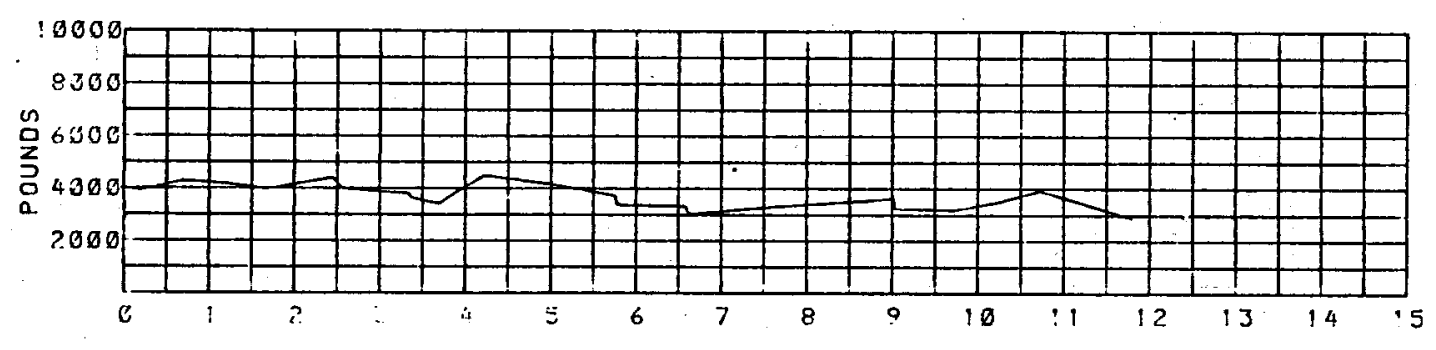

IIME IN MINUTES CONM 20 $13 \quad 28 \quad 00 \quad 1979$

Figure D-15. Drilling with Conventional HQ Core Bit during Reentry into Hole 79-1: Drilling in very Plastic, but not Liquid, Rock 

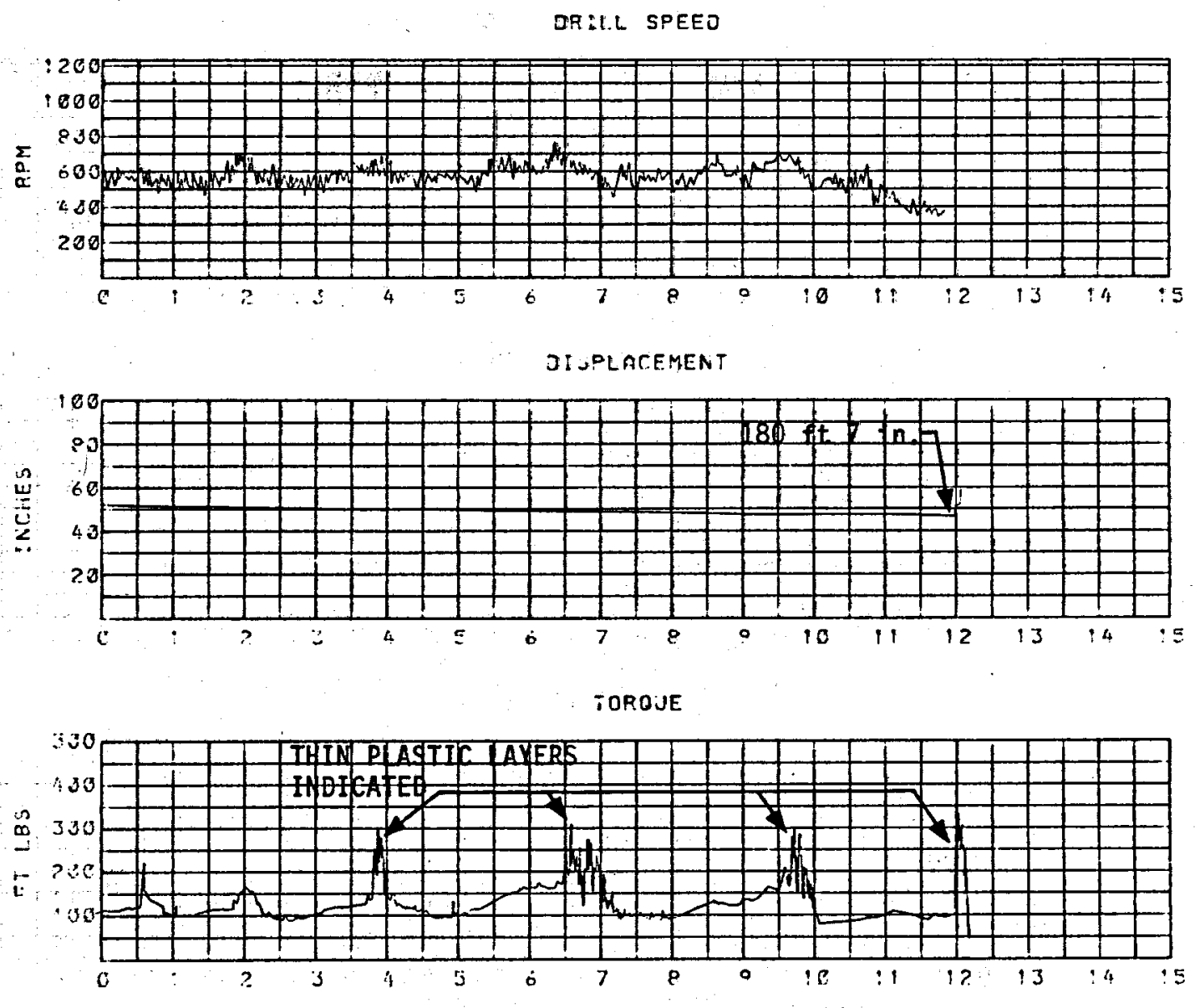

B: I FOPCE

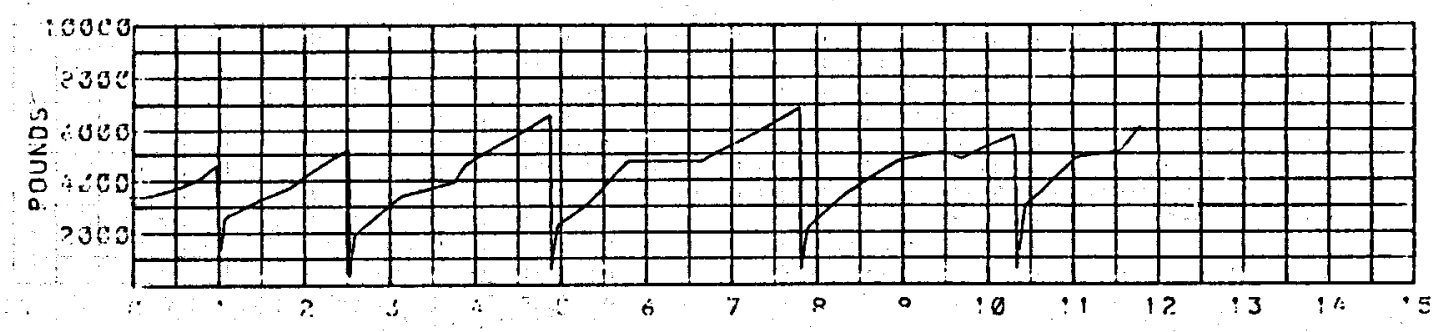

TIME AN MINUTFS FPOM 261343031979

Figure D-16. Drilling with Conventional HQ Core Bit during Reentry into Hole 79-1: Drilling through plastic zones 
DRILL SPEED

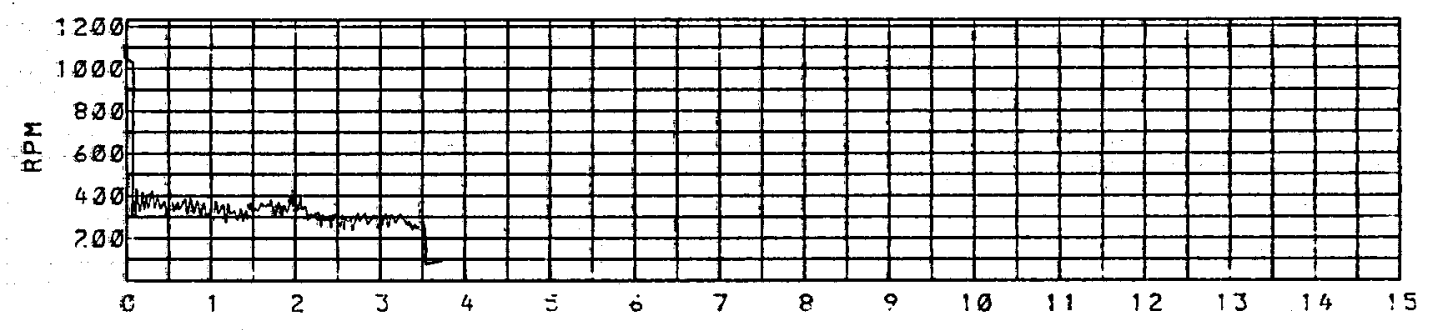

DISPLACEMENT

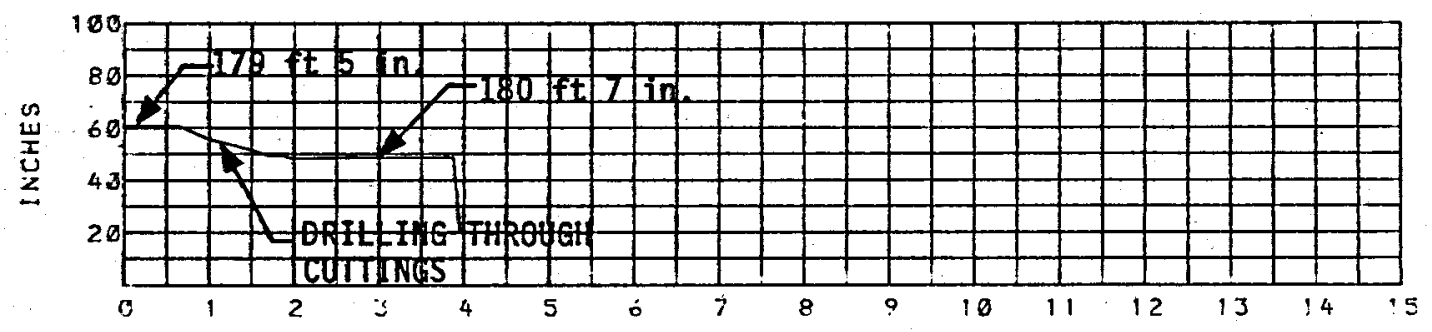

TOROUE
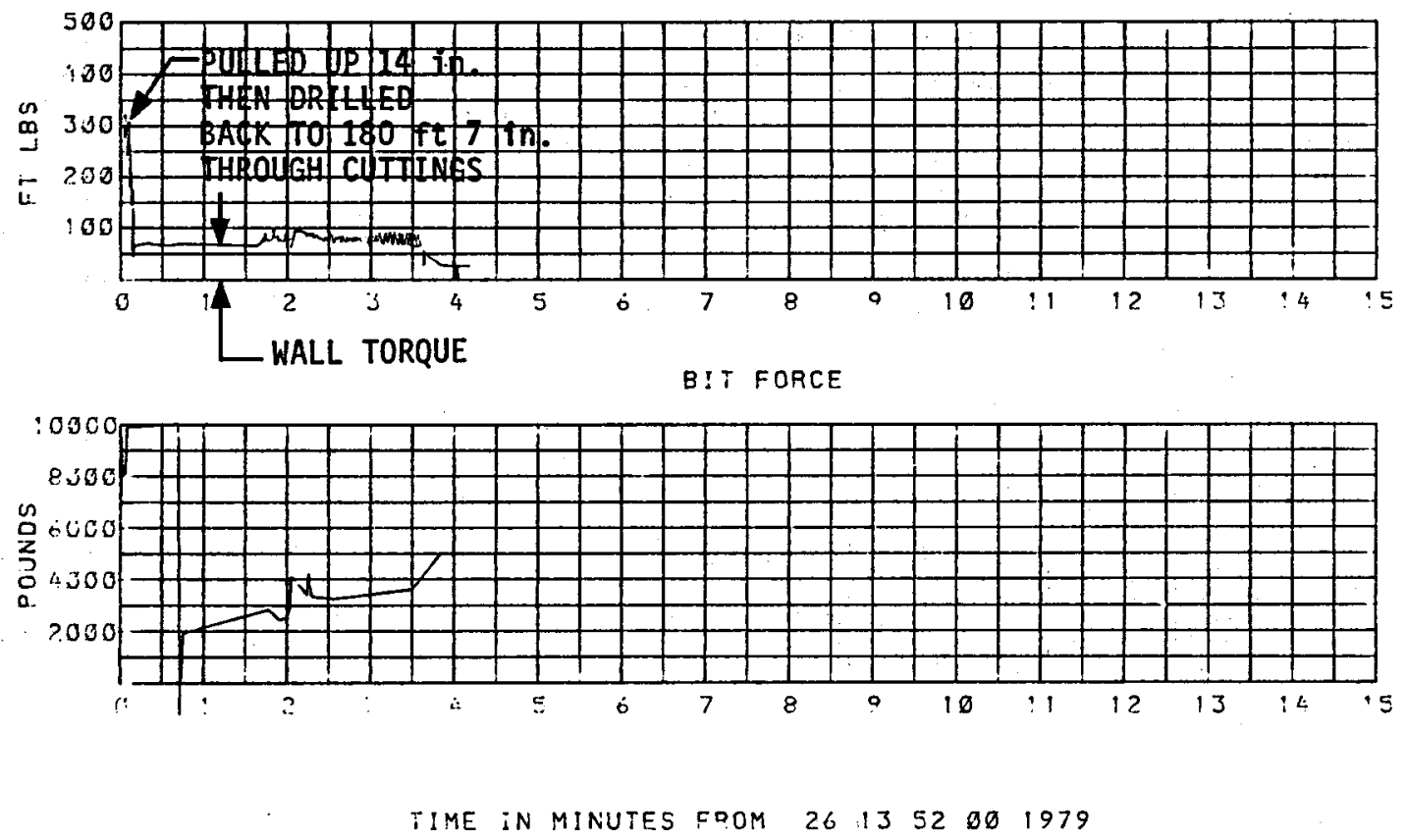

Figure D-17. Final Drilling with Conventional HQ Core Bit during Reentry into Hole 79-1 
DRILL SPEEO
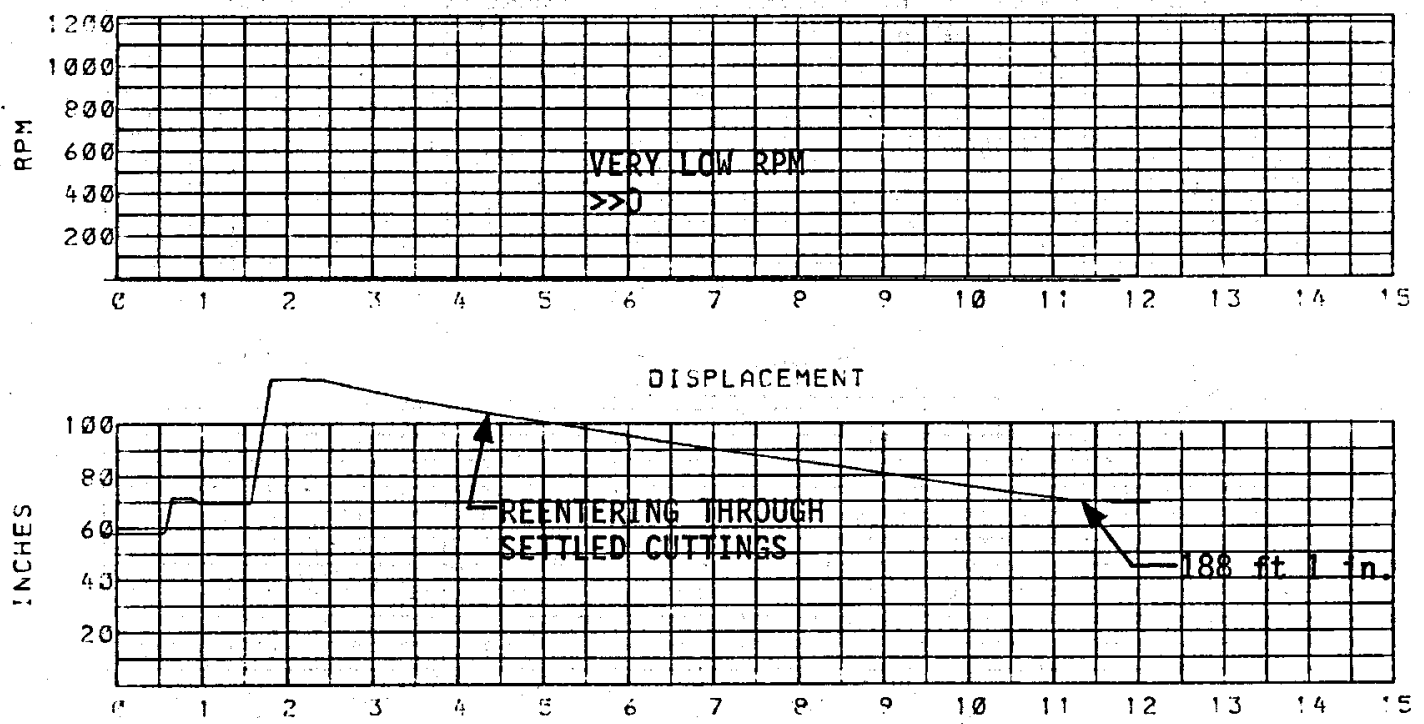

TOROUE
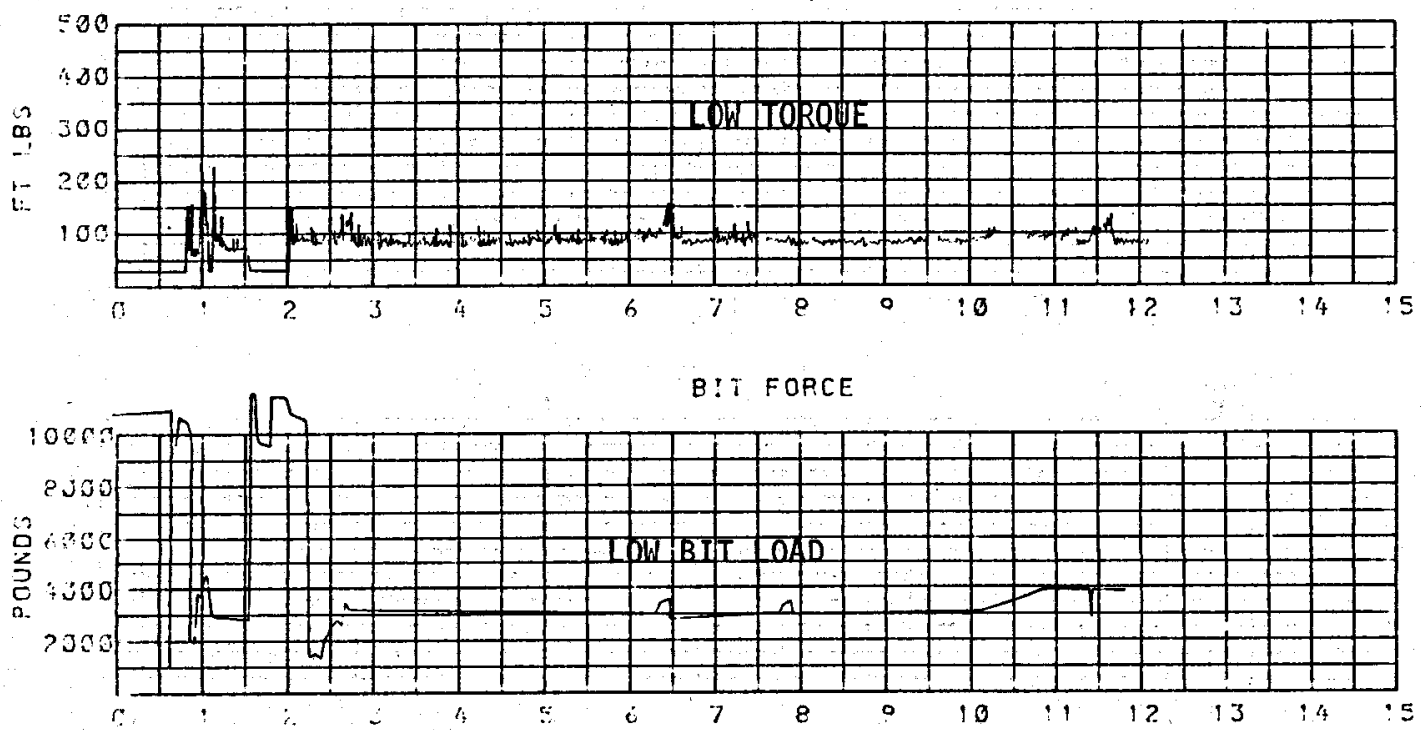

TIME IN MINUTES FOOM $29 \quad 3938 \quad 00 \quad 1979$

Figure D-18. Commencing Drilling with Jet Core Bit during Reentry into Hole 79-1 

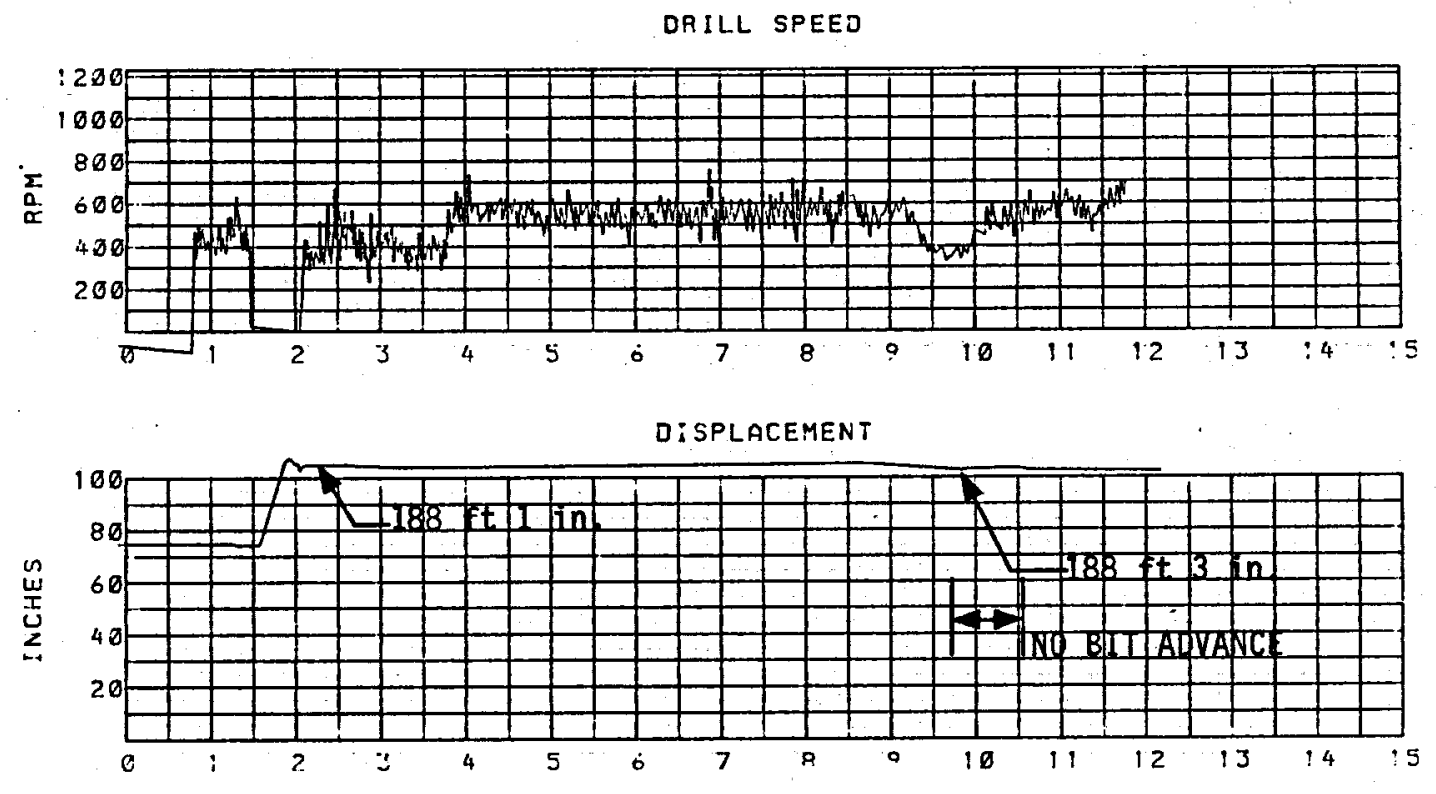

TOROJE
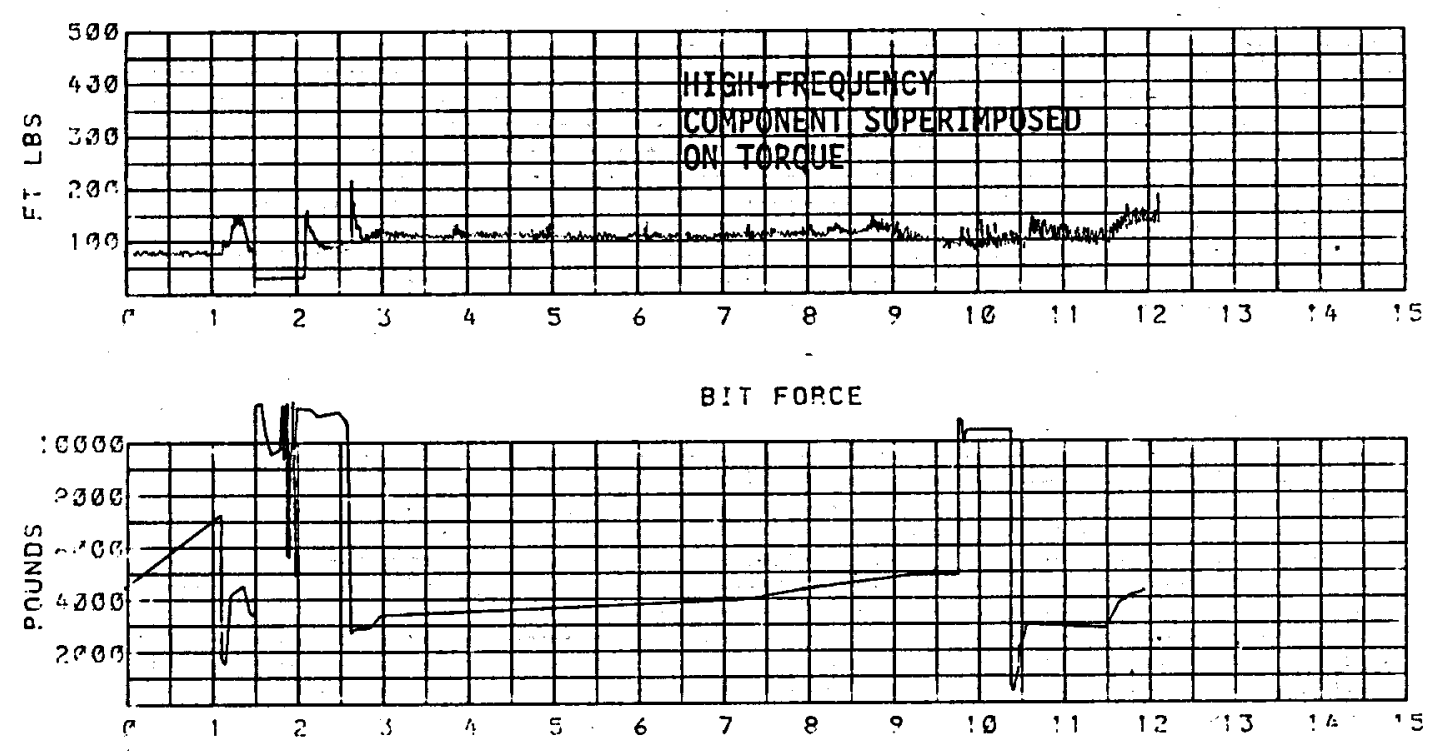

TINE IN MINUTES FDOM $29 \quad 39 \quad 20 \quad 00 \quad 1979$

Figure D-19. Drilling with Jet Core Bit during Reentry into Hole 79-1 
DRILL SPEED
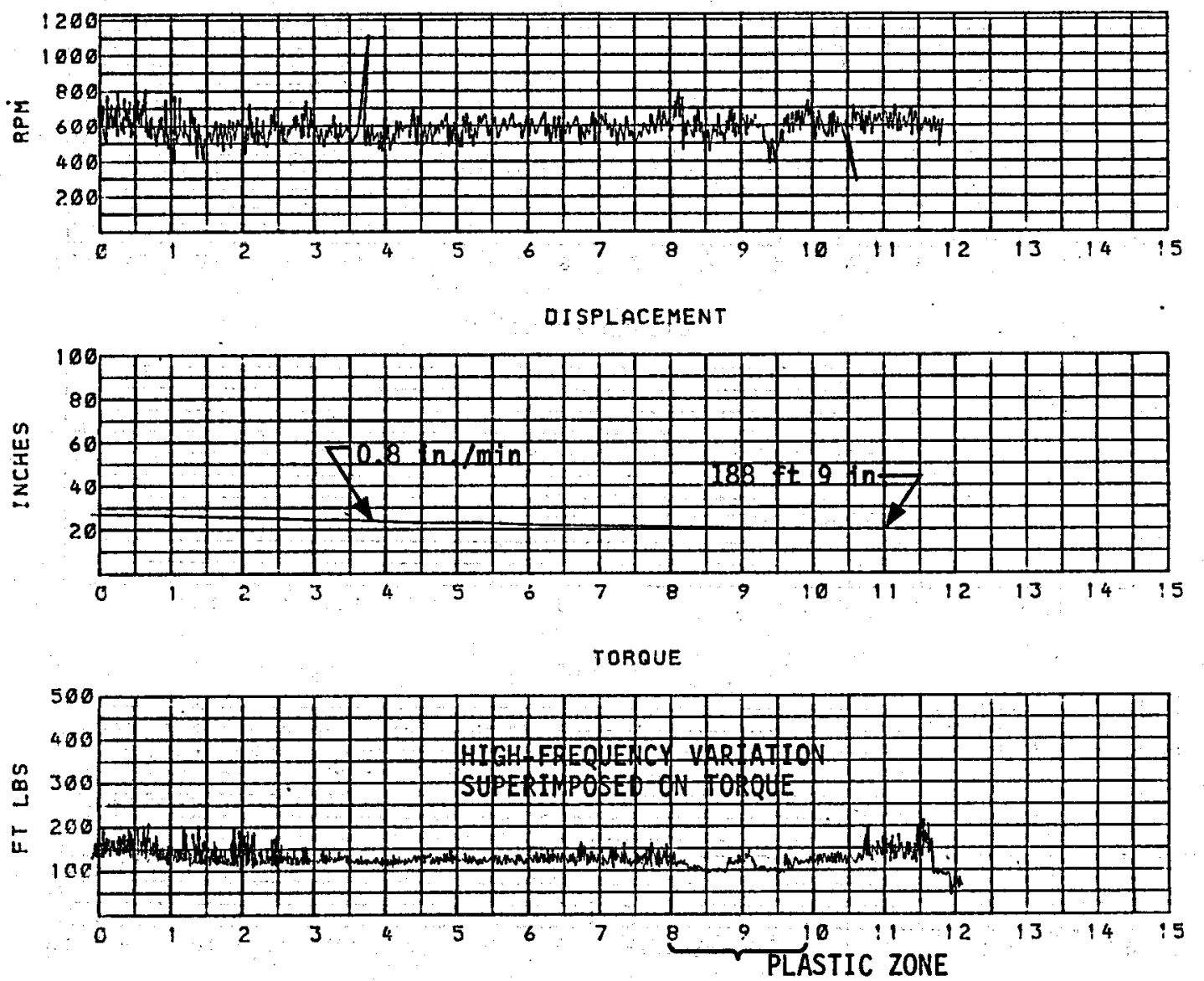

BIT FORCE

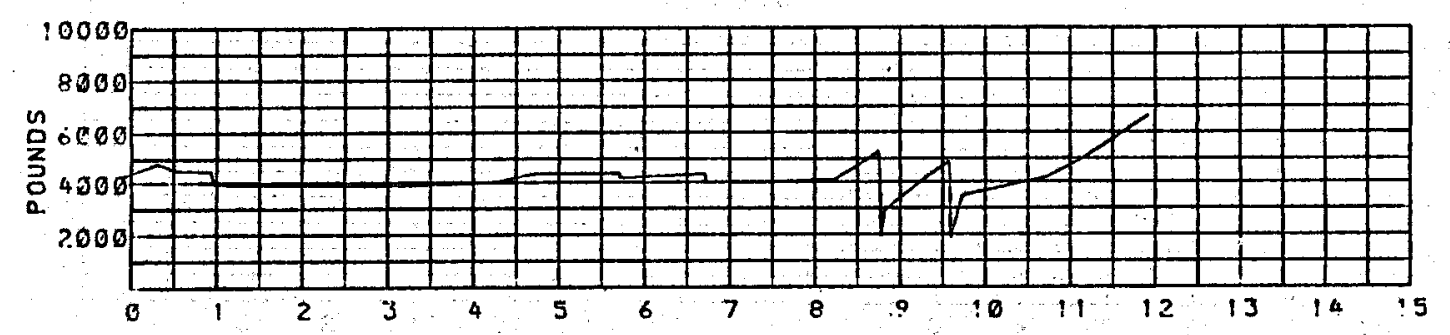

TIME :N MINUTES FROM 290932001979

Figure D-20. Drilling with Jet Core Bit during Reentry into Hole 79-1 
DRILL SPEED

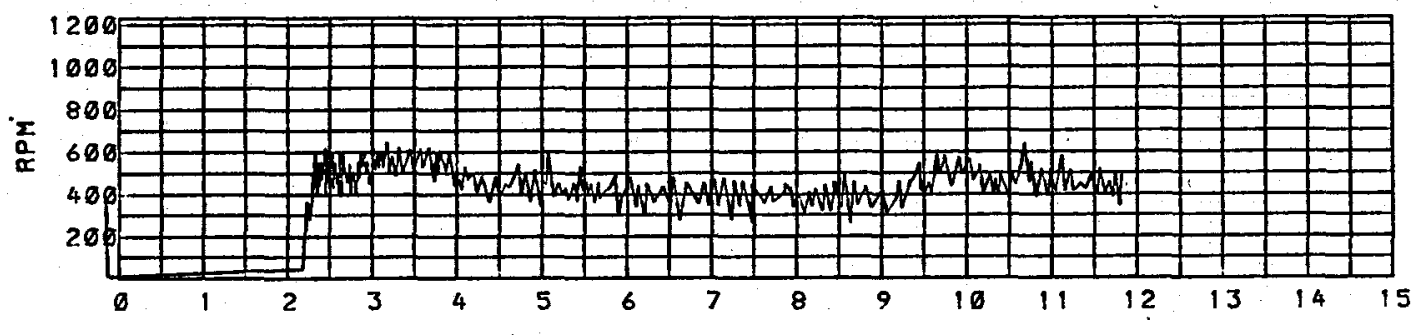

DISPLACEMENT
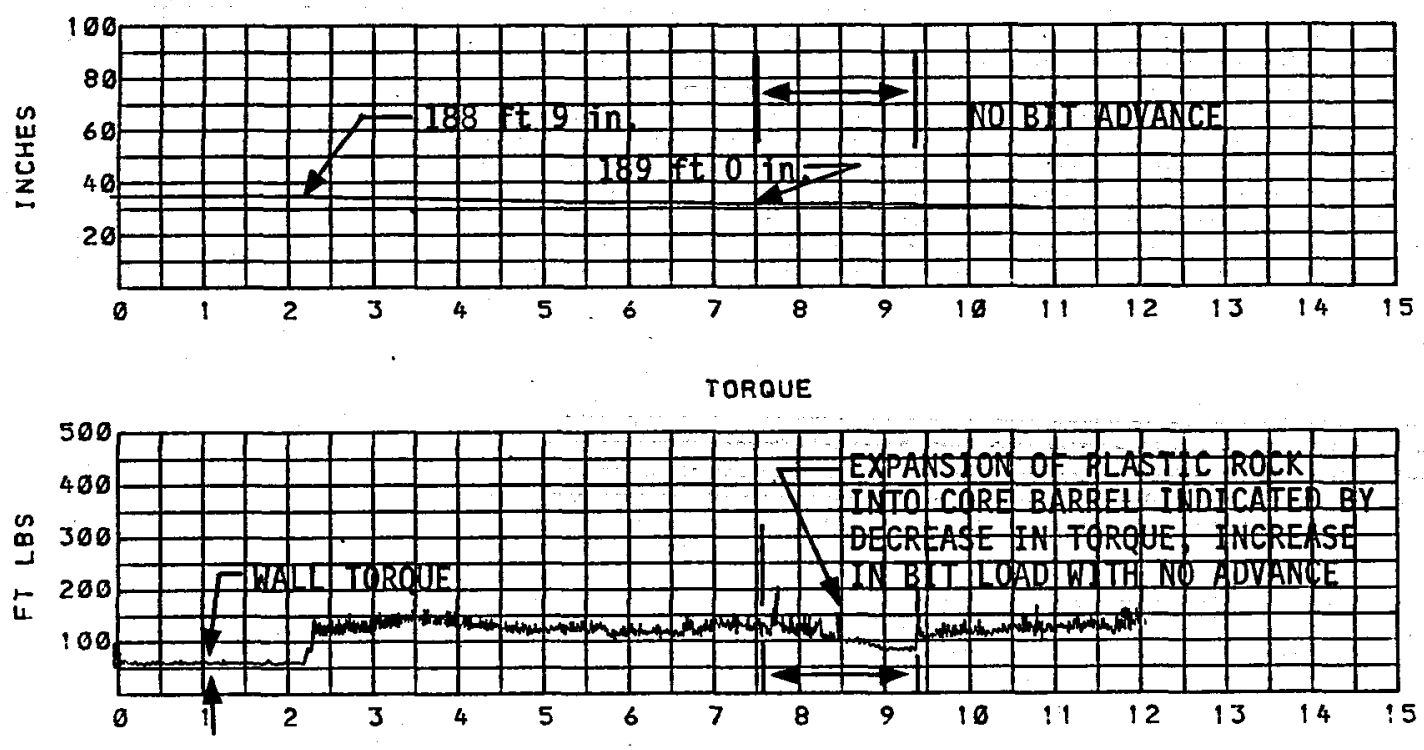

BIT FORCE

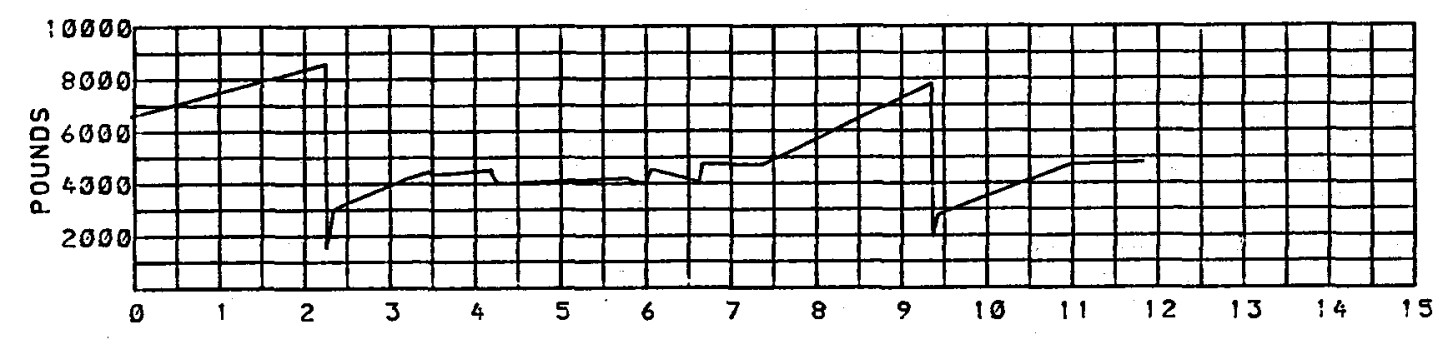

TIME IN MINUTES FROM $2909 \quad 44 \quad$ D0 1979

Figure D-21. Drilling with Jet Core Bit during Reentry into Hole 79-1: Drilling High Viscosity Plastic Rock which Flowed into Core Barrel 
DRILL SPEED

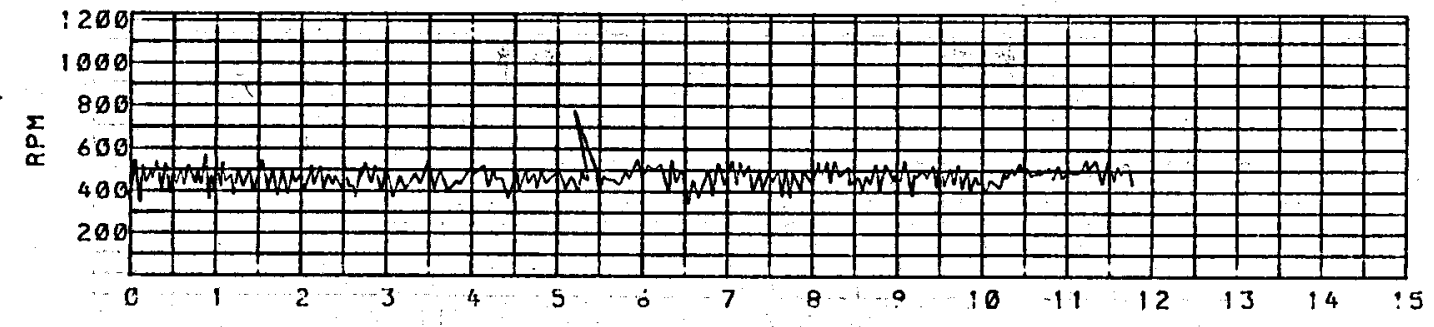

DISPLACEMENT

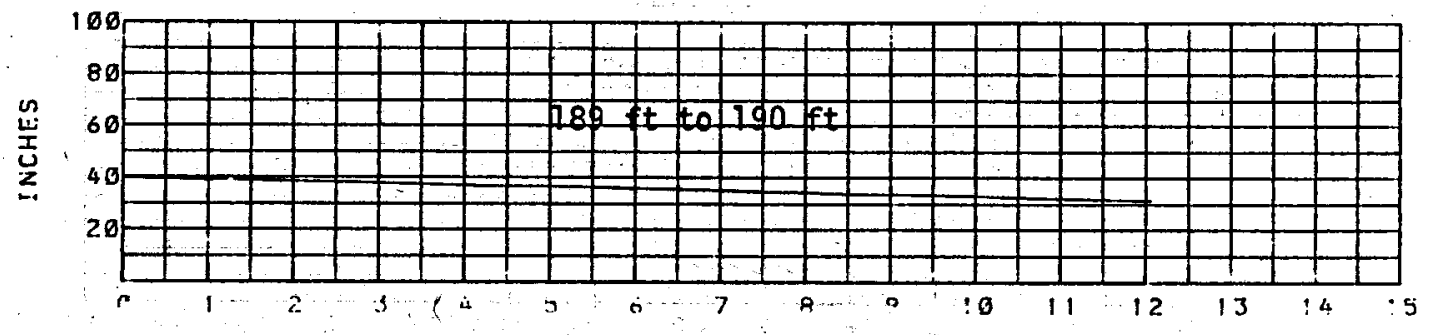

TOROUE

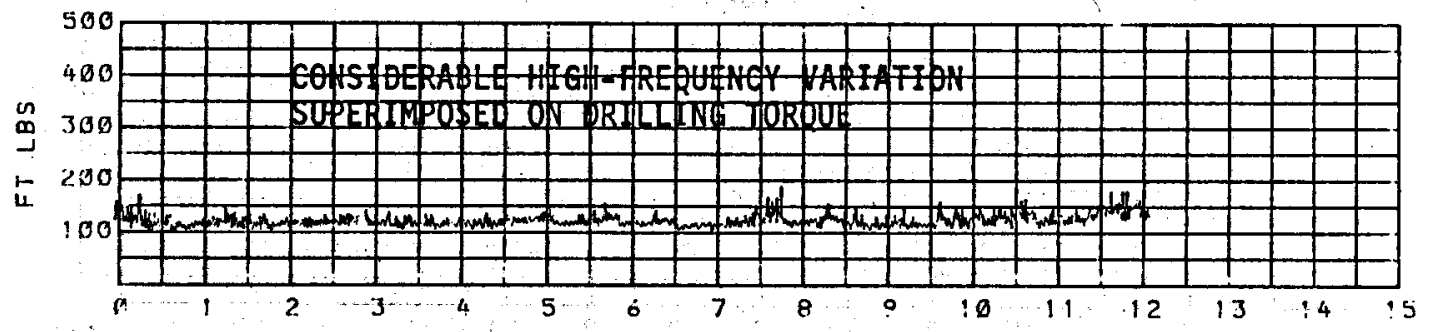

B:T FORCE

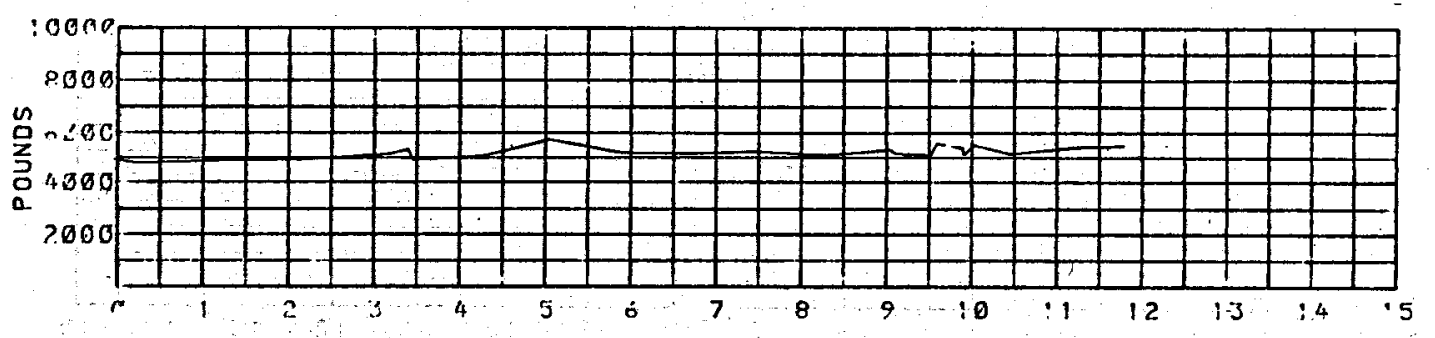

TIME IN MINUTES TROM $29 \quad 3956 \quad 90 \quad 1979$ Figure D-22. Drilling with Jet Core Bit during Reentry into
Hole 79-1. 


\section{DPILL SPEED}

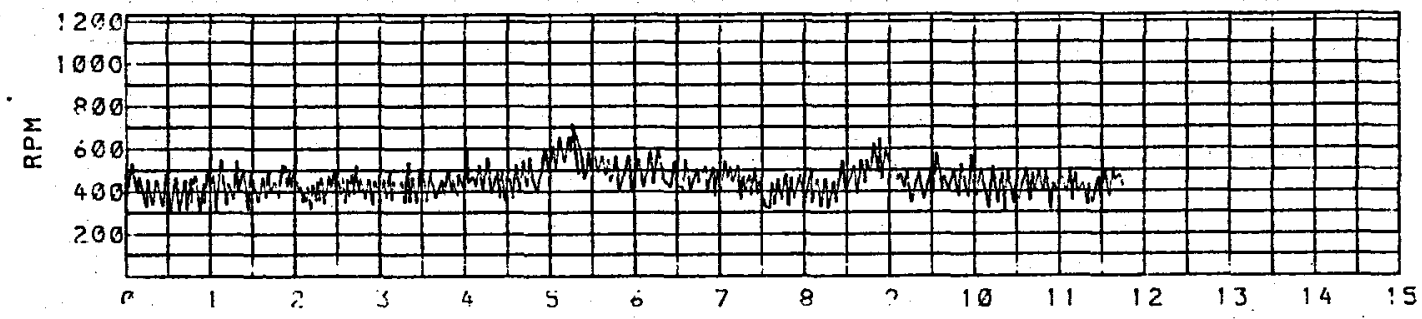

DISPLACEMENT

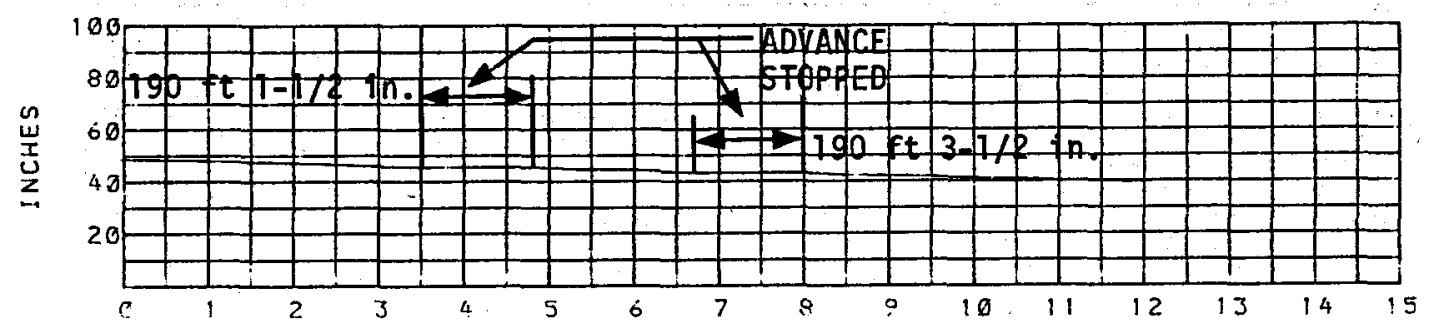

TOROUE

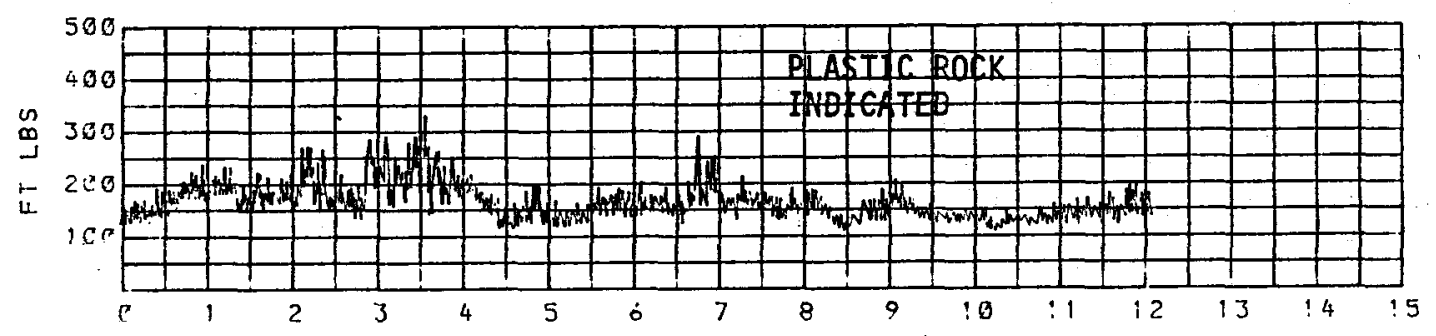

BIT FOPCE

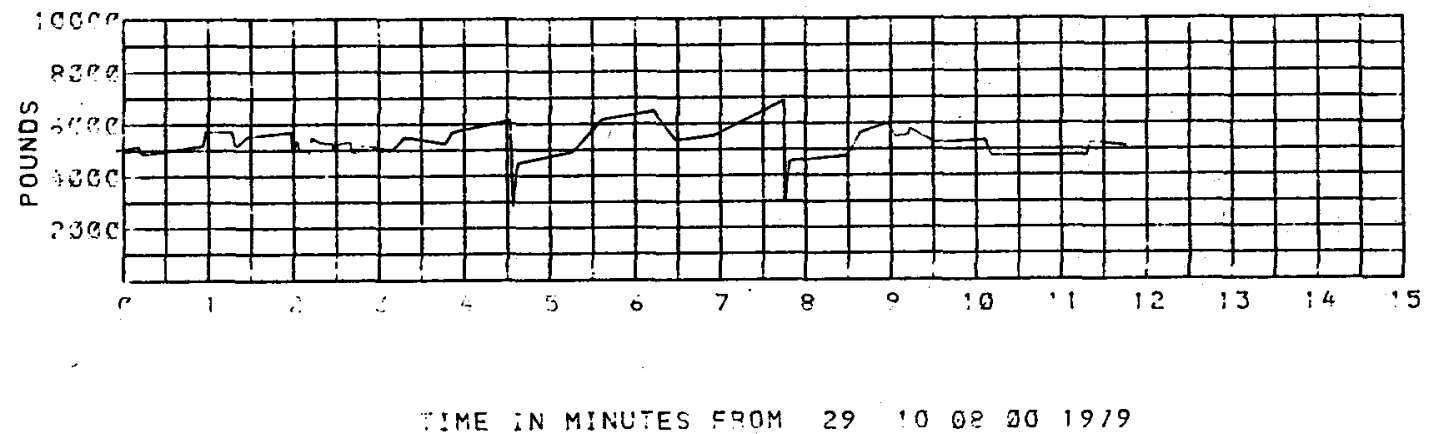

Figure D-23. Drilling with Jet Core Bit during Reentry into Hole 79-1 
DRILL SPEED

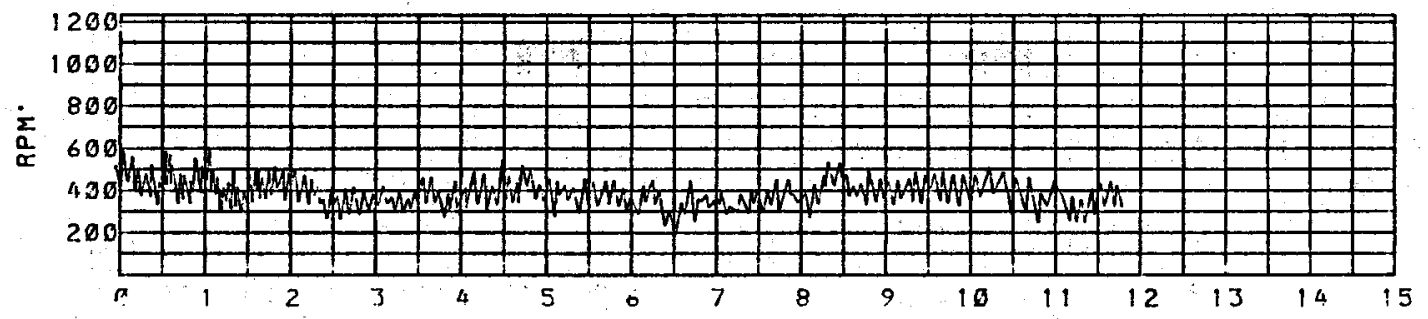

DISPLACEMENT
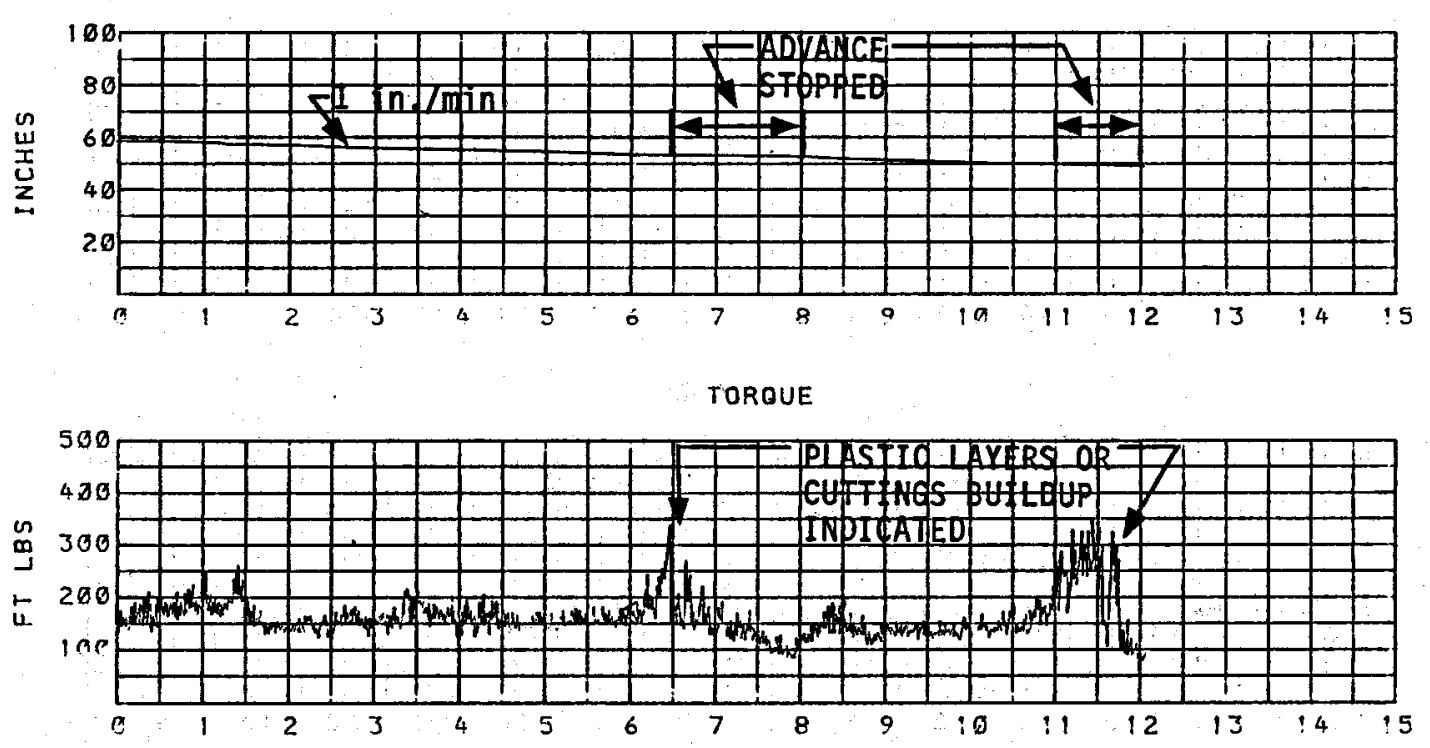

BIT COACE

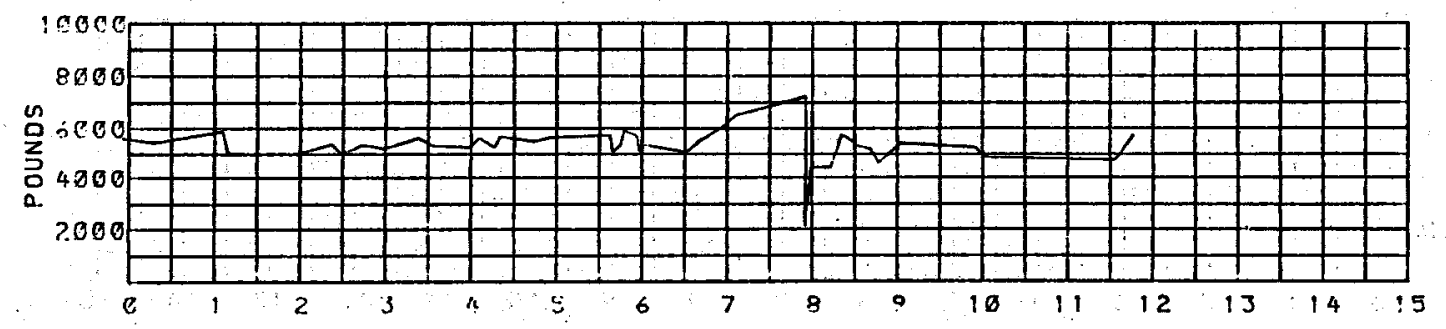

TIME IN MINUTES FROM 29:10 20001979

Figure D-24. Drilling with Jet Core Bit during Reentry into Hole 79-1 

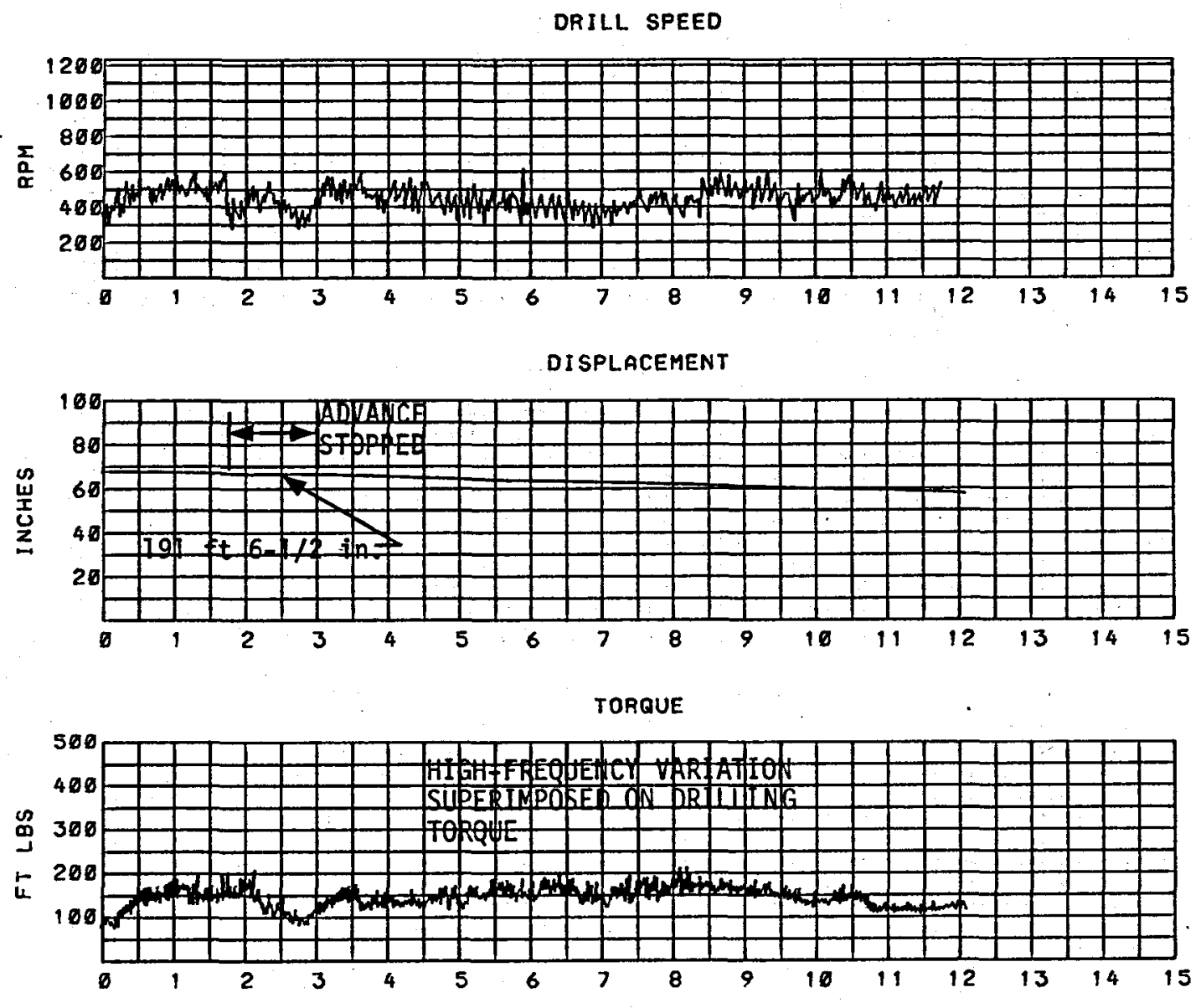

BIT FORCE

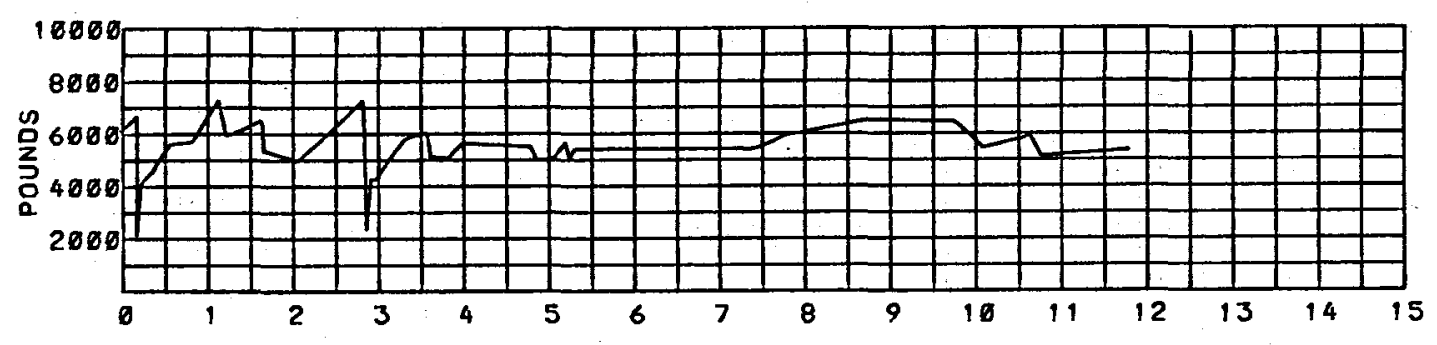

TIME IN MINUTES FROM $29 \quad 10 \quad 32 \quad 60 \quad 1979$

Figure D-25. Drilling with Jet Core Bit during Reentry into Hole 79-1 

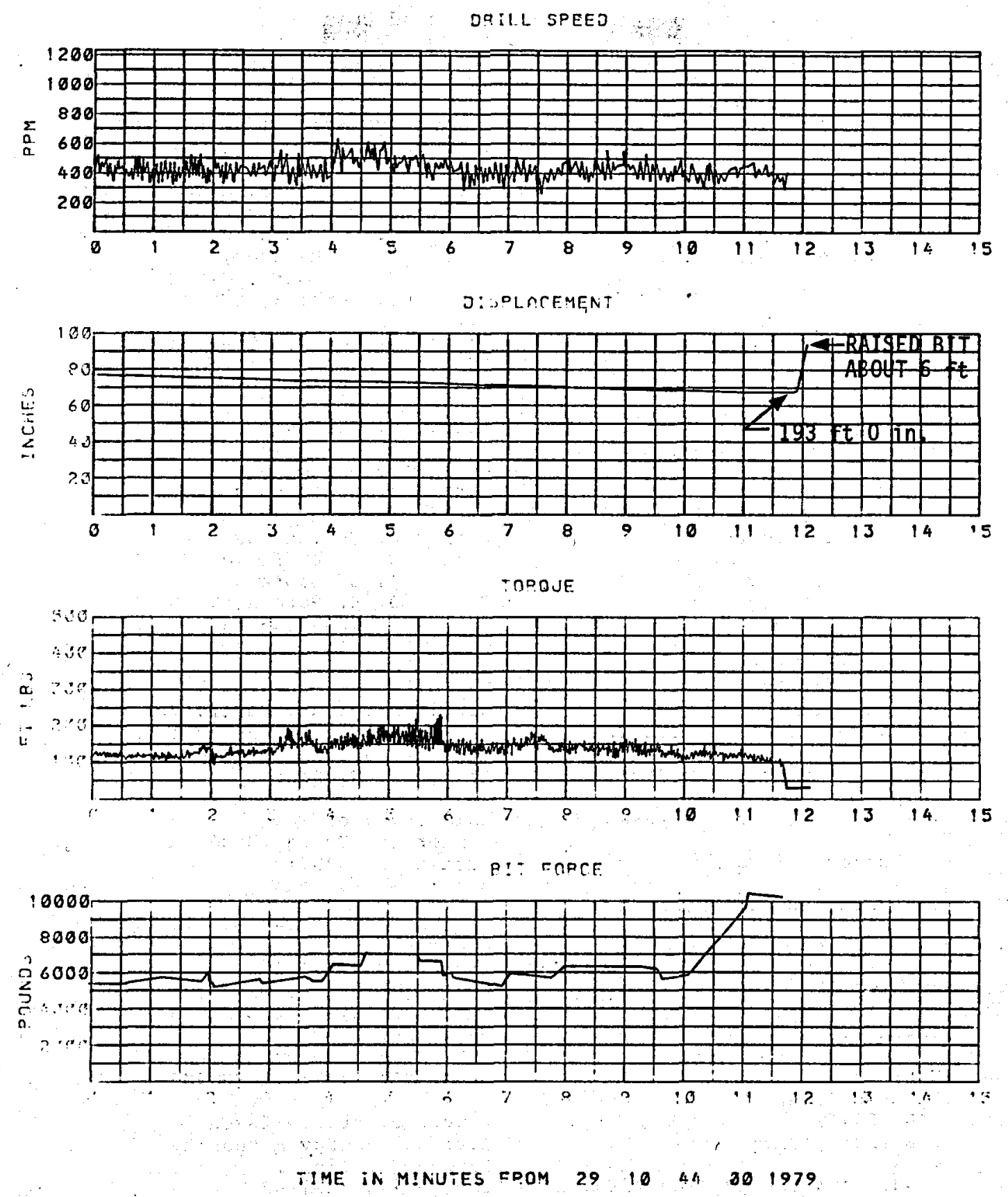

Figure D-26. Drilling with Jet Core Bit during Reentry into Hole 79-I 


\section{DISTRIBUTION :}

DOE/TIC-4500-R67 UC-66 (235)

Massachusetts Institute of of Technology

Dept of Earth Science

Cambridge, MA 02139

Attn: Keiiti.Aki, 54-526

Lawrence Berkeley Laboratory

University of California

Berkeley, CA 94720

Attn: J. A. Apps

I. S. Carmichael

P. A. Witherspoon

Shigeo Aramaki

Earthquake Research Inst

University of Tokyo

Bunkyo-ku

Tokyo 113, Japan

University of California

Lawrence Livermore Laboratory

P.O. Box 808

Livermore, CA 94550

Attn: R. Austin, Proj Leader Geothermal Program

US Department of Energy

Div of Geothermal Energy

washington, DC 20545

Attn: L. Ball

C. Carwile, Chief Adv Tech Br

J. W. Sal isbury Hydrothermal Support $B r$

J. Walker, MS $3122 \mathrm{C}$ Chief, Technology Div

United National Inst for Trn \& Res (UNITAR)

801 United Nations Plaza

New York, NY 10017

Attn: J. Barnea, Special Fellow

Sveinbjörn Björnsson

Science Institute

University of Iceland

Bunhaga 3

107 Reykjavik, Iceland

Argonne National Laboratory

9700 South Cass Avenue

Argonne, IL 60439

Attn: M. Blander, Bldg 205

Office of Nucl and Energy Tech Affairs Department of State

Washington, DC 20520

Attn: J. L. Bloom

Oregon state University

Corvallis, on 97331

Attn: G. Bodvarsson

University of Texas

Engineering - Sci Bldg 623

Austin, $\mathrm{Tx} 78712$

Attn: F. X. Bostick

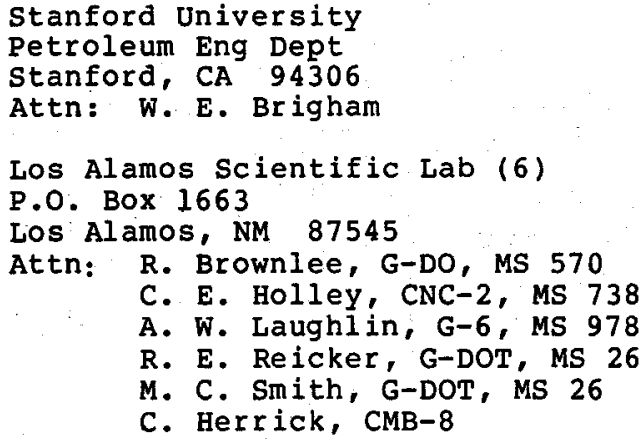

US Geological Survey Hawaiian Volcano Observatory Hawaii Volcanoes National Park Hawai 96718

Attn: R. W. Decker

University of Texas

Center for Energy Studies

Austin, TX 78712

Attn: M. Dorfman

US Geological Survey

956 National Center

Reston, VA 22092

Attn: G. Eaton, MS 911

R. T. Helz, MS 959

D. Peck, Chief Geologist, MS 911

R. Tilling, MS 906

Ingvar B. Fridleifsson

National Energy Authority Laugavegur 116

Reykjavik, Iceland

Texas A\&M University

Center for Tectonophysics

College Station, TX 77843

Attn: M. Friedman

US Geological Survey

Box 25046

Denver Federal Center

Denver, CO 80225

Attn: F. Frischknecht, MS 964

C. Zablocki, MS 964 
University of Hawai at Manoa Hawailan Inst of Geophysics Honolulu, HI 96722

Attn: A. S. Furumoto

University of Hawaii (2)

Hawaii Inst of Geophysics

Honolulu, HI 96822

Attn: C. Helsley, Head M. Ryan

Brown University

Dept of Geological Sciences

Providence, RI 02912

Attn: J. F. Hermance

Stanford University

Geology Dept

Stanford, CA 94305

Attn: R. Holcomb

Stephen Keruse

New Zealand - American

Association (Inc.)

P.O. Box 3241

Auckland, New Zealand

C. A. Kezar

Technical Consultant

Subcommittee on Adv Energy and Technologies

House committee on science and Technology

Rayburn office Bldg B374

Washington, DC 20515

University of Alaska

Geophysical Institute

Fairbanks, AK 99701

Attn: J. Kienle

us Dept of Energy (11)

Office of Basic Energy Science

Washington, DC 20545

Attn: G. A. Kolstad, MS J-309 (10)

I. MacGregor, MS J-309

Oak Ridge National Lab ?

P.O. BoX $X$

Oak Ridge, TN 37830

Attn: W. L. Marshall

Kazuaki Nakamura

Earthquake Research Inst

University of Tokyo

Hongo

Tokyo 113, Japan

Hans-Ulrich Schmincke

Rohr-Universitat Bochum

Institut fur Mineralogie

D-463 Bochum Postfach 102148

West Germany

Daisuke Shimozuru

Earthquake Research Institute

University of Tokyo

Bunkyo-ku

Tokyo 113, Japan
University of Hawail at Manoa

College of Engineering

Honolulu, HI 96822

Attn: Dean John Shupe

University of Minnesota

Inst of Technology

107 Lind Hall

207 Church St SE

Minneapolis, MN 55455

Attn: Dean Roger Staehle

Dartmouth College

Dept of Earth Science

Hanover, $\mathrm{NH} 03755$

Attn: R. E. Stoiber

Super intendent

Hawaii Volcanoes Natl Park

Hawaii 96718

University of Hawaii

Hawaii Geothermal Project

240 Holmes Hall

2540 Dole st

Honolulu, HI 96822

Attn: $P$. C. Yuen

Dr. Richard Taschek

203547 th st

Los Alamos, NM 87544

2355 P. C. Lysne

4000

4700

4710

4720

4730

4732

4733

4734

4734

4737

4740

4741

4742

4743

5000

5500

5510

5512

5512

5512

5520

5521

5541

5541

5800

5820

5822

5830

5831

5836

8266

3141

3151

A. Narath ${ }^{*}$. H. Scott

G. E. Brandyold*

V. L. Dugan

H. M. Stoller

D. A. Northrop*

C. L. Schuster

A. L. Stevens

R. R. Neel

B. E. Bader*

R. K. Traeger

S. G. Varnado*

A. F. Veneruso*

J. L. Colp $(30)$

J. K. Galt*

O. E. Jones*

D. B. Hayes

H. C. Hardee

J. C. Dunn

D. W. Larsqn

T. B. Lane

S. N. Burchett

W. C. Luth

T. M. Gerlach

R. S. Claassen ${ }^{*}$

R. E. Whan

E. J. Graeber

M. J. Davis

D. L. Douglass

J. L. Ledman

E. A. Aas

T. L. Werner (5)

W. L. Garner (3)

For DOE/TIC (Unlimited Release)

\footnotetext{
*To receive abstract only.
} 